\title{
Happy Together or Home Alone: A Structural Model of the Role of Health Insurance in Household Joint Retirement
}

\author{
Dina Guo \\ Wuhan, China
}

M.A. Economics, University of Virginia, 2010

M.A. Economics, Wuhan University, 2008

B.A. Economics and Finance, Wuhan University, 2006

B.S. Mathematics, Wuhan University, 2006

\begin{abstract}
A Dissertation presented to the Graduate Faculty of the University of Virginia in Candidacy for the

Degree of Doctor of Philosphy
\end{abstract}

Department of Economics

University of Virginia

October, 2016 
(c) Copyright by Dina Guo

All Rights Reserved

October 2016 


\section{Acknowledgments}

I would like to thank my advisors Steven Stern, Leora Friedberg, and John Pepper for their time and guidance and Christopher Ruhm for serving as the outside reader for my dissertation committee. I have benefited from conversations with speakers for the Bankard Public Economics workshop and the Bankard Applied Microeconomics workshop. I am grateful for the help of graduate students in the Economics Department. I would also like to thank the University of Virginia's Bankard Fund and the Dissertation Fellowship from Center for Retirement Research at Boston College for financial support, my parents and friends for their emotional support. Any errors are my own. 


\begin{abstract}
The baby boomers are approaching retirement, and the majority of them are married. Simultaneously, employers are less likely to provide retiree or spousal health insurance, making it important to understand how health insurance affects couples' joint retirement decisions. I develop a dynamic programming model of household retirement in which married couples jointly decide when to retire, how to use available insurance, and how much to save. Insurance plans vary by plan characteristics (including premium, deductible, and coinsurance rates). The members of each couple coordinate their retirement decisions in response to the following motivations: (1) they share economic resources through the household budget constraint; (2) they care about spending leisure time with each other; and (3) their health insurance coverage choices are interdependent. I also model two channels through which people value health insurance: (1) insurance smooths consumption by reducing the mean and volatility of medical expenses; and (2) insurance can improve health and thus decrease individuals' value of leisure relative to work.

I estimate my model with Maximum Simulated Likelihood estimation using data from the Health and Retirement Study and the Medical Expenditure Panel Survey. I find that employer-provided health insurance (EPHI) plays an important role in retirement decisions. For workers with tied health insurance, who lose employer-provided coverage if they retire, gaining employer-provided retiree coverage would decrease the average retirement age by 1.1 and 0.5 years for husbands and wives, respectively. Similarly, raising the Medicare eligibility age is predicted to delay retirement (by 0.7 and 0.4 years), while the Affordable Care Act (ACA), which makes health insurance independent of employment status, is predicted to accelerate it (by 0.4 and 0.3 years). The effects of Medicare are bigger than the effects of the ACA but smaller than the effects of EPHI due to the differences in plan quality, which has been overlooked in the previous literature. In addition, in decomposing the employment response to EPHI coverage, I find that over $80 \%$ of the response reflects the valuation of the consumption smoothing effects of health insurance, and less than $20 \%$ reflects the valuation of the health improvement effects. Furthermore, I find that spousal coverage motivates simultaneous retirement by delaying husbands' retirement and
\end{abstract}


accelerating wives' retirement, and it explains about one-fourth of the simultaneous retirement observed in the data. Lastly, I find that husbands and wives enjoy spending leisure time together, which explains nearly one-third of the observed simultaneous retirement.

JEL Classification: I13, J26, H31, C51

Keywords: household retirement, health insurance, Medicare, saving, spousal insurance coverage, health insurance plan characteristics 


\section{Contents}

$\begin{array}{lll}1 & \text { Introduction } & 1\end{array}$

\begin{tabular}{|lll}
\hline 2 & Literature Review & 7
\end{tabular}

$2.1 \quad$ Health Insurance and an Individual's Retirement . . . . . . . . . . . . . . 7

2.2 Married Couples' Retirement . . . . . . . . . . . . . . . . . . . 8

2.3 Health Insurance and Married Couples' Retirement . . . . . . . . . . . . . 12

\begin{tabular}{lll}
\hline 3 & Theoretical Model & 15
\end{tabular}

3.1 Discrete Choice Set . . . . . . . . . . . . . . . . 16

$3.1 .1 \quad$ Retirement Status . . . . . . . . . . . . . . . . . . . . 16

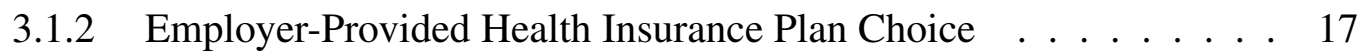

3.2 Preferences . . . . . . . . . . . . . . . . . . . 18

3.3 Budget Constraints . . . . . . . . . . . . . . . . . 20

3.4 Medical Expenditure $\ldots \ldots \ldots \ldots \ldots \ldots$

3.4.1 Out-of-Pocket Medical Expenditure . . . . . . . . . . . . 21

3.4 .2 Total Medical Expenditure . . . . . . . . . . . . . . 22

3.5 Social Security and Pension Benefits . . . . . . . . . . . . . 23

3.5 .1 Social Security Benefits . . . . . . . . . . . . 23

3.5 .2 Pension Benefits . . . . . . . . . . . . 25

3.6 Health Transitions and Survival Rates . . . . . . . . . . . . . . . . . 28

3.6.1 Household Health Transitions . . . . . . . . . . . . . . . . . . . 28

3.6 .2 Household Survival Rates . . . . . . . . . . . . . . . . . . 29

3.7 Death and Bequest Function $\ldots \ldots \ldots$. . . . . . . . . . . 30

3.8 Value Function $\ldots \ldots \ldots \ldots$

\begin{tabular}{lll}
\hline Data & 33 \\
\hline
\end{tabular}

4.1 Data Sources . . . . . . . . . . . . . . . . . . . . 33

4.2 Sample $\ldots \ldots \ldots \ldots \ldots \ldots \ldots$

4.3 Health Insurance Eligibility $\ldots \ldots \ldots \ldots$ 
4.4 Employment . . . . . . . . . . . . . . . . . . . . . . . . 39

4.5 Employer-Provided Health Insurance Plan Characteristics . . . . . . . . . . 42

$4.5 .1 \quad$ Censored Data Problem _. . . . . . . . . . . . . . . . 43

4.5 .2 Measurement Error Problem . . . . . . . . . . . . . . . . . 44

4.6 Wage . . . . . . . . . . . . . . . . . . . . . . 47

4.7 Average Indexed Monthly Earnings (AIME) $\ldots \ldots \ldots$

4.8 Bargaining Power $\ldots \ldots \ldots \ldots$. . . . . . . . . . . . . . . . . 52

4.9 Summary Statistics $\ldots \ldots \ldots \ldots$. . . . . . . . . . . . . . . 52

$\begin{array}{lll}5 & \text { Estimation } & 55\end{array}$

$5.1 \quad$ Error Structure $\ldots \ldots \ldots \ldots \ldots \ldots$

5.1 .1 Idiosyncratic Error $\ldots \ldots \ldots 5$

5.1 .2 Unobserved Heterogeneity . . . . . . . . . . . . . . . 55

5.2 Likelihood Function $\ldots \ldots \ldots \ldots \ldots$

$5.2 .1 \quad$ Optimal Consumption $\ldots \ldots \ldots \ldots$. . . . . . . . 57

5.2 .2 Choice Probabilities . . . . . . . . . . . . . . . . . 59

5.2 .3 Likelihood Function $\ldots \ldots$. . . . . . . . . . . 60

5.2 .4 Estimation Strategy $\ldots \ldots$. . . . . . . . . . . . . . 63

5.3 Identification . . . . . . . . . . . . . . . . . 65

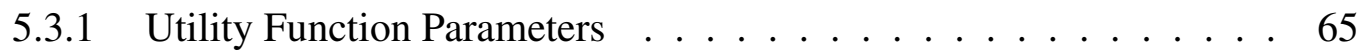

5.3.2 Medical Expenditure Function Parameters . . . . . . . . . . . . 67

5.3 .3 Health Transitions and Survival Rates Parameters . . . . . . . . . . 69

$\begin{array}{lll}6 & \text { Results } & \mathbf{7 0}\end{array}$

6.1 Model Parameter Estimates . . . . . . . . . . . . . . . . . . . 70

6.2 Specification Tests $\ldots \ldots \ldots \ldots \ldots$. . . . . . . . . . . . . . . . .

6.2 .1 Model Fit . . . . . . . . . . . . . . . . . 73

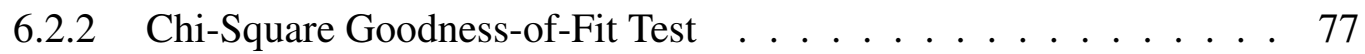

6.2 .3 Lagrange Multiplier Test . . . . . . . . . . . . . . . . 80 
\begin{tabular}{lll}
\hline 7 & Counterfactual Simulations & 83
\end{tabular}

7.1 Causal Inferences . . . . . . . . . . . . . . . . . . . . 83

7.1.1 The Effects of Employer-Provided Retiree Health Insurance . . . . 83

7.1.2 The Importance of Including the Health Channel . . . . . . . . . . 86

7.1.3 Spousal Coverage and Household Retirement . . . . . . . . . . . . 89

7.1.4 Complementarity in Leisure and Simultaneous Retirement . . . . . 91

7.2 Policy Simulations $\ldots \ldots \ldots$. . . . . . . . . . . . . . . . 92

7.2.1 The Implementation of the ACA $\ldots \ldots$. . . . . . . . . . . . . 92

7.2.2 Raising the Medicare Eligibility Age to 67 . . . . . . . . . . 95

7.2 .3 Raising the Normal Retirement Age to 67 . . . . . . . . . . . . . 97

$\begin{array}{lll}8 & \text { Conclusion } & 99\end{array}$

\begin{tabular}{ll}
\hline A Appendix & 110
\end{tabular}

A.1 The Choice Set of Household EPHI Plans . . . . . . . . . . . . . . . . . 110

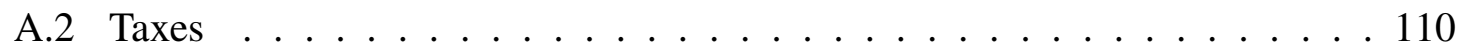

A.3 Social Security and Pension Benefits . . . . . . . . . . . . . . . 113

A.3.1 PIA Formula . . . . . . . . . . . . . . . . . . . . 113

A.3.2 Social Security Benefits . . . . . . . . . . . . . . 114

A.3.3 DB Pension Benefits . . . . . . . . . . . . . . . 116

A.4 Employer-Provided Health Insurance Eligibility . . . . . . . . . . . . . 117

A.5 Wage Imputation Model Estimates ． . . . . . . . . . . . . . . . 120

A.6 AIME and Earnings History $\ldots \ldots \ldots$

A.6.1 AIME Updating Function . . . . . . . . . . . . . . . . 122

A.6.2 Earnings History . . . . . . . . . . . . . . . . . . 123

A.7 Bargaining Power . . . . . . . . . . . . . . . . . . . . . . . 124

A.8 $\quad$ First Stage Parameter Estimates $\ldots \ldots$. . . . . . . . . . . . 126

A.8.1 Total Medical Expenditure Parameter Estimates . . . . . . . . . . . 126

A.8.2 Health Transitions Parameter Estimates . . . . . . . . . . . . . . 129

A.8.3 Survival Rates Parameter Estimates . . . . . . . . . . . . . . . 130 


\section{List of Figures}

$4.1 \quad$ Full-Time Job Participation Rates: Husband . . . . . . . . . . . . . . . . . 40

4.2 Full-Time Job Participation Rates: Wife . . . . . . . . . . . . . . . . . . 40

4.3 Full-Time Job Exit Rates: Husband . . . . . . . . . . . . . . . . . . . . . 41

4.4 Full-Time Job Exit Rates: Wife . . . . . . . . . . . . . . . . . . . . . . . . 41

$6.1 \quad$ Husband Participation Rates: Tied EPHI . . . . . . . . . . . . . . . . . . . 74

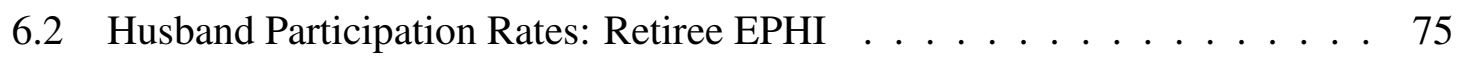

6.3 Husband Participation Rates: No EPHI . . . . . . . . . . . . . . . . . 75

6.4 Wife Participation Rates: Tied EPHI . . . . . . . . . . . . . . . . 75

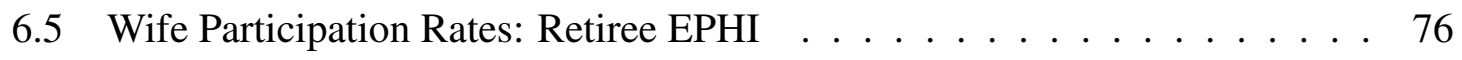

6.6 Wife Participation Rates: No EPHI . . . . . . . . . . . . . . . . . . . 76

6.7 Husband Job Exit Rates: Tied EPHI $\ldots \ldots$. . . . . . . . . . . . . . . 77

6.8 Husband Job Exit Rates: Retiree EPHI $\ldots \ldots \ldots$. . . . . . . . . . . . . . . . 78

6.9 Husband Job Exit Rates: No EPHI . . . . . . . . . . . . . . . . . . . . . 78

6.10 Wife Job Exit Rates: Tied EPHI . . . . . . . . . . . . . . . . . 78

6.11 Wife Job Exit Rates: Retiree EPHI . . . . . . . . . . . . . . . . . . . 79

6.12 Wife Job Exit Rates: No EPHI . . . . . . . . . . . . . . . . . . . 79

7.1 Effects of EPRHI on Job Participation Rates . . . . . . . . . . . . . . . 84

7.2 Effects of EPRHI on Job Exit Rates f . . . . . . . . . . . . . . . 85

7.3 Job Participation Rates without the Health Channel . . . . . . . . . . . . . 87

7.4 Job Exit Rates without the Health Channel . . . . . . . . . . . . . . . . . 87

7.5 Effects of EPRHI on Participation Rates without the Health Channel . . . . 88

7.6 Effects of EPRHI on Exit Rates without the Health Channel . . . . . . . . . 89

$7.7 \quad$ Distribution of Retirement Age . . . . . . . . . . . . . . . . . . . 90

7.8 Distribution of the Difference in Retirement Year . . . . . . . . . . . . . . 91

7.9 Effects of the ACA on Job Participation Rate: Tied Insurance . . . . . . . . 93

7.10 Effects of the ACA on Job Exit Rate: Tied Insurance $\ldots \ldots$. . . . . . . . 93

7.11 Effects of the ACA on Job Participation Rates: Sample . . . . . . . . . . . 94

7.12 Effects of the ACA on Job Exit Rates: Sample . . . . . . . . . . . . . . . . 94 
7.13 Effects of Medicare on Participation Rates: Tied Insurance . . . . . . . . . 96

7.14 Effects of Medicare on Exit Rates: Tied Insurance . . . . . . . . . . . . . 96

7.15 Effects of Medicare on Participation Rates: Sample . . . . . . . . . . . . . 97

7.16 Effects of Medicare on Exit Rates: Sample . . . . . . . . . . . . . . . . . . 97

7.17 Effects of the Normal Retirement Age on Participation Rates: Sample . . . 98

7.18 Effects of the Normal Retirement Age on Exit Rates: Sample . . . . . . . . 98

A1 Flowchart of Survey Questions about Health Insurance Eligibility in the HRS117 


\section{List of Tables}

$1 \quad$ Spouse $i$ 's EPHI Eligibility, $e_{i t}=\left(e_{i t}^{w 1}, e_{i t}^{w 2}, e_{i t}^{r 1}, e_{i t}^{r 2}\right) \ldots \ldots \ldots 17$

2 Sample Selection Criteria for the HRS Sample . . . . . . . . . . . . . . 34

$3 \quad$ EPHI Eligibility . . . . . . . . . . . . . . . . . . 37

$4 \quad$ EPHI Eligibility Distribution in 1992: Husband . . . . . . . . . . . . . . 38

$5 \quad$ EPHI Eligibility Distribution in 1992: Wives . . . . . . . . . . . . . 38

$6 \quad$ EPHI Characteristics in Private Sector (Year 2002) . . . . . . . . . . . . 43

$7 \quad$ EPHI Characteristics in Public Sector (Year 2002) $\ldots \ldots \ldots$. . . . . . . . . 43

$8 \quad$ Sample Statistics for Initial Annualized AIME . . . . . . . . . . . . . . 51

$9 \quad$ Summary Statistics For The Initial Distribution $\ldots \ldots \ldots$

10 Estimates of Preference Parameters . . . . . . . . . . . . . . . 72

11 Chi-Square Goodness-of-Fit Analysis on Employment ～. . . . . . . . . . 80

A1 The Choice Set of Household EPHI Plan Choices $\mathscr{J}_{t} \ldots \ldots$. . . . . 111

A2 Table A1 Continued . . . . . . . . . . . . . . . . . . . . . 112

A3 Value of $\gamma$ by Retirement Age . . . . . . . . . . . . . . 116

A4 $\quad$ EPHI Coverage Outcome $\ldots \ldots \ldots \ldots$

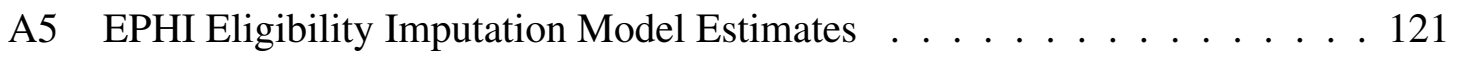

A6 Covariance Matrix Estimates . . . . . . . . . . . . . . . . . . . . . . 122

A7 $\quad$ Annual Wage Imputation Model Estimates . . . . . . . . . . . . . . . . 123

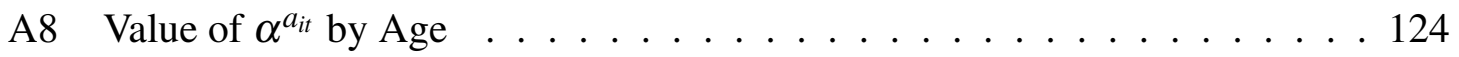

A9 Modified AR(1) Process Estimates . . . . . . . . . . . . . . . . . . 125

A10 Parameter Estimates For The Probability Of Having Zero Total Medical Expenses . . . . . . . . . . . . . . . . . . 127

A11 Parameter Estimates For Positive Total Medical Expenses . . . . . . . . . 128

A12 Health Transitions Parameter Estimates . . . . . . . . . . . . . . 130

A13 Survival Rates Parameter Estimates ． . . . . . . . . . . . . . . . . 131 


\section{Introduction}

In the United States, the absence of retiree health insurance coverage might be one of the biggest obstacles to retiring before age 65 . People with health insurance are not only better protected financially in case of serious accident or sickness; they also tend to be healthier because they are more likely to get preventative care. Health insurance coverage is particularly important for people facing retirement, who tend to have more health problems and usually are less able to financially recover from costly medical expenses. Many American workers are reluctant to retire before becoming eligible for Medicare at age 65 because they fear losing their employer-provided health insurance and because health insurance from the private market is expensive.$^{1}$ The link between health insurance and retirement is even more complicated in a household in which two spouses face different employment conditions but coordinate their retirement decisions. This paper studies how health insurance affects retirement decisions at the family level.

Many papers have studied the effect of retiree health insurance availability on individuals (usually men's) retirement decisions (Madrian et al. (1994), Gruber and Madrian (1995), Rust and Phelan (1997), Blau and Gilleskie (2008), and French and Jones (2011)).

Indeed, many have found that people coordinate their retirement with that of their spouse (Blau (1998), Maestas (2001), Blau and Gilleskie (2006), Gustman and Steinmeier (2000. 2004, 2009), and Casanova (2010)). This arises because spouses share economic resources and because their health insurance coverage may be interdependent $2^{2}$ Thus, an individual's retirement decision may also affect his or her spouse's access to health insurance. For example, if a wife cannot receive health insurance from her employer, her husband may choose to work until she is eligible for Medicare, even if the husband can receive retiree health insurance or Medicare. Also significant are the characteristics of the available health insurance plans such as the coinsurance rate and deductible. Therefore, even if both spouses have health insurance available through their own employers, one spouse might

\footnotetext{
${ }^{1}$ According to a Kaiser Family Foundation survey of employers, only 28 percent of large firms with 200 or more workers offered retiree health insurance in 2010, down from 66 percent in 1988. Only three percent of small firms that have between three and 199 workers offer health plans for retirees.

${ }^{2}$ According to an annual survey of more than 130 companies by Conrad Siegel Actuaries, 69 percent of the employers surveyed in 2014 provided health insurance that cover spouses, down from 80 percent in 2012.
} 
delay retirement to give the other higher-quality insurance.

Understanding the effects of health insurance on couples' joint retirement decisions is important for evaluating health insurance policy. The baby boomer generation is approaching retirement, and most of them are married. At the same time, the health insurance system has undergone massive changes. If the elderly delay their retirement due to a lack of retiree health insurance, the Affordable Care Act (ACA), which makes health insurance widely available and independent of employment, could increase the rate of early retirement (Dague et al. (2014), and Baicker et al. (2013)).

In this paper, I develop a model of household retirement that accounts for the coordination between spouses and includes heterogeneity in the availability of health insurance plans and in health insurance plan characteristics. I develop a dynamic structural model wherein households in which both spouses work make three decisions to maximize expected lifetime household utility: (1) when each spouse will retire; (2) how each spouse will receive health insurance, given their available options; and (3) how much the household should save and consume. A household's utility is the weighted average of each spouse's utility (weighted by each spouse's bargaining power). Each spouse's utility depends on total household consumption, his or her own leisure, and his or her own unobserved tastes for retirement and health insurance plan choices. The preference for leisure is determined by age, health status, and the spouse's leisure. In addition, two spouses' health transitions and medical expenses are allowed to be correlated. My model captures unobserved heterogeneity in household-level tastes for two household decisions-retirement decisions and health insurance plan choices-that make evaluating the likelihood function computationally difficult. Following Heckman and Singer (1985), I assume that there are two types of unobserved tastes for retirement decision and health instance plan choices (Keane and Wolpin (1997), Cameron and Heckman (1998), Mroz and Guilkey (1992), and Mroz (1999)). Each household belongs to each type with a probability. I estimate the unobserved heterogeneity parameters jointly with the preference parameters.

This paper makes three key contributions to the literature. First, it allows health insurance to affect retirement decisions through two channels: (1) insurance smooths con- 
sumption by reducing the mean and volatility of medical expenses; and (2) insurance can improve health and thus decrease individuals' value of leisure relative to work. The extant literature on health insurance and retirement takes into account only the first channel. According to Rust and Phelan (1997), individuals who are facing retirement value health insurance because they are risk averse to uncertain medical expenses. I model changes in health as an additional channel that links health insurance and retirement and that, moreover, allows access to insurance to influence health (Currie and Gruber (1996), Levy and Meltzer (2008), Zimmer (2012), and Gustman and Steinmeier (2014)).

Second, my model includes the interdependence of two spouses' health insurance coverage as an additional factor that motivates coordinated retirement. This means that one spouse's retirement decision can affect the other spouse's health insurance coverage. Papers in the previous literature that either overlook or simplify this interdependence would risk underestimating the effect of health insurance on couples' retirement.

Third, this paper differentiates each spouse's employer-provided plan by plan characteristics (premium, deductible, and coinsurance rate). Including the heterogeneity in plan characteristics enables me to model the endogenous choice of EPHI coverage. In my model, when a spouse is eligible for the plans provided by both spouses' employers, he or she chooses a plan by comparing the two plans' characteristics. This is because plan characteristics affect both the amount and the risk of out-of-pocket medical expenses 3 In other words, this paper evaluates two dimensions of health insurance: coverage and plan characteristics. The latter dimension has been largely overlooked in the literature. Whereas the effect of health insurance coverage has been intensively studied (Madrian et al.(1994), Lumsdaine et al. (1994), Gustman and Steinmeier (1994), Gruber and Madrian (1995), Rust and Phelan (1997), and French and Jones (2011)), very little attention has been paid to how health insurance plan characteristics affect retirement (Gustman et al. (1994), Gustman and Steinmeier (2000), and Fields and Mitchell (1984)).

\footnotetext{
${ }^{3}$ Total medical expenditures are defined as the sum of direct payments for care provided during a period, including out-of-pocket payments and payments by insurance. I model total medical expenditures as a function of health insurance coverage, labor supply, health status, household income, and some other demographic characteristics. Then, out-of-pocket medical expenditures are determined by total medical expenditures and observed insurance plan characteristics. Details are discussed in model section.
} 
The main data source that I use to estimate my model is the Health and Retirement Study (HRS), which collects extensive information about household characteristics, labor force participation, health insurance coverage, health, income, and assets. But the HRS provides little information about total medical expenditures or health insurance plan characteristics, which in my model are necessary to compare health insurance plans that have different characteristics. I collect information about total medical expenses from the Medical Expenditure Panel Survey (MEPS), which is a set of large-scale surveys of families and individuals, their medical providers, and their employers. The MEPS also provides averages (including average paid premium, average co-insurance rate, and average deductible) of employer-provided plans by industry type and firm size, and I use these to impute the "generic" paid premium, co-insurance rate, and deductible for each possible health insurance plan for each household in my sample. Note that I cannot observe individuals' earning history before they enter into the HRS. $4^{4}$ Full earnings histories are needed to compute Social Security benefits. To solve this problem, I use the Panel Study of Income and Dynamics (PSID) to estimate a labor income growth function. Then, I use the income growth function and the income observed in the first wave of the HRS to recover the earning history.

I estimate my model using the Maximum Simulated Likelihood (MSL) estimation (Keane and Wolpin (1997), Rust and Phelan (1997), and Brien et al. (2006), and Blau and Gilleskie (2008)). The parameter estimates are similar to those in the literature, and the predicted labor market behavioral patterns match the sample patterns well. Using the parameter estimates, I run several counterfactual simulations to measure the causal effects of health insurance on spouses' retirement behavior. I find that employer-provided health insurance has an important influence on retirement. For workers with tied health insurance, who lose employer-provided coverage if they retire, gaining employer-provided retiree coverage would decrease the average retirement age by 1.1 and 0.5 years for husbands and wives, respectively. In decomposing the employment response to EPHI coverage, I find that over $80 \%$ of the response reflects the valuation of the consumption smoothing effects

\footnotetext{
${ }^{4}$ The HRS collects individuals' earning history in a restricted file. It takes more time to get the restricted file and it requires no internet access while using this file. However, I need internet access to use the HPC (High-Performance computing) system in University of Virginia because my code needs parallel computing.
} 
of health insurance, and less than $20 \%$ reflects the valuation of the health improvement effects. Furthermore, I find that spousal coverage motivates simultaneous retirement by delaying husbands' retirement and accelerating wives' retirement, and it explains about 24\% of the simultaneous retirement observed in the data. Lastly, I find that husbands and wives enjoy spending leisure time together, which explains $34 \%$ of the observed simultaneous retirement.

I also conduct several policy simulations to predict labor supply responses to the implementation of the ACA, which makes health insurance independent of employment status $5^{5}$ and responses to changes in the Medicare and Social Security retirement rules. According to my simulation results, for the workers who have tied coverage, the implementation of the ACA is predicted to accelerate retirement by 0.4 years for husbands and 0.3 years for wives. Raising the Medicare eligibility age from 65 to 67 is predicted to delay retirement by 0.7 years for husbands and 0.4 years for wives. The effects of Medicare are bigger than the effects of the ACA but smaller than the effects of EPRHI due to the differences in plan characteristics. For the whole sample, the implementation of the ACA is predicted to accelerate retirement by 0.12 years for husbands and 0.09 years for wives. Raising the Medicare eligibility age from 65 to 67 is predicted to delay retirement by 0.17 years for husbands and 0.12 years for wives. Comparatively, increasing the Social Security full retirement age from 65 to 67 delays retirement by 0.11 years for husbands and 0.08 years for wives.

The rest of the paper proceeds as follows. In Section 2, I discuss how my work relates to the literature on household retirement behavior and the relationship between health insurance and retirement decisions. I present my dynamic programming model of household joint retirement in Section 3, and, in Section 4, I describe the different data sets used to estimate the model. In Section 5, I explain the estimation strategy. Section 6 presents

\footnotetext{
${ }^{5} \mathrm{~A}$ key component of the ACA is that it requires people without health insurance to purchase insurance from the health insurance marketplace. The Health Insurance Marketplace, also called the Health Insurance Exchange, "is the place where people without health care insurance can find information about health insurance options and also purchase health care insurance. Information can also be found regarding eligibility for help with paying premiums and reducing out-of-pocket costs."

${ }^{6}$ In addition to the federally-facilitated Marketplace, there are state-based Marketplaces. Whether an individual uses the federally-facilitated Marketplace or a state-based Marketplace depends on the state in which he or she lives. Source: https://www.irs.gov/Affordable-Care-Act/
} 
the estimates of my structural parameters and tests how well the model performs in various aspects. In Section 7, I run several counterfactual simulations to examine the causal effects of health insurance on retirement and to predict the labor supply responses to relevant policies. Section 8 concludes. 


\section{Literature Review}

My paper draws from two important branches of the literature on retirement. The first branch considers the relationship between health insurance and an individual's retirement decisions. The second branch examines married couples' coordinated retirement decisions. Papers in the second branch identify two main factors that lead spouses to coordinate their retirement decisions: preference for shared leisure, and shared economic resources. However, there are very few studies that combine both branches to examine the role of health insurance in a couple's joint retirement decisions. My paper contributes to this limited literature by considering the interdependence of husbands' and wives' health insurance coverage, which is also a crucial factor in spousal retirement coordination. In addition, I model both health and medical expenses as channels linking health insurance and retirement behavior, whereas previous studies consider medical expenses as the only channel. I also add to the existing literature by modeling the heterogeneity in health insurance plan characteristics. In the subsequent sections, I comprehensively review the current literature and identify my contribution to ongoing research in these areas.

\subsection{Health Insurance and an Individual's Retirement}

Researchers have used different models to examine the effect of health insurance on individuals (usually elderly men's) retirement behavior, but their findings do not align. Madrian et al. (1994) and Gruber and Madrian (1995) regress the individuals' retirement decision on health insurance coverage. Madrian et al. (1994) uses the data from the 1987 National Medical Expenditure Survey (NMES), and Gruber and Madrian (1995) use the data from the Current Population Survey (CPS) and the Survey of Income and Program Participation (SIPP). Both papers find that having health insurance can significantly increase the propensity to retire. Lumsdaine et al. (1994) and Gustman and Steinmeier (1994) develop structural models assuming that individuals value health insurance at the cost paid by employers. Lumsdaine et al. (1994) estimate their model using data from a large company, and Gust- 
man and Steinmeier (1994) use the data from the 1977 NMES.7.$^{7}$ Both papers conclude that health insurance coverage has only a moderate effect on early retirement. However, if workers are risk-averse and if health insurance allows them to smooth consumption when facing volatile medical expenses, they might value health insurance well beyond the cost paid by employers. Rust and Phelan (1997) and Blau and Gilleskie (2008) construct dynamic programming models that account for uncertain medical expenses as well as risk aversion. Both papers estimate their models using Maximum Likelihood Estimation (MLE), but they use different data sets. Rust and Phelan (1997) use the Retirement History Survey (RHS) and Blau and Gilleskie (2008) use the Health and Retirement Study (HRS). Both find larger effects of health insurance on older men's retirement behavior. However, these two studies overlook the possibility that older people can "self-insure" against out-of-pocket medical expenses through savings. French and Jones (2011) address this shortcoming by estimating a dynamic model that includes saving and retirement decisions, using the data from the HRS and Generalized Method of Moments (GMM). They find that individuals whose health insurance coverage depends on their employment status retire half a year later than those who have retiree health insurance coverage. Their findings provide empirical evidence that models which exclude saving decisions overstate the effect of health insurance. Following French and Jones (2011), my paper develops a dynamic structural model of saving and retirement decisions that accounts for health insurance and uncertain medical expenses.

In contrast to my study, which examines the effects of health insurance on family retirement decisions, most papers in the literature on health insurance and individual retirement ignore spousal retirement coordination, and they exclude the dynamic relationship between one spouse's retirement and the other spouse's health insurance coverage. Ignoring this dynamic relationship may cause biased estimates of the effects of health insurance.

\subsection{Married Couples' Retirement}

With the increase in women's labor force participation since the 1960s, a growing number of scholars study the retirement of married couples. Regardless of the data set used, re-

\footnotetext{
${ }^{7}$ The data used in Lumsdaine et al. (1994) are drawn from the personnel records of all persons employed by the firm at any time between 1979 and 1988 .
} 
searchers find evidence of coordinated retirement among couples. Hurd (1990), Gustman and Steinmeier (2000), Blau (1998), and Coile (2004) use data from variety of sources: the United States New Beneficiary Survey (NBS), the National Longitudinal Survey of Mature Women (NLS), the Retirement History Survey (RHS), and the Health and Retirement Study (HRS). All these studies find that couples coordinate the timing of their retirement. For example, Hurd (1990) finds that, for spouses who retire after age 54, one-fourth retire within one year of their spouse.

Economists have identified two motivations that can lead spouses to coordinate their retirement: (1) the complementarity in leisure (preference for shared leisure time); and (2)financial incentives (shared economic factors affecting both spouses). First, regardless of the empirical strategy used, several papers find that the propensity of one spouse retiring is higher if the other spouse is retired, and these papers identify the complementarity in leisure as an important factor that motivates spouses to coordinate their retirement. Gustman and Steinmeier (2000, 2004) develop a non-cooperative bargaining model to represent the decision-making process in a family. They model the marginal utility of leisure for one spouse as a function of the retirement status of the other spouse. Thus, the parameter associated with the spousal retirement status measures the complementarity in leisure. Gustman and Steinmeier (2000) solve the model by finding a Nash equilibrium graphically and using the data from the NLS of Mature Women. The estimates show that husbands value shared leisure much more than wives do. Gustman and Steinmeier (2004) re-estimate the model established in Gustman and Steinmeier (2000) by using MLE and more recent data-namely, the HRS, which includes detailed information on pension and Social Security benefits. They simulate the probability of simultaneous retirement under the full base model and the model without spousal retirement. The simulation results show that simultaneous retirement is largely due to the complementarity in leisure. Banks et al. (2010) run IV regressions to examine the effect on husbands' retirement of their wife's retirement status. The wife's retirement status is instrumented with indicators of whether she has reached the full retirement age. They find that the husband enjoys retirement more when his wife is also retired, and the authors interpret these results as evidence of complementarity in leisure. 
Second, several papers find evidence of the effects of financial incentives on simultaneous retirement. The economic environment affecting both spouses in a household causes a positive correlation in the two spouses' retirement dates. Both husband and wife provide income and share household wealth; thus, they can potentially insure each other against shocks to wages, health, or medical expenditures. This means that one spouse is affected not only by his own Social Security and pension benefits, but also by the other spouse's benefits. Both reduced-form and structural models find that one spouse's financial incentives have spillover effects on the other spouse's retirement decision. Blau (1998) develops a discrete choice model of household labor supply. He models the value function of a household as a linear function of variables affecting preferences and state-specific budget constraints, such as wage, current Social Security benefits, and pension coverage. He does not include pension benefits as an explanatory variable because the data he uses is the RHS, which lacks the necessary detail to construct accurate pension benefits. He finds that husbands exit the labor force earlier if their wife has pension coverage. Michaud (2003), Coile (2004), and Kapur and Rogowski (2007) construct accurate pension benefits using the data from the HRS, which includes detailed information on pension benefits. These papers include pension benefits as a measure of financial incentives that affect spouses' retirement decisions. Michaud (2003) and Coile (2004) estimate probit models to test the spillover effect of one spouse's financial incentives on the other spouse's retirement decision. Both papers find that men are very responsive to their wives' financial incentives, but women are not responsive to their husbands' financial incentives. Kapur and Rogowski (2007) estimate a multinomial logit model to test the effects of the two spouses' financial incentives (pension benefits) on the household retirement decision. They find asymmetric spillover effects: for couples in which the husband has high pension benefits from delaying retirement, the wife is more likely to retire first, while for couples in which the wife has high pension benefits from delaying retirement, simultaneous retirement is more common than other household retirement status.

The main limitation of above papers is that they do not consider uncertainty in future environments because they employ static models. Yet uncertainty plays an increasing 
role at older ages because the incidence of negative shocks to health, out of pocket medical expenditures, and survival is much larger than when individuals are young. Van der Klaauw and Wolpin (2008), Guvenen (2009), and Casanova (2010) expand on this literature by developing dynamic structural models that account for the following: complementarity in leisure, shared household budget constraints, and the uncertainty of future income, health costs, and survival upon retirement. They also contribute to this literature by jointly analyzing retirement and saving decisions. Guvenen (2009) add uncertainty into the model developed in Gustman and Steinmeier (2000, 2004), and allow spouses to make sequential decisions. Both Van der Klaauw and Wolpin (2008) and Casanova (2010) model the household utility as a weighted sum of each spouse's utility. Van der Klaauw and Wolpin (2008) model the weight (sharing rule) as a function of the state space for a couple, and Casanova (2010) assumes a constant weight across time and households. To account for the complementarity in leisure, Van der Klaauw and Wolpin (2008) model the product of the two spouses' labor supply as a factor that affects each spouse's utility. The researchers assume that the parameters associated with this product are the same for both spouses. Casanova (2010) assumes that the measure of a spouse's leisure depends on whether the two spouses retire simultaneously or not. All these papers use the HRS to estimate their dynamic models but with different estimation methods. Van der Klaauw and Wolpin (2008) use Maximum Simulated Likelihood (MSL) estimation, and Guvenen (2009) and Casanova (2010) use the Method of Simulated Moments (MSM). Following the literature, my dynamic model incorporates complementarity in leisure, correlation in economic environments, and uncertainty in future environments 8

Most papers in the literature on married couples' retirement do not pay enough attention to health insurance coverage. However, health insurance is an important factor that can link spouses' retirement behaviors for two reasons. First, health insurance can affect the household out-of-pocket medical expenditures, which in turn can affect the household

\footnotetext{
${ }^{8}$ In my model, household utility is defined as a weighted sum of each spouse's utility (Van der Klaauw and Wolpin (2008) and Casanova (2010), and the weight is imputed using spouses' discrete responses to a question in the HRS about who has the final say when major household decisions are made (Friedberg and Webb (2006)). The weight varies across households but is constant over time. The marginal utility of leisure for one spouse is modeled as a function of age, health, and the other spouse's retirement status (Gustman and Steinmeier (2000, 2004, 2009)).
} 
budget constraints. Second, one spouse's retirement decision might affect the other spouse's health insurance coverage. In the next subsection, I discuss the few studies that focus on the effects of health insurance on married couples' retirement.

\subsection{Health Insurance and Married Couples' Retirement}

There is very little research examining the effects of health insurance on married couples' retirement (Blau and Gilleskie (2006) and Kapur and Rogowski (2007)), even though most people coordinate their retirement decisions with their spouses. Kapur and Rogowski (2007) estimate a reduced-form, multinomial logit model of spouses' simultaneous retirement decisions, using the data from the HRS. They conclude that the availability of wives' retiree health insurance almost doubles the probability of simultaneous retirement, while the availability of husbands' retiree health insurance has only a small effect. Blau and Gilleskie (2006) develop a dynamic model of older couples' retirement decisions that accounts for risk aversion and uncertain medical expenses. They model out-of-pocket medical expenditures as a function of health insurance plan characteristics and total medical expenditures, and they assume that future uncertain total medical expenditures follow a three-point discrete distribution (Heckman and Singer (1985)). This approach connects retirement decisions, health insurance coverage, and medical expenditure risk in a realistic and tractable way. The authors estimate the model using the HRS, and they find moderate effects of health insurance on the husband's retirement and very small effects on the wife's retirement.

These two papers do not include the interdependence of the two spouses' health insurance coverage, which is a factor that can link two spouses' retirement behaviors. For example, Blau and Gilleskie (2006) make two simplifying assumptions about health insurance coverage: (1) if a worker's employer does not provide retiree health insurance, he will lose health insurance after he retires, even if he could be covered by his spouse; and (2) someone covered by spousal health insurance always has health insurance. However, these two assumptions are problematic: an individual, for example, could lose health insurance coverage if his or her spouse retires. Analysts who overlook this interdependence 
risk underestimating the effect of health insurance on couples' retirement. This is because one spouse's retirement decision might affect the other spouse's health insurance coverage, which in turn affects both spouses' retirement decisions.

My paper contributes to the existing literature in three ways. First, I carefully model the interdependence of the two spouses' health insurance coverage. Using the information on the two spouses' employer-provided health insurance eligibility, my model constructs the available insurance plans for each spouse under each possible household retirement decision. Different household retirement decisions cause different household health insurance coverage. Thus, each spouse's health insurance coverage is modeled to depend on both spouses' retirement decisions.

Second, my paper includes heterogeneity in health insurance plan characteristics. For spouses who are eligible for both the husband and wife's employer-provided health insurance plans, my model allows them to choose one plan after comparing the plan characteristics (including paid premium, co-insurance rate, and deductible). By including this heterogeneity, I can evaluate the effects on retirement choices of policies affecting health insurance plan characteristics 9

Last, my paper models health as an additional channel that links health insurance and retirement. Previous papers studying health insurance and retirement assume that people value health insurance because they are risk averse and face uncertain future medical expenses (Rust and Phelan (1997), Blau and Gilleskie (2006, 2008), and French and Jones (2011)). ${ }^{10}$ Besides the medical expense channel, my paper models health status as an additional channel that connects health insurance coverage to the retirement decision. Health insurance can indirectly affect one's decision to retire by affecting one's health. People with health insurance tend to be healthier because they are more likely to use preventive

\footnotetext{
${ }^{9}$ In the literature on pension and retirement, several papers, such as Gustman et al. (1994), Gustman and Steinmeier (2000), and Fields and Mitchell (1984), find that workers with different pension plan types (or descriptions) have different retirement behaviors. Similarly, apply insurance plans with different characteristics to the same amount of total medical expenses can result out-of-pocket medical expenses with different volatility and mean. In other words, insurance plans with different characteristics can generate different financial incentives for spouses making retirement decisions.

${ }^{10}$ In the literature on health insurance and retirement, the medical expense channel is considered as the only channel through which health insurance can affect retirement decisions.
} 
medication, ${ }^{11}$ and being healthier can make people enjoy working more. Therefore, having health insurance may decrease people's preference for retirement.

The identification of two parameters of particular interest is warranted. First, the degree of risk aversion is identified by the co-variation in household savings and future uncertainty. A household with health insurance will save less than a household without insurance for two reasons: (1) the one with insurance has less uncertainty about future medical expenses (the "risk reducing" aspect of insurance); and (2) the insurance company helps to pay part of the medical expenses for the insured household (the "gift" aspect of insurance). For healthy people, the effect of the gift aspect of insurance on saving decisions is limited because their expected total medical expenses are small. Therefore, the degree of risk aversion is actually identified by the extent to which healthy, insurance-eligible households save less than healthy, ineligible households. Second, the parameters representing the husband's and wife's preferences for shared leisure are both identified by the co-variation in the two spouses' retirement choices: retiring simultaneously or not. Thus, the parameters representing the spouses' preferences for shared leisure cannot be identified separately. Following Van der Klaauw and Wolpin (2008) and Blau and Gilleskie (2006, 2008), I assume the two spouses' preferences for shared leisure to be the same 12

\footnotetext{
${ }^{11}$ Several papers (e.g., Currie and Gruber (1996), Levy and Meltzer 2008), Zimmer (2012), and Gustman and Steinmeier (2014)) find that people with health insurance tend to be healthier.

${ }^{12}$ Gustman and Steinmeier (2000, 2004, 2009) allow the husband and the wife to have asymmetric preferences for spending leisure with the other spouse. Their ability to separately identify these two parameters relies on an important assumption: the decision-making process in a family is a non-cooperative bargaining process.
} 


\section{Theoretical Model}

In this section, I develop a finite-horizon, discrete-time, dynamic model to show how households make decisions about retirement, employer-provided health insurance (EPHI) plans, and household consumption. Each household consists of two spouses ("husband" and "wife") who are both initially working, each with his or her own preferences ${ }^{13} \mid 14$

At the beginning of the first period, a household knows both spouses' labor incomes and pension benefits, both spouses' EPHI eligibilities, and the characteristics (premium, coinsurance rate, and deductible) of the insurance plans provided by both spouses' employers for all periods ${ }^{15} 16$ In addition, at the beginning of each period, the household observes household assets and the two spouses' health and survival statuses for the period. Although the household does not observe the two spouses' medical expenditures until the end of the period, it does know the joint distribution of the two spouses' medical expenditures. 17

With the above information in hand, a household makes three decisions at the beginning of each period: whether each spouse should retire if he or she is working; how to use available insurance; and how much the household should consume this period. ${ }^{18}$ These three decisions remain fixed for the duration of the period 19

During each two-year period, from $1992(t=1)$ to a known terminal period $(t=$ $T$ ), each household makes the three decisions with the goal of maximizing the expected discounted value of remaining lifetime utility, subject to budget constraints. The terminal

\footnotetext{
${ }^{13}$ In the rest of this paper, I use "he" as a generic pronoun.

${ }^{14}$ This paper does not include same-sex couples or cohabitants. Details are discussed in the data section.

${ }^{15}$ For each spouse, employer-provided health insurance eligibility includes four pieces of information: 1 ) whether he is eligible for his EPHI when he is working; 2) if yes, whether this working health insurance can cover his spouse; 3) whether he is eligible for his EPHI when he is retired; and 4) if yes, whether this retiree health insurance can cover his spouse.

${ }^{16}$ I assume that EPHI eligibility does not depend on job choice. If individuals could become eligible for employer-provided retiree health insurance by changing jobs, then the effect of health insurance on their employment decisions might be less than what the model finds because the incentive to stay employed, and thus keep health insurance coverage, is weaker (Madrian et al. (1994)).

${ }^{17}$ I assume that a household observes the two spouses' period- $t$ medical expenses after period- $t$ household decisions have been made. Blau and Gilleskie (2006) employ the same assumption.

${ }^{18}$ I define retirement as a state where an individual works less than full-time. Thus, I treat part-time work as retirement. Details about retirement decision are discussed in subsection 3.1.

${ }^{19}$ In reality, the household makes health treatment decisions, and so it can adjust its total medical expenditures on medical care. To reduce the computational burden, and following papers in the health insurance literature (e.g., Rust and Phelan (1997), Blau and Gilleskie (2008), and French and Jones (2011)), I assume that total medical expenditure is an exogenous variable that is a function of state variables (such as age, health, and retirement choice) and some random medical shocks. Details are discussed in subsection 3.4.
} 
period $T$ is a period by which both spouses in a household have retired permanently ${ }^{20}$ Let $T^{*}$ be the period by which both spouses in a household have died 21 For $T \leq t<T^{*}$, a household makes only the decision about consumption. The main features of the model are described in the following subsections.

\subsection{Discrete Choice Set}

At each discrete period $t$, other than a continuous household consumption choice, a household makes two discrete choices: the household retirement status and the EPHI plan choice.

\subsubsection{Retirement Status}

I define retirement as a state where an individual works less than full-time 22 Let

$$
L_{i t}=\left\{\begin{array}{ll}
1 & \text { if spouse } i \text { is in retirement in period } t \\
0 & \text { if spouse } i \text { is working in period } t
\end{array} \quad i=\{m, f\},\right.
$$

where $i$ is $m$ for the husband and $f$ for the wife. Retirement is assumed to be an absorbing state: once retired, one cannot return to work full-time in any future period. ${ }^{23}$ Let $\mathscr{L}_{\text {it }}$ denote the set of retirement statuses available to spouse $i$ in period $t$,

$$
\mathscr{L}_{i t}=\left\{L_{i, t-1} \cup 1\right\}
$$

The household retirement status consists of the two spouses' retirement statuses, $L_{t}=$ $\left(L_{m t}, L_{f t}\right)$. The choice set of household retirement status in period $t$ is

$$
\mathscr{L}_{t}=\mathscr{L}_{m t} \times \mathscr{L}_{f t}
$$

\footnotetext{
${ }^{20} \mathrm{I}$ assume that everyone has retired at age 72 (Blau and Gilleskie (2006)). $T$ is the period in which the younger spouse in a household turns 72 .

${ }^{21}$ I assume that everyone has died at age 100. $T^{*}$ is the period in which the younger spouse in a household turns 100 .

${ }^{22}$ Recall that all spouses are initially working full-time. I define both full retirement and part-time jobs as retirement because, according to the Hewitt survey of American businesses in the late 1990s, most (more than $75 \%$ of) part-time jobs did not offer health insurance. Consequently, the transition from a full-time job to a part-time job or full retirement might cause the loss of EPHI. Blau and Gilleskie (2006) also define part-time jobs as retirement.

${ }^{23}$ Very few people (less than $1 \%$ ) in my sample go back to full-time work from either part-time work or full retirement. Therefore, I assume in this paper that retirement is an absorbing state, and thus I do not model the transition from retirement to work. While Berkovec and Stern (1991) include reverse flows (from retirement to work) in their analysis, Hausman and Wise (1985) and Gustman and Steinmeier (2004) treat retirement as an absorbing state.
} 


\subsubsection{Employer-Provided Health Insurance Plan Choice}

A household also chooses the EPHI plan for each spouse. Let $j_{t}$ denote the household EPHI plan choice, which consists of the two spouses' EPHI plan choices, $j_{t}=\left(j_{m t}, j_{f t}\right)$. For each spouse $i, j_{i t}$ is defined as

$$
j_{i t}= \begin{cases}0 & \text { if spouse i hasnoEPHI coverage } \\ m & \text { if spouse i is covered by the husband's EPHI plan } \\ f & \text { if spouse i iscovered by the wife's EPHI plan. }\end{cases}
$$

If no EPHI plan is available to spouse $i$, then he has no EPHI coverage. If he is eligible for just one employer-provided plan-either his own or that of his spouse-then he automatically chooses to be covered by the plan. If he is eligible for insurance plans provided by both spouses' employers, then he picks one of the two plans. ${ }^{24}$

The choice set of household EPHI plans in period $t, \mathscr{J}_{t}$, depends on the household retirement status, $L_{t}$, and the household EPHI eligibility, $e_{t}=\left(e_{m t}, e_{f t}\right)$. Each spouse's EPHI eligibility, $e_{i t}$, is expressed using a vector of four dummy variables, $e_{i t}=\left(e_{i t}^{w 1}, e_{i t}^{w 2}, e_{i t}^{r 1}, e_{i t}^{r 2}\right)$.

Table 1 defines these four variables. See the Appendix for details about how the household

Table 1: Spouse $i$ 's EPHI Eligibility, $e_{i t}=\left(e_{i t}^{w 1}, e_{i t}^{w 2}, e_{i t}^{r 1}, e_{i t}^{r 2}\right)$

\begin{tabular}{|l|l|}
\hline $\mathrm{e}_{i t}^{w 1}=1$ & if spouse i's employer provides health insurance while he is working; \\
$\mathrm{e}_{i t}^{w 1}=0$ & otherwise. \\
\hline $\mathrm{e}_{i t}^{w 2}=1$ & if the working insurance provided by i's employer can cover the other spouse; \\
$\mathrm{e}_{i t}^{w 2}=0$ & otherwise. \\
\hline $\mathrm{e}_{i t}^{r 1}=1$ & if spouse i's employer provides health insurance while he is retired; \\
$\mathrm{e}_{i t}^{r 1}=0$ & otherwise. \\
\hline $\mathrm{e}_{i t}^{r 2}=1$ & if the retiree insurance provided by i's employer can cover the other spouse; \\
$\mathrm{e}_{i t}^{r 2}=0$ & otherwise.
\end{tabular}

EPHI eligibility, $e_{t}$, and the household retirement status, $L_{t}$, affect the choice set of household EPHI plan, $\mathscr{J}_{t}$.

The health insurance plans available to a person change when he turns 65 because he becomes eligible for Medicare ${ }^{25}$ Some people lose EPHI and have only Medicare available

\footnotetext{
${ }^{24}$ I assume that people always choose to be covered by some EPHI plan if they are eligible for one because that is what I observe in the data.

${ }^{25}$ Some spouses are eligible for Medicare before 65 if they have been receiving Social Security disability benefits for two years.
} 
to them when they turn 65 , while others continue to have EPHI available to them along with Medicare (McArdle et al. (2014)). In addition, some EPHI policies change when the person turns 65, either to supplement Medicare or to reduce benefits in order to induce people to switch to Medicare 26 This information is not observed in the data. Even if it were in the data, a model that took into account all of these characteristics would be computationally burdensome. To overcome this data problem and simplify the model, I assume that retirees switch from EPHI (if available) to Medicare at 65, and non-retirees are covered by both EPHI (if available) and Medicare until they retire 27

\subsection{Preferences}

The household utility flow in period $t$ is defined as the weighted sum of each spouse's utility. For each spouse $i$, his individual utility flow is a function of his retirement status, $L_{i t}$, the household consumption, $C_{t}$, and unobserved preferences, $\varpi_{i t}\left(d_{t}, l_{d t}\right)$, for the household discrete choice, $d_{t}=\left(L_{t}, j_{t}\right)$. Let $u_{i}\left(L_{i t}, C_{t}, \varpi_{i t}\left(d_{t}, l_{d t}\right)\right)$ denote spouse $i$ 's utility flow and

$$
U\left(d_{t}, C_{t}, \iota_{d t}\right)=\gamma u_{m}\left(L_{m t}, C_{t}, \varpi_{m t}\left(d_{t}, \iota_{d t}\right)\right)+(1-\gamma) u_{f}\left(L_{f t}, C_{t}, \varpi_{f t}\left(d_{t}, \iota_{d t}\right)\right)
$$

be the household utility function, where $\gamma$ is the husband's bargaining power (or some household sharing rule), which I assume is constant over time but differs across households 28

The utility flow for each spouse, $u_{i}$, is assumed to be non-decreasing and twice differentiable in household consumption, $C_{t}$. The function $u_{i}$ is assumed to take the form

$$
u_{i}\left(L_{i t}, C_{t}, \varpi_{i t}\left(d_{t}, u_{d t}\right)\right)=\frac{C_{t}^{1-\alpha}}{1-\alpha}+\exp \left\{\beta^{i} X_{t}^{i}\right\} L_{i t}+\varpi_{i t}\left(d_{t}, u_{d t}\right)
$$

where $\alpha$ measures the degree of risk aversion over consumption, and $\exp \left\{\beta^{i} X_{t}^{i}\right\}$ determines

\footnotetext{
${ }^{26}$ For example, some employers increase premiums and/or reduce coverage of plans provided to retirees.

${ }^{27}$ I make this assumption because the HRS data provides information only about whether an employer provides health insurance for retirees until they turn 65 , and less than $6 \%$ of spouses in my sample did not enroll in Medicare when they turned 65.

${ }^{28}$ I use a unique survey question in the HRS to impute the value of $\gamma$ for each household. Details are discussed in data section 4.8 .
} 
the value of leisure to spouse $i$. Spousal retirement status, $L_{-i, t}$, is a variable included in the vector of $X_{t}^{i}{ }^{29}$ The parameter associated with $L_{-i, t}$ measures spouse $i$ 's preference for retiring at the same time as his spouse (simultaneous retirement) (Gustman and Steinmeier (2000, 2004, 2009) $)^{30}$

The unobserved preference for the household discrete choice, $\varpi_{i t}\left(d_{t}, t_{d t}\right)$, is modeled as the sum of three unobserved variables:

$$
\varpi_{i t}\left(d_{t}, \iota_{d t}\right)=\eta_{L_{i t}}^{i}+\tau_{j_{i t}}^{i}+\iota_{d t}
$$

where the first two variables, $\eta_{L_{i t}}^{i}$ and $\tau_{j_{i t}}^{i}$, represent spouse $i$ 's time-invariant unobserved preferences for his retirement status, $L_{i t}$, and EPHI plan choice, $j_{i t}$, respectively. Including these sources of unobserved heterogeneity can help explain why some spouses always choose to work and why some always choose to be covered by their own EPHI plan, even when their spousal EPHI plan has better characteristics. The last variable, $t_{d t}$, is an idiosyncratic shock to the individual utility flow that spouse $i$ receives at time $t$ resulting from the household choice $d{ }^{31}$ For computational purposes, I assume that the two spouses receive the same idiosyncratic shock resulting from the household discrete choice. Including this assumption makes the household's idiosyncratic shock equal to each spouse's idiosyncratic shock. In this way, the household's shock is also distributed Extreme Value (EV) ${ }^{32}$ In addition, I assume that the two spouses' time-persistent choice-specific individual preferences, $\left(\eta_{L_{i t}}^{i}, \tau_{j_{i t}}^{i}\right)$, are known to the household at the beginning of the first period and that the idiosyncratic shock, $\imath_{d t}$, is known to the household at the beginning of period $t 33$

\footnotetext{
${ }^{29}$ The subscript $-i$ denotes the spouse of $i$.

${ }^{30}$ Note that the two spouses' preferences for simultaneous retirement cannot be separately identified. I assume that the husband's and wife's preferences for simultaneous retirement are equal. Details are discussed in the estimation section.

${ }^{31}$ In the literature, it is standard to include in the individual utility an Extreme Value (EV) distributed idiosyncratic shock resulting from an individual choice. This paper allows widows or widowers to make choices to maximize their individual choice-specific value function. I assume that each spouse's idiosyncratic shock is distributed EV, so the value function of surviving spouses has a closed-form expression. Details are discussed in the estimation section.

${ }^{32}$ Note that the idiosyncratic shock to the household is a weighted sum of the shock to each spouse. If the shocks to the two spouses are different, the shock to the household is not distributed EV, even if both spouses' individual shock are distributed EV.

${ }^{33}$ I discuss the empirical specification for the distributions of these unobserved preferences in the estimation section.
} 


\subsection{Budget Constraints}

In each period $t$, a household has household assets saved from the last period, $A_{t}$. In addition, the household receives household income during this period. The household has several sources of income: household asset income, $r A_{t}$, where $r$ is the constant asset return rate, ${ }^{34}$ the two spouses' labor incomes, $\sum_{i} w_{i t}\left(1-L_{i t}\right)$, where $w_{i t}$ denotes wage; pension benefits, $\sum_{i} b_{i t}$; Social Security benefits, $\sum_{i} s_{i t}$; and household government transfers, $g_{t}$. The household post-tax income, $y_{t}$, is a function of taxable income (including $r A_{t}$, $\sum_{i} w_{i t}\left(1-L_{i t}\right)$, and $\left.\sum_{i} b_{i t}\right)$, which captures the tax structure ${ }^{35}$ I describe the computation of $y_{t}$ in the Appendix.

The household spends money on consumption, $C_{t}$, and on household out-of-pocket medical expenditures, $\sum_{i=m, f} o_{i t}$, this period. The rest of the household's money is the household assets saved for the next period, $A_{t+1}$. Thus, the asset accumulation equation is

$$
A_{t+1}=A_{t}+y_{t}+\sum_{i=m, f} s_{i t}+g_{t}-\sum_{i=m, f} o_{i t}-C_{t}
$$

Households cannot borrow against future Social Security benefits, and it is very difficult to borrow against future pension benefits. Thus, I assume that the household faces the borrowing constraint,

$$
C_{t} \leqslant A_{t}+y_{t}+\sum_{i=m, f} s_{i t}+g_{t}
$$

Following Hubbard, Skinner, and Zeldes (1994, 1995), government transfers are modeled as

$$
g_{t}=\max \left\{0, C_{\min }-\left(A_{t}+y_{t}+\sum_{i=m, f} s_{i t}\right)\right\}
$$

The parameter $C_{\min }$, which I will estimate, is the consumption floor: the minimum amount,

\footnotetext{
${ }^{34}$ I assume that the asset return rate is constant over time. With this assumption, my model ignores the stochastic return to assets. Gustman and Steinmeier (2002) find that a stock market boom (in the late 1990s) can raise retirement rates by three percentage points per year. Later, Gustman et al. (2010) find that the decline in household assets due to a market downturn (in 2007) has very limited effects on retirement. The reason for the limited effects is that, for average households on the cusp of retirement, stock market holdings account for a small portion of their total assets.

${ }^{35}$ Some people who get Social Security must pay federal income taxes on their benefits if their modified adjusted gross income (AGI) exceeds a certain amount. I assume that Social Security benefits are not taxable because the HRS data has limited information to compute modified AGI.
} 
or sustenance level of consumption, that a household needs in every period. Although the data on government transfers does not always support equation (3.6) ${ }^{36}$ this equation is useful because it captures the penalty on saving behavior of asset-based means-tested programs (e.g., food stamps) in a simplified way ${ }^{37}$

In the next two subsections, I describe how I model three important parts of household budget constraints: each spouse's out-of-pocket medical expenditures, $o_{i t}$; Social Security benefits, $s_{i t}$; and pension benefits, $b_{i t}$.

\subsection{Medical Expenditure}

I model medical expenditure as a channel through which health insurance affects retirement decisions. Health insurance can affect both total medical expenditures and out-of-pocket medical expenditures. In this subsection, I first describe how I calculate each spouse's outof-pocket medical expenditures, given the characteristics of health insurance plans and the total medical expenditures. Then, I discuss the processes that generate the two spouses' total medical expenditures.

\subsubsection{Out-of-Pocket Medical Expenditure}

Spouse $i$ 's out-of-pocket medical expenditures, $o_{i t}$, are computed by applying the insurance plan characteristics (including paid premium, $\Gamma_{i t}$, co-insurance rate, $\Lambda_{i t}$, and deductible, $\Xi_{i t}$ ) to the total medical expenditures, $m_{i t}{ }^{38}$

$$
o_{i t}=m_{i t}-\left(1-\Lambda_{i t}\right) \max \left\{0,\left(m_{i t}-\Xi_{i t}\right)\right\}+\Gamma_{i t} .
$$

\footnotetext{
${ }^{36}$ In my sample, 41 households have financial resources (household assets plus household income) less than $\$ 7,734$ (the estimate of $C_{\text {min }}$ ) and receive no government transfers; and 36 households have financial resources more than $\$ 7,734$ and receive some government transfers.

${ }^{37}$ Several papers in the literature on health insurance (e.g., Casanova (2010), and French and Jones (2011)) model government transfers in the same way.

${ }^{38} \mathrm{I}$ assume that plan characteristics are exogenous. Workers do not make job choices based on the plan characteristics. Employers also do not choose plan characteristics based on their employees' health, nor do they structure plans to influence the distribution of workers with respect to health.
} 


\subsubsection{Total Medical Expenditure}

I assume that each spouse's total medical expenditures are generated by two separate processes: (1) whether each spouse has zero or positive total medical expenditures; and (2) the amount of total medical expenditures conditional on having positive total medical expenditures ${ }^{39}$ Within each process, I assume that the total medical expenditures depend on four components: (i) the individual's health insurance coverage, $I_{i t}$, because spouses with health insurance might visit doctors more often and choose more health care treatments: ${ }^{40}$ (ii) the individual's health status, $H_{i t}$, because healthier people usually need less medical care; (iii) the individual's retirement status, $L_{i t}: 41$ and (iv) the individual's demographic and socioeconomic factors (including age, race, education level, and household wealth), $X_{i t}$, because these factors have been found useful in explaining the variation in medical expenditures (Gao $(2007)) \cdot 42$

To model the first process, I use a probit framework. Let an indicator variable, $P_{i t}$, denote whether spouse $i$ has positive total medical expenditures in period $t$. The latent variable, $P_{i t}^{*}$, is modeled as a function of the four components and an error term, $\vartheta_{i t}$,

$$
\begin{gathered}
P_{i t}^{*}=P\left(I_{i t}, H_{i t}, L_{i t}, X_{i t}\right)+\vartheta_{i t} \\
\left(\begin{array}{c}
\vartheta_{m t} \\
\vartheta_{f t}
\end{array}\right) \sim N\left[\left(\begin{array}{l}
0 \\
0
\end{array}\right),\left(\begin{array}{cc}
1 & \rho_{\vartheta} \\
\rho_{\vartheta} & 1
\end{array}\right)\right] .
\end{gathered}
$$

To model the second process, I assume that positive total medical expenditures, $m_{i t}^{P}$, are a function of the same four components and an error term, $u_{i t}$. Medical expenditures for

\footnotetext{
${ }^{39}$ Following the literature on health cost (e.g., Pohlmeier and Ulrich (1995), Diehr et al. (1999), Buntin and Zaslavsky (2004), and Frees et al. (2011)), I consider the process that generates zero medical expenditures different from the one that generates positive medical expenditures. Casanova (2010) also considers two separate processes that generate medical expenditures.

${ }^{40}$ Health insurance coverage, $I_{i t}$, is a vector of both private (EPHI) and public (Medicare) insurance coverage.

${ }^{41}$ Frees et al. (2011) find that, on average, working people have less medical expenditures than those who do not work. This correlation means that retirement status is useful in explaining the variation in medical expenditures. I estimate equations for total medical expenditures outside of my structural model because the HRS data has no information on total medical expenses (explained in data section 4.1). Thus, my model cannot separately identify the causal effects of retirement status on medical expenses and the causal effects of medical expenses on retirement status.

${ }^{42}$ These demographic and socioeconomic factors have been included as explanatory variables for medical expenditures in a large health care literature that is summarized by $\mathrm{GaO}$ (2007).
} 
spouses facing retirement have two main features: (1) the distribution of medical expenditures has a long right tail (Casanova (2010)); and (2) medical expenditures are volatile, and the variance of medical expenditures varies across people (De Nardi et al. (2010)) ${ }^{43}$ To capture these two features, I model the log of positive total medical expenditures as

$$
\begin{gathered}
\ln \left(m_{i t}^{P}\right)=\mu\left(I_{i t}, H_{i t}, L_{i t}, X_{i t}\right)+\sigma\left(I_{i t}, H_{i t}, L_{i t}, X_{i t}\right) u_{i t}, \\
\left(\begin{array}{c}
u_{m t} \\
u_{f t}
\end{array}\right) \sim N\left[\left(\begin{array}{c}
0 \\
0
\end{array}\right),\left(\begin{array}{cc}
1 & \rho_{u} \\
\rho_{u} & 1
\end{array}\right)\right] .
\end{gathered}
$$

Combining the two processes described above, spouse $i$ 's total medical expenditures, $m_{i t}$, are

$$
m_{i t}=P_{i t} m_{i t}^{P}
$$

\subsection{Social Security and Pension Benefits}

Two sources of income, Social Security and pension benefits, can generate retirement incentives. I model these two programs in detail.

\subsubsection{Social Security Benefits}

Social Security benefits are determined by the age at which a worker claims the benefits and by his average indexed monthly earnings (AIME), which roughly equal his average labor income during his 35 highest earnings years, adjusted for inflation. Precisely calculating AIME requires keeping track of a worker's entire earnings history, which is computationally burdensome. To simplify the computation, I follow French and Jones (2011) in assuming that spouse $i$ 's annualized AIME in the next year is a function of his annualized AIME, wage, retirement status, and age this year (described in data section 4.7) ${ }^{44}$

The Social Security system has four features. First, for individuals who work less than 35 years, working more years automatically increases their AIME; and for individuals

\footnotetext{
43 De Nardi et al. (2010) find that the variance of medical expenditures rises with age, bad health, and income.

${ }^{44}$ Although AIME is a function of wage, it does not increase the size of the state space. This is because I assume that, at the beginning of the first period, a household observes the two spouses' wages for all periods.
} 
who have already worked more than 35 years, working more years increases their benefits only if labor income earned later is higher than income earned in some previous years. Because Social Security benefits increase in AIME, this decreases work incentives after 35 years of work.

Second, the age at which the individual claims Social Security affects the level of benefits. A worker can start his Social Security benefits as early as age 62. If he claims benefits at his normal retirement age (65), the Social Security benefits he receives are the Primary Insurance Amount (PIA), which is a monotone increasing function of his AIME ${ }^{45}$ If he claims benefits before age 65 , his benefits are reduced by $6.67 \%$ for every year before age 65 . But, if he claims benefits after age 65 , his benefits rise by $5.5 \%$ for every year after age 65 up until age 70. Thus, spouse $i$ 's benefits based on his own earnings history, $s_{i t}^{O}$, are a function of his age this period, $a_{i t}$, and his age and PIA at the time of claiming benefits, $\left(a_{i}^{c}, \Upsilon_{i}^{c}\right)$

$$
s_{i t}^{O}=s^{O}\left(a_{i t}, a_{i}^{c}, \Upsilon_{i}^{c}\right)
$$

Third, each spouse is eligible for spousal benefits when he is at least 62 and his spouse is receiving Social Security benefits. If he claims spousal benefits at his normal retirement age (65) or older, the spousal benefits equal one half of his spouse's benefits. If he claims benefits before age 65 , the benefits are reduced by $6.67 \%$ for every year before age 65.46 This rule may give spouses (usually those who have higher lifetime earnings in a household) incentives to retire earlier once their spouse turns 62. A worker's spousal benefits, $s_{i t}^{S}$, are a function of his age this period, $a_{i t}$, his age at the time of claiming benefits, $a_{i}^{c}$, and his spouse's benefits, $s_{-i, t}^{O}\left(a_{-i, t}, a_{-i}^{c}, \Upsilon_{-i}^{c}\right)$,

$$
s_{i t}^{S}=s^{S}\left(a_{i t}, a_{i}^{c} ; s_{-i, t}^{O}\right) .
$$

Fourth, widows or widowers are entitled to survivor benefits. The full retirement age for survivors is age 66. Survivors can get their deceased spouse's benefits at age 66 or older, and can get reduced benefits as early as age $60 .{ }^{47}$ If a survivor is getting benefits

\footnotetext{
${ }^{45}$ The details of the PIA formula are presented in the Appendix.

${ }^{46} \mathrm{An}$ individual cannot apply for spousal benefits and then later switch to his own benefits, or vice versa.

${ }^{47}$ If a spouse claims survival benefits before age 66 , the benefits he receives are reduced by $6 \%$ for every year before age 66 .
} 
(either spousal or their own benefits) when the other spouse dies, he can switch to survivor benefits if they are higher than the benefits he received before his spouse died. A worker's survivor benefits, $s_{i t}^{W}$, are a function of his age, $a_{i t}$, his age at the time of claiming survivor benefits, $a_{i}^{c W}$, and the deceased spouse's basic benefits, $s_{-i}^{D}$,

$$
s_{i t}^{W}=s^{W}\left(a_{i t}, a_{i}^{c W} ; s_{-i}^{D}\right) .
$$

In summary, the Social Security benefits that one receives depend on his own benefits, $s_{i t}^{O}$, the survival status of his spouse, $S_{-i, t}$, his spousal benefits, $s_{i t}^{S}$, and his survivor benefits, $s_{i t}^{W}$. Thus, spouse $i$ 's Social Security benefits in period $t, s_{i t}$, are

$$
s_{i t}=s\left(s_{i t}^{O}, S_{-i, t}, s_{i t}^{S}, s_{i t}^{W}\right)
$$

I describe the computation of $s_{i t}$ in more detail in the Appendix.

I assume that a spouse starts claiming benefits when he retires, or at age 62 if he retires earlier than $622^{48}$ This assumption simplifies the dynamic problem because it treats Social Security benefits as a variable determined by the retirement decision and previous work and earnings history. 49

\subsubsection{Pension Benefits}

There are two main types of pension plans: defined-benefit (DB) plans and defined-contribution (DC) plans. Different types of pension plans generate different incentives. DB plans give strong incentives for retirement at specific ages: the pension accrual rate is greatly reduced after a certain number of years of service in a firm, or past the early or normal retirement age 50 On the other hand, benefits from DC plans are determined by a worker's salary, his

\footnotetext{
${ }^{48}$ In my sample, $26 \%$ of spouses claim benefits either before or after they retire. Although, I might be able to model and estimate this decision, I choose not to because it would add two additional state variables into my model. Casanova (2010) tested this assumption by comparing the actual and assumed Social Security claiming data; the two series are very close.

${ }^{49}$ Individuals who continue to work after they claim benefits might be subject to the Social Security Earnings Test (SSER). I do not apply the earning test rule in this paper because: (1) benefits lost due to the earnings test are returned later with an actuarially fair increase; and (2) I assume that people claim benefits when they retire; thus, the earning test is not relevant to them. Recall that I aggregate part-time job to retirement. Thus, labor income from a part-time job is assumed away.

${ }^{50}$ In a DB plan, the employer guarantees that the employee will receive a definite amount of benefit upon retirement. Most defined benefit schemes provide benefits based on four key elements: (1) job tenure; (2)
} 
and his employer's contribution rates, and the asset return rate. This does not encourage or discourage retirement at specific ages (Lumsdaine et al. (1996)). However, most DC pension plans, such as 401(K) plans or IRAs, specify an early withdrawal age of age 59 1/2. Withdrawing benefits before this age is strongly penalized. This may encourage spouses with low household wealth to continue working at least until the early withdrawal age.

I model the pension benefits for DC and DB plans differently. If spouse $i$ has a DC plan, I assume that he withdraws the pension wealth when he retires, or at the early withdrawal age if he retires earlier ${ }^{51}$ His pension wealth in period $t, b_{i t}^{w}$, depends on pension wealth in the last period, $b_{i, t-1}^{w}$, and the pension accrual this period, $b_{i t}^{A}$,

$$
b_{i t}^{w}=(1+r) b_{i, t-1}^{w}+b_{i t}^{A},
$$

where $r$ is the constant asset return rate ${ }^{52}$ and $b_{i t}^{A}$ is a function of his labor income, $w_{i t}(1-$ $\left.L_{i t}\right)$, his contribution rate, $r_{i t}^{o}$, and his employer's contribution rate, $r_{i t}^{e}$,

$$
b_{i t}^{A}=w_{i t}\left(1-L_{i t}\right)\left(r_{i t}^{o}+r_{i t}^{e}\right) .
$$

Spouse $i$ 's DC pension benefits in period $t, b_{i t}^{D C}$, are a function of his pension wealth this period, $b_{i t}^{w}$, his age this period, $a_{i t}$, and his age at the time of his retirement, $a_{i}^{r}$,

$$
b_{i t}^{D C}\left(b_{i t}^{w}, a_{i t}, a_{i}^{r}\right)=\left\{\begin{array}{cc}
b_{i t}^{w} & \text { if } a_{i t}=a_{i}^{r}, \\
0 & \text { otherwise. }
\end{array}\right.
$$

Computing the pension benefits for DB plan recipients requires detailed data on DB plan characteristics, including normal and early retirement ages, job tenure, pensionable salary, and the pension accrual rate which varies with job tenure. This information is often pensionable salary (which is usually the average of salaries in years immediately before taking one's pension); (3) accrual rate (which could be a fixed number or a variable that varies with job tenure); and (4) the circumstances when benefits were taken from the scheme (such as retirement and early payment).

${ }^{51}$ Most DC plan recipients withdraw their pension wealth when they retire, and treat their pension wealth as household wealth.

${ }^{52}$ With a constant asset return rate, my model ignores an important feature of DC pension plans: the employees incur all of the risk associated with the random asset return rate. Yet, the effects on retirement of ignoring the randomness in asset return rates are very limited (explained in subsection 3.3). 
missing 53 Even if it were in the data, a model that took into account all of these characteristics would be computationally burdensome 54 To overcome this data problem and simplify the model, following French and Jones (2011), I model spouse $i$ 's DB pension benefits, $b_{i t}^{D B}$, as a function of his age this period, $a_{i t}$, and his age, PIA, and EPHI eligibility type at the time of his retirement, $\left(a_{i}^{r}, \Upsilon_{i}^{r}, e_{i}^{r}\right)$,

$$
b_{i t}^{D B}=b^{D B}\left(a_{i t}, \Upsilon_{i}^{r}, e_{i}^{r} ; \gamma^{a_{i}^{r}}\right),
$$

where $\gamma^{a_{i}^{r}}$ is a vector of parameters; it is the same across spouses but varies with retirement age 55 Accounting for the differences in DB pension benefits across different types of EPHI eligibility is important in isolating the effects of EPHI on retirement. As found in French and Jones (2011), workers who have retiree EPHI are likely to have greater pension benefits than others ${ }_{56}$ In other words, workers who have retiree EPHI might choose to retire earlier because: (1) their health insurance coverage is independent of their employment status; and (2) they have higher pension accrual rates than others.

In summary, spouse $i$ 's pension benefits, $b_{i t}$, are

$$
b_{i t}=b_{i t}^{D C} 1_{[D C]}+b_{i t}^{D B} 1_{[D B]},
$$

where $1_{[D C]}$ is a variable indicating whether spouse $i$ has a DB plan, and $1_{[D B]}$ is a variables

\footnotetext{
${ }^{53}$ The HRS data matches with a data on pensions from a survey of the employers of HRS sample members. The data on pensions provides crucial information to calculate DB plan benefits. However, some HRS respondents do not have matched pension data, and this data can be used only on a computer that is not connected to the internet. I cannot use this data because, to run parallel computing for my code, I need to use the High-Performance Computing system at University of Virginia, and this requires internet access.

${ }^{54}$ In the literature on retirement, papers that address the difficulty in modeling the DB pension benefits use different simplification methods. Some papers exclude people who are covered by a DB plan (Van der Klaauw and Wolpin (2008)) or by any pension plan (Benitez-Silva et al. (1999, 2004)). Other papers use data on pension plan characteristics to calculate DB plan benefits, and reduce the computational burden by simplifying other parts of the model. For example, Gustman and Steinmeier (2008) simplify the model by taking the spousal labor market decision as exogenous; and Fields and Mitchell (1984) simplify the model by ignoring the variation in individuals' earnings and years of service.

${ }^{55}$ The function that determines the DB pension benefits is the same for everyone. Details about this function are discussed in the Appendix.

56 French and Jones (2011) divide EPHI eligibility into three types: no EPHI, tied EPHI and retiree EPHI. Tied EPHI means that employer-provided health insurance is available to a spouse only when he continues to work, while retiree EPHI means that employer-provided insurance is available whether he continues to work or retires.
} 
indicating whether he has a DC plan.

\subsection{Health Transitions and Survival Rates}

In every period $t$, the household is uncertain about future health and survival status of the two spouses. The household adjusts its behavior in every period based on its subjective belief about future health and survival status. In this subsection, I model a household's subjective belief about health and survival status in the next period, conditional on state variables in the current period.

\subsubsection{Household Health Transitions}

In a household, the two spouses' health transitions may be interdependent because they experience similar events that can affect health 57 I use a bivariate probit framework to model the household health transitions 58 I model health transitions as a second channel through which health insurance can affect retirement decisions. ${ }^{59}$ Health insurance (especially private health insurance) can affect health, and health is a factor that determines spouses' preference for leisure (equation 3.2 ) ${ }^{60}$ Let an indicator variable, $H_{i t}$, denote whether spouse $i$ has good health in period $t$. The latent variable, $H_{i t}^{*}$, represents the true (continuous) health status of spouse $i$ in period $t . H_{i t}^{*}$ is modeled as a function of health insurance coverage, $I_{i, t-1}$, health status, $H_{i, t-1}{ }^{61}$ and demographic information, $X_{i, t-1}$, in

\footnotetext{
${ }^{57} \mathrm{As}$ Wilson (2002) points out, the health status of the two spouses in a household often are interdependent due to marriage sorting, similar lifestyles, or shared family income and health insurance coverage.

${ }^{58}$ Previous papers (e.g., Blau (1998), and French and Jones (2004)) that study the retirement behavior of married couples ignore the possible correlation between the husband's and wife's health transitions and calculate them separately.

${ }^{59}$ Recall that the first channel (described in subsection 3.4) is that health insurance can affect retirement decisions through spouses' out-of-pocket medical expenditures, which are part of the household budget constraint.

${ }^{60}$ While Finkelstein et al. (2013) find no significant effects of Medicaid coverage on health, Dor et al. (2006), Levy and Meltzer (2008), and Zimmer (2012) find positive effects of health insurance (especially private health insurance) on health.

${ }^{61}$ It is more realistic to model the health transition, the utility flow, and total medical expenses as functions of the true continuous health status, $H_{i t}^{*}$. However, it is difficult to incorporate $H_{i t}^{*}$ in the model because: (1) $H_{i t}^{*}$ is not observed; and (2) health status becomes a continuous state variable. In the future, I can extend my model using the technique developed in Brien et al. (2006), which shows how to use a modified GHK algorithm (Geweke (1989), Hajivassiliou (1990), and Keane (1994)) to solve a dynamic structural model that includes an unobserved continuous state variable.
} 
the last period, and an error term, $u_{i t}^{H}$,

$$
\begin{gathered}
H_{i t}^{*}=H\left(I_{i, t-1}, H_{i, t-1}, X_{i, t-1}\right)+u_{i t}^{H}, \\
\left(\begin{array}{c}
u_{m t}^{H} \\
u_{f t}^{H}
\end{array}\right) \sim N\left[\left(\begin{array}{l}
0 \\
0
\end{array}\right),\left(\begin{array}{cc}
1 & \rho_{H} \\
\rho_{H} & 1
\end{array}\right)\right] .
\end{gathered}
$$

\subsubsection{Household Survival Rates}

Similar to the way that I model household health transitions, I use a bivariate probit framework to model household survival rates. ${ }^{62}$ Let an indicator variable, $S_{i t}$, denote whether spouse $i$ is alive at period $t$. The latent variable, $S_{i t}^{*}$, measures the underlying continuous propensity for spouse $i$ to survive at period $t . S_{i t}^{*}$ is modeled as a function of demographics, $X_{i, t-1}$, and health status, $H_{i, t-1}$, in the last period, and an error term, $u_{i t}^{S} 63$

$$
\begin{gathered}
S_{i t}^{*}=S\left(X_{i, t-1}, H_{i, t-1}\right)+u_{i t}^{S} \\
\left(\begin{array}{c}
u_{m t}^{S} \\
u_{f t}^{S}
\end{array}\right) \sim N\left[\left(\begin{array}{c}
0 \\
0
\end{array}\right),\left(\begin{array}{cc}
1 & \rho_{S} \\
\rho_{S} & 1
\end{array}\right)\right] .
\end{gathered}
$$

The two error terms, $u_{i t}^{H}$ and $u_{i t}^{S}$, denote spouse $i$ 's idiosyncratic health shock and mortality shock, respectively. One spouse's health shock, mortality shock, and medical expense-related shocks, $\left(\vartheta_{i t}, u_{i t}\right)$, might be correlated. Limitations in my data prevent me from modeling the possible correlation between medical expense-related shocks and the other two shocks. ${ }^{64}$ And I assume that a spouse's health shock is independent from his life shock. Ignoring the correlation between these two shocks may cause biased estimates. ${ }^{65}$

\footnotetext{
${ }^{62}$ In the literature on married couples' retirement (e.g., Blau and Gilleskie (2006), and Gustman and Steinmeier (2004)), the husband's and wife's survival rates are calculated separately.

${ }^{6} 3$ Casanova (2010) assumes that the survival rate is a function of age and gender. French and Jones (2004) model the survival rate as a function of previous health status and age.

${ }^{64}$ The HRS data has no information on total medical expenses, and I use a different data set to estimate medical expense-related equations, separately from estimating health transitions and survival rates (explained in data section 4.1).

${ }^{65}$ If one spouse's health shock and life shock are positively correlated, ignoring this correlation might underpredict the probability of being alive in the next period. Then, the model might overpredict the household savings. The overprediction of household savings may cause a downward bias in the estimate of risk aversion parameter. In the health insurance literature, some papers (e.g., Blau and Gilleskie (2008) model the possi-
} 
In the next subsection, I discuss how I model the household utility function when one or both spouses die.

\subsection{Death and Bequest Function}

If one spouse dies, the surviving spouse continues to choose retirement status and consumption in order to maximize the household's remaining lifetime utility ${ }^{66}$ The household utility flow now is the surviving spouse's individual utility flow times his original bargaining power. If both spouses die, following De Nardi (2004), the household utility flow is modeled as a function of assets, $A_{t}$, bequeathed to survivors in the family,

$$
B\left(A_{t}\right)=\theta_{B} \frac{\left(A_{t}+K\right)^{1-\alpha}}{1-\alpha}
$$

where $\theta_{B}$ is the intensity of the bequest motive, and $K$ determines the extent to which bequests are luxury goods. ${ }^{67}$

\subsection{Value Function}

I assume households are forward-looking. Each period, a household makes choices in order to maximize its present discounted value of expected lifetime utility subject to the budget constraints. Let $z_{t}=\left(A_{t}, H_{t}, S_{t}, l_{d t}\right)$ be the state variables in period $t$ that are either endogenous or stochastic ${ }^{68}$ Note that $H_{t}=\left(H_{m t}, H_{f t}\right)$ denotes household health status, and $S_{t}=\left(S_{m t}, S_{f t}\right)$ denotes household survival status. The optimization problem can be represented in terms of choice-specific value functions which give the lifetime discounted value of a vector of household choices, $\left(d_{t}, C_{t}\right)$, for a given set of state variables, $z_{t}$.

ble correlation between one's health and life shocks, while others (e.g., Rust and Phelan (1997)) ignore this possible correlation.

${ }^{66}$ The surviving spouse is usually no longer eligible for the deceased spouse's EPHI. I assume that a surviving spouse is covered by his own EPHI (if available).

${ }^{67}$ This paper ignores divorce because less than $1 \%$ of couples in the sample divorce. Thus, I do not have enough observations to estimate any parameters associated with divorce. For a similar reason, I ignore remarriage of a widow or widower.

${ }^{68}$ Recall that I assume a household observes the two spouses' wage and EPHI eligibility for all period. Thus, wage and EPHI eligibility are neither endogenous nor stochastic state variables. 
The value function for a household in period $t$ is

$$
\begin{gathered}
V\left(z_{t}\right)=\underset{\left(d_{t}, C_{t}\right)}{\operatorname{Max}}\left\{v\left(d_{t}, C_{t} ; z_{t}\right)\right\} \\
\text { subject to } \\
A_{t+1}=A_{t}+y_{t}+\sum_{i=m, f} s_{i t}+g_{t}-\sum_{i=m, f} o_{i t}-C_{t}, \\
C_{t} \leqslant A_{t}+y_{t}+\sum_{i=m, f} s_{i t}+g_{t}, \\
g_{t}=\max \left\{0, C_{\min }-\left(A_{t}+y_{t}+\sum_{i=m, f} s_{i t}\right)\right\} .
\end{gathered}
$$

The term $v\left(d_{t}, C_{t} ; z_{t}\right)$ in equation 3.20$)$ is the choice-specific value function

$$
\begin{aligned}
v\left(d_{t}, C_{t} ; z_{t}\right) & =E_{m}\left\{v\left(d_{t}, C_{t} ; z_{t} \mid m_{t}\right)\right\} \\
& =U\left(d_{t}, C_{t}, l_{d t}\right)+\beta E_{m}\left\{E\left[V\left(z_{t+1}\right) \mid A_{t}, H_{t}, S_{t}, d_{t}, C_{t}, m_{t}\right]\right\}
\end{aligned}
$$

where $\beta$ is the time discount factor. $E\left[V\left(z_{t+1}\right) \mid A_{t}, H_{t}, S_{t}, d_{t}, C_{t}, m_{t}\right]$ is the expected value function in period $t+1$, conditional on three state variables, $\left(A_{t}, H_{t}, S_{t}\right)$, household choices $\left(d_{t}, C_{t}\right)$, and the two spouses' total medical expenses, $m_{t}=\left(m_{m t}, m_{f t}\right)$, in period $t$. Given the household consumption choice in period $t$, the household assets at the beginning of the next period, $A_{t+1}$, depends on the two spouses' total medical expenses in current period, $m_{t}$. Different realizations of $m_{t}$ generate different values of $A_{t+1}$, and then generate different values of $E\left[V\left(z_{t+1}\right) \mid A_{t}, H_{t}, S_{t}, d_{t}, C_{t}, m_{t}\right]$. Recall that the household does not know the realization of $m_{t}$ at the beginning of period $t$, and thus, when the household makes choices, it knows only the expected value of $E\left[V\left(z_{t+1}\right) \mid A_{t}, H_{t}, S_{t}, d_{t}, C_{t}, m_{t}\right]$ with respect to the joint distribution of $m_{t}, F(\cdot)$,

$$
E_{m}\left\{E\left[V\left(z_{t+1}\right) \mid A_{t}, H_{t}, S_{t}, d_{t}, C_{t}, m_{t}\right]\right\}=\int_{m_{t}} E\left[V\left(z_{t+1}\right) \mid A_{t}, H_{t}, S_{t}, d_{t}, C_{t}, m_{t}\right] d F\left(m_{t}\right)
$$

Expectations in the term $E\left[V\left(z_{t+1}\right) \mid A_{t}, H_{t}, S_{t}, d_{t}, C_{t}, m_{t}\right]$ are taken over the idiosyncratic utility shock, $\imath_{d, t+1}$, and future household health and survival status, $\left(H_{t+1}, S_{t+1}\right)$. At period $t$, a household does not know the two spouses' health and survival statuses in the 
next period, but it has subjective beliefs about each spouse's probability of being in good health and probability of being alive in the next period. Let $\pi\left(H_{t+1}, S_{t+1} \mid A_{t}, H_{t}, S_{t}, d_{t},\right)$ denote the household's subjective beliefs about household health and survival status in the next period, $\left(H_{t+1}, S_{t+1}\right)$, conditional on three state variables, $\left(A_{t}, H_{t}, S_{t}\right)$, and household discrete choices in the current period, $d_{t}$. Then, the expected value function in period $t+1$ can be expressed as

$$
E\left[V\left(z_{t+1}\right) \mid A_{t}, H_{t}, S_{t}, d_{t}, C_{t}, m_{t}\right]=\sum_{\left(H_{t+1}, S_{t+1}\right)} E V\left(z_{t+1} \mid C_{t}, m_{t}\right) \pi\left(H_{t+1}, S_{t+1} \mid A_{t}, H_{t}, S_{t}, d_{t}\right)
$$

where

$$
E V\left(z_{t+1} \mid C_{t}, m_{t}\right)=\underset{\left(d_{t+1}, C_{t+1}\right)}{\operatorname{Emax}}\left\{v\left(d_{t+1}, C_{t+1} ; z_{t+1} \mid C_{t}, m_{t}\right)\right\}
$$

The household uses the value functions to determine the optimal choices each period. 


\section{Data}

\subsection{Data Sources}

I use data from three sources: the Health and Retirement Study (HRS), the Medical Expenditure Panel Survey (MEPS), and the Panel Study of Income and Dynamics (PSID). The primary source of data is the HRS, which is a detailed panel survey of individuals over age 50 and their spouses. It collects extensive information about household characteristics, labor force participation, health insurance coverage, health transitions, income, assets, pension plans, and health care expenditures. The HRS began in 1992 and, since then, it has re-interviewed the same households every two years. ${ }^{69}$ I use data from the first nine waves, which cover 1992 to 2008 .

Although the HRS provides most of the information I need to estimate my model, it is not an ideal data set for two types of information: total medical expenditures and health insurance plan characteristics. ${ }^{70}$ First, the HRS data have no information on individuals' total medical expenses, which I need to predict out-of-pocket expenses on alternative plans ${ }^{71}$ To overcome this problem, I impute total medical expenses using MEPS, which is "a set of large-scale surveys of families and individuals, their medical providers, and their employers.' ${ }^{72}$ The MEPS began in 1996 and provides precise information about household total medical expenses. I use households in the MEPS to estimate the part of the model that determines total medical expenses (equations (3.8)-(3.9)), and then use the estimates to impute total medical expenses for each spouse each period.

Second, the HRS data have no information on health insurance plan characteristics. To impute plan characteristics for each spouse, I use MEPS, which provides the average plan characteristics (including average paid premium, co-insurance rate, and deductible) of employer-provided plans by industry type and firm size in the private sector and for government institutions in the public sector. I assign the averages of insurance plan characteristics

\footnotetext{
${ }^{69}$ New cohorts are added every three waves.

${ }^{70}$ Health insurance plan characteristics include premiums and deductibles (for both family and single plans), as well as the coinsurance rate.

${ }^{71}$ The HRS only collects data on out-of-pocket medical expenses.

${ }^{72}$ See the Medical Expenditure Panel Survey homepage: http://meps.ahrq.gov/mepsweb/
} 
to each spouse in my sample according to his employment industry type, firm size, and sector 73

Another problem with the HRS is that it collects individuals' labor income histories in a restricted file, and I cannot use this file because it can be used only on a computer that is not connected to other computers..$^{74}$ Yet, I need a worker's earnings history to calculate his average indexed monthly earnings (AIME), Social Security benefits, and pension benefits. To solve this data problem, I assume that an individual's labor income follows a modified AR(1) process (described in subsection 4.7) (Guvenen (2009)). With the estimates of this modified AR(1) process, I construct each individual's earnings history backward from the labor income recorded in the 1992 HRS. A useful data set for estimating the modified AR(1) process is the PSID, which is a longitudinal household survey that has been operating since 1968. The PSID collects data on employment and income for individuals in a nationally representative sample of households. In subsection 4.7, I describe how I use the PSID and the HRS together to impute an individual's earnings history before 1992.

\subsection{Sample}

I restrict my sample to couples in long-term marriages 85 in which both spouses were fulltime workers in the first wave ${ }^{76}$ Table 2 describes the criteria that I use and the number of couples I delete due to each criterion.

Table 2: Sample Selection Criteria for the HRS Sample

\begin{tabular}{lcc}
\hline \hline Criteria & $\begin{array}{c}\text { Observation } \\
\text { Deleted }\end{array}$ & $\begin{array}{c}\text { Observation } \\
\text { Remaining }\end{array}$ \\
\hline Couples with only one spouse interviewed & & 4,746 \\
Changed spouses after age 35 & 1,310 & 3,436 \\
Not both full-time workers in 1992 & 2,513 & $\mathbf{9 2 3}$ \\
\hline \hline
\end{tabular}

\footnotetext{
${ }^{73}$ The MEPS divides firms into two sectors: private and public. Firms in the private sector are divided into 10 industry types using the two-digit SIC (Standard Industrial Classification) codes (e.g., construction, wholesale, and retail, etc.). Details about averages of plan characteristics are discussed in subsection 4.5.

${ }^{74}$ I cannot use this restricted file because, to run parallel computing for my code, I need to use the HighPerformance Computing system at University of Virginia, and this violates the restrictive of data rules.

${ }^{75}$ Long-term marriages are defined as beginning before both spouses were aged 35. As Gustman and Steinmeier (2002) point out, in the cases of those who change spouses after age 35, it is necessary to consider how much wealth each spouse brings into the marriage and how they split obligations to children-factors that are not recorded in the HRS data.

${ }^{76}$ Full-time work is defined as $30+$ hours per week and $36+$ weeks per year.
} 
The resulting estimation sample is 923 couples and 6461 household-period observations. My sample does not include cohabitants because the HRS does not survey them about the length of their current relationship, and my sample requires couples in long-term relationships. In addition, my sample does not include same-sex couples because same-sex marriage was not recognized in 1992, and same-sex couples were documented as "partners" (meaning cohabitants) in the HRS.

\subsection{Health Insurance Eligibility}

My structural model requires information about employer-provided health insurance (EPHI) eligibility for both spouses in a household ${ }^{77}$ However, in the HRS, the only people who report their EPHI eligibility are those covered by their own EPHI plan. Consequently, there is no information about the EPH eligibility of those who are covered by their spouse's employer. ${ }^{78}$

To solve the missing data problem, I need a model that accounts for two elements: (1) the relationship between the observed EPHI eligibility and explanatory variables for those who report their EPHI eligibility; and (2) the selection of reporting EPHI eligibility. It would be ideal to use structural equations to model the observed EPHI eligibility and the selection of reporting EPHI eligibility. However, modeling the EPHI eligibility in a structural way requires modeling how workers choose a job based on employer-provided plan characteristics. Job choice-related information is not recorded in the HRS data. In addition, although my structural model describes the spouses' health insurance coverage choice, using my structural model to explain the selection of reporting EPHI eligibility makes EPHI eligibility a vector of four state variables. To simplify the dynamic computation, rather than treating EPHI eligibility as a vector of four state variables, I instead assume that, at the beginning of the first period, a worker knows his EPHI eligibility for all periods. I use a multivariate probit framework to model the EPHI eligibility and the selection of reporting EPHI eligibility, and I use the estimates to impute EPHI eligibility for spouses who do not

\footnotetext{
${ }^{77}$ The details of EPHI eligibility are discussed in model section 3.1.2.

${ }^{78}$ Figure A1 in the Appendix shows how the HRS surveys households about their EPHI coverage.
} 
report their EPHI eligibility. 79

First, I model a spouse's EPHI eligibility. Recall that I use a vector of four dummy variables, $e_{i t}=\left(e_{i t}^{w 1}, e_{i t}^{w 2}, e_{i t}^{r 1}, e_{i t}^{r 2}\right)$, to represent spouse $i$ 's EPHI eligibility ${ }^{80}$ Note that $e_{i t}^{w 2}=$ 0 if $e_{i t}^{w 1}=0, e_{i t}^{r 1}=0$ if $e_{i t}^{w 1}=0$, and $e_{i t}^{r 2}=0$ if $e_{i t}^{r 1}=0$ or $e_{i t}^{w 2}=0$. Spouses who have more education are more likely to have a job that provides health insurance, and employers who provide pension benefits are more likely to provide health insurance (especially retiree health insurance). Thus, the latent variable of each of these dummy variables is modeled as a function of one's demographic characteristics (including race, gender, age, health, and education), $X_{i t}^{d}$, his employment characteristics (including firm size, working hours, hourly wage, tenure, and pension availability), $X_{i t}^{E}$, and an error term. These four latent variables can be expressed as

$$
\begin{gathered}
e_{i t}^{w 1 *}=e\left(X_{i t}^{d}, X_{i t}^{E} ; \varsigma_{w 1}\right)+\omega_{i t}^{w 1}, \\
\left.e_{i t}^{w 2 *}\right|_{\left[e_{i t}^{w 1}=1\right]}=e\left(X_{i t}^{d}, X_{i t}^{E} ; \varsigma_{w 2}\right)+\omega_{i t}^{w 2}, \\
\left.e_{i t}^{r 1 *}\right|_{\left[e_{i t}^{w 1}=1\right]}=e\left(X_{i t}^{d}, X_{i t}^{E} ; \varsigma_{r 1}\right)+\omega_{i t}^{r 1}, \\
\left.e_{i t}^{r 2 *}\right|_{\left[e_{i t}^{r 1}=1 ; e_{i t}^{w 2}=1\right]}=e\left(X_{i t}^{d}, X_{i t}^{E} ; \varsigma_{r 2}\right)+\omega_{i t}^{r 2} .
\end{gathered}
$$

Different combinations of these four binary variables represent different types of EPHI eligibility. I assume that there are three mutually exclusive categories of EPHI eligibility. The first category is None, which consists of workers whose employers provide no health insurance at all. The second category is Tied, where workers receive their employer-provided insurance as long as they continue to work. The third category is Retiree, where workers keep their health insurance even after leaving their jobs. Each category consists of one or more types of EPHI eligibility. Table 3 defines the three categories and the six types of EPHI eligibility using the four binary variables.

Next, I model the selection of reporting EPHI eligibility. Let an indicator variable, $e_{i t}^{s}$, denote whether spouse $i$ reports his EPHI eligibility. Spouses who report EPHI eligibility are those who are covered by their own EPHI plan, either because they are not

\footnotetext{
${ }^{79}$ Because the multivariate probit model is used to impute EPHI eligibility, I hereafter describe it as the EPHI eligibility imputation model.

${ }^{80}$ The definitions of these dummy variables are discussed in model section 3.1.2.
} 
Table 3: EPHI Eligibility

\begin{tabular}{c|c|cccc}
\hline \hline Eligibility Category & Eligibility Type & $e^{w 1}$ & $e^{w 2}$ & $e^{r 1}$ & $e^{r 2}$ \\
\hline None & N1N2 & 0 & 0 & 0 & 0 \\
\hline Tied & T1N2 & 1 & 0 & 0 & 0 \\
& T1T2 & 1 & 1 & 0 & 0 \\
\hline Retiree & R1N2 & 1 & 0 & 1 & 0 \\
& R1T2 & 1 & 1 & 1 & 0 \\
& R1R2 & 1 & 1 & 1 & 1 \\
\hline \hline
\end{tabular}

Note: In the eligibility type column, N, T, and R are short for None, Tied, and Retiree, and numbers 1 and 2 represent self and spouse, respectively. For example, T1T2 means that a sposue is eligible for his EPHI only when he is working, and this working health insurance can cover his spouse.

eligible for their spouse's EPHI, or because their employer provides better plans than their spouse's employer. I assume that one's own EPHI plan characteristics are correlated with employment characteristics. Spouses who have similar employment characteristics might have different coverage. For example, some are covered by their own EPHI plan because their spouse has a part-time job that does not provide insurance; while others are covered by their spousal EPHI plan because their spouse works for a big firm that provides a good spousal plan. Thus, whether a spouse is covered by his own EPHI is correlated with his own and his spouse's employment characteristics. The latent variable, $e_{i t}^{s *}$, is modeled as

$$
e_{i t}^{s *}=e^{s}\left(X_{i t}^{d}, X_{i t}^{E}, X_{-i, t}^{E} ; \varsigma_{s}\right)+\omega_{i t}^{s}
$$

where $X_{i t}^{d}, X_{i t}^{E}$, and $X_{-i, t}^{E}$ represent spouse $i$ 's demographic characteristics, his employment characteristics, and his spouse's employment characteristics, respectively; and $\omega_{i t}^{S}$ is an error term. Let $\omega_{i t}=\left(\omega_{i t}^{w 1}, \omega_{i t}^{w 2}, \omega_{i t}^{r 1}, \omega_{i t}^{r 2}, \omega_{i t}^{S}\right)^{\prime}$, and assume that $\omega_{i t} \sim N\left(0, \Sigma_{\omega}\right)$. The EPHI eligibility imputation model consists of equations (4.1)-4.5. To estimate this model, I use married people who are working in the HRS. The estimates are used to predict the probability of the occurrence of each type of EPHI eligibility for spouses in my sample who do not report their EPHI eligibility 81

Tables 4 and 5 list the sample statistics for EPHI eligibility for husbands and wives,

\footnotetext{
${ }^{81}$ The details of the estimation of the EPHI eligibility imputation model are discussed in the Appendix.
} 
respectively, in the first wave. 82 In both tables, the third column lists the statistics for observed (binary) EPHI eligibility for those who report their EPHI eligibility. The fourth column lists the statistics for imputed (continuous) EPHI eligibility for those who do not report their EPHI eligibility. The last columns in tables 4 and 5 list statistics for EPHI eligibility for all husbands and all wives, respectively.

Table 4: EPHI Eligibility Distribution in 1992: Husband

\begin{tabular}{l|c|cc|cc|cc}
\hline \hline \multirow{2}{*}{ Category } & & \multicolumn{2}{|c|}{ Observed } & \multicolumn{2}{c|}{ Imputed } & \multicolumn{2}{c}{ All Husbands } \\
& Type & Mean & Std. Dev. & Mean & Std. Dev. & Mean & Std. Dev. \\
\hline None & N1N2 & 0.144 & $(0.35)$ & 0.196 & $(0.40)$ & 0.156 & $(0.35)$ \\
\hline Tied & T1N2 & 0.034 & $(0.18)$ & 0.107 & $(0.31)$ & 0.051 & $(0.17)$ \\
& T1T2 & 0.192 & $(0.39)$ & 0.149 & $(0.33)$ & 0.182 & $(0.44)$ \\
\hline Retiree & R1N2 & 0.005 & $(0.07)$ & 0.009 & $(0.01)$ & 0.006 & $(0.06)$ \\
& R1T2 & 0.024 & $(0.15)$ & 0.054 & $(0.15)$ & 0.031 & $(0.16)$ \\
& R1R2 & 0.601 & $(0.49)$ & 0.485 & $(0.33)$ & 0.574 & $(0.44)$ \\
\hline \hline
\end{tabular}

Note: See the note in Table 3 for an explanation of the type column.

Table 5: EPHI Eligibility Distribution in 1992: Wives

\begin{tabular}{l|c|cc|cc|cc}
\hline \hline \multirow{2}{*}{ Category } & & \multicolumn{2}{|c|}{ Observed } & \multicolumn{2}{c|}{ Imputed } & \multicolumn{2}{c}{ All Wives } \\
& Type & Mean & Std. Dev. & Mean & Std. Dev. & Mean & Std. Dev. \\
\hline None & N1N2 & 0.142 & $(0.35)$ & 0.146 & $(0.33)$ & 0.144 & $(0.33)$ \\
\hline Tied & T1N2 & 0.042 & $(0.20)$ & 0.102 & $(0.14)$ & 0.070 & $(0.16)$ \\
& T1T2 & 0.243 & $(0.43)$ & 0.228 & $(0.34)$ & 0.236 & $(0.31)$ \\
\hline Retiree & R1N2 & 0.012 & $(0.11)$ & 0.008 & $(0.02)$ & 0.010 & $(0.09)$ \\
& R1T2 & 0.030 & $(0.17)$ & 0.028 & $(0.21)$ & 0.029 & $(0.15)$ \\
& R1R2 & 0.531 & $(0.49)$ & 0.488 & $(0.32)$ & 0.511 & $(0.44)$ \\
\hline \hline
\end{tabular}

Note: See the note in Table 3 for an explanation of the type column.

The percentage of spouses in the tied category equals the sum of percentages of spouses in types $\mathrm{T} 1 \mathrm{~N} 2$ and $\mathrm{T} 1 \mathrm{~T} 2$, and the percentage of spouses in the retiree category equals the sum of percentages of spouses in types R1N2, R1T2, and R1R2 ${ }^{83}$ Compared to spouses who report their EPHI eligibility (observed), spouses who do not report their eligibility (imputed) have higher percentages of individuals in the none or the tied category, and they have a smaller percentage of spouses in the retiree category. These differences

\footnotetext{
${ }^{82}$ In the data, the observed EPHI eligibility type rarely changes over time, and thus, I assume that each spouse's EPHI eligibility type remains the same.

${ }^{83}$ For example, for those who report their eligibility, the percentages of husbands in the none, the tied, and the retiree categories are $14.4 \%, 22.6 \%$, and $63 \%$, respectively. For those who do not report their eligibility, the percentages of husbands in the none, the tied, and the retiree categories are $19.6 \%, 25.6 \%$, and $54.8 \%$, respectively.
} 
between the imputed and the observed EPHI eligibility distributions can be explained by the selection pattern of reporting EPHI eligibility in the HRS. Spouses who do not report their eligibility are those who are covered by their spouse's EPHI plan, either because they are not eligible for their own EPHI, or because their employer provides worse plans than their spouse's employer. On average, employers who provide tied health insurance provide less generous plans than employers who provide retiree insurance $(\operatorname{Miller}(2015))$. Thus, spouses who do not report their eligibility are more likely to be in the none or the tied category, and they are less likely to be in the retiree category.

The last column in Table 4 shows that about $63 \%$ of husbands in my sample are in the retiree category, and $23.3 \%$ of them are in the tied category. The last column in Table 5 shows that about $55 \%$ of wives in my sample are in the retiree category, and $30.6 \%$ of them are in the tied category. In contrast, the Department of Labor estimates that in 1993, 44\% of full-time employees in medium and large private establishments offered retiree health insurance (Clark (1999)). Kaiser (2006) estimates that, during the mid-1990s, about 50\% of large firms offered tied heath insurance. My sample might overpredict the percentage of people in the retiree category and underpredict the percentage of people in the tied category.

\subsection{Employment}

Figures 4.14 .4 present some of the labor market behavior that my model should explain. Figures 4.1 and 4.2 show the HRS full-time job participation rates by health insurance category. Regardless of the health insurance category, the full-time job participation rate declines with age, and the decline is especially sharp between the ages of 62 and 65 . Those in the tied category have the highest participation rates, while those in the retiree category have the lowest participation rates. Note that the participation rates for workers in the none category are higher than those for workers in the retiree category. This may be because, in my sample, most workers in the none category are self-employed. On average, selfemployed workers have a strong labor market attachment. 84

\footnotetext{
${ }^{84}$ Several papers (e.g., Zissimopoulos et al. (2007), and Hochguertel (2015) ) find that self-employed workers aged 50 and over are less likely to retire than wage and salary workers. One potential reason for this phenomenon is that self-employed workers have low access to pension benefits.
} 
Figure 4.1: Full-Time Job Participation Rates: Husband

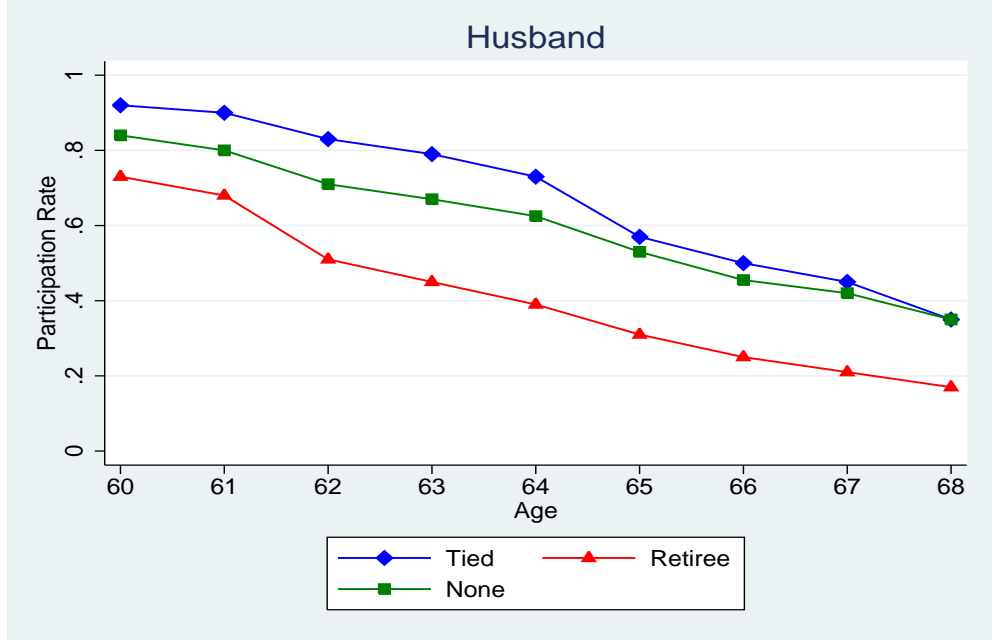

Figure 4.2: Full-Time Job Participation Rates: Wife

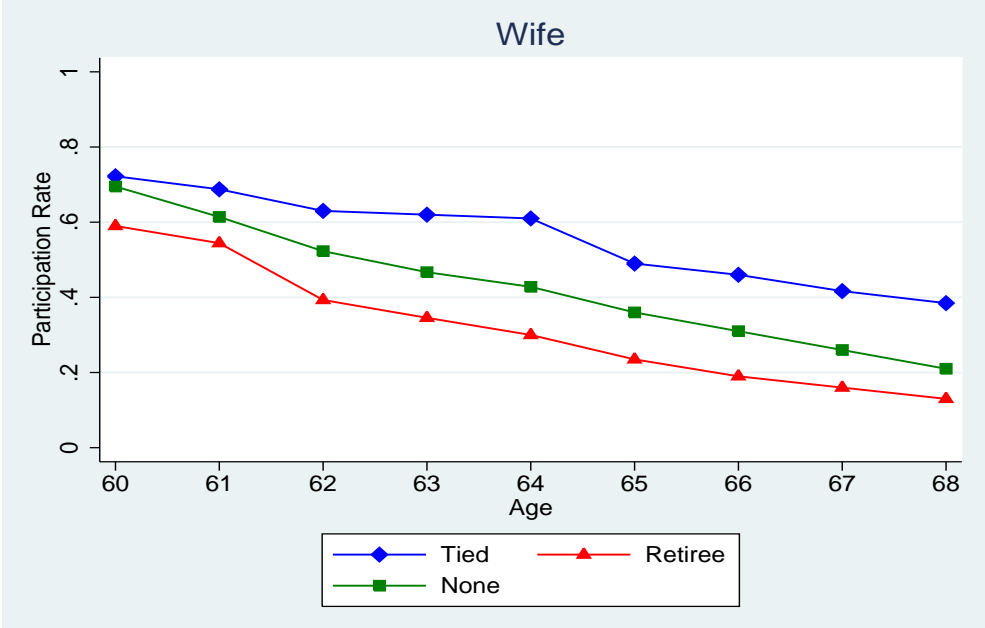

Figures 4.3 and 4.4 show the HRS full-time job exit rates by health insurance category. For both husbands and wives, the job exit rates jump at age 62 and at age 65 . At age 62 , the jump in the job exit rates is large for workers in the retiree category. This pattern provides evidence that being eligible for SSB gives workers in the retiree category incentives to retire. At age 65, the jump in the job exit rates is large for workers in the tied category. This pattern provides evidence that workers in the tied category tend to work until age 65, when they become eligible for Medicare. French and Jones (2011) also find these patterns for males in different insurance categories. Casanova (2010) finds jumps in the job exit rates at age 62 and at age 65 for both husbands and wives, but she does not distinguish between spouses in different insurance categories.

At age 65 , the job exit rate is similar for those in the tied and the retiree categories. 
Figure 4.3: Full-Time Job Exit Rates: Husband

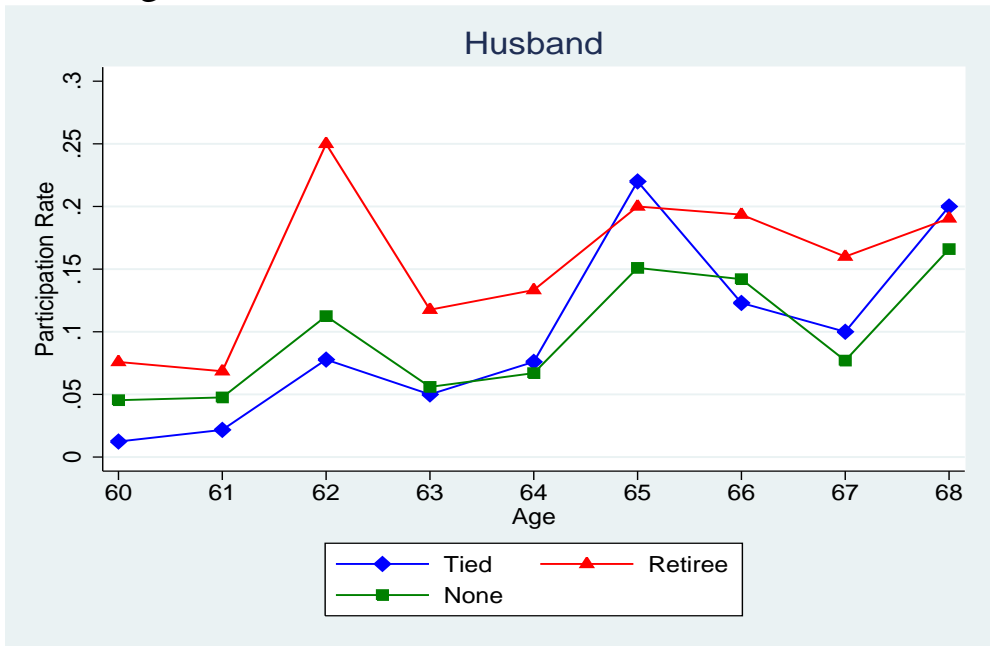

Figure 4.4: Full-Time Job Exit Rates: Wife

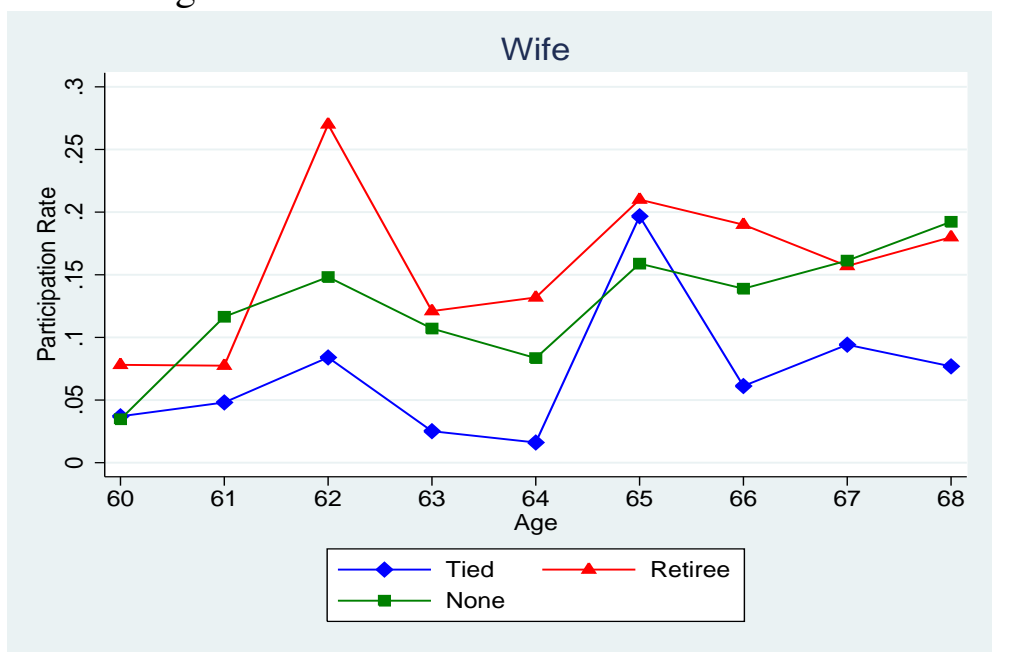

At almost every age other than 65 , workers in the tied category have lower job exit rates than those in the retiree or the none category. For example, at age 62, the job exit rates for husbands in the tied, retiree, and none categories are $7.8 \%, 25 \%$, and $11.3 \%$, respectively. In Rust and Phelan (1997), at around age 62, the job exit rates for males in the tied and the non-tied (including the retiree and the none) categories are $7.5 \%$ and $25.9 \%$, respectively. Compared to Rust and Phelan (1997), I find a smaller job exit rate for males in the non-tied category. This might be because: (1) the males in my sample have higher household incomes, and thus, the social security benefits account for a smaller portion of their retirement income and generate smaller incentives for them to retire ${ }^{85}$ and (2) most of the males in

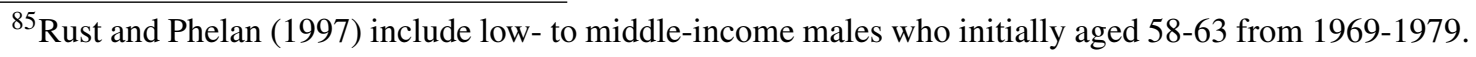
For this generation, the labor force participation rate of married women is low (Goldin (1986)), and thus, the husband is usually the only income earner in a household. The males in my sample are from a younger 
the none category in my sample are self-employed workers, and they, on average, have a strong labor market attachment.

Furthermore, at almost every age, the job exit rates for workers in the tied category are lower than those for workers who are eligible for retiree insurance. This suggests that factors other than differences in health insurance eligibility cause differences in job exit rates 86

\subsection{Employer-Provided Health Insurance Plan Characteristics}

To compute household budget constraints, this paper requires the following information about EPHI plan characteristics: the co-insurance rate, the paid premium and deductible for family coverage, and the paid premium and deductible for single coverage. Unfortunately, the HRS data have no information on plan characteristics. To solve this data problem, I use information provided in MEPS to impute plan characteristics for each spouse in my sample. The MEPS Insurance Component surveys private- and public-sector employers to collect data on their private health insurance plan characteristics. Firms in the private sector are divided into cells by industry type and firm size. Specifically, there are ten industry types and two firm size categories (more or less than 100 employees), which leads to total of 20 cells. All firms in the public sector are treated as one cell. The data are used to generate the average of each EPHI plan characteristic for these 21 cells. For each spouse in my sample, I define his EPHI plan characteristics as the averages of the cell to which his firm belongs. Table 6 lists the 2002 EPHI plan characteristics in the private sector by industry type and firm size, and Table 7 lists the 2002 EPHI plan characteristics in the public sector.

Using the cell averages in the MEPS to impute the plan characteristics of each spouse in my sample poses two problems: (1) the MEPS does not contain data before 1996 (the "censored data problem" discussed in 4.5.1); and (2) the cell averages of plan characteristics can differ significantly from the true individual plan characteristics (the "measurement

generation (those who aged over 50 in 1992), and both them and their wives are full-time workers in 1992. Thus, the males in my sample have higher household income because they have higher income (more than $60 \%$ of the husbands have DB or DC pension), and their wife can bring additional income to the household.

${ }^{86}$ As French and Jones (2011) point out, those who are eligible for retiree health insurance usually have higher pension wealth than those who are eligible for tied health insurance. Thus, pension wealth could be another factor that causes workers who have retiree health insurance to retire earlier. 
Table 6: EPHI Characteristics in Private Sector (Year 2002)

\begin{tabular}{|c|c|c|c|c|c|c|c|c|c|c|c|}
\hline \multicolumn{2}{|l|}{ Cells } & \multicolumn{10}{|c|}{ "EPHI Characteristics } \\
\hline \multirow[b]{3}{*}{ Industry } & \multirow[b]{3}{*}{ Firm Size } & \multirow{2}{*}{\multicolumn{2}{|c|}{ Co-insurance Rate }} & \multicolumn{4}{|c|}{ Family Coverage } & \multicolumn{4}{|c|}{ Single Coverage } \\
\hline & & & & \multicolumn{2}{|c|}{ Premium } & \multicolumn{2}{|c|}{ Deductible } & \multicolumn{2}{|c|}{ Premium } & \multicolumn{2}{|c|}{ Deductible } \\
\hline & & Mean & S.D. & Mean & S.D. & Mean & S.D. & Mean & S.D. & Mean & S.D. \\
\hline \multirow[t]{2}{*}{ Agric.,fish.,forest. } & $<100$ & $22.2 \%$ & $(3.2 \%)$ & 1,182 & (983) & 1,699 & (418) & 435 & (266) & 743 & (287) \\
\hline & $\geq 100$ & $16.7 \%$ & $(7.4 \%)$ & 867 & (894) & 929 & (399) & 397 & (284) & 436 & (229) \\
\hline \multirow[t]{2}{*}{ Mining and manufact. } & $<100$ & $16.8 \%$ & $(2.9 \%)$ & 1,239 & (309) & 1,469 & $(402)$ & 468 & (133) & 611 & (97) \\
\hline & $\geq 100$ & $17.5 \%$ & $(0.9 \%)$ & 921 & (359) & 778 & (45) & 485 & (53) & 375 & (38) \\
\hline \multirow[t]{2}{*}{ Construction } & $<100$ & $17.3 \%$ & $(1.8 \%)$ & 1,391 & (361) & 1,231 & (140) & 526 & (105) & 595 & (77) \\
\hline & $\geq 100$ & $16.7 \%$ & $(2.3 \%)$ & 1,586 & $(1,114)$ & 1,195 & (361) & 540 & (180) & 513 & (119) \\
\hline \multirow[t]{2}{*}{ Utilities and transp. } & $<100$ & $16.9 \%$ & $(4.5 \%)$ & 1,151 & (867) & 1,075 & (409) & 508 & (306) & 610 & (202) \\
\hline & $\geq 100$ & $17.2 \%$ & $(2.7 \%)$ & 916 & (510) & 746 & (198) & 537 & (117) & 345 & (72) \\
\hline \multirow[t]{2}{*}{ Wholesale trade } & $<100$ & $22.0 \%$ & $(6.7 \%)$ & 1,643 & (808) & 1,533 & (274) & 428 & (171) & 697 & (108) \\
\hline & $\geq 100$ & $15.9 \%$ & $(2.7 \%)$ & 1,063 & (687) & 850 & (129) & 500 & (59) & 413 & (37) \\
\hline \multirow[t]{2}{*}{ Fin. svs. and real estate } & $<100$ & $17.1 \%$ & $(2.9 \%)$ & 1,580 & (455) & 1,350 & (188) & 356 & (94) & 602 & (106) \\
\hline & $\geq 100$ & $18.3 \%$ & $(3.3 \%)$ & 1,281 & $(380)$ & 900 & (127) & 606 & (63) & 374 & (37) \\
\hline \multirow[t]{2}{*}{ Retail trade } & $<100$ & $19.6 \%$ & $(1.3 \%)$ & 1,582 & (307) & 1,386 & (279) & 602 & (124) & 608 & (77) \\
\hline & $\geq 100$ & $17.2 \%$ & $(1.3 \%)$ & 1,417 & (453) & 953 & (138) & 695 & (43) & 392 & (33) \\
\hline \multirow[t]{2}{*}{ Professioal services } & $<100$ & $18.3 \%$ & $(1.8 \%)$ & 1,341 & (284) & 1,353 & (162) & 404 & (81) & 582 & (56) \\
\hline & $\geq 100$ & $16.5 \%$ & $(1.7 \%)$ & 1,228 & (454) & 851 & (154) & 580 & (67) & 381 & $(51)$ \\
\hline \multirow[t]{2}{*}{ Other services } & $<100$ & $19.0 \%$ & $(1.6 \%)$ & 1,330 & (388) & 1,361 & (461) & 566 & (89) & 560 & (38) \\
\hline & $\geq 100$ & $17.6 \%$ & $(1.8 \%)$ & 1,429 & (402) & 948 & (134) & 702 & (71) & 418 & (45) \\
\hline
\end{tabular}

Source: Medical Expenditure Panel Survey, 2002

Table 7: EPHI Characteristics in Public Sector (Year 2002)

\begin{tabular}{lc|rrrr|rrrr}
\hline & & \multicolumn{3}{|c|}{ Family Coverage } & \multicolumn{4}{c}{ Single Coverage } \\
\multicolumn{2}{l}{$\begin{array}{l}\text { Co-insurance Rate } \\
\text { Mean }\end{array}$} & \multicolumn{2}{|c|}{ Premium } & \multicolumn{2}{c}{ Deductible } & \multicolumn{2}{c}{ Premium } & Deductible \\
\hline $18.4 \%$ & $(0.8 \%)$ & Mean & S.D. & Mean & S.D. & Mean & S.D. & Mean & S.D. \\
\hline \hline
\end{tabular}

Source: Medical Expenditure Panel Survey, 2002

error problem" discussed in 4.5.2). In the rest of this subsection, I first describe and address the censored data problem. Then, I discuss how the measurement error problem is likely to affect the model estimates.

\subsubsection{Censored Data Problem}

The MEPS collecting information about paid premiums and deductibles in 1996, and it began collecting information about co-insurance rates in 2002. Thus, I cannot observe paid premiums and deductibles for periods before 1996, and I cannot observe co-insurance rates for periods before 2002. To impute missing information about paid premiums and 
deductibles, I assume that the real paid premiums and deductibles in 1992 and 1994 are the same as those in 1996. This assumption is reasonable because the paid premiums increased only modestly from the mid-1990s to the late 1990s (Cutler (2003)) ${ }^{87}$ I calculate the nominal values of the paid premiums and deductibles in 1992 and 1994 using the Medical Care Price Index (MCPI) from the St. Louis Federal Reserve Bank as a deflator 88

To impute missing information about co-insurance rates, I assume that the coinsurance rates in 1992, 1994, 1996, 1998, and 2000 equal those in 2002. This assumption is reasonable because the co-insurance rates remained approximately the same from the mid-1990s to the early 2000s (Elbner and Marquis (2008) ${ }^{89}$

\subsubsection{Measurement Error Problem}

Using the cell averages of EPHI plan characteristics to impute individual plan characteristics creates a measurement error problem in my model. In Tables 6 and 7 , the numbers in the parentheses are standard deviations associated with these averages. The high standard deviations show that the plan characteristics within each cell are spread out over a wide range of values. Thus, the observed cell averages of plan characteristics (also called the observed data) and the true individual plan characteristics (also called the error-free data) may be significantly different.

In my model, the measurement errors cause two problems. First, measurement error may cause the estimates of the structural model to be inconsistent and biased. As is well known (see Carroll et al. (2006) and Wooldridge (2010)), in linear regression, the effect of measurement error is to bias the slope estimate in the direction of 0 (also called attenuation bias). In my model, the effects of measurement error on model estimates are more complex than the attenuation bias because my model is nonlinear. In my structural model, the value function is a nonlinear function of parameters and plan characteristics (equation 3.20), and the likelihood function is a nonlinear function of value functions 90 This means that the

\footnotetext{
${ }^{87}$ Cutler (2003) finds that the nominal paid premiums increased by less than 6\% between 1993 and 1999 .

${ }^{88}$ The Medical Care Price index (MCPI) was 190.058, 211.025, and 228.267 in 1992, 1994 and 1996, respectively.

${ }^{89}$ Elbner and Marquis (2008) find that the co-insurance rates either declined modestly or remained about the same from 1995 to 2003.

${ }^{90}$ The likelihood function is described in estimation section 5.2.
} 
likelihood function is a nonlinear function of parameters and plan characteristics. Because the parameter estimates are the values that maximize the likelihood function, the parameter estimates can be expressed as

$$
\hat{\theta}=f\left(X_{1}, Z_{2}\right)
$$

where $X_{1}$ is a vector of variables without measurement error, and $Z_{2}$ is a vector of observed plan characteristics. Let $X_{2}$ be a vector of plan characteristics in the error-free data, then $Z_{2}$ can be expressed as

$$
Z_{2}=X_{2}+e
$$

where $e$ represents the measurement error in plan characteristics. A second-order Taylor series expansion of $f\left(X_{1}, Z_{2}\right)$ around $Z_{2}$ at $X_{2}$ is

$$
f\left(X_{1}, Z_{2}\right) \approx f\left(X_{1}, X_{2}\right)+\frac{\partial f\left(X_{1}, Z_{2}\right)}{\partial Z_{2}}\left(Z_{2}-X_{2}\right)+\frac{1}{2}\left(Z_{2}-X_{2}\right)^{\prime} \frac{\partial^{2} f\left(X_{1}, Z_{2}\right)}{\partial Z_{2} \partial Z_{2}^{\prime}}\left(Z_{2}-X_{2}\right)
$$

Assuming that $\hat{\theta}^{c}=f\left(X_{1}, X_{2}\right)$ is a consistent estimate, then equation 4.8 ) can be rewritten as

$$
\hat{\boldsymbol{\theta}} \approx \hat{\theta^{c}}+\frac{\partial f\left(X_{1}, Z_{2}\right)}{\partial Z_{2}} e+\frac{1}{2} e^{\prime} \frac{\partial^{2} f\left(X_{1}, Z_{2}\right)}{\partial Z_{2} \partial Z_{2}^{\prime}} e .
$$

Because the observed plan characteristics are the averages of the true plan characteristics, $E(e)=0$. Thus, $\operatorname{plim} \frac{\partial f\left(X_{1}, Z_{2}\right)}{\partial Z_{2}} e=0$ if $e$ is uncorrelated with $X_{1}$ and $X_{2}$. Equation 4.9 p shows that $\operatorname{plim} \hat{\boldsymbol{\theta}}=\hat{\theta}^{c}$ if the term $e^{\prime} \frac{\partial^{2} f\left(X_{1}, Z_{2}\right)}{\partial Z_{2} \partial Z_{2}^{\prime}} e$ equals zero. This term equals zero only if $\frac{\partial^{2} f\left(X_{1}, Z_{2}\right)}{\partial Z_{2} \partial Z_{2}^{\prime}}=0$. However, the term $\frac{\partial^{2} f\left(X_{1}, Z_{2}\right)}{\partial Z_{2} \partial Z_{2}^{\prime}}$ is unlikely to equal zero because the function $f(\cdot)$ is unlikely to be linear in $Z_{2}$. This means that the measurement errors in plan characteristics cause inconsistent estimates.

The second problem caused by the measurement errors in my model is the observed data exhibit relationships not present in the error-free data. In the error-free data, different plan characteristics are correlated. For example, a plan with a high premium usually has a low deductible, whereas a plan with a low premium usually has a high deductible. The relationships between different plan characteristics are nonlinear. Assuming that the insurance market is competitive, and an insurance company adapts plan characteristics to gain 
zero profit, then the relationships between different plan characteristics can be expressed as

$$
\Gamma=(1-\Lambda)(m(\Gamma, \Lambda, \Xi)-\Xi)
$$

Variables $\Gamma, \Lambda$, and $\Xi$ represent the premium, the co-insurance rate, and the deductible, respectively, and $m(\cdot)$ represents the total medical expenses, which are a function of plan characteristics. The derivative of the premium with respect to the deductible is

$$
\frac{\partial \Gamma}{\partial \Xi}=(1-\Lambda)\left(\frac{\partial m(\Gamma, \Lambda, \Xi)}{\partial \Xi}-1\right)
$$

Equation (4.11) shows that, if the total medical expenses are nonlinear in the deductible, then the premium is nonlinear in the deductible. Next, I use a simple example to show that the total medical expenses are nonlinear in the deductible. I assume that individuals choose their total medical expenses, $m$, and consumption, $C$, to maximize their utility. An individual's optimization problem is

$$
\text { s.t. } \begin{cases}\max U(m(\Gamma, \Lambda, \Xi), C) \\ y \geqslant m+C & \text { if } m \leqslant \Xi, \\ y \geqslant \Xi+\Lambda(m-\Xi)+C & \text { if } m \geqslant \Xi,\end{cases}
$$

where $y$ represents income. The First Order Condition (FOC) is

$$
U_{1}(m, C)=\left\{\begin{array}{l}
U_{2}(m, C) \quad \text { if } m \leqslant \Xi \\
\Lambda U_{2}(m, C) \text { if } m \geqslant \Xi .
\end{array}\right.
$$

Equation (4.13) shows that the utility function, $U(\cdot)$, is nondifferentiable in total medical expenses. This nondifferentiability implies that $m$ might be nondifferentiable in $\Xi$. This equation also shows that the relationship between $m$ and $C$ depends on $U_{1}(m, C)$ and $U_{2}(m, C)$, and thus, the relationship is unlikely to be linear. In summary, the total medical expenses, $m$, are likely to be nonlinear and nondifferentiable in $\Xi$. Therefore, as equation 
(4.8) shows, the premium, $\Gamma$, is also likely to be nonlinear and nondifferentiable in the deductible, $\Xi$. Let

$$
\Gamma=g(\Xi)
$$

represent the relationship between the premium and the deductible. The nonlinear relationship between the premium and the deductible means that $g(\cdot)$ is a nonlinear function. Let $\Gamma^{*}$ and $\Xi^{*}$ represent the observed premium and deductible. Because the plan characteristics in the observed data are the averages of the true plan characteristics, $\Xi^{*}$ and $\Gamma^{*}$ can be expressed as

$$
\begin{aligned}
& \Xi^{*}=\int \Xi d F_{\Xi}(\Xi), \\
& \Gamma^{*}=\int g(\Xi) d F_{\Xi}(\Xi) .
\end{aligned}
$$

where $F_{\Xi}(\Xi)$ is the distribution of the deductible in the error-free data. The nonlinearity in $g(\cdot)$ implies that

$$
\int g(\Xi) d F_{\Xi}(\Xi) \neq g\left(\int \Xi d F_{\Xi}(\Xi)\right)
$$

Equation (4.13) implies that

$$
\Gamma^{*} \neq g\left(\Xi^{*}\right)
$$

Equations (4.11) and (4.14) show that the relationships between the true plan characteristics are different from the relationships between the observed plan characteristics 91

I do not address these measurement error problems in this paper, but future analysis of these problems would be worthwhile.

\subsection{Wage}

Annual wage is defined as the product of hourly wage, working hours per week, and working weeks per year. However, in the HRS, information about annual wage can be missing for two reasons. First, some individuals did not report one or more of these variables. Second, as in the well-known wage selection problem, econometricians cannot observe what annual wage retired people would have earned.

\footnotetext{
${ }^{91}$ Carroll et al. (2006) conclude that one of the potential effects of measurement error is that the observed data exhibit relationships not present in the error-free data.
} 
To solve the missing data problem, I use a wage equation to impute annual wage for spouses whose wage cannot be observed in the HRS. I model the log real annual wage in period $t$ as

$$
\ln \left(w_{i t}\right)=\beta^{w} X_{i t}^{w}+u_{i t}
$$

where $X_{i t}^{w}$ is a vector of explanatory variables (including age, gender, education, and annual working hours), and $u_{i t} \sim N\left(0, \sigma_{u}^{2}\right)$ is an error term. Simultaneously estimating this wage equation and my structural model is computationally burdensome. This is because including the wage equation increases the number of parameters, and the computational time increases more than linearly in the number of parameters.

Due to this computational burden, I estimate the wage equation separately from my structural model. One resulting problem is that the error term in the wage equation, $u_{i t}$, might be correlated with the error terms (e.g., the idiosyncratic shock $v_{d t}$ ) in my structural model that affect individuals' retirement decisions. Ignoring this correlation causes inconsistent estimates. To capture the correlation between the error that affects the log wage and the error that affects the labor supply, I use a probit framework to model the probability of working. Let an indicator variable, $D_{i t}$, denote whether spouse $i$ is working in period $t$. The latent variable, $D_{i t}^{*}$, is modeled as

$$
D_{i t}^{*}=\gamma^{D} X_{i t}^{D}+\varepsilon_{i t}
$$

where $X_{i t}^{D}$ is a vector of explanatory variables (including age, race, gender, and marital status) and $\varepsilon_{i t} \sim N(0,1)$. The wage imputation model consists of equations (4.18) and 4.19). The exclusion restriction is that marital status is assumed to affect only the probability of working (equation (4.19) ) and not affect the real wage (equation (4.18)).

I use the two-step Heckman selection method to estimate the wage imputation model. The Heckman method assumes that

$$
\left(\begin{array}{c}
u_{i t} \\
\varepsilon_{i t}
\end{array}\right) \sim N\left[\left(\begin{array}{c}
0 \\
0
\end{array}\right),\left(\begin{array}{cc}
\sigma_{u}^{2} & \rho_{u} \sigma_{u} \\
\rho_{u} \sigma_{u} & 1
\end{array}\right)\right] .
$$


Under this assumption, the log real wage conditional on working is

$$
\left.\ln \left(w_{i t}\right)\right|_{D_{i t}=1}=\beta^{w} X_{i t}^{w}+\rho_{u} \sigma_{u} \lambda\left(\gamma^{D} X_{i t}^{D}\right)+v_{i t}
$$

where $\lambda\left(\gamma^{D} X_{i t}^{D}\right)$ is the inverse Mills ratio evaluated at $\gamma^{D} X_{i t}^{D}$ and $v_{i t}$ is

$$
\begin{aligned}
v_{i t} & =u_{i t}-E\left[u_{i t} \mid D_{i t}=1\right] \\
& =u_{i t}-\rho_{u} \sigma_{u} \lambda\left(\gamma^{D} X_{i t}^{D}\right)
\end{aligned}
$$

Following Heckman (1979), in the first step, I use a probit regression to estimate $\gamma^{D}$ in equation 4.19). In the second step, I compute $\lambda\left(\hat{\gamma}^{D} X_{i t}^{D}\right)$ and I use a least squares regression to estimate equation (4.18). Although including the probit equation reduces the asymptotic bias of the estimate of $\beta^{w}$, the two-step Heckman estimates are still inconsistent because the probit equation differs from my structural model of individuals' labor supply (or retirement) behavior.

I use individuals in the HRS to estimate the wage imputation model (equations (4.18)-(4.19)). Table A7 in the Appendix lists parameter estimates of this wage imputation model. Using the resulting estimates, I compute the expectation of wage conditional on working, which I use as my annual wage data.

\subsection{Average Indexed Monthly Earnings (AIME)}

As described in model section 3.5, a spouse's AIME is a key factor that determines Social Security and pension benefits. Precisely calculating AIME requires keeping track of a worker's entire earnings history, which is computationally burdensome. Following French and Jones (2011), I assume that spouse $i$ 's annualized AIME in the next year is a function of his annualized AIME, $\Delta_{i t}$, labor income, $w_{i t} L_{i t}$, and age, $a_{i t}$, in the current year ${ }^{92}$ I refer to this function as the AIME updating function hereafter.

Using the AIME updating function and the annualized AIME in 1992, I compute the annualized AIME under each possible retirement choice for every year after 1992. To calculate the AIME in 1992, I need a worker's earnings history up to 1992. Due to the HRS

\footnotetext{
${ }^{92}$ The details of the AIME updating function are described in the Appendix.
} 
data usage restriction of individuals' earnings history. ${ }^{93} \mathrm{I}$ impute the earnings history prior to 1992 for each spouse in my sample.

I construct a worker's earnings history in two steps. In the first step, the log real labor income in period $t$ is modeled as 94

$$
\ln \left(w_{i t}\right)=\rho^{L} \ln \left(w_{i, t-1}\right)+\theta^{L} X_{i t}^{L}+\varepsilon_{i t}^{L}
$$

where $X_{i t}^{L}$ is a vector of explanatory variables (including education, race, and age) and $\varepsilon_{i t}^{L}$ is white noise ${ }^{95}$ To estimate equation 4.22 , I use the PSID, which is a longitudinal household survey that began in 1968. The PSID collects data about employment and income for individuals in a nationally representative sample of households. I include husbands and wives who were between the ages of 20 and 40 in 1968, and I track their earnings history until 1988. I use this sample to estimate equation (4.22) for husbands and wives separately 96 Table $\mathrm{A9}$ in the Appendix reports the estimates of equation 4.22 . In the second step, given the estimates of equation (4.22) and each spouse's annual labor income in 1992, I derive a spouse's earnings history backwards from 1992 to the year when he was 20 years old 97 With the constructed earnings histories in hand, I compute the annualized AIME in 1992 for each spouse in my sample 98

In the literature on labor income processes, there are two leading views about the nature of the income process. As summarized in Guvenen (2009), the first view (the "Heterogeneous Income Profile" (HIP) model) is that individuals are subject to shocks with modest persistence, but face life-cycle profiles that are individual-specific. The second

\footnotetext{
${ }^{93}$ For an explanation of the data usage restriction, see data section 4.1.

${ }^{94}$ Real labor income equals nominal labor income divided by the Consumer Price Index (CPI). The reference base for the CPI is 1992.

${ }^{95}$ Most literature about the labor income process models labor income as a function of both explanatory variables and an income shock that follows an AR(1) process. See Guvenen (2009) for a summary.

${ }^{96}$ I cannot observe how much labor income non-working people would have earned. Thus, to estimate the modified AR(1) process, I include only the labor income of those who are working. However, this introduces a selection problem, which I ignore here.

${ }^{97}$ To derive a spouse's earnings history using equation 4.22 , I need to know the variables in $X_{i t}^{L}$ for years prior to 1992 . The only variable in $X_{i t}^{L}$ that changes over time is age, which can be easily calculated for these years.

${ }^{98}$ If a spouse is older than 55 in 1992, then the AIME as of 1992 is the average monthly labor income during his 35 highest earnings years. If one spouse is younger than 55 in 1992, then his earnings history is less than 35 years, and his AIME is the sum of his labor income over the history divided by $35 \times 12$.
} 
view (the "Restricted Income Profile" (RIP) model) is that individuals are subject to extremely persistent shocks, but face similar life-cycle income profiles. The RIP models get higher estimates of the level of persistence than the HIP models ${ }_{99}^{99}$ Because I do not include the individual-specific effect in equation (4.22), I may overestimate the level of persistence of a worker's income and underestimate the consistent difference between two workers' labor incomes over time. However, for each spouse in each year, the imputed labor income using equation 4.22 is still a mostly accurate prediction of the real labor income. This is because the individual-specific effect on labor income is absorbed in the estimate of $\rho^{L}$.

Table 8 compares the sample statistics of husbands' annualized AIME ${ }^{100}$ in 1992 using my imputed earnings histories and those calculated by French and Jones (2011), who use the restricted SSER file.

Table 8: Sample Statistics for Initial Annualized AIME

\begin{tabular}{c|cc|cc}
\hline \hline EPHI Eligibility Category & \multicolumn{2}{|c|}{ Imputed Earnings History } & \multicolumn{2}{c}{ SSER File } \\
& Mean & Std. Dev. & Mean & Std. Dev. \\
\hline Retiree & 24.8 & $(5.0)$ & 24.9 & $(9.1)$ \\
Tied & 24.6 & $(4.5)$ & 24.9 & $(8.6)$ \\
None & 21.9 & $(4.3)$ & 16.0 & $(9.0)$ \\
\hline \hline
\end{tabular}

Note: Numbers are measured in thousands of dollars

Compared to the annualized AIME calculated using the SSER file, the annualized AIME that I calculate for husbands has similar sample means and has smaller standard deviations ${ }^{101}$ The smaller standard deviations might be because I ignore the individual-specific effect in equation 4.22, 102 Yet, it is still reasonable to use equation 4.22 because the purpose of the process is to impute annual labor income prior to 1992 but not to explain the nature of the income process.

\footnotetext{
${ }^{99}$ In HIP models, the estimated level of persistence in income shocks ranges from 0.5 to 0.7 (Lillard and Weiss (1979), Baker (1997), and Haider (2001)); in RIP models, the estimated level of persistence is close to 1 (MaCurdy (1982), Abowd and Card (1989), and Topel and Ward (1992)).

${ }^{100}$ Annualized AIME equals AIME times 12 months.

${ }^{101}$ The only exception is that, for husbands in the none category (who have no insurance), I calculated a larger sample mean of AIME than French and Jones (2011). This might be because, in my sample, many husbands who have no EPHI are self-employed, and self-employed workers have higher labor income than salary workers (Hochguertel (2015)).

${ }^{102}$ For husbands in my sample, $27.6 \%$ of the standard deviation of the AIME is due to the error, and $72.4 \%$ is due to the variation in $X^{L}$.
} 


\subsection{Bargaining Power}

In the first wave, the HRS asks each spouse a question about decision-making power: "When it comes to making major family decisions, who has the final say-you or your (husband/wife/partner)?"103 Individuals could answer that they themselves had the final say, that their spouse did, or that the division of responsibility was about equal. 104 Because retirement is described as a major family decision, ${ }^{105}$ answers to the HRS question can be used to predict the true continuous bargaining power for households facing retirement. The answers are discrete and, in some households, the two spouses' answers differ. Friedberg and Webb (2006) treat the answers as noisy discrete measures of the true continuous bargaining power, and they develop a bivariate ordered probit model to examine the effects of explanatory variables on bargaining power ${ }^{106}$ Using the estimates and the explanatory variables included in Friedberg and Webb (2006), I impute the continuous bargaining power for each husband in my sample. I find that the imputed bargaining power for husbands in my sample varies from 0.16 to $0.76 \sqrt{107}$ The sample mean of the imputed bargaining power is 0.51 and the standard deviation is 0.1 .

\subsection{Summary Statistics}

Table 9 shows the summary statistics for the first period for the variables used in my model ${ }^{108}$ Two variables that I haven't previously discussed are household race and health status. Household race is defined as white if both spouses are white, black if both spouses are black, and other if otherwise. Most (84\%) households in my sample are white, and very

\footnotetext{
${ }^{103}$ See the Health and Retirement Study Questionnaire, Question E135.

${ }^{104}$ For two reasons, I do not consider the dynamics of bargaining power. First, households in my sample consist of older couples who have had long marriages, and this indicates that their marriages have been happier and more harmonious than average. I can treat the reported decision-making power as the steady-state of a repeated game. Second, Friedberg and Webb (2006) find that average past earnings have a substantially greater impact on decision-making power than current earnings. This indicates that the retirement decision may not have much effect on decision-making power.

${ }^{105}$ As the HRS survey states, "by major family decisions we mean things like when to retire, where to live, or how much money to spend on a major purchase."

${ }^{106}$ Details of the bivariate ordered probit model developed by Friedberg and Webb (2006) are described in the Appendix.

${ }^{107}$ A small number means that a husband has limited bargaining power in making major family decisions, including retirement.

${ }^{108}$ Because the summary statistics for EPHI eligibility are listed in Tables 4 and 5 , I exclude them from Table 9
} 
few $(5 \%)$ households have mixed races.

Table 9: Summary Statistics For The Initial Distribution

\begin{tabular}{|c|c|c|}
\hline Variables & Mean & Std Dev \\
\hline Bargaining Power & 0.51 & 0.10 \\
\hline Household Assets $^{a}$ & 197 & 229 \\
\hline AIME_h ${ }^{a}$ & 24.6 & 4.34 \\
\hline $\mathrm{AIME} \_\mathrm{W}^{a}$ & 13.8 & 2.71 \\
\hline Annual Income_h ${ }^{a}$ & 35.7 & 21.5 \\
\hline Annual Income_w ${ }^{a}$ & 21.9 & 13.8 \\
\hline Health_h ${ }^{b}$ & 0.89 & 0.32 \\
\hline Health_w ${ }^{b}$ & 0.93 & 0.25 \\
\hline Age_h & 54.5 & 3.02 \\
\hline Age_w & 51.6 & 3.11 \\
\hline \multicolumn{3}{|l|}{ EPHI Plan Characteristics } \\
\hline co-insurance rate_h & 0.18 & 0.02 \\
\hline paid premium-Family_h ${ }^{c}$ & 1220 & 198 \\
\hline deductible-Family_h ${ }^{c}$ & 1026 & 269 \\
\hline paid premium-Single_ $\mathrm{h}^{c}$ & 295 & 62 \\
\hline deductible-Single_ $\mathrm{h}^{c}$ & 464 & 114 \\
\hline co-insurance rate_w & 0.18 & 0.01 \\
\hline paid premium-Family_w ${ }^{c}$ & 1333 & 164 \\
\hline deductible-Family_w ${ }^{c}$ & 1045 & 238 \\
\hline paid premium-Single_w ${ }^{c}$ & 303 & 58 \\
\hline deductible-Single_w ${ }^{c}$ & 456 & 94 \\
\hline \multicolumn{3}{|l|}{ Household Race } \\
\hline white & 0.84 & 0.36 \\
\hline black & 0.11 & 0.31 \\
\hline other & 0.05 & 0.21 \\
\hline \multicolumn{3}{|l|}{ Education_h } \\
\hline no degree & 0.16 & 0.37 \\
\hline high school & 0.60 & 0.49 \\
\hline college+ & 0.24 & 0.43 \\
\hline \multicolumn{3}{|l|}{ Education_w } \\
\hline no degree & 0.12 & 0.32 \\
\hline high school & 0.70 & 0.46 \\
\hline college+ & 0.18 & 0.39 \\
\hline
\end{tabular}

Note: a: measured in thousands of dollars; b: fraction in good health; c: measured in dollars.

To measure the health status of the HRS respondents, I examine their answer to the question: "Would you say your health is excellent, very good, good, fair or poor?'109 Health status is defined as good if the answer is excellent, very good, or good, and bad if the answer is fair or poor. Although several researchers raise concerns about the reliability of

${ }^{109}$ See the Health and Retirement Study Questionnaire, Question B1. 
self-reported health status (e.g., O'Donnell et al.(1998), and Dwyer and Mitchell (1999)), I assume, following Benitez-Silva et al. (2004), that it is reported accurately. ${ }^{110}$ The statistics show the fraction of people who are in good health in the first wave of the HRS survey: $89 \%$ of husbands and $93 \%$ of wives.

\footnotetext{
${ }^{110}$ Benitez-Silva et al. (2004) argue that respondents tend to report their true health status because the HRS data have a very high level of confidentiality.
} 


\section{Estimation}

In this section, I first define the structure of errors in my theoretical model (see subsection 5.1). Secondly, I use the error structure to define the likelihood function and describe the estimation strategy (see subsection 5.2). I conclude by discussing how the parameters in the model are identified (see subsection 5.3).

\subsection{Error Structure}

The household utility function includes two types of errors: an idiosyncratic error, $\imath_{d t}$, and unobserved heterogeneity terms, $\left(\eta_{L_{i}}^{i}, \tau_{j_{i}}^{i}\right)$ (equation $(3.3)$ ). As described in the model section, the term $v_{d t}$ accounts for the household utility shock that varies across discrete choices and time. The term $\eta_{L_{i}}^{i}$ is spouse $i$ 's time-invariant preference for his retirement status $L_{i}$, and the term $\tau_{j_{i}}^{i}$ is spouse $i$ 's time-invariant preference for his EPHI plan choice $j_{i}$. Both types of errors are assumed to be known to the household but not the econometrician. I proceed by discussing the empirical specification for each type of error.

\subsubsection{Idiosyncratic Error}

I assume that idiosyncratic errors (or household utility shocks), $\imath_{d t}$, are independent across households, time, and discrete choices. Specifically, I assume that $t_{d t} \sim \operatorname{iid} E V$. The distribution function of $v_{d t}$ is

$$
F\left(\imath ; \sigma_{l}\right)=\exp \left\{-\exp \left\{-\frac{\imath}{\sigma_{l}}\right\}\right\}
$$

The parameter $\sigma_{l}$ is the scale of the distribution of the idiosyncratic error. ${ }^{111}$

\subsubsection{Unobserved Heterogeneity}

The vector of unobserved heterogeneity terms is $u^{h}=(\eta, \tau)$ where $\eta=\left(\eta_{0}^{m}, \eta_{1}^{m}, \eta_{0}^{f}, \eta_{1}^{f}\right)$ represents the vector of the two spouses' unobserved time-invariant preferences for different retirement statuses and $\tau=\left(\tau_{0}^{m}, \tau_{m}^{m}, \tau_{f}^{m}, \tau_{0}^{f}, \tau_{m}^{f}, \tau_{f}^{f}\right)$ represents the vector of the two

\footnotetext{
${ }^{111}$ The identification of $\sigma_{l}$ is discussed in subsection 5.3.
} 
spouses' unobserved time-invariant preferences for different EPHI plan choices ${ }^{112}$ It is common to assume that $u^{h}$ has a multivariate normal distribution, and then to use a GHK simulator (Geweke (1989), Hajivassiliou (1990), and Keane (1994)) or a mixed logit simulator (McFadden and Train (2000) $)$ to approximate the choice probabilities. However, the assumed multivariate normal distribution adds 55 parameters to the model, which is computationally burdensome ${ }^{113}$ In order to reduce the computational burden, I use the method developed by Heckman and Singer (1985). I assume that the vector of unobserved heterogeneity takes two values, $u_{1}^{h}, u_{2}^{h}$, with probabilities $p^{u}, 1-p^{u}$, and I restrict $u_{1}^{h}=0$. Keane and Wolpin (1997), Cameron and Heckman (1998), Mroz and Guilkey (1992), and Mroz (1999)). This method adds only 11 parameters to the model, $u_{2}^{h}$ and $p^{u}$.

\subsection{Likelihood Function}

As described in the model section, before both spouses in a household retire, the household makes three decisions at the beginning of each period to maximize the expected present discounted value (EPDV) of its remaining lifetime utility. The three decisions include two discrete choices (household retirement status and EPHI plan choice, $d_{t}=\left(L_{t}, j_{t}\right)$ ) and one continuous choice (household consumption, $C_{t}$ ). After both spouses in a household retire, the household chooses only the household consumption, $C_{t}$, at the beginning of each period to maximize the EPDV of its remaining lifetime utility.

Including the density of the observed $C_{t}$ in the likelihood function not only increases the computational burden; it also requires a data set with quality information about household assets and tracks each household's asset transitions over time.114 However, the HRS fails to keep track of asset transitions. 115 To avoid the computational burden and the data

\footnotetext{
${ }^{112}$ Recall that $\eta_{0}^{i}$ and $\eta_{1}^{i}$ represent spouse $i$ 's time-invariant tastes for working and being in retirement, respectively; and $\tau_{0}^{i}, \tau_{m}^{i}$, and $\tau_{f}^{i}$ represent spouse $i$ 's time-invariant tastes for being covered by no EPHI plan, by the husband's EPHI plan, and by the wife's EPHI plan, respectively.

${ }^{113}$ The vector $u^{h}$ includes ten unobserved heterogeneity terms. If I assume a multivariate normal distribution for unobserved heterogeneity terms, the variance-covariance matrix of $u^{h}$ contains $55(=[(1+10) \times$ 10]/2) parameters.

${ }^{114}$ The household consumption decision this period affects household assets at the beginning of the next period. Thus, including the density of the observed $C_{t}$ in the likelihood function requires a data set that keeps track of asset transitions for each household.

${ }^{115}$ For example, for several households in my sample, the difference between the household assets observed in two adjacent waves is much bigger than the observed household income gained during the period.
} 
problem, I assume that, in each period, households optimally choose $C_{t}$, conditional on the discrete decision $d_{t}(\overline{\operatorname{Rust}}(1988)$ and Casanova $(2010))$. This means that the Bellman equation (equation 3.20 ) can be rewritten as

$$
V\left(z_{t}\right)=\max _{d_{t}}\left\{\max _{C_{t}}\left\{v\left(d, C_{t} ; z_{t}\right) \mid d_{t}=d\right\}\right\}
$$

where $z_{t}=\left(A_{t}, H_{t}, S_{t}, l_{d t}\right)$ is a vector of state variables in period $t$ (defined in model section 3.8) and $v\left(d_{t}, C_{t} ; z_{t}\right)$ is the choice-specific value function (defined in equation (3.21)). Equation (5.2) implies that optimal household consumption can be expressed as a function of the discrete choices. Because I assume that a household stops making discrete choices after both spouses retire, the likelihood function includes terms only up to the period when both spouses retire.

In the rest of this subsection, I first describe how to compute optimal consumption, conditional on a discrete decision $d_{t}$ (see 5.2.1). Next, I discuss how to compute choice probabilities (see 5.2.2). Then, I derive the likelihood function (see 5.2.3). Finally, I discuss the estimation strategy (see 5.2.4).

\subsubsection{Optimal Consumption}

As defined in the model section (equations (3.21) $), v\left(d_{t}, C_{t} ; z_{t}\right)$ is

$$
v\left(d_{t}, C_{t} ; z_{t}\right)=U\left(d_{t}, C_{t} ; z_{t}, \imath_{d t}\right)+\beta E_{m}\left\{E\left[V\left(z_{t+1}\right) \mid z_{t}, d_{t}, C_{t}, m_{t}\right]\right\}
$$

where $E_{m}\left\{E\left[V\left(z_{t+1}\right) \mid z_{t}, d_{t}, C_{t}, m_{t}\right]\right\}$ is defined in equation $3.22,116$ Given any $d_{t}$, optimal household consumption, denoted as $C^{*}\left(d_{t}\right)$, satisfies the First Order Condition (FOC) of equation (5.3),

$$
\frac{\partial U\left(d_{t}, C_{t} ; z_{t}\right)}{\partial C_{t}}+\beta \frac{\partial E_{m}\left\{E\left[V\left(z_{t+1}\right) \mid z_{t}, d_{t}, C_{t}, m_{t}\right]\right\}}{\partial A_{t+1}} \frac{\partial A_{t+1}\left(C_{t}\right)}{\partial C_{t}}=0
$$

\footnotetext{
${ }^{116}$ The term $v\left(d_{t}, C_{t} ; z_{t}\right)$ is strictly concave in $C_{t}$ because: (1) the household utility flow (equations 3.1)(3.2) ), $U(\cdot)$, is strictly concave in $C_{t}$; (2) the distribution function of $m_{t}$ (equations $(3.8)-(3.10)$ ) are independent of $C_{t}$; and (3) the transition functions in $E\left[V\left(z_{t+1}\right) \mid z_{t}, d_{t}, C_{t}, m_{t}\right]$ (equation $(3.23)$ ) are independent of $C_{t}$. Thus, given any $d_{t}$, there exists a unique household consumption decision that maximizes $v\left(d_{t}, C_{t} ; z_{t}\right)$.
} 
The functional form of household utility flow (equations 3.1$)-(3.2)$ ) implies that $\frac{\partial U\left(d_{t}, C_{t} ; z_{t}\right)}{\partial C_{t}}$ $=\frac{1}{C_{t}^{\alpha}}$. Similarly, the budget constraint (equation $\sqrt{3.4 p)}$ ) implies that $\frac{\partial A_{t+1}\left(C_{t}\right)}{\partial C_{t}}=-1$. Thus, the FOC can be rewritten as

$$
C_{t}=\left\{\beta \frac{\partial E_{m}\left\{E\left[V\left(z_{t+1}\right) \mid z_{t}, d_{t}, C_{t}, m_{t}\right]\right\}}{\partial A_{t+1}}\right\}^{-(1 / \alpha)}
$$

Computing the term $\frac{\partial E_{m}\left\{E\left[V\left(z_{t+1}\right) \mid z_{t}, d_{t}, C_{t}, m_{t}\right]\right\}}{\partial A_{t+1}}$ analytically is computationally burdensome. My approach is to use several linear splines to approximate $E_{m}\left\{E\left[V\left(z_{t+1}\right) \mid z_{t}, d_{t}, C_{t}, m_{t}\right]\right\}$. Then, instead of computing $\frac{\partial E_{m}\left\{E\left[V\left(z_{t+1}\right) \mid z_{t}, d_{t}, C_{t}, m_{t}\right]\right\}}{\partial A_{t+1}}$ at every point of $A_{t+1}$, I compute the slope of each linear spline.

I first discretize the household assets using five points $\left(A^{1}, A^{2}, A^{3}, A^{4}, A^{5}\right)$ Then, I calculate $E_{m}\left\{E\left[V\left(z_{t+1}\right) \mid z_{t}, d_{t}, C_{t}, m_{t}\right]\right\}$ at these five points. Let

$$
D^{q}\left(d_{t}\right)=E_{m}\left\{E\left[V\left(z_{t+1}\left(A^{q}\right)\right) \mid z_{t}, d_{t}, C_{t}, m_{t}\right]\right\} \quad q=\{1,2,3,4,5\}
$$

denote the value of $E_{m}\left\{E\left[V\left(z_{t+1}\right) \mid z_{t}, d_{t}, C_{t}, m_{t}\right]\right\}$ when $A_{t+1}=A^{q}$. Therefore, the slope of the linear spline that connects $D^{q}$ and $D^{q+1}$ is

$$
S^{q}\left(d_{t}\right)=\frac{D^{q+1}\left(d_{t}\right)-D^{q}\left(d_{t}\right)}{A^{q+1}-A^{q}} \quad q=\{1,2,3,4\}
$$

For each $S^{q}\left(d_{t}\right)$, there exist corresponding assets, denoted as $A_{t+1}\left(d_{t}, q\right)$. If $A_{t+1}\left(d_{t}, q\right)$ is located inside of $\left[A^{q}, A^{q+1}\right]$, I replace the term $\frac{\partial E_{m}\left\{E\left[V\left(z_{t+1}\right) \mid z_{t}, d_{t}, C_{t}, m_{t}\right]\right\}}{\partial A_{t+1}}$ in the FOC (equation 5.5) with $S^{q}\left(d_{t}\right)$. The optimal household consumption for the $q^{\text {th }}$ spline, conditional on $d_{t}$, is

$$
C\left(d_{t}, q\right)=\left\{\beta S^{q}\left(d_{t}\right)\right\}^{-(1 / \alpha)}
$$

If $A_{t+1}\left(d_{t}, q\right)$ is located outside of $\left[A^{q}, A^{q+1}\right]$, I update $A_{t+1}\left(d_{t}, q\right)$ with $A^{q}$ or $A^{q+1}$, whichever is closer to $A_{t+1}\left(d_{t}, q\right)$. Given the updated $A_{t+1}\left(d_{t}, q\right)$, I then update $C\left(d_{t}, q\right)$ in equation (5.8) with the amount of consumption that satisfies the household budget con-

\footnotetext{
${ }^{117}$ These five points are defined by the mean, $m_{A}$, and the standard deviation, $s t d_{A}$, of the distribution of the household assets observed in the first wave: $A^{1}=m_{A}-2 s t d_{A}, A^{2}=m_{A}-s t d_{A}, A^{3}=m_{A}, A^{4}=m_{A}+s t d_{A}$, and $A^{5}=m_{A}+2 s t d_{A}$.
} 
straint 118 I derive $C\left(d_{t}, q\right)$ for each of the four splines, and the optimal household consumption, conditional on $d_{t}$, is

$$
C^{*}\left(d_{t}\right)=\underset{C_{t} \in\left\{C\left(d_{t}, q\right), q=1, \ldots, 4\right\}}{\operatorname{argmax}}\left\{v\left(d_{t}, C_{t} ; z_{t}\right)\right\}
$$

\subsubsection{Choice Probabilities}

Equations (5.2) and (5.9) show that, before the two spouses in a household retire, the household's optimization problem in each period is to choose the $d_{t}$ that maximizes $v\left(d_{t}, C^{*}\left(d_{t}\right) ; z_{t}\right)$. Because $v\left(d_{t}, C^{*}\left(d_{t}\right) ; z_{t}\right)$ is a function of $d_{t}$ only, I simplify the notation by rewriting it as $v^{*}\left(d_{t}, ; z_{t}\right)$. I decompose the term $v^{*}\left(d_{t} ; z_{t}\right)$ as the sum of three parts:

$$
v^{*}\left(d_{t} ; z_{t}\right)=\hat{v}\left(d_{t} ; z_{t}\right)+\left(\eta_{L}+\tau_{j}\right)+u_{d t}
$$

where $\eta_{L}=\gamma \eta_{L_{m}}^{m}+(1-\gamma) \eta_{L_{f}}^{f}$ and $\tau_{j}=\gamma \tau_{j_{m}}^{m}+(1-\gamma) \tau_{j_{f}}^{f}$ are the household's time-invariant preferences for the household retirement status, $L$, and the household EPHI plan choice, $j$, respectively, 119 In any period before both spouses retire, the probability of interest for a household is the probability that the observed discrete decision $d^{*}=\left(L^{*}, j^{*}\right)$ generates a higher value of $v^{*}\left(d_{t} ; z_{t}\right)$ than any other possible discrete choice $d=(L, j)$. This choice probability can be expressed as

$$
\begin{aligned}
P_{t}\left(d_{t}=d^{*} ; z_{t}, \theta \mid e, \eta, \tau\right)= & \operatorname{Prob}\left[\hat{v}\left(d^{*} ; z_{t} \mid e\right)+\left(\eta_{L^{*}}+\tau_{j^{*}}\right)+\iota_{d^{*} t}\right. \\
& \left.\left.\geqslant \hat{v}\left(d ; z_{t} \mid e\right)+\left(\eta_{L}+\tau_{j}\right)+\iota_{d t} ; \forall d \neq d^{*}\right]\right\}
\end{aligned}
$$

where $\theta$ is the full set of parameters to be estimated and $e$ is the household EPHI eligibility type ${ }^{120}$ Because the idiosyncratic error, $t_{d t}$, is assumed to be distributed Extreme Value, the choice probability, conditional on the household EPHI eligibility type and the unobserved

\footnotetext{
${ }^{118}$ Although the introduction of the spline function simplifies the computation of the optimal consumption, it creates kink points in the value function. See section 5.2.4 for a discussion about the estimation problem caused by these kinks.

${ }^{119}$ As introduced in model section 3.2, the parameter $\gamma$ is the husband's bargaining power.

${ }^{120}$ As I described in data section 4.3, I assume that EPHI eligibility type does not change over time.
} 
heterogeneity, $(e, \eta, \tau)$, is

$$
P_{t}\left(d_{t}=d^{*} ; z_{t}, \theta \mid e, \eta, \tau\right)=\frac{\exp \left\{\left[\hat{v}\left(d^{*} ; z_{t} \mid e\right)+\left(\eta_{L^{*}}+\tau_{j^{*}}\right)\right] / \sigma_{l}\right\}}{\sum_{d \in \mathscr{L}_{t} \times \mathscr{J}_{t}} \exp \left\{\left[\hat{v}\left(d ; z_{t} \mid e\right)+\left(\eta_{L}+\tau_{j}\right)\right] / \sigma_{l}\right\}}
$$

Next, I derive the likelihood function using the choice probabilities.

\subsubsection{Likelihood Function}

Let $T_{n}^{R}$ be the period by which both spouses in household $n$ have retired, and let $T_{n}^{L}$ be the last period by which the household has stayed in the HRS. For household $n$, the number of periods included in its likelihood contribution is

$$
T_{n}=\min \left\{T_{n}^{R}, T_{n}^{L}\right\}
$$

Given panel data $\left\{z_{t}^{n} ; d_{t}^{n}\right\}\left(t=1, \ldots, T_{n} ; n=1, \ldots, N\right)$ on the observed states and discrete decisions of $N$ households, the likelihood contribution for household $n$, conditional on the household EPHI eligibility type and the unobserved heterogeneity, $\left(e^{n}, \eta, \tau\right)$, is

$$
L^{n}\left(\theta \mid e^{n}, \eta, \tau\right)=\prod_{t=1}^{T_{n}}\left\{P_{t}\left(d_{t}^{n} ; z_{t}^{n}, \theta \mid e^{n}, \eta, \tau\right) \pi_{t}\left(z_{t}^{n}, \theta_{\pi} \mid z_{t-1}^{n}, d_{t-1}^{n}\right)\right\}
$$

where $\pi_{t}(\cdot \mid \cdot)$ represents the household's health transition probabilities and survival rates. The vector of parameters $\theta=\left(\theta_{P}, \theta_{m}, \theta_{\pi}\right)$ includes three parts: (1) the vector of parameters that affect the household utility function and the consumption floor, $\theta_{P}$; (2) the vector of parameters that affect household total medical expenses, $\theta_{m}$; and (3) the vector of parameters that affect the the household's subjective belief about future events, $\theta_{\pi} 121$

Recall that $u^{h}=(\eta, \tau)$ is assumed to take two values, $u_{1}^{h}=\left(\eta^{1}, \tau^{1}\right)$ and $u_{2}^{h}=$ $\left(\eta^{2}, \tau^{2}\right)$, with probabilities $p^{u}$ and $\left(1-p^{u}\right)$. Thus, the likelihood contribution for household $n$, conditional on the household EPHI eligibility type, $e^{n}$, is

$$
L^{n}\left(\theta \mid e^{n}\right)=\sum_{k=1}^{2}\left\{p^{k} L^{n}\left(\theta \mid e^{n}, \eta^{k}, \tau^{k}\right)\right\}
$$

\footnotetext{
${ }^{121}$ This decomposition is useful later in the estimation strategy (see section 5.2.4.).
} 
where $p^{1}=p^{u}$ and $p^{1}=1-p^{u}$.

As described in data section 4.3, for spouses who are covered by their spouse's EPHI plan, their EPHI eligibility is not reported in the HRS. For these spouses, I use the EPHI eligibility imputation model (equations (4.1)-(4.5) to impute the probability for each of the six possible types of EPHI eligibility. ${ }^{122}$ This means that, for some households, I know only the distribution of the household EPHI eligibility over the 36 possible types 123 For households in which both spouses' EPHI eligibilities are reported in the HRS, I assign 1 to the probability for the observed household EPHI eligibility type and assign 0 to all of the other 35 household EPHI eligibility types. Let $P_{n}^{e}\left(e^{n}=e\right)$ represent the probability of having a particular EPHI eligibility type for household $n$. Then, a household likelihood contribution over the distribution of the household EPHI eligibility type is

$$
L^{n}(\theta)=\sum_{e=1}^{36} P_{n}^{e}\left(e^{n}=e\right) L^{n}(\theta \mid e) .
$$

The likelihood function is

$$
L(\theta)=\prod_{n=1}^{N} L^{n}(\theta)
$$

\section{Initial Conditions}

The likelihood function (equation (5.16) $)$ ignores the initial conditions problem: the observed EPHI eligibility is not exogenous, and it is determined by the process generating the panel sample. For example, individuals who prefer to retire early might tend to find a job that provides retiree insurance. Ignoring the initial conditions problem might overestimate the effects of retiree insurance eligibility on retirement, and my parameter estimates might be inconsistent (Heckman (1981) ). In future research, I can control for this initial conditions problem by including the probability of being in a particular insurance eligibility category in the likelihood function. The probability of being in a particular insurance eligibility category is modeled as a logistic function of a worker's initial state vector, including

\footnotetext{
${ }^{122}$ Different types of individual EPHI eligibility are defined in data section 4.3.

${ }^{123}$ There are six possible types of EPHI eligibility for a spouse, and thus, there are 36 possible types of household EPHI eligibility for a household.
} 
age, wage, health status, wealth, and pension eligibility (Keane and Wolpin (1997), and Van der Klaauw and Wolpin (2008)). The parameters in the logistic function are estimated jointly with parameters in my structural model.

\section{Simulation}

A key part of computing the likelihood function, $L(\theta)$, is to compute the term $\hat{v}\left(d_{t} ; z_{t} \mid e\right)$, which is

$$
\left[U\left(d_{t}, C^{*}\left(d_{t}\right) ; z_{t}, \iota_{d t} \mid e\right)-\left(\eta_{L}+\tau_{j}\right)-\imath_{d t}\right]+\beta E_{m}\left\{E\left[V\left(z_{t+1}\right) \mid e, z_{t}, d_{t}, m_{t}\right]\right\}
$$

Thus, computing $\hat{v}\left(d_{t} ; z_{t} \mid e\right)$ requires an evaluation of integrals over the joint distribution of the two spouses' total medical expenses, $m_{t}=\left(m_{m t}, m_{f t}\right)$. Recall that, when a household makes decisions, it does not observe the two spouses' medical expense-related shocks, $\left(\vartheta_{m t}, \vartheta_{f t}, u_{m t}, u_{f t}\right)$, which later determine the two spouses' total medical expenses, $m_{t}{ }^{124}$ Thus, $\hat{v}\left(d_{t} ; z_{t} \mid e\right)$ can be expressed as

$$
\hat{v}\left(d_{t} ; z_{t} \mid e\right)=\int \hat{v}\left(d_{t} ; z_{t} \mid e, \vartheta_{m t}, \vartheta_{f t}, u_{m t}, u_{f t}\right) d G\left(\vartheta_{m t}, \vartheta_{f t}, u_{m t}, u_{f t}\right)
$$

where $G(\cdot)$ is the joint distribution of $\left(\vartheta_{m t}, \vartheta_{f t}, u_{m t}, u_{f t}\right)$. This means that computing $\hat{v}\left(d_{t} ; z_{t} \mid e\right)$ requires an evaluation of the four-dimensional integrals over the joint distribution of $\left(\vartheta_{m t}, \vartheta_{f t}, u_{m t}, u_{f t}\right)$.

Evaluation of the four-dimensional integrals in $\hat{v}\left(d_{t} ; z_{t} \mid e\right)$ is not possible analytically, so I calculate the value of $\hat{v}\left(d_{t} ; z_{t} \mid e\right)$ numerically using a simulation method. As described in the model section (equations (3.8) and (3.9)),

$$
\left(\begin{array}{l}
\vartheta_{m t} \\
\vartheta_{f t} \\
u_{m t} \\
u_{f t}
\end{array}\right) \sim N\left[\left(\begin{array}{l}
0 \\
0 \\
0 \\
0
\end{array}\right),\left(\begin{array}{cccc}
1 & \rho_{\vartheta} & 0 & 0 \\
\rho_{\vartheta} & 1 & 0 & 0 \\
0 & 0 & 1 & \rho_{u} \\
0 & 0 & \rho_{u} & 1
\end{array}\right)\right] .
$$

\footnotetext{
${ }^{124}$ As described in model section 3.4.2, each spouse has two medical expense-related shocks, $\left(\vartheta_{i t}, u_{i t}\right)$. The first determines whether a spouse has positive medical expenses, and the second determines the total medical expenses conditional on having positive medical expenses.
} 
I make $R$ draws of $\left(\vartheta_{m t}, \vartheta_{f t}, u_{m t}, u_{f t}\right)$ from the distribution defined above and compute the term $\hat{v}\left(d_{t} ; z_{t} \mid e, \vartheta_{m t}^{r}, \vartheta_{f t}^{r}, u_{m t}^{r}, u_{f t}^{r}\right)$ for each random draw. I define the simulated analog to $\hat{v}\left(d_{t} ; z_{t} \mid e\right)$ as

$$
\hat{v}^{R}\left(d_{t} ; z_{t} \mid e\right)=\frac{1}{R} \sum_{r=1}^{R} \hat{v}\left(d_{t} ; z_{t} \mid e, \vartheta_{m t}^{r}, \vartheta_{f t}^{r}, u_{m t}^{r}, u_{f t}^{r}\right) .
$$

The simulated choice probability, $P_{t}^{R}\left(d_{t} ; z_{t}, \theta \mid e, \eta, \tau\right)$, is computed by replacing all $\hat{v}\left(d_{t} ; z_{t} \mid e\right)$ terms in equation 5.12 with their simulated analogs, $\hat{v}^{R}\left(d_{t} ; z_{t} \mid e\right)$. The simulated conditional likelihood contribution for household $n, L^{n R}\left(\theta \mid e^{n}, \eta, \tau\right)$, is computed by replacing $P_{t}\left(d_{t} ; z_{t}, \theta \mid e, \eta, \tau\right)$ in equation 5.13 with their simulated analogs, $P_{t}^{R}\left(d_{t} ; z_{t}, \theta \mid e, \eta, \tau\right)$. The simulated unconditional likelihood contribution is

$$
L^{n R}(\theta)=\sum_{e=1}^{36} P_{n}^{e}\left(e^{n}=e\right)\left[\sum_{k=1}^{2} p^{k} L^{n R}\left(\theta \mid e, \eta^{k}, \tau^{k}\right)\right]
$$

and the simulated likelihood is

$$
L^{R}(\theta)=\prod_{n=1}^{N} L^{n R}(\theta)
$$

The estimate $\hat{\theta}$ is the vector of parameter values that maximizes the simulated likelihood function $L^{R}(\theta)$. Although the Maximum Simulated Likelihood (MSL) estimator, $\hat{\theta}$, is inconsistent, the magnitude of the inconsistency is frequently small, and with a modest $R$, MSL estimation can construct an practically consistent estimator (Börsch-Supan and Hajivassiliou (1993) and Hajivassiliou (2000)). Next, I describe the estimation strategy that I use to estimate $\theta$.

\subsubsection{Estimation Strategy}

While a relatively small number (16) of parameters are used to specify a household's preferences, a large number (98) of parameters are needed to specify its health transition function and survival function and to specify the distribution of the two spouses' medical expenses (I refer to it as computational burden problem). In addition, the HRS data have no information on the two spouses' total medical expenses (I refer to it as omitted variables problem). 
Due to the computational burden and the omitted variables problem, I use a twostage estimation procedure to estimate the model (Rust (1987, 1988), Rothwell and Rust (1997), Rust and Phelan (1997), Gourinchas and Parker (2002), Laibson et al. (2007), and French and Jones (2011)). In the first stage, I use the HRS demographic data and Maximum Likelihood (ML) Estimation to estimate the parameters $\left(\theta_{\pi}\right)$ that determine household health transitions (equation 3.17 ) and survival rates (equation 3.18 ) 125 I also use the MEPS data and ML Estimation to estimate the parameters $\left(\theta_{m}\right)$ that determine total medical expenditures (equations 3.8 - 3.10$)$ (26 In the second stage, I use my HRS sample and MSL Estimation (Keane and Wolpin (1997), Rust and Phelan (1997), Brien et al. (2006), and Blau and Gilleskie (2008)) to estimate the parameters $\left(\theta_{P}\right)$ that determine utility function (equations $3.1-(3.3$ ) and the consumption floor (equation 3.6 ) 127

In my model, the idiosyncratic errors in the second stage that associated with discrete choices and time are correlated with the errors in the first stage that affect total medical expenses and health transitions $\sqrt{128}$ This correlation makes my two-stage estimators inconsistent. Several papers (e.g., Amemiya (1978) and Rust (1994)) provide correction formulae that yield consistent estimates. I don't use these correction formulae because the data I use to estimate some first stage parameters (medical expenses parameters) is independent from the data I use to estimate second stage parameters. This means that there is no information to identify the correlation between the errors in the two stages. Therefore, I assume that the first stage errors are independent from the second stage errors, and the two-stage estimation method is appropriate in this paper.

The second stage partial simulated likelihood function is

$$
L_{2}^{R}(\theta)=\prod_{n=1}^{N}\left\{\sum_{e=1}^{36} P_{n}^{e}\left(e^{n}=e\right)\left[\sum_{k=1}^{2} p^{k} \prod_{t=1}^{T_{n}} P_{t}^{R}\left(d_{t}^{n} ; z_{t}^{n}, \theta_{P}, \hat{\theta}_{m}, \hat{\theta}_{\pi} \mid e, \eta^{k}, \tau^{k}\right)\right]\right\}
$$

I maximize this partial simulated likelihood function using BHHH (Berndt et al. (1974)). I

\footnotetext{
${ }^{125}$ The likelihood function used to estimate $\theta_{\pi}$ includes only the product of the $\pi_{t}$ terms.

${ }^{126}$ The likelihood function used to estimate $\theta_{m}$ is the product of the probability of having the observed household total medical expenses outcome across different households and different periods.

${ }^{127}$ As discussed in Rust and Phelan (1997), the two-stage estimation procedure is not as efficient as the full likelihood estimation using the full likelihood function (equation $5.19 \mathrm{p})$.

${ }^{128}$ For example, when a household suffers a negative health shock at the beginning of a period, the household is more likely to choose retirement, have high medical expenses, and be unhealthy in the next period.
} 
implement my estimation routine using FORTRAN and MPI for parallel processing.

The parameter estimates delivered by the BHHH algorithm might not be optimal due to the kinks in the value function. There are two sources of the kinks in the value function. First, the tax, Social Security, and pension rules cause several kinks in the household budget constraint. Second, I discretize household assets, which makes the value function a piecewise linear function of household assets. These kinks in the value function might cause the likelihood function to become nondifferentiable in some parameters. Due to this nondifferentiability, the derivative on one side of a kink in the likelihood function is not informative about the derivative on the other side of the kink. Therefore, the BHHH algorithm (a fast hill-climbing optimization algorithm) might get stuck at a local maximum that is not the global maximum.

\subsection{Identification}

In this subsection, I discuss how the functions of interest in my model are identified separately from one another. I begin by discussing how preference parameters in the household utility function are identified. Then I describe how the parameters that determine the distribution of total medical expenditures are identified. Lastly, I examine the identification of parameters in the household health transition functions and the household survival functions.

\subsubsection{Utility Function Parameters}

Recall that household utility is defined as the weighted sum of each spouse's utility, $u_{i}$. Spouse $i$ 's utility depends on household consumption, $C_{t}$, his retirement status, $L_{i t}$, and his unobserved preferences, $\varpi_{i t}\left(d_{t}, l_{d t}\right)$, for household discrete choices, $d_{t} \sqrt[129]{ }$ As defined in model section 3.2, spouse $i$ 's utility function is

$$
u_{i}\left(L_{i t}, C_{t} ; \varpi_{i t}\left(d_{t}, u_{d t}\right)\right)=\frac{C_{t}^{1-\alpha}}{1-\alpha}+\exp \left\{\beta^{i} X_{t}^{i}\right\} L_{i t}+\varpi_{i t}\left(d_{t}, u_{d t}\right) \quad i \in\{m, f\}
$$

where

$$
\beta^{i} X_{t}^{i}=\beta_{0}^{i}+\beta_{1}^{i} a_{i t}+\beta_{2}^{i} H_{i t}+\beta_{3}^{i} L_{-i, t} .
$$

\footnotetext{
${ }^{129}$ As I defined in model section 3.2, $L_{-i, t}$ denotes the other spouse's leisure (or retirement status).
} 
The risk aversion parameter $\alpha$ is identified by the co-variation in household savings and future uncertainty. For example, suppose that two risk averse households are similar in everything except that one has family health insurance coverage and one does not. The household with health insurance coverage will save less than the household without insurance coverage for two reasons. First, the one with insurance coverage has less uncertainty about future medical expenses (the "risk reducing" aspect of insurance). Second, the health insurance company helps to pay part of the medical expenses for the household with insurance coverage (the "gift" aspect of insurance). For healthy people, the effect of the gift aspect of insurance on saving decisions is limited because their expected total medical expenses are small. Therefore, the degree of risk aversion is identified by the extent to which healthy, insurance-eligible households save less than healthy, ineligible households.

For spouse $i, \beta^{i}$ is a vector of parameters that affect his preference for leisure. The parameters associated with spouse $i$ 's age and health, $\left(\beta_{1}^{i}, \beta_{2}^{i}\right)$, are identified by the covariation in spouse $i$ 's retirement status, $L_{i t}$, and his age and health status, $\left(a_{i t}, H_{i t}\right)$, conditional on other observable characteristics. The last element of $\beta^{i}, \beta_{3}^{i}$, represents spouse $i$ 's preference for spending leisure time with the other spouse (simultaneous retirement). Both $\beta_{3}^{m}$ and $\beta_{3}^{f}$ are identified by the co-variation in the two spouses' retirement choices: retiring together or not. Thus, these two parameters, $\left(\beta_{3}^{m}, \beta_{3}^{f}\right)$, cannot be identified separately, and I assume that $\beta_{3}^{m}=\beta_{3}^{f} 130$

Recall that $u^{h}$ represents the vector of the two spouses' unobserved time-invariant preferences for different discrete household choices ${ }^{131}$ The vector $u^{h}$ differs across households, but its distribution remains the same. I assume that $u^{h}$ takes two values, $u_{1}^{h}, u_{2}^{h}$, with probabilities $p^{u}, 1-p^{u}$, and I restrict $u_{1}^{h}=0$. The parameters $u_{2}^{h}$ and $p^{u}$ are identified by the variance of the household time-specific residuals and the variance of the household-specific residuals.

\footnotetext{
130 Friedberg and Stern $\sqrt{2014}$ ) make an analogous assumption. They restrict covariates to have the same effect on both spouses' happiness, as they found no major differences in estimates with and without this restriction. Gustman and Steinmeier (2000, 2004) and Guvenen (2009) allow the husband and the wife to have asymmetric preferences for spending leisure with the other spouse. Their ability to separately identify these two parameters relies on an important assumption: the decision-making process in a family is a noncooperative bargaining process.

${ }^{131}$ Details of $u^{h}$ are explained in section 5.1.1.
} 
An identification problem I face is the difficulty of separately identifying the effects of unobserved heterogeneity from duration dependence. This is because both factors can account for the observed decreasing hazard out of employment over time. Elbers and Ridder (1982) prove that variations in observed explanatory variables that are included in hazard functions provide enough restrictions on the observed hazard to separately identify the effects of unobserved heterogeneity and duration dependence ${ }^{132}$ Because the choice probability functions (or hazard functions) in my model include explanatory variables that vary across people and time, the effects of unobserved heterogeneity can be separately identified from duration dependence.

Additionally, there are three parameters that affect household choices but do not appear in the household utility function directly. These parameters are: (1) the time discount factor, $\beta$; (2) the consumption floor, $C_{\min }$; and (3) the scale of the distribution of idiosyncratic utility shocks, $\sigma_{l} \cdot{ }_{133}$ The time discount factor is identified by the co-variation in household asset quantile and retirement decision. The consumption floor is identified by the same co-variation in households in the bottom asset quantile. If the consumption floor is sufficiently low, the risk of a catastrophic medical expense shock will encourage work (delaying retirement) among the poor. Conversely, a high consumption floor discourages work among the poor (Hubbard et al. (1995)) ${ }^{134}$ The scale parameter can be identified separately from other parameters because the value function is nonlinear in other parameters (equation 5.12) 135

\subsubsection{Medical Expenditure Function Parameters}

Recall that two independent processes are modeled to determine each spouse's total medical expenditures: (1) whether he has positive medical expenses; and (2) the amount of total medical expenses conditional on having positive medical expenses. I use a Bivariate Probit framework to model the first process. Let $P_{i t}$ be a binary variable indicating whether

\footnotetext{
${ }^{132}$ See Elbers and Ridder (1982) for details of the proof.

${ }^{133}$ The idiosyncratic shocks are assumed to be distributed EV (equation 5.1 ).

${ }^{134}$ As emphasized by Hubbard et al. (1995), the consumption floor can be considered a $100 \%$ tax on the savings of those who have high medical expenses, and low income and assets.

135 Rust and Phelan (1997) and Blau and Gilleskie (2006) include EV distributed idiosyncratic shocks in their models, and they normalize the scale parameter to 1 .
} 
spouse $i$ has positive total medical expenses in period $t$. As described in model section 3.4.2 (equation (3.8), the latent variable, $P_{i t}^{*}$, is modeled as

$$
\begin{gathered}
P_{i t}^{*}=\xi_{1}^{i} I_{i t}+\xi_{2}^{i} H_{i t}+\xi_{3}^{i} L_{i t}+\xi_{4}^{i} X_{i t}+\vartheta_{i t}, \\
\left(\begin{array}{c}
\vartheta_{m t} \\
\vartheta_{f t}
\end{array}\right) \sim N\left[\left(\begin{array}{l}
0 \\
0
\end{array}\right),\left(\begin{array}{cc}
1 & \rho_{\vartheta} \\
\rho_{\vartheta} & 1
\end{array}\right)\right]
\end{gathered}
$$

The parameters associated with the explanatory variables, $\xi^{i}$, are identified by the co-variation in whether spouse $i$ has positive medical expenses and the explanatory variables, $\left(I_{i t}, H_{i t}, L_{i t}, X_{i t}\right)$. The correlation between the two spouses' error terms, $\rho_{\vartheta}$, is identified by the co-variation in the residuals of the two spouses' probits.

In the second process, the log of positive total medical expenditures, $\ln \left(m_{i t}^{P}\right)$, is modeled as a function of the four components used in the first process, $\overrightarrow{X_{i t}}=\left(I_{i t}, H_{i t}, L_{i t}, X_{i t}\right)$, and an idiosyncratic shock, $u_{i t}$. Additionally, I assume that the vector of explanatory variables, $\overrightarrow{X_{i t}}$, can affect both the mean, $\mu(\cdot)$, and the variance, $\sigma(\cdot)$, of $\ln \left(m_{i t}^{P}\right)$. Thus, $\ln \left(m_{i t}^{P}\right)$ is modeled as (equation (3.9))

$$
\begin{gathered}
\ln \left(m_{i t}^{P}\right)=\mu\left(\overrightarrow{X_{i t}}\right)+\sigma\left(\overrightarrow{X_{i t}}\right) u_{i t} \\
\left(\begin{array}{c}
u_{m t} \\
u_{f t}
\end{array}\right) \sim N\left[\left(\begin{array}{l}
0 \\
0
\end{array}\right),\left(\begin{array}{cc}
1 & \rho_{u} \\
\rho_{u} & 1
\end{array}\right)\right],
\end{gathered}
$$

where

$$
\begin{aligned}
& \mu\left(\overrightarrow{X_{i t}}\right)=\chi_{1}^{i} I_{i t}+\chi_{2}^{i} H_{i t}+\chi_{3}^{i} L_{i t}+\chi_{4}^{i} X_{i t}, \\
& \sigma\left(\overrightarrow{X_{i t}}\right)=\pi_{1}^{i} I_{i t}+\pi_{2}^{i} H_{i t}+\pi_{3}^{i} L_{i t}+\pi_{4}^{i} X_{i t} .
\end{aligned}
$$

The parameters that affect the mean of the log of total medical expenditures, $\chi^{i}$, are identified by the co-variation in the log of total medical expenditures and the explanatory variables. The parameters that affect the volatility of the log of total medical expenditures, $\pi^{i}$, are identified by the co-variation in the two spouses' squared residuals of the log of total medical expenditures and the explanatory variables. With the estimated parameters $\widehat{\pi^{i}}$ and 
the vector of observed explanatory variables $\overrightarrow{X_{i t}}$, I can calculate each spouse's preference for medical expenditure shocks, $\sigma\left(\widehat{\pi^{i}} \overrightarrow{X_{i t}}\right) \sqrt{136}$ The co-variation in the two spouses' residuals divided by $\sigma\left(\widehat{\pi^{i}} \overrightarrow{X_{i t}}\right)$ identifies the correlation between the two spouses' error terms, $\rho_{u}$.

\subsubsection{Health Transitions and Survival Rates Parameters}

In the household health transitions function, $H_{i t}$ is a binary variable that indicates whether spouse $i$ is in good health in period $t$. As described in model section 3.6.1, the latent variable, $H_{i t}^{*}$, is modeled as

$$
\begin{gathered}
H_{i t}^{*}=\kappa_{1}^{i} I_{i, t-1}+\kappa_{2}^{i} H_{i, t-1}+\kappa_{3}^{i} X_{i, t-1}+u_{i t}^{H}, \\
\left(\begin{array}{c}
u_{m t}^{H} \\
u_{f t}^{H}
\end{array}\right) \sim N\left[\left(\begin{array}{l}
0 \\
0
\end{array}\right),\left(\begin{array}{cc}
1 & \rho_{H} \\
\rho_{H} & 1
\end{array}\right)\right] .
\end{gathered}
$$

The parameters associated with the explanatory variables, $\kappa^{i}$, are identified by the co-variation in the health status in this period, $H_{i t}$, and the explanatory variables in the last period, $\left(I_{i, t-1}, H_{i, t-1}, X_{i, t-1}\right)$. The correlation between the two spouses' health shocks, $\rho_{H}$, is identified by the co-variation in the residuals of the two probits.

In the household survival rates function, $S_{i t}$ is a binary variable that indicates whether spouse $i$ is alive in period $t$. As described in model section 3.6.2, the latent variable, $S_{i t}^{*}$, is modeled as

$$
\begin{gathered}
S_{i t}^{*}=\zeta_{1}^{i} H_{i, t-1}+\zeta_{2}^{i} X_{i, t-1}+u_{i t}^{S}, \\
\left(\begin{array}{c}
u_{m t}^{S} \\
u_{f t}^{S}
\end{array}\right) \sim N\left[\left(\begin{array}{l}
0 \\
0
\end{array}\right),\left(\begin{array}{cc}
1 & \rho_{S} \\
\rho_{S} & 1
\end{array}\right)\right] .
\end{gathered}
$$

The parameters associated with the explanatory variables, $\zeta^{i}$, are identified by the co-variation in the survival status in this period and the explanatory variables in the last period, $\left(H_{i, t-1}, X_{i, t-1}\right)$. The correlation between the two spouses' life shocks, $\rho_{S}$, is identified by the co-variation in the residuals of the two probits.

\footnotetext{
${ }^{136} \sigma(\vec{X} \pi)$ shows that spouses who have different values of explanatory variables, $\vec{X}$, react to the medical expenditure shock differently.
} 


\section{Results}

In this section, I first discuss the parameter estimates. Then, I assess the model's performance using three different specification tests.

\subsection{Model Parameter Estimates}

Recall that I use a two-stage estimation procedure to estimate the model ${ }^{137}$ In the first stage, I use the HRS demographic data and Maximum Likelihood (ML) Estimation to estimate the parameters that determine household health transitions (equation (3.17)) and survival rates (equation (3.18)). I also use the MEPS data and ML Estimation to estimate the parameters that determine the distribution of total medical expenditures (equations (3.8)(3.10)). In the second stage, I use my HRS sample and Maximum Simulated Likelihood (MSL) Estimation to estimate the parameters that determine utility function (equations (3.1)-(3.3) and the consumption floor (equation (3.6). In this subsection, I present the preference parameter estimates in the second stage that affect household utility. I discuss the parameter estimates in the first stage that determine the distribution of total medical expenditures, health transitions, and survival rates in Appendix A.8.

As described in model section 3.2, a household's utility is the weighted average of each spouse's utility, weighted by each spouse's bargaining power (equation (3.1)). A spouse's utility function depends on his leisure, his time-invariant preferences for discrete choices (unobserved heterogeneity), household consumption, and an idiosyncratic shock (equation (3.2)). His preference for leisure depends on his age, his health, and the other spouse's leisure.

Table 10 presents estimates of preference parameters that affect household utility. The first and the second panels list the estimates of parameters that determine husbands' and wives' preferences for leisure, respectively. The sign of these parameter estimates are as expected and are significant at $1 \%$ significance level. The estimates show that, for both husbands and wives, their preferences for leisure increase with age. Husbands and wives value leisure more if they are in bad health or their spouse is retired. The estimated coeffi-

\footnotetext{
${ }^{137}$ Details of the estimation strategy are discussed in estimation section 5.2.4.
} 
cients of age and health are similar to those found in Gustman and Steinmeier (2000, 2004). Unlike these two papers, I assume that husbands and wives value spousal leisure (shared retirement) equally. I make this assumption because the two parameters representing the two spouses' preferences for shared leisure cannot be separately identified (explained in estimation section 5.3.1). For Gustman and Steinmeier (2000, 2004), their ability to separately identify these two parameters relies on an important assumption: the decision-making process in a family is a non-cooperative bargaining process 138 My estimated coefficient of spousal leisure falls between the estimates of the husbands' and wives' preferences for shared retirement found in these two papers ${ }^{139}$ To put the size of the estimates into perspective, I compute the average marginal effect (AME) for each of these variables. The AMEs show that increasing the age by one year increases the propensity to retire by 0.9 and 1.2 percentage points for husbands and wives, respectively. Being in good health decreases the propensity to retire by 3.3 and 2.9 percentage points for husbands and wives, respectively. Spending leisure with the other spouse increases the propensity to retire by 2.4 and 3.2 percentage points for husbands and wives, respectively.

The third panel presents the parameter estimates associated with the distribution of unobserved heterogeneity. The first estimate in this panel, 0.72 , is the estimated probability of being Type I unobserved heterogeneity. Recall that Type I unobserved heterogeneity is assumed to be a vector of zeros. The rest of the estimates in this panel are the estimated Type II unobserved heterogeneity. These estimates show that there exists, at least, one factor that makes husbands prefer working over retirement and prefer obtaining health insurance from their own employer rather than from their wife's employer. In addition, this factor makes wives prefer retirement over working and prefer obtaining insurance from their husband's employer rather than from their own employer. This factor could be the unobserved ability/willingness to do house work and care for family members. The estimate of the wife's preference for her own employer-provided health insurance (EPHI) relative to

\footnotetext{
${ }^{138}$ In Gustman and Steinmeier (2000, 2004), each spouse is modeled to maximize his or her own utility with respect to budget constraints. The marginal utility of leisure for one spouse is modeled as a function of the retirement decision of the other spouse.

${ }^{139}$ Gustman and Steinmeier 2000, 2004) found that the wife's preference for retirement is small and statistically insignificant and the husband's preference for shared retirement is large and statistically significant.
} 
Table 10: Estimates of Preference Parameters

\begin{tabular}{lrrr}
\hline \hline & Estimate & Std. Err. & AME \\
\hline Husband's Preference for Leisure & & & \\
H's age & $0.589^{* *}$ & 0.143 & 0.009 \\
H has good health & $-0.573^{* *}$ & 0.147 & -0.033 \\
W's leisure & $0.792^{* *}$ & 0.129 & 0.024 \\
Constant & $-1.583^{* *}$ & 0.353 & \\
\hline Wife's Preference for Leisure & & & \\
W's age & $0.503^{* *}$ & 0.035 & 0.012 \\
W has good health & $-1.262^{* *}$ & 0.378 & -0.029 \\
H's leisure & $0.792^{* *}$ & 0.129 & 0.032 \\
Constant & $-1.523^{* *}$ & 0.269 & \\
\hline Unobserved Heterogeneity & & & \\
Probability of type I & $0.724^{* *}$ & 0.024 & \\
H's taste for working relative to retirement & $0.555^{* *}$ & 0.144 & \\
H's taste for own EPHI relative to spousal EPHI & $0.425^{* *}$ & 0.109 & \\
W's taste for working relative to retirement & $-0.819^{* *}$ & 0.247 & \\
W's taste for own EPHI relative to spousal EPHI & $-4.561^{* *}$ & 0.488 & \\
\hline Relative risk aversion & $1.674^{* *}$ & 0.019 & \\
Time discount factor & $0.942^{* *}$ & 0.163 & \\
Consumption floor & $7,734^{* *}$ & 1,578 & \\
The Scale of idiosyncratic errors $\left(\sigma_{l}\right)$ & $0.816^{* *}$ & 0.204 & \\
\hline \hline Note: 1) $*$ is 5 percent significance level, and ** is 1 percent significance level; & \\
2) variable age here is (age-55); & & & \\
3) the column AME lists average marginal effects of variables on the propensity to retire.
\end{tabular}

spousal EPHI has a much larger scale than other estimates, which indicates that my model does not explain the observed wives' EPHI coverage choices very well. This might be because my model does not include the notion that many wives prefer to let husbands provide family health insurance coverage, which allows wives to be more flexible and to take care of family members.

The last panel shows other parameters that affect household utility. My estimated relative risk-aversion coefficient is 1.67 , which lies within the range of $[1,5]$ that many economists believe contains this parameter (Chetty (2006) $) .140$ This implies that my estimate of the coefficient of relative risk aversion is reasonable. Another important estimate is the time discount factor. Each period contains two years, and thus, the estimated time discount factor 0.94 is a biannual discount factor. The yearly time discount factor is 0.97 ,

\footnotetext{
${ }^{140}$ The estimated values of the relative risk-aversion coefficient reported by Rust and Phelan (1997), Blau and Gilleskie (2006. 2008), and French and Jones (2011) are 1.1, 1.8, 1.0 and 5.0, respectively.
} 
which matches the empirical time discount factor widely assumed in the literature. For example, Blau and Gilleskie (2006) fix the annual time discount factor at 0.96; Rust and Phelan (1997) fix it at 0.98. My estimated household consumption floor is $\$ 7,734$ per year, which is similar to the consumption floor assumed or estimated in the literature. For example, Casanova (2010) assumes that the household consumption floor is $\$ 7,596,141$ and French and Jones (2011) estimate that the individual consumption floor is $\$ 4,380$.

\subsection{Specification Tests}

I conduct three different specification tests to assess my model's performance. First, I test how well the model fits the data by comparing the predicted and observed labor market behavior by age and health insurance types (see 6.2.1). Then, I use a Chi-Square Goodness-ofFit test to assess whether the distribution of predicted probabilities matches the distribution of observed frequencies of household retirement choices (see 6.2.2). Last, I use three Lagrange Multiplier (LM) tests to check whether the model is properly specified (see 6.2.3).

\subsubsection{Model Fit}

To examine how well the structural model fits the data, I simulate full-time work participation rates and job exit rates for each spouse in my sample, using the model and the estimated parameters. I compare these simulated labor market behaviors with the observed labor market choices in the HRS.

\section{Participation Rates}

Figures 6.16 .3 and 6.46 .6 compare the simulated and observed full-time work participation rates by age and health insurance categories for husbands and wives, respectively. The focus is on employment patterns for spouses who are in three different health insurance categories: (1) health insurance is available only while employed ("Tied HI"); (2) health insurance is available while employed and retired ("Retiree HI"); and (3) no insurance is

\footnotetext{
${ }^{141}$ In Casanova (2010), the household consumption floor is set to $\$ 7,596$. This is the average amount of Supplemental Social Security Income that a couple on income support and aged 65 or older would have received in 1992.
} 
available, whether employed or retired ("No HI"). The area between the two grey, smooth lines represents the 95 percent confidence interval for the predicted participation rates. As these figures show, although the simulated data differ from the actual data, the observations fall within the 95 percent confidence interval for all points. This implies that my model fits the overall patterns of full-time work participation rates quite well.

My model is able to replicate three key features of how full-time work participation rates vary with age and health insurance categories. First, my model is able to capture the overall pattern that full-time participation rates decline with age. Second, my model is able to capture several sharp declines around age 62 and 65. Specifically, the model captures (a) the sharp declines in participation rates at age 65 for both husbands and wives who have tied health insurance; (b) the sharp declines at age 62 and 65 for husbands who have retiree insurance; and (c) the sharp decline at age 62 for wives who have retiree insurance. Third, my model is able to capture the large differences in full-time work participation rates across health insurance categories. For example, the model matches the high participation rates of workers who have tied health insurance and the low participation rates of workers who have retiree health insurance.

Figure 6.1: Husband Participation Rates: Tied EPHI

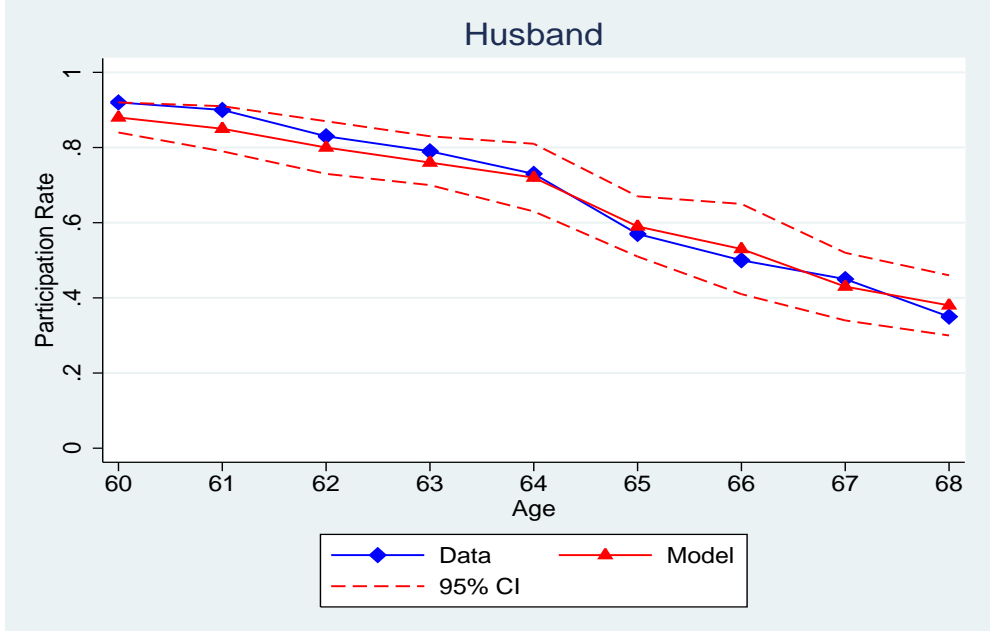

\section{Job Exit Rates}

Figures 6.7 6.9 and 6.10 6.12 compare the simulated and observed full-time job exit rates by age and health insurance categories for husbands and wives, respectively. As these 
Figure 6.2: Husband Participation Rates: Retiree EPHI

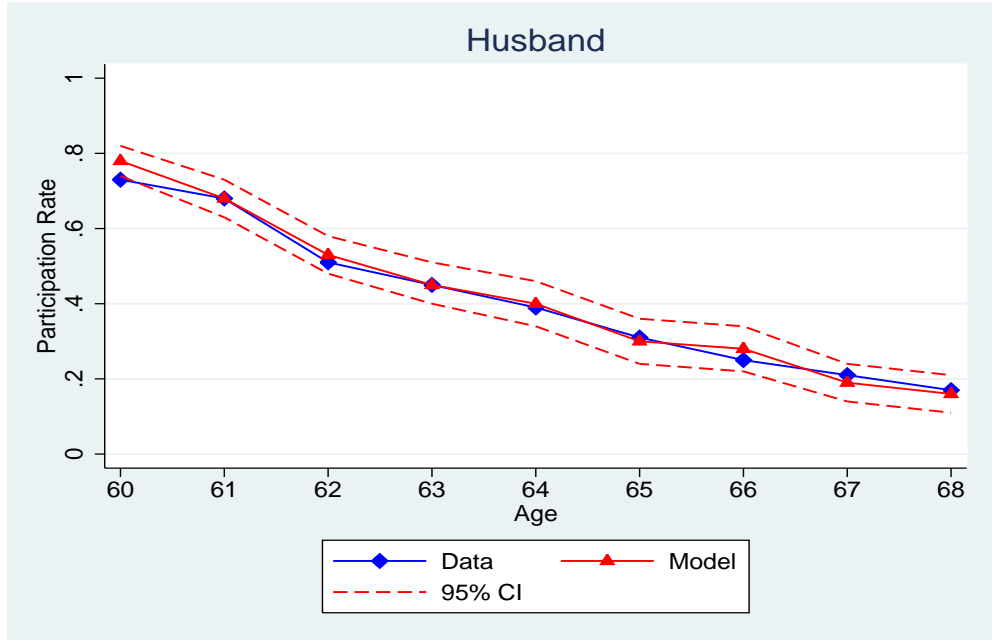

Figure 6.3: Husband Participation Rates: No EPHI

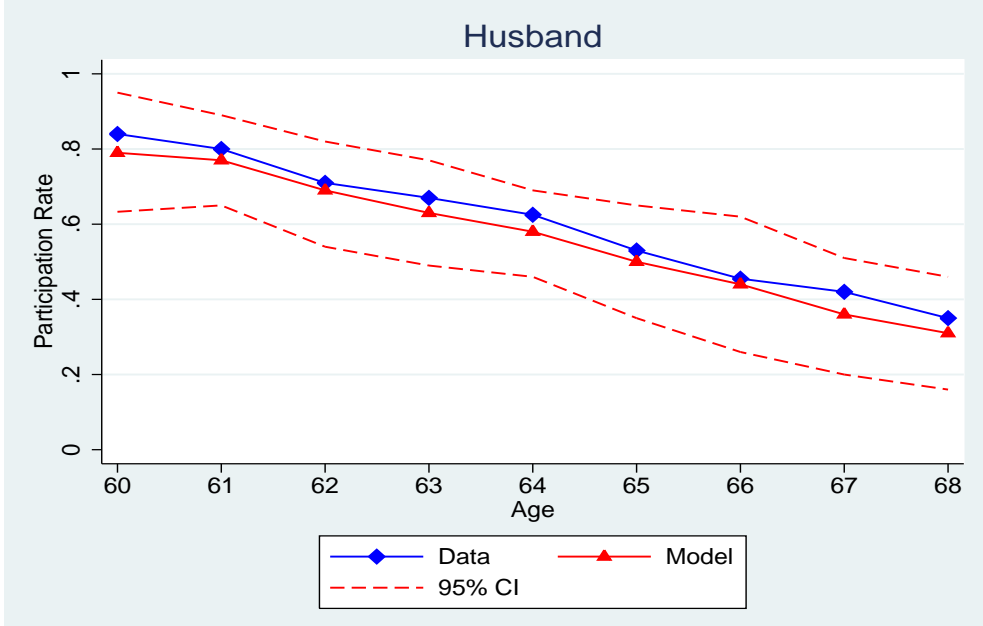

Figure 6.4: Wife Participation Rates: Tied EPHI

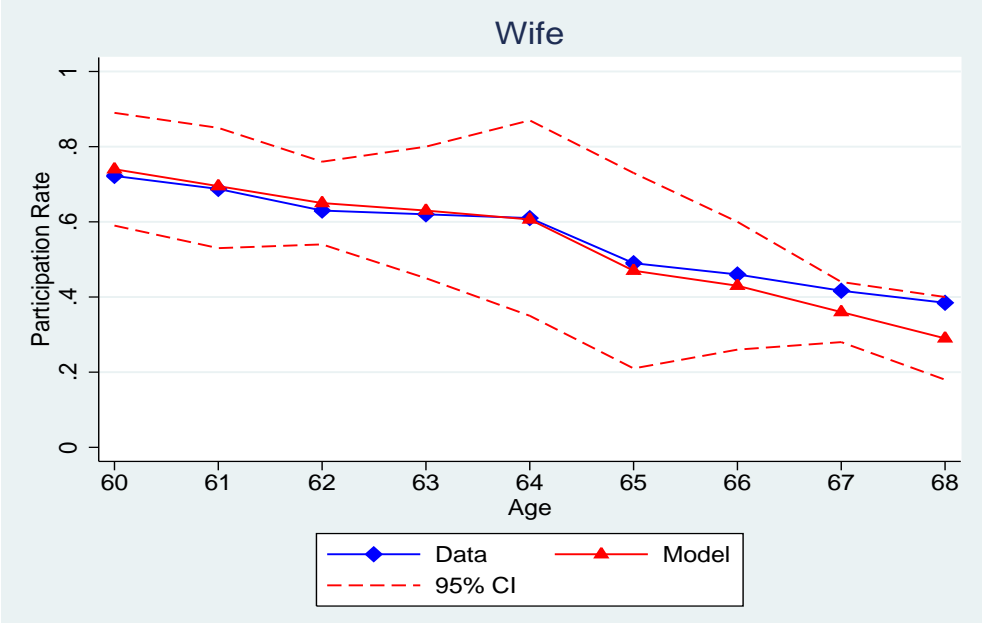

figures show, most of the observations fall within the 95 percent confidence interval for the predicted job exit rates. This indicates that my model fits the overall patterns of job 
Figure 6.5: Wife Participation Rates: Retiree EPHI

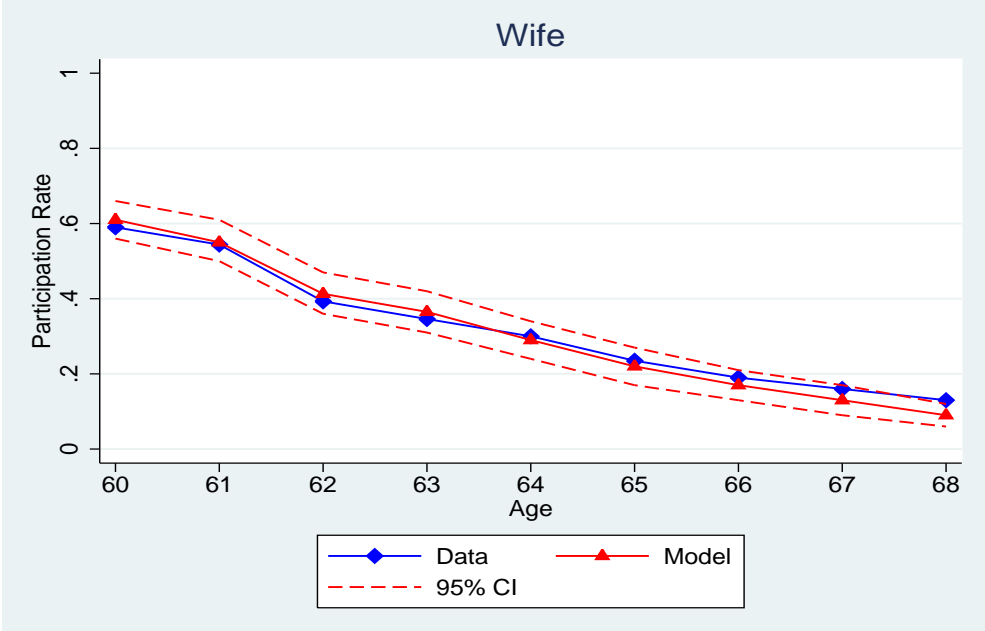

Figure 6.6: Wife Participation Rates: No EPHI

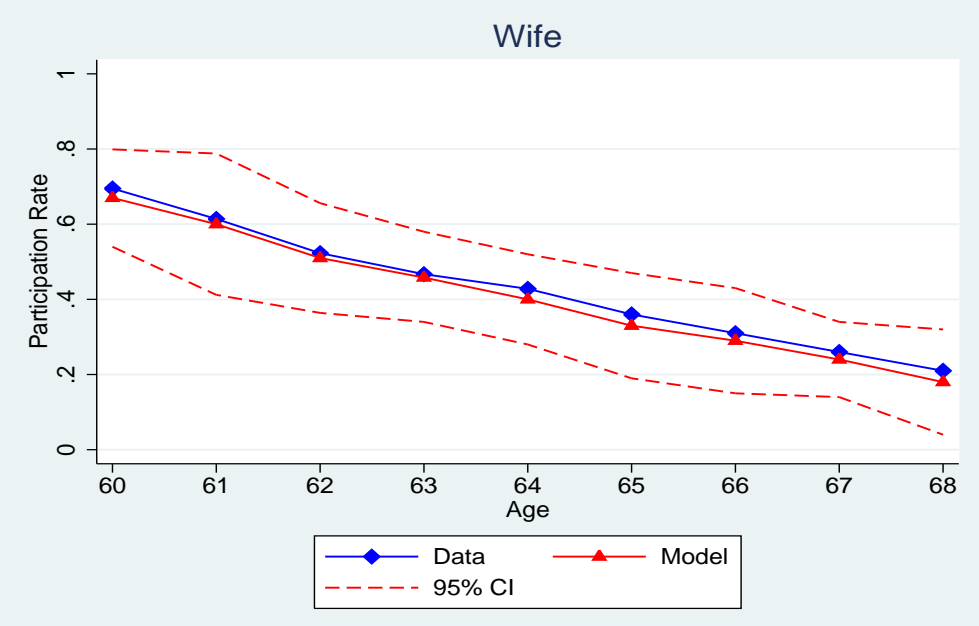

exit rates quite well. To be more specific, the model captures the spike in job exit rates at age 65 for both husbands and wives who have tied health insurance. It also captures the spike in job exit rates at age 62 and 65 for both husbands and wives who have retiree health insurance. However, some differences exist between the simulated data and the actual data. For example, for husbands with tied insurance, the model underpredicts the age-65 job exit rate. For husbands with retiree insurance, the model underpredicts the age62 job exit rate and overpredicts the age- 65 job exit rate. For wives with tied insurance, the model overpredicts the age- 65 job exit rate, and for wives with retiree insurance, the model underpredicts the age-62 job exit rate. For both husbands and wives with no insurance, the model overpredicts the job exit rates at almost every age. The mismatch for spouses with no insurance may be due to the following reasons: (1) the sample size of households that have 
no health insurance is very small; and (2) most spouses who have no EPHI in my sample are self-employed, and self-employed people may have a high preference for working due to some unobserved factors, such as workaholism, that are not included in my model.

The ability of this paper to capture the spikes at ages 62 and 65 relies mostly on two aspects of the model: (1) carefully model the interaction between two spouses' financial benefits (including Social Security and pension benefits); and (2) the interdependence of two spouses' health insurance coverage. Papers ignore the interdependence of two spouses' health insurance coverage may underpredict the high job exit rate at ages 65 . This is because some spouses with retiree insurance may delay their retirement to age 65 , in order to provide health insurance to their spouses. For example, Blau and Gilleskie (2006) do not pick up the especially high exit rates at ages 62-65, and they underpredict the difference in job exit rates between workers with and without retiree insurance. French and Jones (2011) fail to capture the spike at 65 for those who have retiree insurance.

Figure 6.7: Husband Job Exit Rates: Tied EPHI

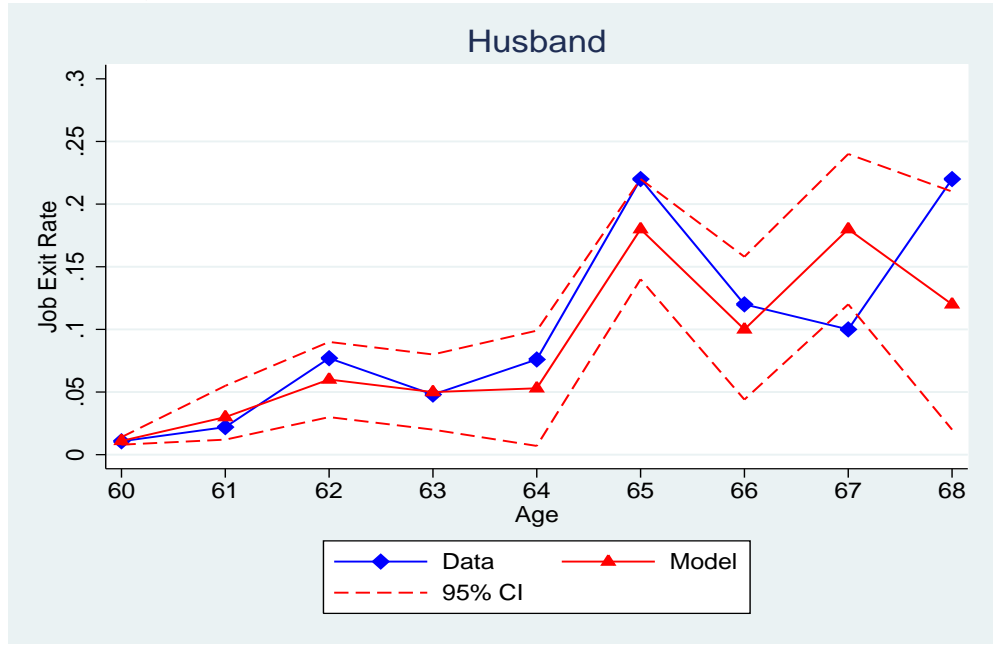

\subsubsection{Chi-Square Goodness-of-Fit Test}

Table 11 summarizes the goodness-of-fit of my model. In my model, there are four possible household labor supply choices: (1) both spouses work full-time; (2) only husband works full-time; (3) only wife works full-time; or (4) both spouses are retired. For each household in my sample, the model predicts the probability of these four household choices. For each household labor supply choice, I divide households into five strata by the percentile of their 
Figure 6.8: Husband Job Exit Rates: Retiree EPHI

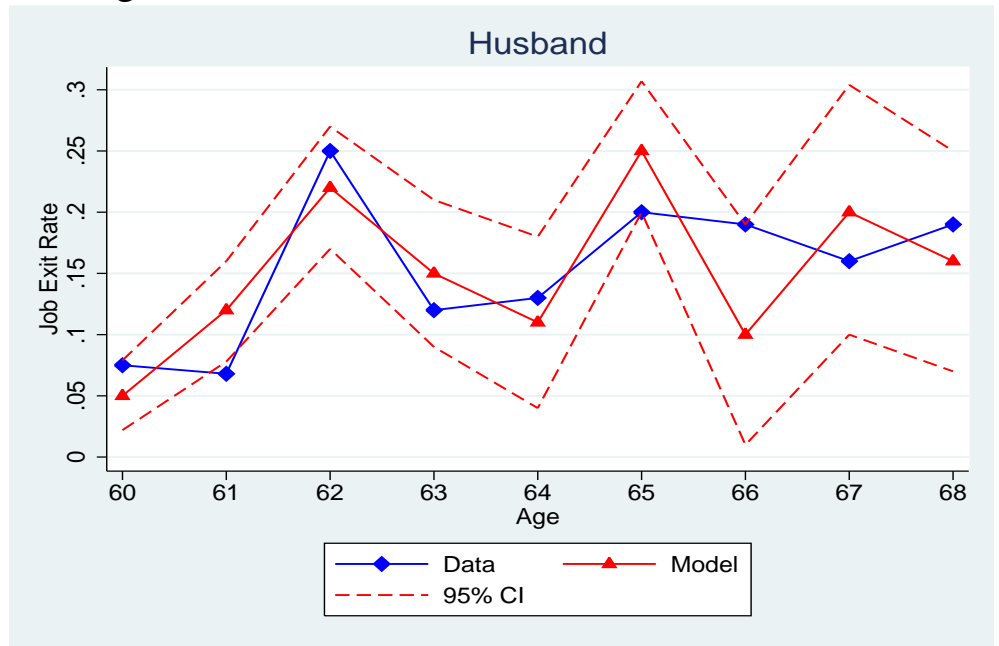

Figure 6.9: Husband Job Exit Rates: No EPHI

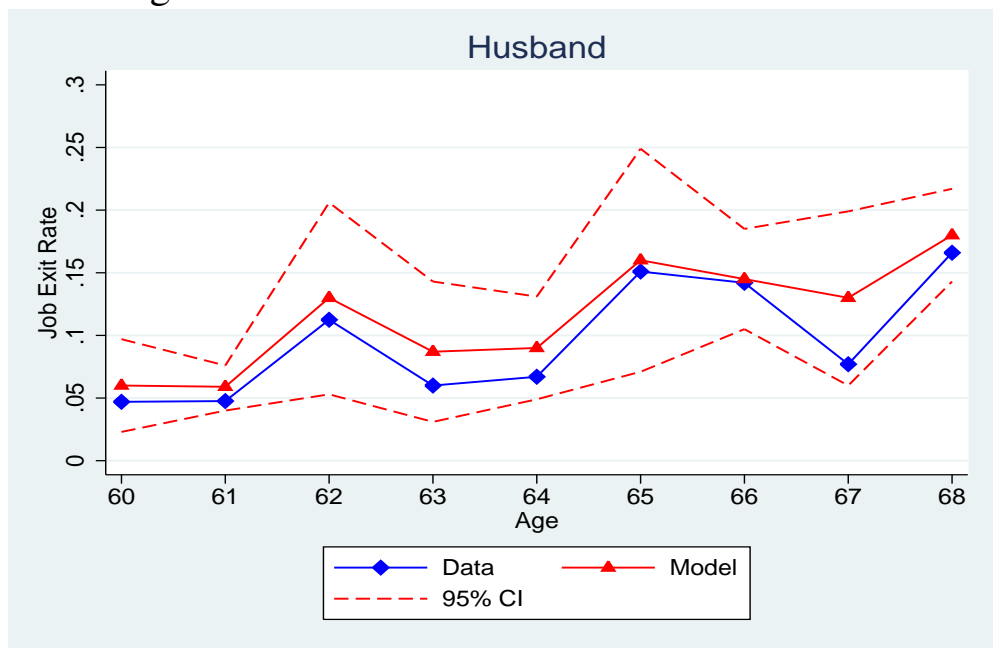

Figure 6.10: Wife Job Exit Rates: Tied EPHI

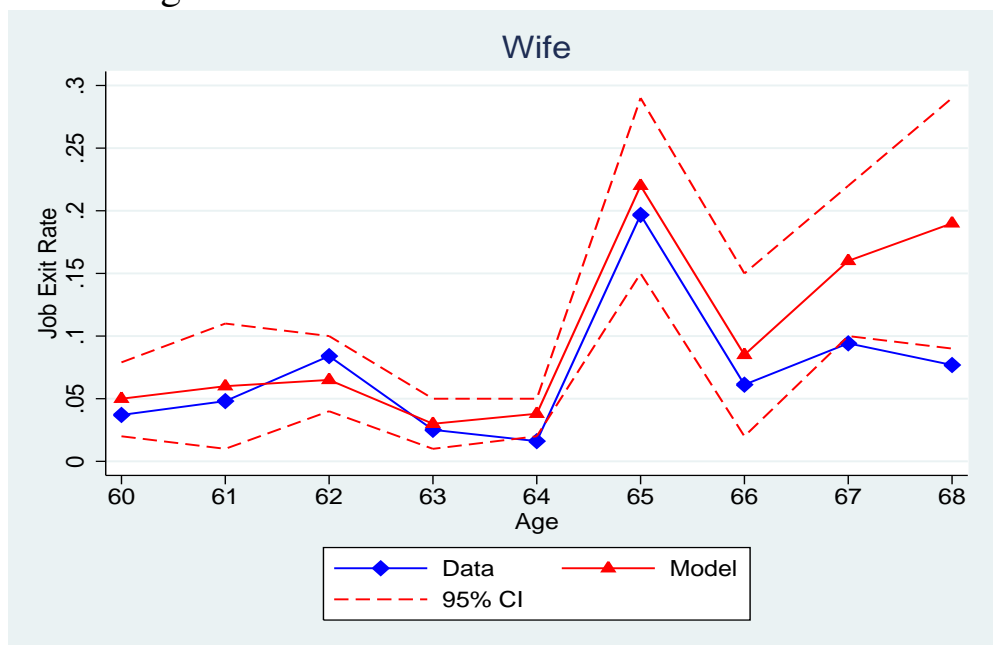

predicted probabilities and then compare the average predicted probabilities to the observed frequencies for each stratum. The null hypothesis I test is that the distributions of observed 
Figure 6.11: Wife Job Exit Rates: Retiree EPHI

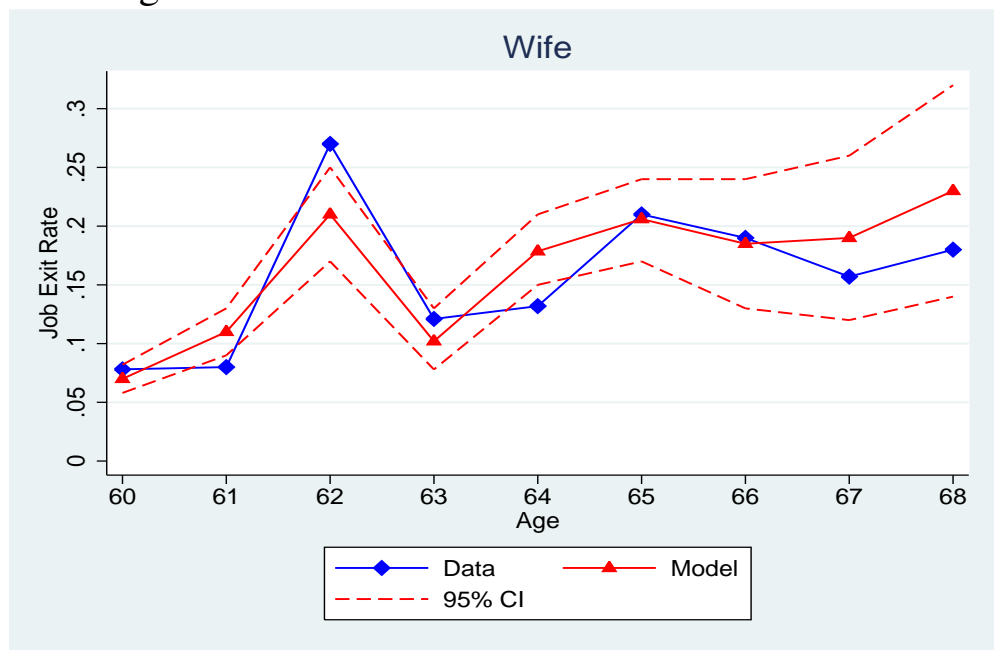

Figure 6.12: Wife Job Exit Rates: No EPHI

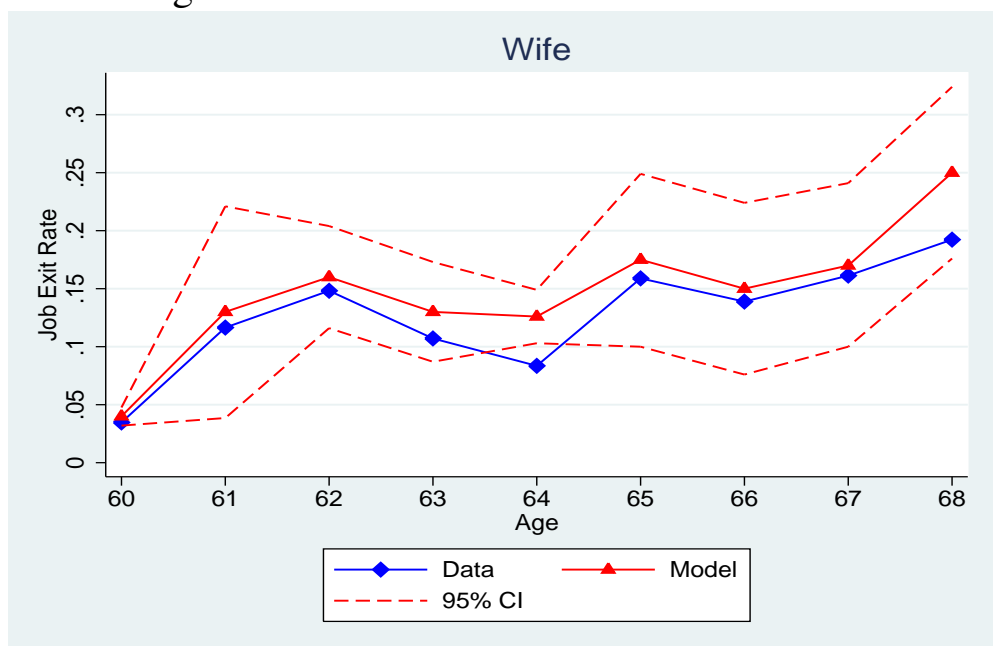

frequencies and predicted probabilities are identical. The Pearson Chi-square test statistic is

$$
\sum_{c=1}^{4} \sum_{g=1}^{5} \frac{\left(O_{c, g} \times N_{g}-P_{c, g} \times N_{g}\right)^{2}}{P_{c, g} \times N_{g}}
$$

where $O_{c, g}$ and $P_{c, g}$ represent the average observed frequency and the average predicted probability for choice $c$ in stratum $g$, and $N_{g}$ is the number of observations in stratum $g$. This Pearson Chi-square test statistic has an $\chi^{2}$ distribution with $19(=c g-1)$ degrees of freedom. For 19 degrees of freedom, the $5 \%$ critical value of the $\chi^{2}$ distribution is 30.14 and the $1 \%$ critical value is 36.19 . The chi-square statistic is 21.8465 , which is well below these critical values. This indicates that there is little evidence that the model does not fit the data well. 
Table 11: Chi-Square Goodness-of-Fit Analysis on Employment

\begin{tabular}{lcccc}
\hline \hline \multicolumn{5}{c}{ Predicted Probabilities } \\
\hline Prob. & Both Work & Husband Works & Wife Works & Both Retired \\
1st & 0.4189 & 0.0089 & 0.0119 & 0.0001 \\
2nd & 0.6832 & 0.0429 & 0.0449 & 0.0021 \\
3rd & 0.8201 & 0.0769 & 0.0941 & 0.0089 \\
4th & 0.9101 & 0.1341 & 0.1528 & 0.0299 \\
5th & 0.9791 & 0.2301 & 0.2201 & 0.1309 \\
\multicolumn{5}{c}{ Observed Frequencies } \\
Cell & Both Work & Husband Works & Wife Works & Both Retire \\
1st & 0.4543 & 0.0166 & 0.0186 & 0.0003 \\
2nd & 0.6993 & 0.0491 & 0.0529 & 0.0029 \\
3rd & 0.8301 & 0.0724 & 0.0901 & 0.0074 \\
4th & 0.8951 & 0.1207 & 0.1527 & 0.0273 \\
5th & 0.9645 & 0.2141 & 0.2121 & 0.1195 \\
\multicolumn{5}{c}{ Statistical Test: $\chi^{2}(19)=21.8465, \mathrm{p}=0.2919$} \\
\hline \hline
\end{tabular}

\subsubsection{Lagrange Multiplier Test}

I use three Lagrange Multiplier (LM) tests to check whether the utility function is properly specified. First, I test the specification of individuals' preference for leisure. In my model, one spouse's preference for leisure is assumed to be an exponential function of age, health status, and the other spouse's leisure. However, other variables, such as the other spouse's health status, could also affect the preference for leisure due to caregiving. I assume spouse $i$ 's true preference for leisure in period $t$ is

$$
\exp \left\{\beta^{i} X_{t}^{i}+Z_{t}^{i} \gamma^{i}\right\}
$$

where $Z_{t}^{i}=H_{-i, t}$ is the other spouse's health, which is omitted in the model. I run an LM test to check whether or not parameters in $\gamma=\left(\gamma^{m}, \gamma^{f}\right)$ are jointly significantly different from zero. The null hypothesis is that $\gamma=0$. The LM test statistic is $\chi^{2}(2)=14.17$, and the P-value is 0.001 . Thus, the null hypothesis can be rejected at the $1 \%$ significance level. This indicates that the omitted variable, spousal health, has a statistically significant effect on individuals' preference for leisure. This suggests the existence of another channel through which spousal retirement may be correlated, and it should be the subject of future research. 
Second, I test whether one spouse cares about the other spouse's utility (also called caring preference). In the model, I assume that each spouse has egoistic preferences and does not value the other spouse's utility. To test caring preferences, I add the product of the two spouses' self-regarding utility functions to the original household utility function. The new household utility funtion is

$$
U_{\text {new }}=U_{\text {old }}+\gamma_{A}\left(u_{h} \times u_{w}\right)
$$

The lowercase $u_{h}$ and $u_{w}$ present the two spouses' self-regarding utility functions, as defined in the model section. The null hypothesis is $\gamma_{A}=0$. The LM test statistic is $\chi^{2}(1)=8.91$ and the P-value is 0.003 . Thus, the null hypothesis can be rejected at the $1 \%$ significance level. This indicates that caring preferences might be more appropriate than egoistic preferences to describe married people's utility. This test result is consistent with the evidence found in Friedberg and Stern (2014).

Last, I test for heteroskedasticity of idiosyncratic errors. In the model, I assume that idiosyncratic utility shocks, $l_{d t}$, are independent across households, time, and discrete choices. Specifically, I assume that idiosyncratic utility shocks are iid EV. In other words, the variance of the idiosyncratic shocks is assumed to be the same across different groups of households. However, this may not always be the case. For example, in healthy households, some spouses may retire from full-time work because they want to travel, while others may continue working full-time because they want to bring in more money. Thus, households in good health may have a greater dispersion in labor supply decisions than households in bad health. To test for heteroskedasticity, I add a vector of observed explanatory variables to the original scale parameter. The new scale parameter is

$$
\sigma_{\text {new }}=\sigma_{l}+X_{\sigma} \gamma_{\sigma}
$$

where $\sigma_{l}$ is the scale parameter under the homoskedasticity assumption. The variable $X_{\sigma}$ is a vector of variables that might affect the variance of idiosyncratic shocks, which includes the two spouses' education level and health status. Then the null hypothesis is $\gamma_{\sigma}=0$, which means that, among people who have different education levels and health statuses, there is no heteroskedasticity of idiosyncratic errors. The LM test statistic is $\chi^{2}(4)=2.95$, and the 
$\mathrm{P}$-value is 0.23 . Therefore, since the null hypothesis cannot be rejected significantly, it is reasonable to assume the homoskedasticity of idiosyncratic errors. 


\section{Counterfactual Simulations}

In this section, I use the model estimates to run several counterfactual simulation experiments for two purposes. First, I run several simulation experiments to identify the following causal inferences: (1) the causal effects of employer-provided retiree health insurance (EPRHI) on spouses' retirement (see 7.1.1); (2) the importance of including the health channel in evaluating the effects of health insurance on retirement (see 7.1.2); (3) the causal effects of spousal coverage on spouses' coordinated retirement (see 7.1.3); and (4) the causal effects of enjoying shared leisure time on household simultaneous retirement (see 7.1.4). Second, I conduct several policy simulations to predict the consequences of the following potential policy reforms: (1) the implementation of the Affordable Care Act (ACA) (see 7.2.1); (2) raising the Medicare eligibility age to 67 (see 7.2.2); and (3) raising the normal retirement age to 67 (see 7.2.3).

\subsection{Causal Inferences}

In the simulation experiments, I either pretend people are slightly different in their pension benefits or spousal coverage, or set some parameter estimates to zero, to see how spouses' retirement behaviors change.

\subsubsection{The Effects of Employer-Provided Retiree Health Insurance}

As shown in Figures 4.1 and 4.2 in data section 4.4, spouses who have retiree health insurance have lower full-time work participation rates, at every age, than those who have tied health insurance. This may be so for two reasons: (1) risk-averse workers value the effect of health insurance on reducing both the amount and the volatility of future out-of-pocket medical expenses; and (2) workers who have retiree insurance may have greater pension wealth than those with tied insurance. To isolate the effects of EPHI on labor supply from the effects of pension wealth, I assign the average pension accrual rates of workers who have tied health insurance to every spouse in my sample, so that pension incentives are the same across health insurance categories. Next, I conduct two simulation experiments. 
In the first experiment, I assume that all spouses have tied insurance; and in the second experiment, I assume that all spouses have retiree insurance. The difference in these two simulation experiments is a measure of the effects of EPHI on retirement, after controlling for pensions.

Figure 7.1 compares the job participation rates in the two simulation experiments. The two solid lines represent the model-predicted participation rates for spouses with tied insurance and those with retiree insurance, respectively. The two dotted lines represent the simulated participation rates for spouses in these two groups. At almost every age, spouses with tied insurance have higher simulated participation rates than those with retiree insurance. Even after the Medicare eligibility age (65), the simulated participation rates of husbands with tied insurance are still higher than the simulated participation rates of husbands with retiree insurance. This might be because some husbands with tied insurance delay their retirement to provide insurance coverage to their wife until their wife is eligible for Medicare. By contrast, the simulated participation rates of wives with tied insurance are close to the simulated participation rates of wives with retiree insurance even before 65 . This might be because some wives are covered by spousal coverage, and thus, they would retire before 65 without losing insurance coverage.

Figure 7.1: Effects of EPRHI on Job Participation Rates

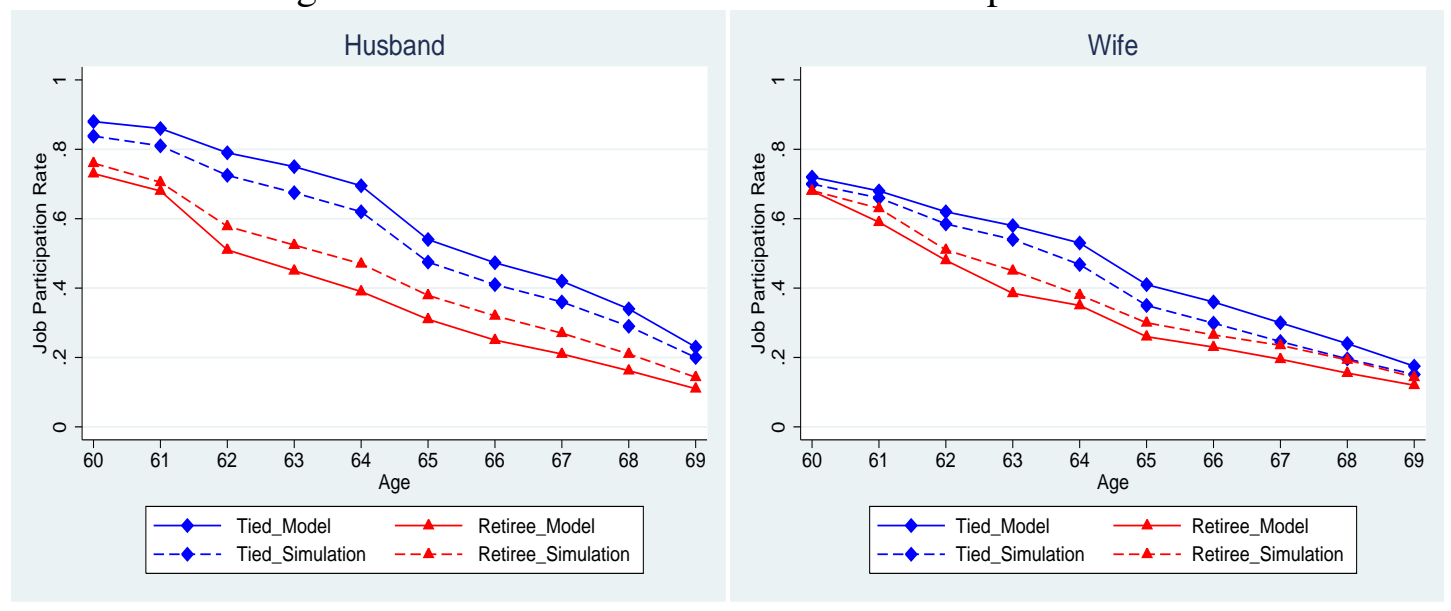

One measurement of the effects of EPRHI is the difference in the average retirement age, which is the sum of the differences in the two dotted lines for all ages between 60 and 69 (French and Jones (2011)). The results show that, giving employer-provided retiree 
insurance to spouses with tied insurance, the average retirement age decreases by 1.1 and 0.5 years for husbands and wives, respectively. Comparatively, the sum of the differences in the model-predicted participation rates in two insurance categories (retiree insurance and tied insurance) is 2.3 and 1.2 years for husbands and wives, respectively. Thus, the low job participation rates of workers who have retiree coverage are due partly to more generous pensions. However, even after controlling for pensions, health insurance remains an important factor that explains more than $40 \%$ of the difference in the job participation rates for spouses in the two insurance categories.

In the literature, another measurement of the effects of EPHI used is the difference in the age-62 job exit rates (Rust and Phelan (1997)). Figure 7.2 compares the job exit rates in the two simulation experiments. The difference at age 62 means that, giving retiree coverage to spouses with tied insurance increases the age- 62 job exit rate by 9 and 8 percentage points for husbands and wives, respectively. ${ }^{142}$

Figure 7.2: Effects of EPRHI on Job Exit Rates

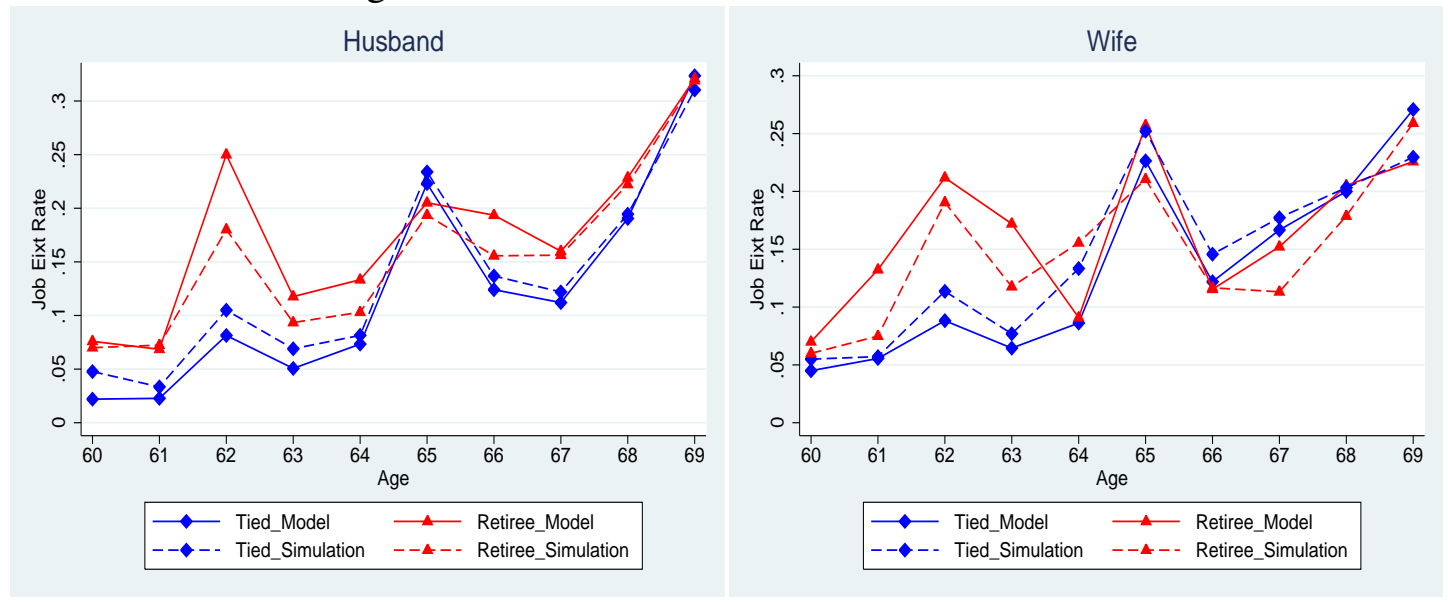

This paper finds larger effects of health insurance on retirement than previous structural studies that include risks related to medical expenses. For example, Rust and Phelan (1997) find that being eligible for employer-provided retiree insurance increases men's age62 job exit rate by about 8 percentage points 143 French and Jones (2011) find that retiree

\footnotetext{
${ }^{142}$ If all spouses are eligible for retiree insurance rather than tied insurance, the husbands' age-62 job exit rate would increase from 9 to 18 percentage points, and the wives' age-62 job exit rate would increase from 8 to 16 percentage points.

${ }^{143}$ See Table VIII in Rust and Phelan (1997).
} 
coverage reduces men's average retirement age by 0.34 year ${ }^{144}$ Blau and Gilleskie 2006 , 2008) find that retiree coverage reduces married men's average participation rates by 1.7 percentage points. By contrast, I find that retiree coverage increases husbands' age-62 exit rate by 9 percentage points, accelerates husbands' retirement by 1.1 years, and reduces husbands' average participation rates by 11 percentage points. The reason why I find larger effects of health insurance on retirement may be because my model accounts for the interdependence of both spouses' insurance coverage, which has been overlooked in the previous studies. My estimates of the effects of health insurance lie within the range of estimates that have been provided by previous reduced-form studies. For example, Madrian et al. (1994) find that retiree coverage reduces men's retirement age by $0.4-1.2$ years.

\subsubsection{The Importance of Including the Health Channel}

Recall that this paper models two channels through which health insurance affects household retirement decisions: medical expense and health. The medical expense channel is the only one that has been considered in the literature on health insurance and retirement. To evaluate the importance of including the health channel in my model, I run several simulation experiments to answer two research questions. First, without including the health channel, how well does my model explain the observed labor market behaviors? Second, does EPRHI raise job exit rates primarily through the medical expense channel or the health channel?

To answer the first question, I simulate household labor supply by taking out the health channel, which appears in health transition functions (equation (3.17)). I set the parameters of health status in health transition functions to zero. Figure 7.3 compares observed job participation rates in the data, model-predicted participation rates with both channels, and simulated participation rates without the health channel. Figure 7.4 compares observed, model-predicted, and simulated job exit rates. For both husbands and wives, without the health channel, the model would overpredict the job participation rates and

\footnotetext{
${ }^{144}$ Structural studies that omit risks related to medical expenses find even smaller effects of health insurance. For example, Gustman and Steinmeier (1994) find that retiree coverage reduces years in the labor force by 0.1 years. Lumsdaine et al. (1994) find even smaller effects.
} 
underpredict the job exit rates, at almost every age. This is because, without the health channel, spouses would expect worse health in the model. This would affect their retirement decisions in two directions: (1) spouses with worse health have higher preference for leisure relative to work, and thus, they would retire earlier; and (2) spouses with worse health would expect higher and more volatile medical expenses, and thus, they would delay their retirement to have better financial protection. The simulation results show that the second direction outweighs the first one.

Figure 7.3: Job Participation Rates without the Health Channel
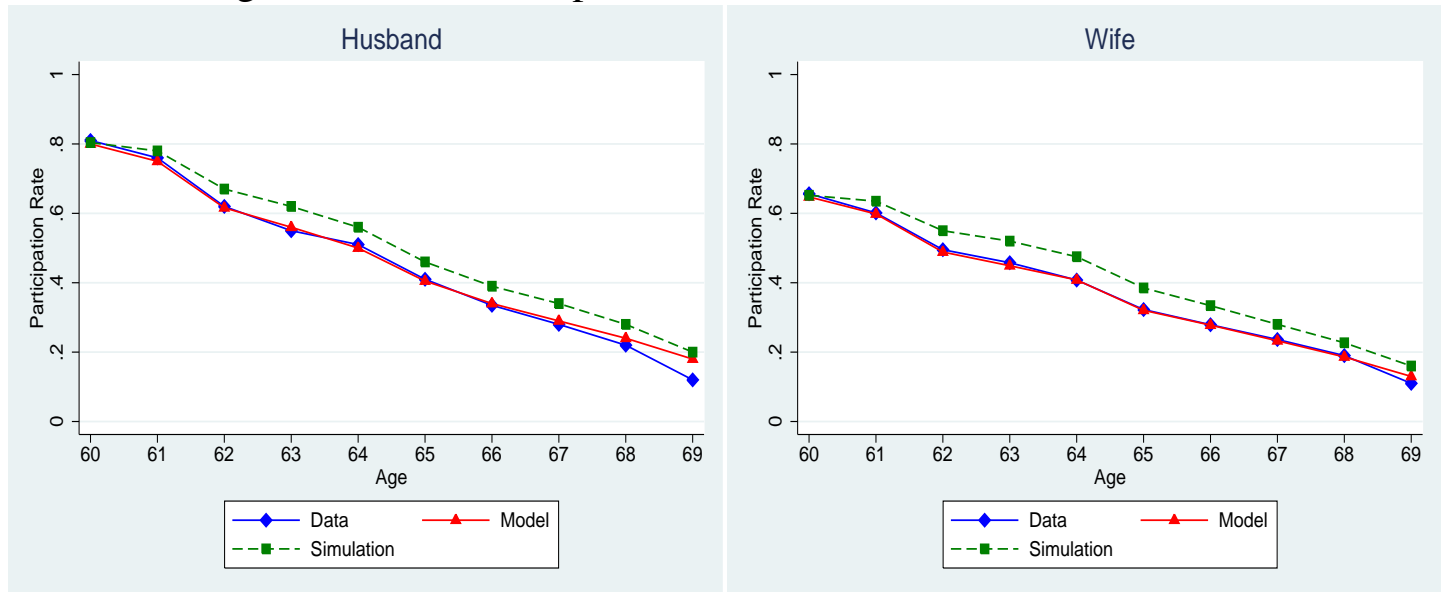

Figure 7.4: Job Exit Rates without the Health Channel
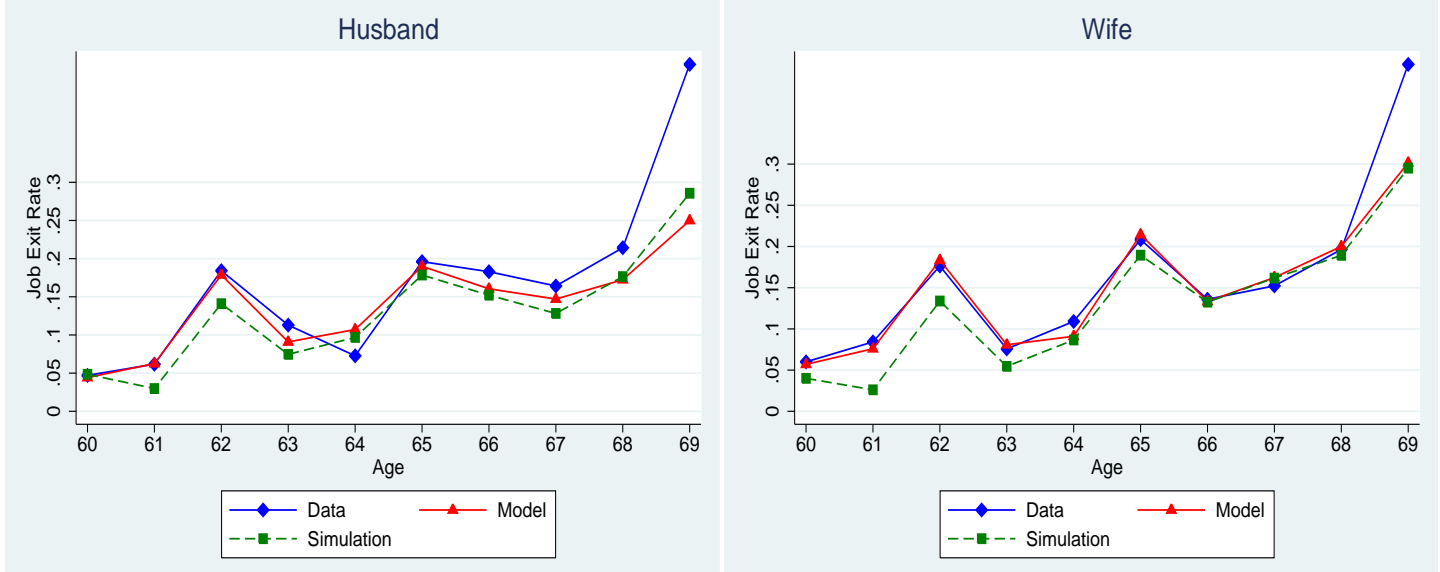

To answer the second question (does EPRHI raise job exit rates primarily through the medical expense channel or the health channel?), I conduct two simulation experiments to separate the effects of health insurance through the medical expense channel from the effects through the health channel. In this subsection (7.1.2), I rerun the two simulations 
from subsection 7.1.1 but take out the health channel. The difference in these two simulation experiments is a measure of the effects of EPRHI on retirement without the health channel. Figure 7.5 compares effects of EPRHI on job participation rates with and without the health channel. Without the health channel, although the effects of EPHI on participation rates becomes smaller at almost every age, the model still captures most of the effects. For example, without the health channel, EPHI coverage accelerates husbands' retirement by 0.9 years, which accounts for about $82 \%$ of the effects of EPHI when both channels are considered. Thus, the health channel accounts for only $18 \%$ of the effects of EPRHI ${ }^{145}$ In summary, most of the value that workers place on health insurance comes through the medical expense channel, which reduces both the amount and the volatility of medical expenses.

Figure 7.5: Effects of EPRHI on Participation Rates without the Health Channel

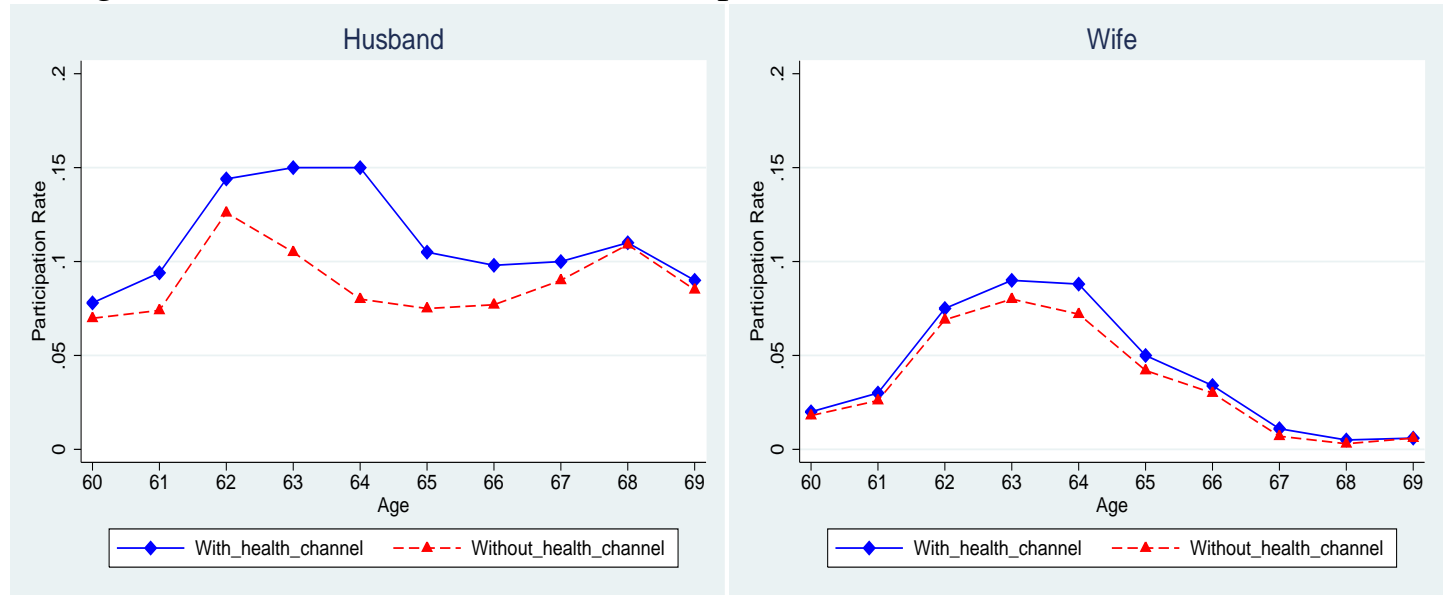

Figure 7.6 compares effects of EPRHI on job exit rates with and without the health channel. Without the health channel, the effects of EPHI on job exit rates become smaller at almost every age before 65 , while the effects become bigger after 65 . This might be because, without the health channel, spouses in my model would expect worse health. Therefore, before they are eligible for Medicare, worse health makes them less likely to retire, in order to keep the employer-provided insurance. After they are eligible for Medicare, worse health makes them more likely to retire in order to have more leisure without losing insurance coverage.

\footnotetext{
${ }^{145}$ Similarly, without the health channel, EPRHI coverage accelerates wives' retirement by 0.4 years, which accounts for about $80 \%$ of the effects of EPRHI when both channels are considered.
} 
Figure 7.6: Effects of EPRHI on Exit Rates without the Health Channel
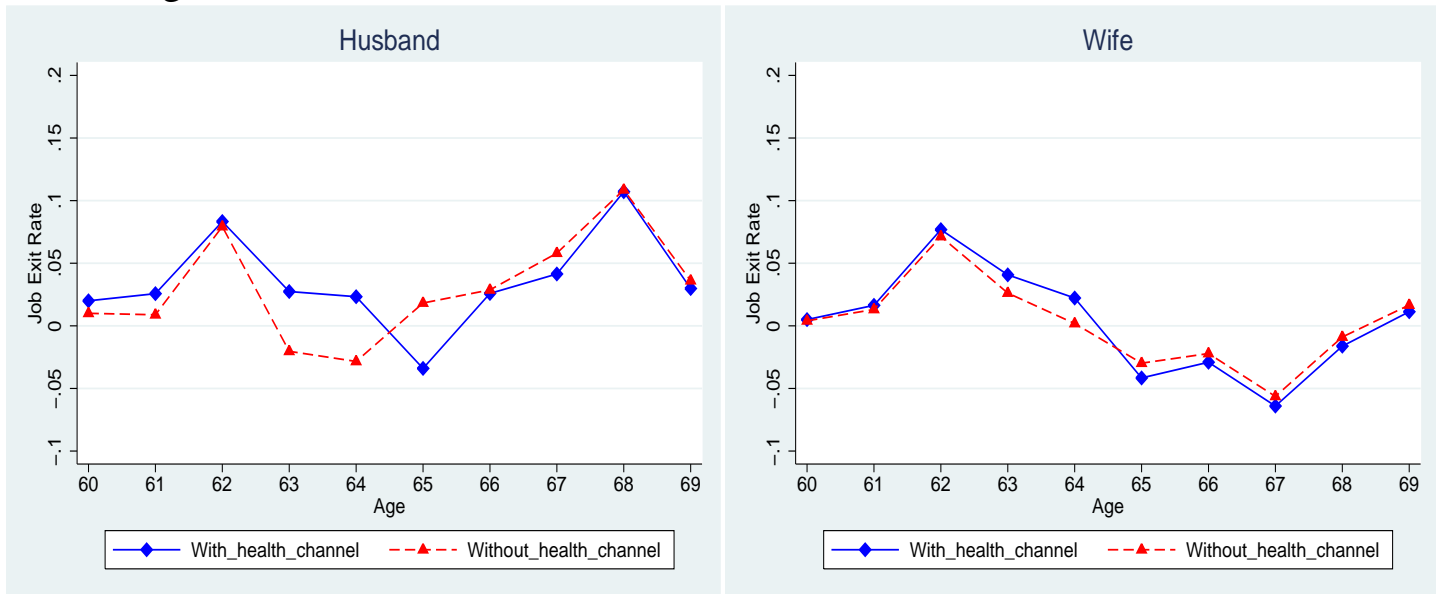

\subsubsection{Spousal Coverage and Household Retirement}

This paper includes spousal coverage as a factor that motivates spouses' coordinated retirement. To evaluate the causal effects of spousal coverage on couples' coordinated retirement, I rerun the two simulations from subsection 7.1 .1 but take out spousal coverage ${ }^{146}$ Figure 7.7 compares the distributions of retirement age for husbands with tied insurance under two circumstances: with and without spousal coverage. The comparison shows that, with spousal coverage, the proportion of husbands who retire around age 65 (between 64.5 and 65.5 ) decreases from $65 \%$ to $20 \%$. The decrease comes from two sources. This is because, if spousal coverage is available, a small group of husbands choose to accelerate their retirement before 65 , and a large group of husbands choose to delay their retirement after 65 when spousal coverage exists. ${ }^{147}$ The variation in husbands' responses to spousal coverage captures the heterogeneity in plan characteristics and individual preference for leisure included in my model. For example, with spousal coverage, many husbands choose to delay their retirement to provide insurance to their younger wife because husbands' employerprovided plans have better quality, while some husbands choose to switch to their wife's employer-provided plan and retire earlier, either because their wife's employer provides a better plan or because they have a high preference for leisure. Similarly, the proportion of wives who retire around age 65 decreases from $56 \%$ to $17 \%$ when spousal coverage exists.

\footnotetext{
${ }^{146}$ Recall that, in subsection 7.1.1, I assume every spouse has spousal coverage in both simulation experiments.

${ }^{147}$ Figure 7.7 shows that spousal coverage increases the proportion of husbands who retire before 65 from $17 \%$ to $20 \%$, and it increases the proportion of husbands who retire after 65 from $18 \%$ to $60 \%$.
} 
The decrease is due to the fact that most wives choose to retire earlier (before 65) when spousal coverage exists ${ }^{148}$ Although spousal coverage accelerates most wives' retirement, the upper-right part of the distribution functions show that a very small group of wives choose to delay their retirement.

Figure 7.7: Distribution of Retirement Age

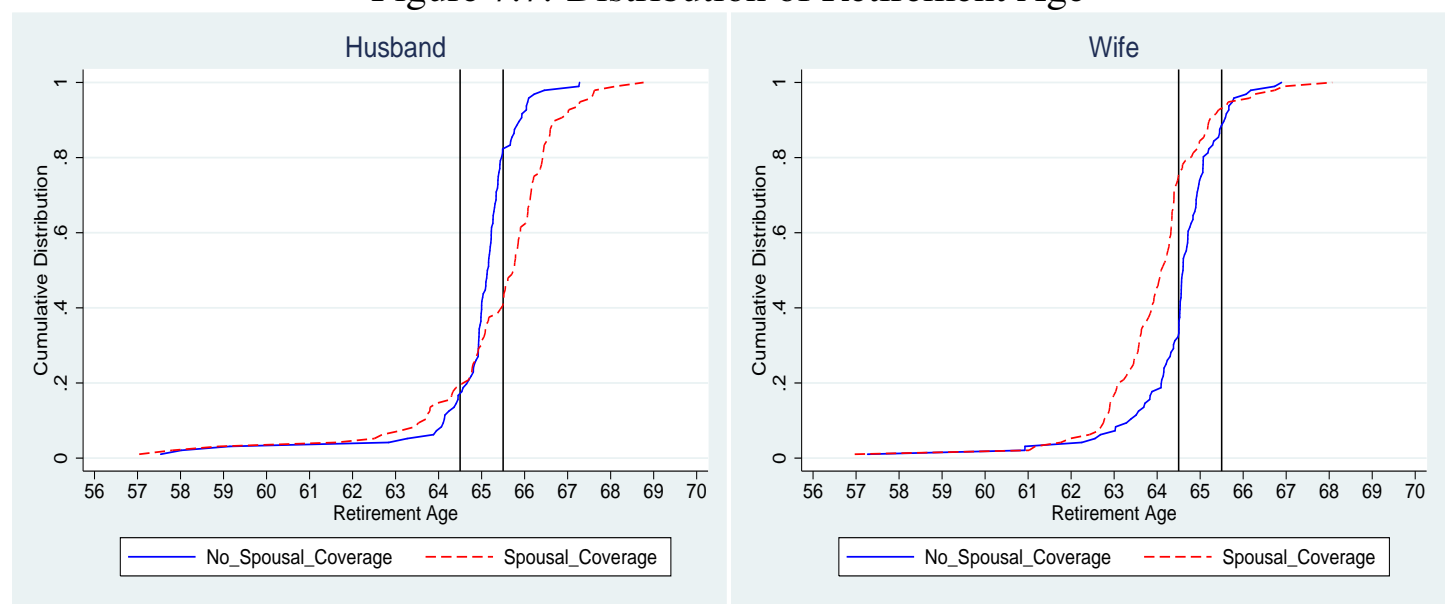

Figure 7.8 compares the distributions of the time interval (years) between husbands' and wives' retirement for households with tied insurance. For most households, the time interval between the husband's and the wife's retirement decreases when spousal coverage exists. For example, for some of these households, the husbands retire more than two years earlier than their wife when there is no spousal coverage, whereas, when spousal coverage exists, these husbands retire within two years either before or after their wife retires. This increases the proportion of households that choose simultaneous retirement (husband and wife retire within one or two years of each other) from $18 \%$ to $33 \%$. Recall that, for many households, spousal coverage delays husbands' retirement and accelerates wives' retirement ${ }^{149}$ Additionally, since the husband is usually a few years older than the wife, pushing their retirement age apart further actually reduces the years between their retirement. This makes households more likely to choose simultaneous retirement.

In summary, spousal coverage motivates simultaneous retirement by delaying husbands' retirement and accelerating wives' retirement. To evaluate the effects of spousal cov-

\footnotetext{
${ }^{148}$ Figure 7.7 shows that spousal coverage increases the proportion of wives who retire before 65 from $32 \%$ to $75 \%$, and it decreases the proportion of wives who retire after 65 from $11 \%$ to $8 \%$.

${ }^{149}$ For example, figure 7.7 shows that spousal coverage increases husbands' median retirement age from 65.1 to 65.7 , and it decreases wives' median retirement age from 64.6 to 64.1.
} 
Figure 7.8: Distribution of the Difference in Retirement Year

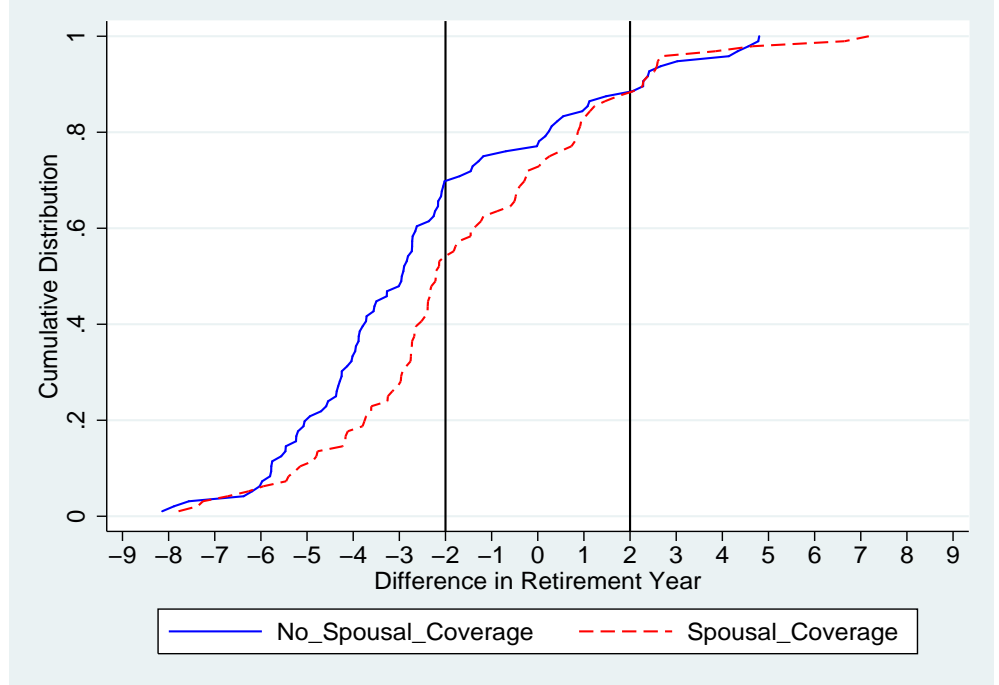

erage on simultaneous retirement for my sample, I take out spousal coverage from spouses whose employer provides it. Then, I simulate the propensity of husbands' and wives' to retire in the same period (simultaneous retirement rate). The results show that taking out spousal coverage decreases the simultaneous retirement rate by 7 percentage points (from 0.29 to 0.22 ), which accounts for $24 \%$ of the model-predicted simultaneous retirement rate.

\subsubsection{Complementarity in Leisure and Simultaneous Retirement}

Complementarity in leisure (spouses' valuation of spending leisure together) could be one of the factors leading to simultaneous retirement in a household. To evaluate the importance of including spousal leisure in modeling household retirement behavior, I set the parameter of spousal leisure in an individual utility function equal to zero, and then I simulate the simultaneous retirement rate. The results show that omitting complementarity in leisure decreases the simultaneous retirement rate by 10 percentage points (from 0.29 to 0.19 ), which explains $34 \%$ of the model-predicted simultaneous retirement rate. My estimated effect of spousal leisure on simultaneous retirement is slightly smaller than the effect found in Gustman and Steinmeier (2004), 150 while my estimated effect is much bigger than the effect found in Casanova (2010) 151

\footnotetext{
150 Gustman and Steinmeier (2004) find that omitting complementarity in leisure decreases the simultaneous retirement rate by 11 percentage points.

${ }^{151}$ Casanova (2010) finds that omitting complementarity in leisure decreases the simultaneous retirement rate by 3.8 percentage points.
} 


\subsection{Policy Simulations}

In this subsection, I use the model to predict how the Patient Protection and Affordable Care Act (PPACA, or, in short, ACA) and the changes in Medicare and Social Security rules would affect retirement behavior.

\subsubsection{The Implementation of the ACA}

A key component of the ACA, which was signed into law on March 23, 2010, is the Health Insurance Marketplace. The Health Insurance Marketplace, also called the Health Insurance Exchange, "is the place where people without health care insurance can find information about health insurance options and also purchase health care insurance. Information can also be found regarding eligibility for help with paying premiums and reducing out-ofpocket costs." 152 The law requires people without health insurance to purchase insurance from the Marketplace. Thus, the ACA helps to make health insurance independent of employment status. Four plans are available in the Marketplace for people who are facing retirement: Bronze, Silver, Gold, and Platinum. The Bronze plan has the lowest premium and coinsurance rate, while the Platinum plan has the highest premium and coinsurance rate ${ }^{153}$ To simplify the computation of the simulation, I use the Silver plan as the representative plan in the Marketplace because it is the most popular insurance option by far. ${ }^{154}$

Because the implementation of the ACA makes health insurance independent of employment status, the ACA reduces the degree of the job-lock generated by employerprovided insurance for workers with tied insurance. To evaluate the effects of the ACA on labor supply of spouses with tied insurance, I assume that every spouse in my sample is eligible for tied health insurance, and I give everyone the average pension accrual rates of workers who have tied health insurance. Then I simulate spouses' labor supply in two simulation experiments: with the implementation of the ACA and without it. Figures 7.9 and 7.10 compare the simulated job participation rates and job exit rates, respectively, in

\footnotetext{
${ }^{152}$ Source: https://www.irs.gov/affordable-care-act/

${ }^{153}$ Coinsurance rate is "the percentage of costs of a covered health care service you pay (20\%, for example) after you've paid your deductible." https://www.healthcare.gov/glossary/co-insurance/

${ }^{154}$ In 2015, about 70 percent of consumers enrolled in Silver plans. Source: "2016 Marketplace Affordability Snapshot," CMS.gov, 10-26-2015. https://www.cms.gov/Newsroom/MediaReleaseDatabase/
} 
these two simulation experiments. The figures show that, for spouses with tied insurance, the ACA decreases participation rates and increases exit rates, mostly between age 61 and 65. Note that the effects of the ACA on participation rates decrease significantly after 65 . This might be because spouses are eligible for Medicare from age 65 onward and Medicare provides better plans than the ACA does. Thus, the ACA is not very attractive after spouses are eligible for Medicare. The sum of the differences in participation rates shows that, over a 10-year period (for ages 60-69), the ACA accelerates retirement by 0.5 and 0.3 years for husbands and wives with tied insurance, respectively.

Figure 7.9: Effects of the ACA on Job Participation Rate: Tied Insurance
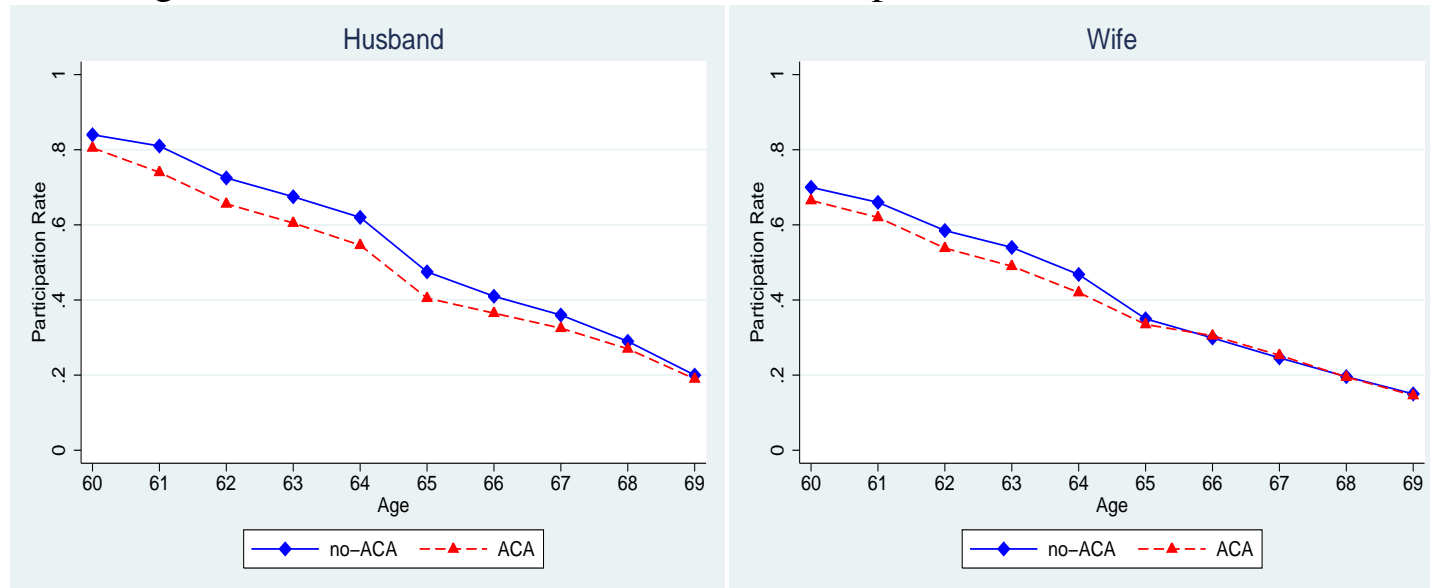

Figure 7.10: Effects of the ACA on Job Exit Rate: Tied Insurance
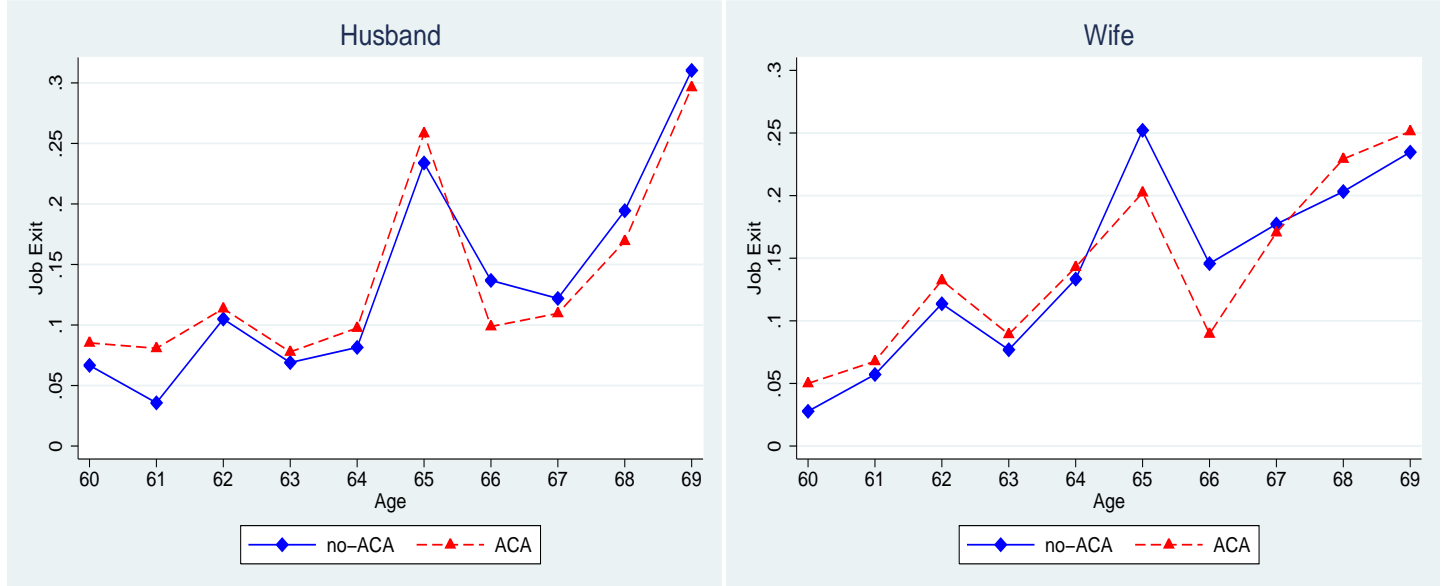

To predict the consequences of recent health care reform, I also simulate labor supply for spouses in my sample assuming the implementation of the ACA. Figures 7.11 shows the effects of the ACA on job participation rates for my sample, and Figures 7.12 shows 
the effects on job exit rates. Over a 10-year period, implementing the ACA accelerates retirement by around 0.12 and 0.09 years for husbands and wives, respectively.

Figure 7.11: Effects of the ACA on Job Participation Rates: Sample
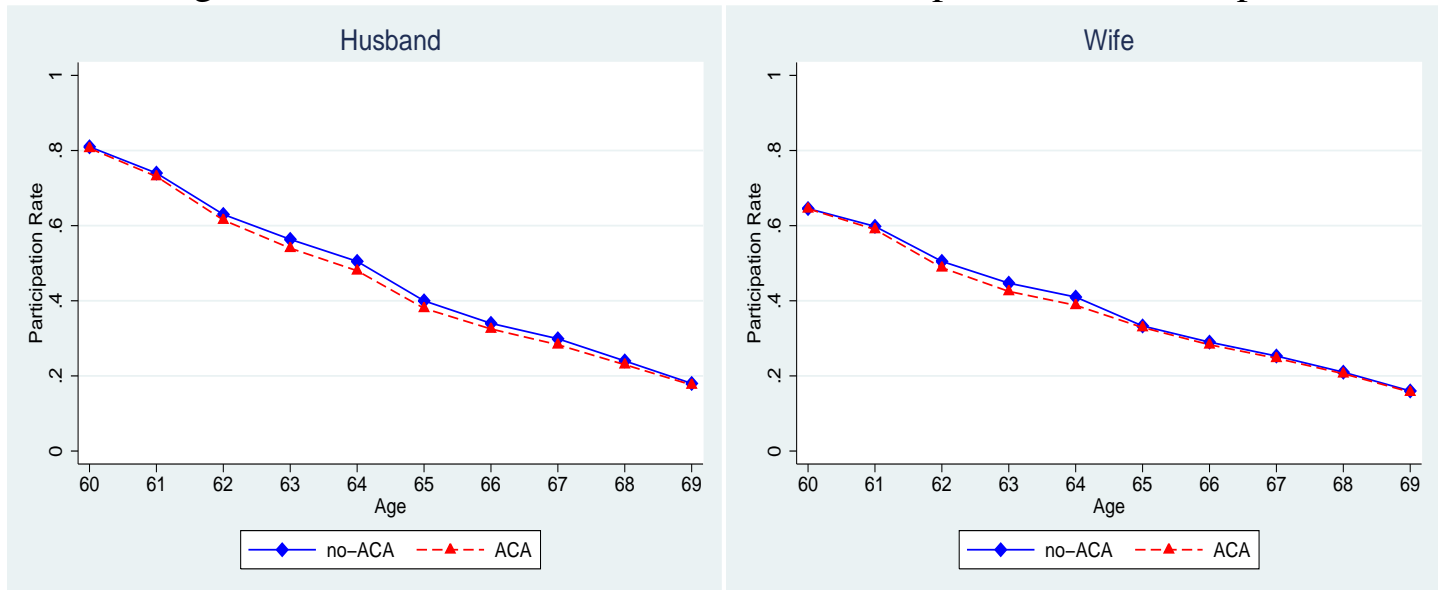

Figure 7.12: Effects of the ACA on Job Exit Rates: Sample
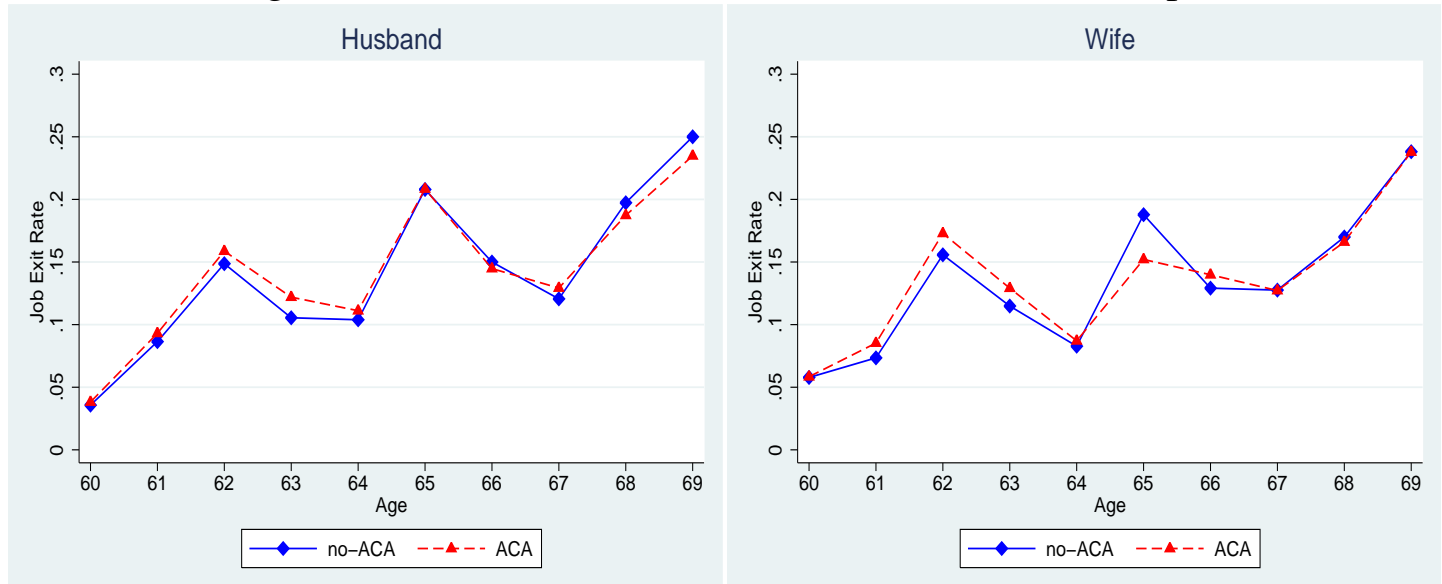

Two features of my model enable me to predict the effects of the implementation of the ACA. First, my model differentiates insurance plans by their quality (plan characteristics). Second, my model allows spouses to choose an insurance plan from available plans by comparing their qualities. Previous papers about health insurance and retirement do not consider the heterogeneity in plan qualities (e.g., Madrian et al. (1994), Gruber and Madrian (1995), and Blau and Gilleskie (2006)). Thus, these papers would largely overpredict the effects of the ACA on retirement because the ACA plan quality is much worse than the quality of employer-provided plans.

My model may still overpredicts the effects of the ACA because my model excludes 
the choice of being uninsured. I assume that workers choose to be covered by health insurance when they are eligible. I make this assumption for two reasons: (1) before the implementation of the ACA, there was no private health insurance available, other than EPHI, to spouses in my sample; and (2) no spouse in my sample chooses to be uninsured when he is eligible for some EPHI. Thus, my model excludes the choice to be uninsured because I do not have data to identify the preference for no insurance. However, even after the implementation of the ACA, a large amount of people still choose to be uninsured. Without capturing the possibility of choosing to be uninsured, my model may overpredict the effect of the ACA on.

\subsubsection{Raising the Medicare Eligibility Age to 67}

Medicare is a public health insurance program that is available to, in general, all persons age 65 and older ${ }^{155}$ Thus, Medicare mitigates the degree of job-lock generated by employerprovided insurance for workers with tied insurance. The Medicare eligibility age is not scheduled to rise, but there are proposals to raise it to 67 . To evaluate the effects of raising the Medicare eligibility age on labor supply of spouses with tied insurance, I assume that every spouse in my sample has tied insurance and has the average pension accrual rates of workers who have tied health insurance. Then I simulate spouses' labor supply with the Medicare eligibility age set at 65 and 67, respectively. Figures 7.13 and 7.14 compare the simulated job participation rates and job exit rates, respectively, in these two simulation experiments. For spouses who have tied insurance, raising the Medicare eligibility age to 67 increases the job participation rates and decreases the job exit rates, mostly between age 64 and $6 7 \longdiv { 1 5 6 }$ In addition, the spike in exit rates moves from age 65 to 67 as the Medicare eligibility age increases from 65 to 67.

Over a 10-year period (for ages 60-69), raising the Medicare eligibility age to 67 delays retirement by 0.8 and 0.4 years for husbands and wives with tied insurance, respectively. Recall that EPRHI delays retirement by 1.1 years for husbands and 0.5 years for

\footnotetext{
${ }^{155}$ People under 65 and receive Social Security Disability Insurance (SSDI) benefits is eligible for Medicare. https://www.ssa.gov/disabilityresearch

${ }^{156}$ After 67 , raising the Medicare eligibility age to 67 still increases husbands' participation rates. This might be because some husbands delay their retirement to provide insurance to their wife.
} 
Figure 7.13: Effects of Medicare on Participation Rates: Tied Insurance
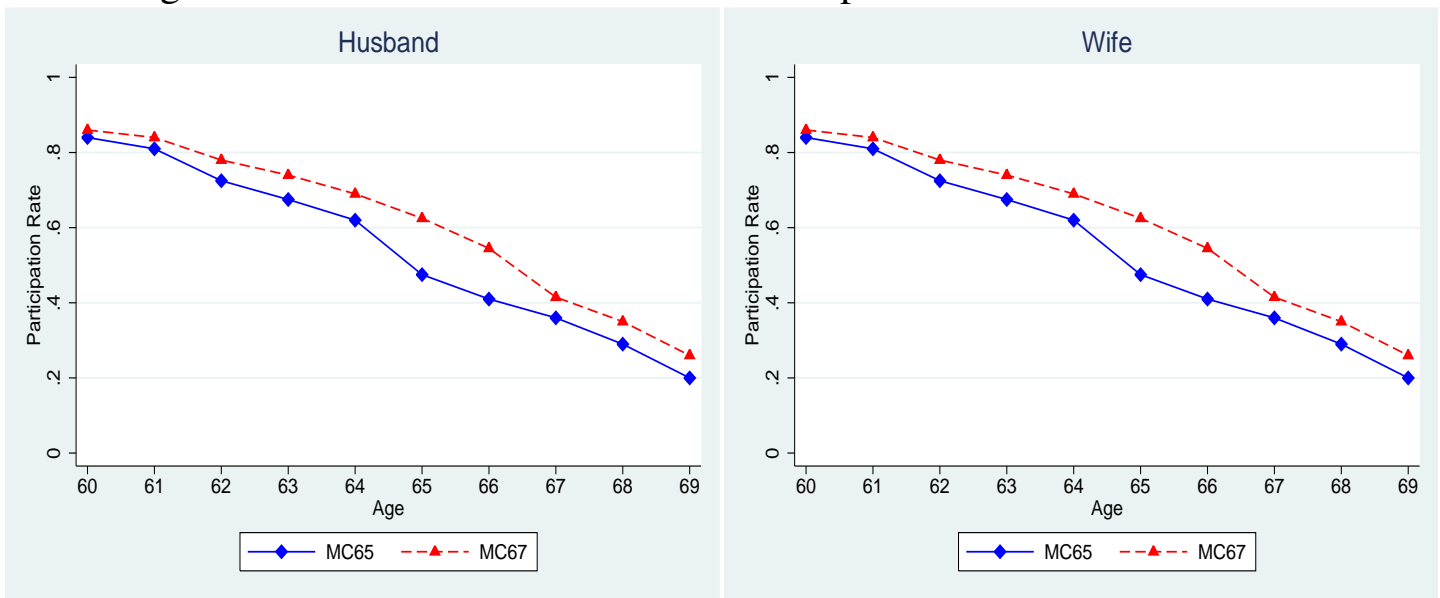

Figure 7.14: Effects of Medicare on Exit Rates: Tied Insurance
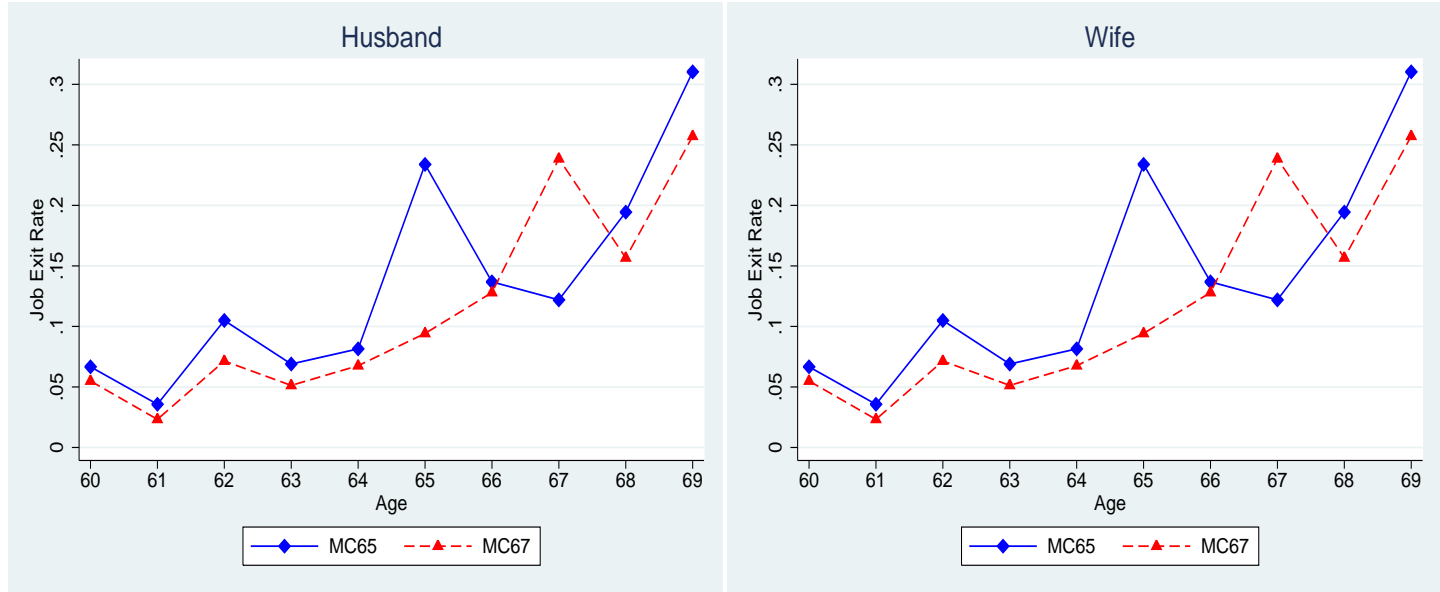

wives. The implementation of the ACA accelerates retirement by 0.5 years for husbands and 0.3 years for wives. Therefore, the effects of Medicare (or raising the Medicare eligibility age to 67) are bigger than the effects of the ACA but are smaller than the effects of EPRHI. We can, perhaps, attribute these differences to plan quality: the employer-provided insurance plan has the best plan characteristics (high co-insurance rate and low paid premium and deductible), and the plans in the Marketplace have the worst plan characteristics.

To predict the consequences of raising the Medicare eligibility age from 65 to 67, I simulate labor supply for spouses in my sample assuming that the Medicare eligibility age is 67 . Figures 7.15 and 7.16 present the effects of raising the age to 67 on job participation rates and job exit rates, respectively. Over a 10-year period, raising the age to 67 delays retirement by 0.17 years for husbands and 0.12 years wives. These amounts are larger than the effects found in the literature. For example, Rust and Phelan (1997), Blau and Gilleskie 
(2006), and French and Jones (2011) find that increasing the Medicare eligibility age to 67 delays men's retirement by $0.13,0.01$ and 0.074 years, respectively. The reason why I find a larger effect of Medicare is that my model accounts for the interdependence of both spouses' insurance coverage, which is the same reason why my model finds big effects of EPRHI on retirement (see 7.1.1).

Figure 7.15: Effects of Medicare on Participation Rates: Sample
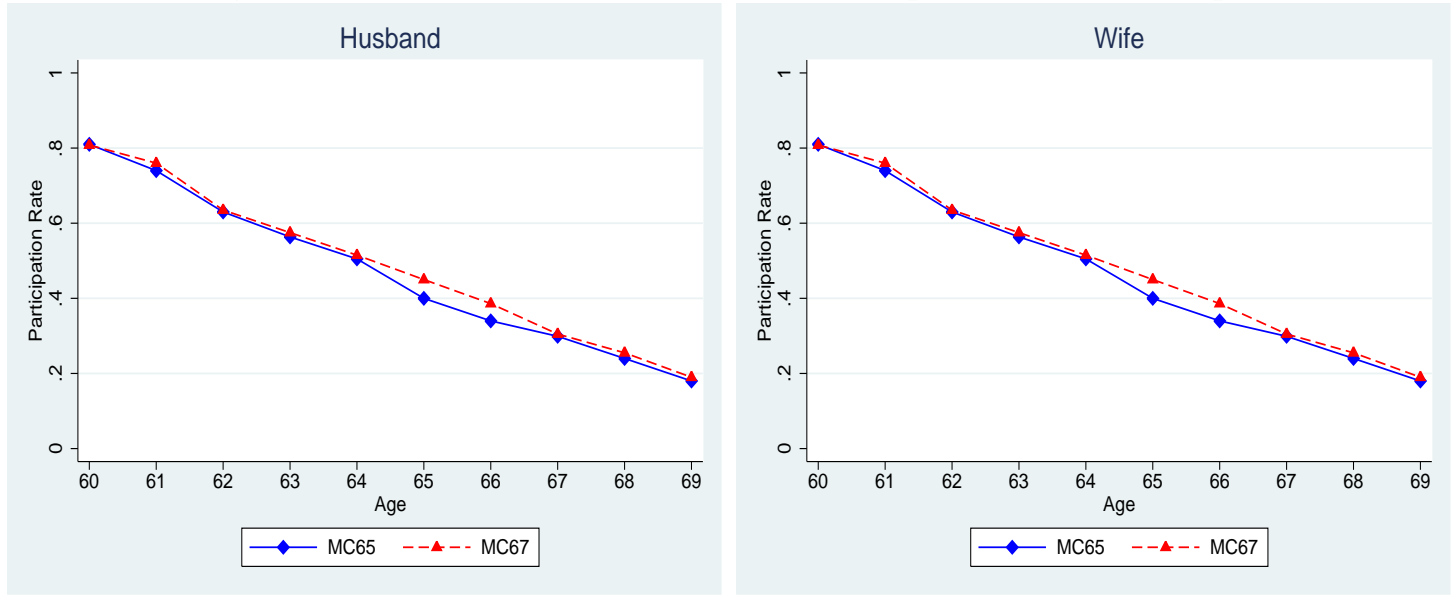

Figure 7.16: Effects of Medicare on Exit Rates: Sample
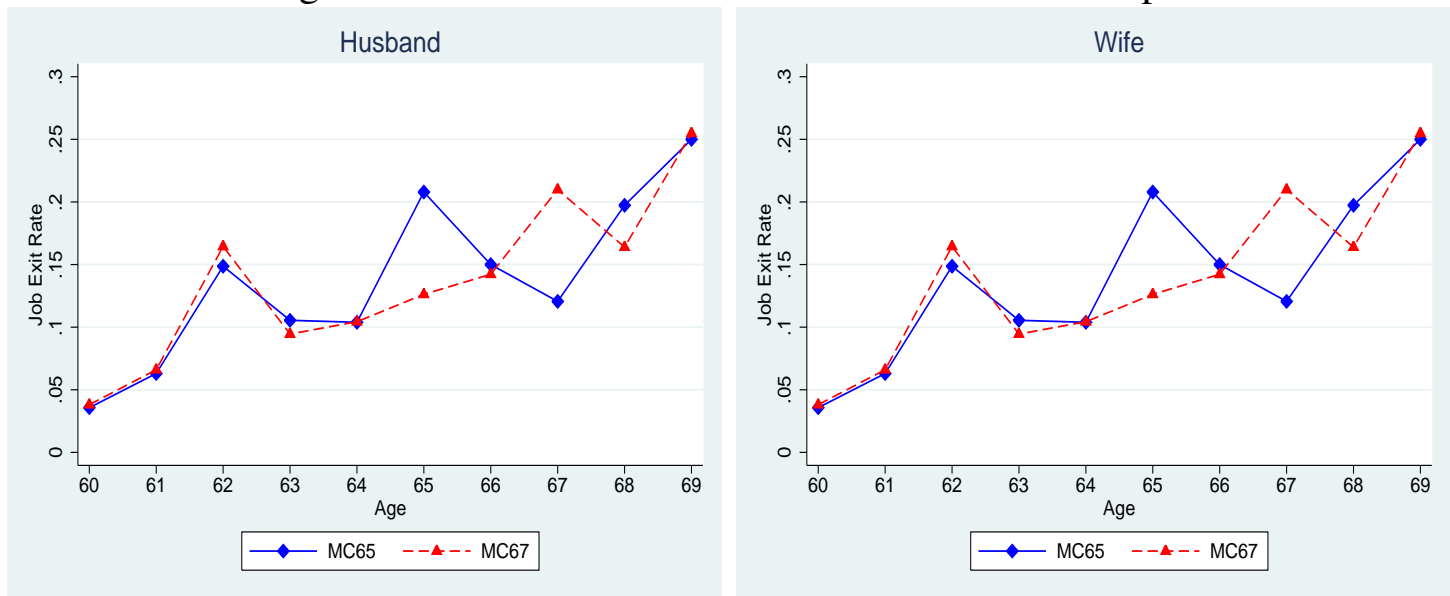

\subsubsection{Raising the Normal Retirement Age to 67}

Finally, I conduct simulation experiments to predict how the normal retirement age (NRA) affects labor supply. The normal retirement age is scheduled to increase from 65 to 67 by 2022, and I simulate labor supply with the normal retirement age set at age 67. Figures 7.17 and 7.18 shows how spouses' labor supply change if the normal retirement age increases 
from 65 to 67.

Figure 7.17: Effects of the Normal Retirement Age on Participation Rates: Sample
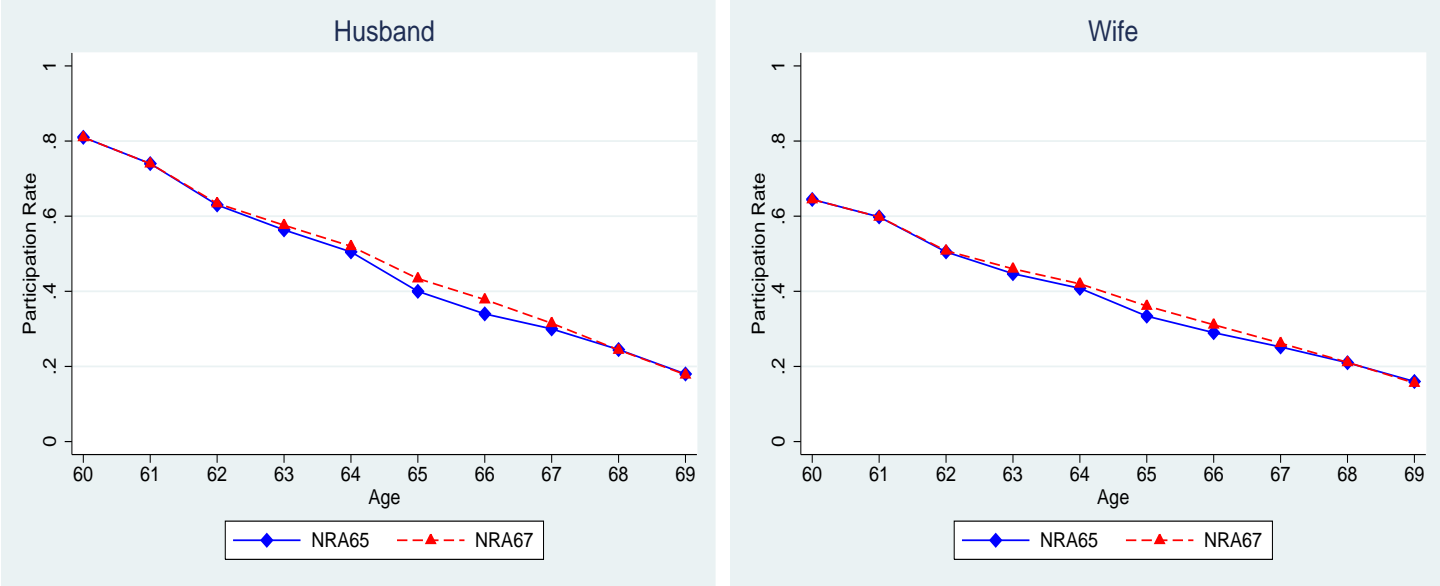

Figure 7.18: Effects of the Normal Retirement Age on Exit Rates: Sample
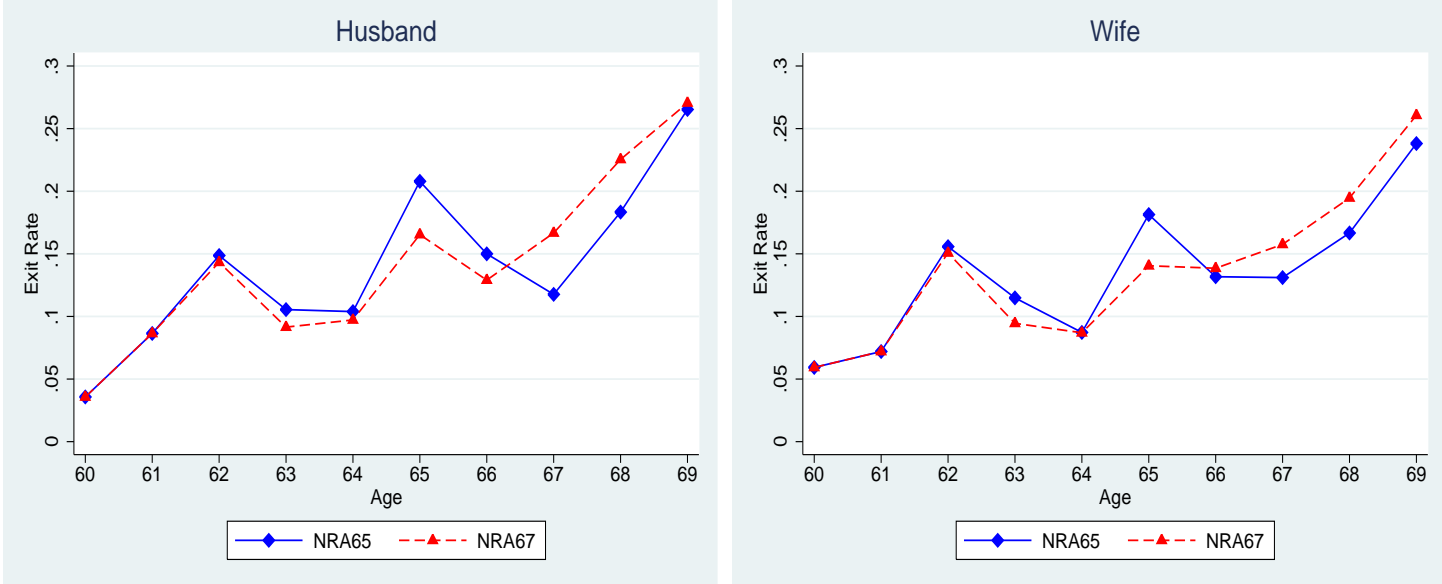

Raising the normal retirement age to 67 increases the job participation rates from age 62 onward, mostly between age 62 and 67. In total, over a ten-year period, this delays retirement by 0.11 years for husbands and 0.08 years wives. These numbers are similar to (though slightly larger than) the effects found by French and Jones (2011), but they are smaller than the effects documented by Rust and Phelan (1997) 157 The reason why Rust and Phelan (1997) find a bigger effect may be because their sample consists of low-income males, whose Since Social Security benefits are the main source of their retirement income. Note that, after increasing the normal retirement age from 65 to 67, the spikes at age 62 and 65 still persist, but the height of the spike at age 65 drops.

\footnotetext{
${ }^{157}$ French and Jones (2011) find that raising the normal retirement age to 67 increases years of work by 0.08 years. Rust and Phelan (1997) find a larger effect of raising the normal retirement age.
} 


\section{Conclusion}

The absence of health insurance coverage could be one of the biggest obstacles to retiring before age 65 . People who have health insurance are better protected financially against serious accident or sickness, and they tend to be healthier because they are more likely to use preventative care. Health insurance coverage is particularly important for potential retirees, who tend to have more health issues and, thus, usually have less ability to recover financially from costly medical expenses. Many American workers are reluctant to retire because of the fear of losing their employer-provided health insurance. The link between health insurance and retirement is especially complicated in a household in which two spouses coordinate their retirement decisions-both because they share economic resources and because spouses' health insurance coverages are interdependent. To examine how health insurance affects household joint retirement decisions, band and wife jointly make decisions about retirement, about whose employer will provide their insurance coverage (if available), and about household savings. My paper adds to the literature by including the interdependence of the two spouses' health insurance coverage (spousal coverage), by evaluating health insurance in terms of both quantity (coverage) and quality (plan characteristics), and by allowing health insurance to affect retirement through two channels: (1) insurance smooths consumption by reducing the mean and volatility of medical expenses; and (2) insurance can improve health and thus decrease individuals' value of leisure relative to work.

Using data from the Health and Retirement Study, I estimate the structural parameters of my model. The estimates of preference parameters are reasonable and the model fits the data well. I find that employer-provided health insurance is an important factor that determines retirement. Moving workers from retiree to tied health insurance coverage delays retirement by 1.1 years for husbands and 0.5 years for wives. In decomposing the employment response to EPHI coverage, I find that over $80 \%$ of the response reflects the valuation of the consumption smoothing effects of health insurance, and less than $20 \%$ reflects the valuation of the health improvement effects. Furthermore, I find that spousal coverage motivates simultaneous retirement by delaying husbands' retirement and accelerating wives' 
retirement, and it explains about $24 \%$ of the simultaneous retirement observed in the data. Lastly, I find that husbands and wives enjoy spending leisure time together, which explains $34 \%$ of the observed simultaneous retirement.

My policy simulations show that health insurance-related policies would have big effects on retirement. For people with tied insurance, the health care reform (ACA) is predicted to accelerate retirement by 0.4 years for husbands and 0.3 years for wives. Raising the Medicare eligibility age from 65 to 67 is predicted to delay retirement by 0.7 years for husbands and 0.4 years for wives. The effects of Medicare are bigger than the effects of the ACA but smaller than the effects of EPRHI due to the differences in plan quality, which has been overlooked in the previous literature. For the whole sample, the implementation of the ACA is predicted to accelerate retirement by 0.12 years for husbands and 0.09 years for wives. Raising the Medicare eligibility age from 65 to 67 is predicted to delay retirement by 0.17 years for husbands and 0.12 years for wives. Comparatively, increasing the Social Security full retirement age from 65 to 67 delays retirement by 0.11 years for husbands and 0.08 years for wives. 


\section{References}

ABowd, J. M. AND D. CARD, "On the Covariance Structure of Earnings and Hours Changes," Econometrica 57 (1989), 411-445.

AmemiYA, T., "On a Two-Step Estimation of a Multivariate Logit Model," Journal of Econometrics 8 (1978), 13-21.

Baicker, K., S. L. Taubman, H. L. Allen, M. Bernstein, J. H. Gruber, J. P. Newhouse, E. C. Schneider, B. J. Wright, A. M. Zaslavsky and A. N. FINKELSTEIN, “The Oregon experiment-effects of Medicaid on clinical outcomes," New England Journal of Medicine (2013).

BAKER, M., "Growth-Rate Heterogeneity and the Covariance Structure of Life-Cycle Earnings," Journal of Labor Economics 15 (1997), 338.

BANKS, J., R. BLUndell AND M. CASANOVA, "The dynamics of retirement behavior in couples: Reduced-form evidence from England and the US," mimeo (2010).

Benitez-Silva, H., M. Buchinsky, H. M. Chan, J. Rust and S. Sheidvasser, "An empirical analysis of the social security disability application, appeal, and award process," Labour Economics (1999), 147-178.

Benitez-Silva, H., M. Buchinsky AND J. Rust, "How large are the classification errors in the social security disability award ...," NBER (2004).

Berkovec, J. AND S. Stern, “Job Exit Behavior of Older Men,” Econometrica 59 (1991), 189-210.

Berndt, E. K., B. H. HAll, R. E. HAll And J. A. HAusman, "Estimation and Inference in Nonlinear Structural Models," Annals of Economic and Social Measurement 3 (1974), 103-116.

BlaU, D. M., “Labor Force Dynamics of Older Married Couples,” Journal of Labor Economicsr 62 (1998), 117-156. 
BlaU, D. M. AND D. B. GilleskiE, "Health insurance and retirement of married couples," Journal of Applied Econometrics 21 (2006), 935-953.

— "The role of retiree health insurance in the employment behavior of older men," International Economic Review 49 (2008), 475-514.

BÖRSCH-SUPAN, A. AND V. A. HAJIVASSILIOU, "Smooth unbiased multivariate probability simulators for maximum likelihood estimation of limited dependent variable models," Journal of Econometrics 58 (1993), 347-368.

Brien, M. J., L. A. Lillard AND S. Stern, "Cohabitation, marriage, and divorce in a model of match quality," International Economic Review 47 (2006), 451-494.

Buntin, M. B. And A. M. ZAslavsky, "Too much ado about two-part models and transformation? Comparing methods of modeling Medicare expenditures," Journal of Health Economics 23 (2004), 525-542.

CAmeron, S. V. And J. J. HeCKMAN, "Life cycle schooling and dynamic selection bias: Models and evidence for five cohorts," Technical Report, National Bureau of Economic Research, 1998.

Carroll, R. J., D. Ruppert, L. A. Stefanski and C. M. Crainiceanu, "Measurement Error in Nonlinear Models: A Modern Perspective," Journal of the American Statistical Association 103 (2006), 427-427.

Casanova, M., "Happy Together: A Structural Model of Couples' Joint Retirement Choices," Working Paper, University of California at Los Angeles (2010).

Chetty, R., “A new method of estimating risk aversion,” American Economic Review 96 (2006), 1821-1834.

Clark, R. L., "Portability of benefits, job changes, and the role of government policies," Taskforce on Reconstructing America's Labor Market Institutions. MITInstitute for Work and Employment Research, Cambridge, MA (1999). 
CoILE, C. C., "Health shocks and couples' labor supply decisions," National Bureau of Economic Research (2004).

CURrie, J. AND J. Gruber, "Health Insurance Eligibility, Utilization of Medical Care, and Child Health," The Quarterly Journal of Economics 111 (1996), 431-466.

Cutler, D. M., "Employee Costs and the Decline in Health Insurance Coverage," Forum for Health Economics \& Policy 6 (2003).

Dague, L., T. DeLeire And L. Leininger, "The effect of public insurance coverage for childless adults on labor supply," Technical Report, National Bureau of Economic Research, 2014.

De Nardi, M., E. French And J. B. Jones, "Why Do the Elderly Save? The Role of Medical Expenses," Journal of Political Economy 118 (2010), 39-75.

DE NARDi, M. C., "Wealth inequality and intergenerational links," Review of Economic Studies 71 (2004), 743-768.

Diehr, P., D. Yanez, A. Ash, M. Hornbrook And D. Y. Lin, "Methods for analyzing health care utilization and costs.," Annual review of public health 20 (1999), 125-44.

Dor, A., J. SUdANO AND D. W. BAKER, "The effect of private insurance on the health of older, working age adults: evidence from the health and retirement study," Health Services Research 41 (2006), 759-787.

DWyer, D. S. AND O. S. Mitchell, "Health problems as determinants of retirement: Are self-rated measures endogenous?," Journal of Health Economics 18 (1999), 173193.

Elbers, C. AND G. RidDER, "True and Spurious Duration Dependence: The Identifiability of the Proportional Hazard Model," The Review of Economic Studies 49 (1982), 403-409.

Elbner, C. AND M. S. MARquis, “Employers' health insurance cost burden, 19962005," Monthly Lab. Rev. 131 (2008), 28. 
FiELDS, G. S. AND O. S. MiTCHELL, "The effects of social security reforms on retirement ages and retirement incomes," Journal of Public Economics 25 (1984), 143-159.

Finkelstein, A. N., K. Baicker, S. L. Taubman, H. L. Allen, M. Bernstein, J. H. Gruber, J. P. Newhouse, E. C. Schneider, B. J. Wright And A. M. ZASLAVSKY, "The Oregon experiment-effects of Medicaid on clinical outcomes," New England Journal of Medicine 368 (2013), 1713-1722.

Frees, E. W., J. Gao And M. A. RosenberG, "Predicting the frequency and amount of health care expenditures," North American Actuarial Journal 15 (2011), 377-392.

FRENCH, E. AND J. B. Jones, "The Effects of Health Insurance and Self-Insurance on Retirement Behavior," Working Paper, Center for Retirement Research (2004).

— , "The Effects of Health Insurance and Self-Insurance on Retirement Behavior," Econometrica 79 (2011), 693-732.

FRIEDbERG, L. AND S. STERn, “Marriage, divorce, and asymmetric information,” International Economic Review 55 (2014), 1155-1199.

FriedberG, L. AND A. WebB, "Determinants and consequences of bargaining power in households," NBER Working Paper Series Working Pa (2006), 1-43.

GAO, J., Modeling Individual Healthcare Expenditures by Extending the Two-Part Model (ProQuest, 2007).

GeweKe, J., "Bayesian Inference in Econometric Models Using Monte Carlo Integration," Econometrica 57 (1989), 1317-1339.

Goldin, C., "The female labor force and American economic growth, 1890-1980," in Long-term factors in American economic growth (University of Chicago Press, 1986), $557-604$.

Gourinchas, P.-O. And J. A. PARKer, "Consumption Over the Life Cycle," Econometrica 70 (2002), 47-89. 
Gruber, J. And B. C. Madrian, "Health-Insurance Availability and the Retirement Decision,” American Economic Review 85 (1995), 938-948.

Gustman, A. And T. Steinmeier, "Retirement and the stock market bubble," NBER working paper (2002).

Gustman, A. L., O. S. Mitchell and T. L. Steinmeier, “The Role of Pensions in the Labor Market: A Survey of the Literature," Industrial and Labor Relations Review 47 (1994), 417-438.

Gustman, A. L. And T. Steinmeier, “Integrating retirement models,”, 2009.

Gustman, A. L. And T. L. Steinmeier, "Employer-Provided Health-Insurance and Retirement Behavior," Industrial \& Labor Relations Review 48 (1994), 124-140.

—_, "Retirement in Dual-Career Families: A Structural Model," Journal of Labor Economics 18 (2000), 503-545.

—_ "Social security, pensions and retirement behaviour within the family," Journal of Applied Econometrics 19 (2004), 723-737.

—, "How Does Modeling of Retirement Decisions at the Family Level Affect Estimates of the Impact of Social Security Policies on Retirement?," Michigan Retirement Research Center Research Paper (2008).

—_, "Integrating Retirement Models: Understanding Household Retirement Decisions," in Factors Affecting Worker Well-being: The Impact of Change in the Labor Market (2014), 79-112.

Gustman, A. L., T. L. Steinmeier And N. Tabatabai, "What the Stock Market Decline Means for the Financial Security and Retirement Choices of the Near-Retirement Population," Journal of Economic Perspectives 24 (2010), 161-182.

Guvenen, F., “An empirical investigation of labor income processes," Review of Economic Dynamics 12 (2009), 58-79. 
HAIDER, S. J., "Earnings instability and earnings inequality of males in the United States: 1967-1991," Journal of Labor Economics 19 (2001), 799-836.

HaJiVASSILIOU, V., "Smooth simulation estimation of panel data LDV models," Department of Economics, Yale University (1990).

_ Press, 2000).

Hausman, J. A. And D. A. Wise, “Technical Problems in Social Experimentation: Cost versus Ease of Analysis,” in \{S\}ocial \{E\}xperimentation (1985), 187-208.

Heckman, J. J., "Sample Selection Bias as a Specification Error," Econometrica 47 (1979), 153-161.

—, "The incidental parameters problem and the problem of initial conditions in estimating a discrete time-discrete data stochastic process.," (1981).

HeCKMAn, J. J. AND B. Singer, “Social science duration analysis," Longitudinal analysis of labor market data (1985), 39-110.

Hochguertel, S., "Self-employment around retirement age," in Entrepreneurship, SelfEmployment and Retirement (Springer, 2015), 209-258.

Hubbard, R. G., J. Skinner And S. P. Zeldes, "Precautionary Saving and Social Insurance,” Journal of Political Economy 103 (1995), 360.

Hurd, M., "The Joint Retirement Decision Of Husbands And Wives," Issues In The Economics of Aging (1990), 231-258.

KAISER, “Employer Health Benefits: 2006 Annual Survey,” (2006).

KAPUR, K. AND J. ROGOWSKI, “The role of health insurance in joint retirement among married couples," Industrial and Labor Relations Review 60 (2007), 397-407.

KeAne, M. P., "A Computationally Practical Simulation Estimator for Panel Data," Econometrica 62 (1994), 95-116. 
Keane, M. P. And K. I. Wolpin, “The Career Decisions of Young Men,” Journal of Political Economy 105 (1997), 473-522.

LAibson, D., A. Repetto And J. TOBACMAn, "Estimating discount functions with consumption choices over the lifecycle," NBER Working Paper Series NBER Worki (2007), $1-50$.

LEVy, H. AND D. MelTZER, "The impact of health insurance on health.," Annual review of public health 29 (2008), 399-409.

Lillard, L. A. AND Y. Weiss, “Components of Variation in Panel Earnings Data : American Scientists 1960-70,” Econometrica 47 (1979), 437-454.

Lumsdaine, R. L., J. H. Stock And D. A. Wise, "Pension plan provisions and retirement: men and women, medicare, and models," in Studies in the Economics of Aging (University of Chicago Press, 1994), 183-222.

—_, "Retirement incentives: The interaction between employer-provided pensions, Social Security, and retiree health benefits," in The economic effects of aging in the United States and Japan (University of Chicago Press, 1996), 261-293.

MACURDY, T. E., "The use of time series processes to model the error structure of earnings in a longitudinal data analysis," Journal of Econometrics 18 (1982), 83-114.

Madrian, B. C., G. Burtless And J. Gruber, "The effect of health insurance on retirement," Brookings Papers on Economic Activity 1994 (1994), 181-252.

Maestas, N., "Labor, love and leisure: complementarity and the timing of retirement by working couples," Berkeley: Xerox (2001).

McArdle, F., T. Neuman And J. HuAng, "Retiree health benefits at the crossroads," Menlo Park, CA: Kaiser Family Foundation. http://kff. org/report-section/retiree-healthbenefits-at-the-crossroadsoverview-of-health-benefits-for-pre-65-and-medicare-eligibleretirees (2014). 
McFadden, D. And K. Train, “Mixed MNL Models for Discrete Response,” Journal of Applied Econometrics 15 (2000), 447-470.

MichaUd, P., “Joint labour supply dynamics of older couples," IZA Discussion paper Nr. $832(2003)$.

Miller, S., "Costs Compared: Public vs. Private Sector Health Plans,” Society for Human Resource Management (2015).

Mroz, T. A., "Discrete factor approximations in simultaneous equation models: Estimating the impact of a dummy endogenous variable on a continuous outcome," journal of Econometrics 92 (1999), 233-274.

Mroz, T. A. AND D. K. GUILKEY, "Discrete factor approximation for use in simultaneous equation models with both continuous and discrete endogenous variables.," (1992).

O'Donnell, O. ET AL., The effect of disability on employment allowing for work incapacity (University of Kent at Canterbury, Department of Economics, 1998).

Pohlmeier, W. And V. Ulrich, “An Econometric Model of the Two-Part Decisionmaking Process in the Demand for Health Care," The Journal of Human Resources 30 (1995), $339-361$.

Rothwell, G. AND J. Rust, “On the Optimal Lifetime of Nuclear Powe Plants," Journal of Business \& Economic Statistics 15 (1997), 195-208.

RUST, J., "Optimal replacement of GMC bus engines: An empirical model of Harold Zurcher," Econometrica: Journal of the Econometric Society (1987), 999-1033.

—_, "Maximum Likelihood Estimation of Discrete Control Processes," SIAM Journal on Control and Optimization 26 (1988), 19.

—, "Structural estimation of Markov decision processes," Handbook of econometrics 4 (1994), 3081-3143. 
Rust, J. AND C. Phelan, "How Social Security and Medicare Affect Retirement Behavior In a World of Incomplete Markets," Econometrica 65 (1997), 781-831.

Topel, R. H. AND M. P. WARD, "Job Mobility and the Careers of Young Men Author," The Quarterly Journal of Economics1 107 (1992), 439-479.

VAN DER KlAauw, W. AND K. I. WOLPIN, "Social Security and the Retirement and Savings Behavior of Low Income Households.," Journal of econometrics 145 (2008), $21-42$.

WILSON, S. E., "The health capital of families: An investigation of the inter-spousal correlation in health status," Social Science and Medicine 55 (2002), 1157-1172.

Wooldridge, J. M., “Econometric Analysis of Cross Section and Panel Data,” (2010).

Zimmer, D. M., “The Dynamic Relationship between Health and Health Insurance," Working Paper, Western Kentucky University (2012).

Zissimopoulos, J., L. KAROLY AND N. MAestas, "Retirement Transitions of the Selfemployed in the United States and England," MRRC WP2007-155. Mercer Select (2007). 


\section{A Appendix}

\section{A.1 The Choice Set of Household EPHI Plans}

Table A1 and A2 in the Appendix show how the household EPHI eligibility, $e_{t}$, and household retirement status, $L_{t}$, affect the choice set of household EPHI plan, $\mathscr{J}_{t}$. The first column lists all possible household EPHI eligibilities, and the first row lists all possible household retirement statuses. Each cell represents the choice set of household EPHI plan decisions, $\mathscr{J}_{t}$, under a specific household EPHI eligibility and a specific household retirement status. Consider, for example, the first cell in Table A1. It shows a household in which both spouses' employers provide health insurance whether they are working or retired, and the insurance can cover the other spouse. When the household decides that both spouses retire, three household EPHI plan choices are available: (1) both spouses are covered by the husband's EPHI, $(m, m)$; (2) both are covered by the wife's EPHI, $(f, f)$; and (3) the husband is covered by his own EPHI and the wife is covered by her own EPHI, $(m, f) 158$ In this paper, I assume that a household makes the EPHI plan choice every period until both spouses are retired 159

\section{A.2 Taxes}

Individuals pay federal, state, and payroll taxes on income. I compute federal taxes using the Federal Income Tax tables for "Married Filing Jointly" in 1998 160 I use the standard deduction 161 and do not allow individuals to claim medical expenses as an itemized deduction. The state income tax rate varies across the U.S., and I use the average state tax rate to calculate state income taxes for each household. For a worker, payroll taxes are $7.65 \%$ up to $\$ 68,400$, and are $1.45 \%$ thereafter.

\footnotetext{
${ }^{158} \mathrm{~A}$ worker has to enroll in his own EPHI plan before he can add the other spouse into the plan. Thus, it is impossible that the husband is covered by the wife's EPHI and the wife is covered by the husband's EPHI. In other words, $(f, m)$ is not a valid choice.

${ }^{159}$ In my sample, no household switches EPHI choices after both spouses retire. Therefore, I assume that a household stops making the EPHI plan choice after both spouses are retired.

${ }^{160}$ For widows or widowers, I compute federal taxes using the Federal Income Tax tables for "Single" in 1998.

${ }^{161}$ The standard deduction is $\$ 12,500$ for a household, and is $\$ 6,250$ for a widow or widower.
} 
Table A1: The Choice Set of Household EPHI Plan Choices $\mathscr{J}_{t}$

\begin{tabular}{|c|c|c|c|c|}
\hline & $L_{t}=(\mathbf{1}, \mathbf{1})$ & $L_{t}=(\mathbf{1 , 0 )}$ & $L_{t}=(\mathbf{0 , 1})$ & $L_{t}=(\mathbf{0 , 0})$ \\
\hline $\begin{array}{l}e_{m}=(1,1,1,1) \\
e_{f}=(1,1,1,1)\end{array}$ & $\begin{array}{c}\mathscr{J}_{t}=\{(\mathrm{m}, \mathrm{m}), \\
(\mathrm{f}, \mathrm{f}),(\mathrm{m}, \mathrm{f})\}\end{array}$ & $\begin{array}{c}\mathscr{J}_{t}=\{(\mathrm{m}, \mathrm{m}), \\
(\mathrm{f}, \mathrm{f}),(\mathrm{m}, \mathrm{f})\}\end{array}$ & $\begin{array}{c}\mathscr{J}_{t}=\{(\mathrm{m}, \mathrm{m}), \\
(\mathrm{f}, \mathrm{f}),(\mathrm{m}, \mathrm{f})\}\end{array}$ & $\begin{array}{c}\mathscr{J}_{t}=\{(\mathrm{m}, \mathrm{m}), \\
(\mathrm{f}, \mathrm{f}),(\mathrm{m}, \mathrm{f})\}\end{array}$ \\
\hline $\begin{array}{l}e_{m}=(1,1,1,1) \\
e_{f}=(1,1,1,0)\end{array}$ & $\begin{array}{c}\mathscr{J}_{t}=\{(\mathrm{m}, \mathrm{m}), \\
(\mathrm{m}, \mathrm{f})\}\end{array}$ & $\begin{array}{c}\mathscr{J}_{t}=\{(\mathrm{m}, \mathrm{m}), \\
(\mathrm{f}, \mathrm{f}),(\mathrm{m}, \mathrm{f})\}\end{array}$ & $\begin{array}{c}\mathscr{J}_{t}=\{(\mathrm{m}, \mathrm{m}), \\
(\mathrm{m}, \mathrm{f})\}\end{array}$ & $\begin{array}{c}\mathscr{J}_{t}=\{(\mathrm{m}, \mathrm{m}), \\
(\mathrm{f}, \mathrm{f}),(\mathrm{m}, \mathrm{f})\}\end{array}$ \\
\hline $\begin{array}{l}e_{m}=(1,1,1,1) \\
e_{f}=(1,1,0,0)\end{array}$ & $\mathscr{J}_{t}=\{(\mathrm{m}, \mathrm{m})\}$ & $\begin{array}{c}\mathscr{J}_{t}=\{(\mathrm{m}, \mathrm{m})\} \\
(\mathrm{f}, \mathrm{f}),(\mathrm{m}, \mathrm{f})\}\end{array}$ & $\mathscr{J}_{t}=\{(\mathrm{m}, \mathrm{m})\}$ & $\begin{array}{c}\mathscr{J}_{t}=\{(\mathrm{m}, \mathrm{m}), \\
(\mathrm{f}, \mathrm{f}),(\mathrm{m}, \mathrm{f})\}\end{array}$ \\
\hline $\begin{array}{l}e_{m}=(1,1,1,1) \\
e_{f}=(1,0,1,0)\end{array}$ & $\begin{array}{c}\mathscr{J}_{t}=\{(\mathrm{m}, \mathrm{m}) \\
(\mathrm{m}, \mathrm{f})\}\end{array}$ & $\begin{array}{c}\mathscr{J}_{t}=\{(\mathrm{m}, \mathrm{m}), \\
(\mathrm{m}, \mathrm{f})\}\end{array}$ & $\begin{array}{c}\mathscr{J}_{t}=\{(\mathrm{m}, \mathrm{m}), \\
(\mathrm{m}, \mathrm{f})\}\end{array}$ & $\begin{array}{c}\mathscr{J}_{t}=\{(\mathrm{m}, \mathrm{m}), \\
(\mathrm{m}, \mathrm{f})\}\end{array}$ \\
\hline $\begin{array}{l}e_{m}=(1,1,1,1) \\
e_{f}=(1,0,0,0)\end{array}$ & $\mathscr{J}_{t}=\{(\mathrm{m}, \mathrm{m})\}$ & $\begin{array}{c}\mathscr{J}_{t}=\{(\mathrm{m}, \mathrm{m}) \\
(\mathrm{m}, \mathrm{f})\}\end{array}$ & $\mathscr{J}_{t}=\{(\mathrm{m}, \mathrm{m})\}$ & $\begin{array}{c}\mathscr{J}_{t}=\{(\mathrm{m}, \mathrm{m}), \\
(\mathrm{m}, \mathrm{f})\}\end{array}$ \\
\hline $\begin{array}{l}e_{m}=(\mathbf{1}, \mathbf{1}, \mathbf{1}, \mathbf{1}) \\
e_{f}=(\mathbf{0 , 0 , 0 , 0 )}\end{array}$ & $\mathscr{J}_{t}=\{(\mathrm{m}, \mathrm{m})\}$ & $\mathscr{J}_{t}=\{(\mathrm{m}, \mathrm{m})\}$ & $\mathscr{J}_{t}=\{(\mathrm{m}, \mathrm{m})\}$ & $\mathscr{J}_{t}=\{(\mathrm{m}, \mathrm{m})\}$ \\
\hline $\begin{array}{l}e_{m}=(1,1,1,0) \\
e_{f}=(1,1,1,1)\end{array}$ & $\begin{array}{c}\mathscr{J}_{t}=\{(\mathrm{f}, \mathrm{f}), \\
(\mathrm{m}, \mathrm{f})\}\end{array}$ & $\begin{array}{c}\mathscr{J}_{t}=\{(\mathrm{f}, \mathrm{f}), \\
(\mathrm{m}, \mathrm{f})\}\end{array}$ & $\begin{array}{c}\mathscr{J}_{t}=\{(\mathrm{m}, \mathrm{m}), \\
(\mathrm{f}, \mathrm{f}),(\mathrm{m}, \mathrm{f})\}\end{array}$ & $\begin{array}{c}\mathscr{J}_{t}=\{(\mathrm{m}, \mathrm{m}), \\
(\mathrm{f}, \mathrm{f}),(\mathrm{m}, \mathrm{f})\}\end{array}$ \\
\hline $\begin{array}{l}e_{m}=(1,1,1,0) \\
e_{f}=(1,1,1,0)\end{array}$ & $\mathscr{J}_{t}=\{(\mathrm{m}, \mathrm{f})\}$ & $\begin{array}{c}\mathscr{J}_{t}=\{(\mathrm{f}, \mathrm{f}), \\
(\mathrm{m}, \mathrm{f})\}\end{array}$ & $\begin{array}{c}\mathscr{J}_{t}=\{(\mathrm{m}, \mathrm{m}), \\
(\mathrm{m}, \mathrm{f})\}\end{array}$ & $\begin{array}{c}\mathscr{J}_{t}=\{(\mathrm{m}, \mathrm{m}), \\
(\mathrm{f}, \mathrm{f}),(\mathrm{m}, \mathrm{f})\}\end{array}$ \\
\hline $\begin{array}{l}e_{m}=(1,1,1,0) \\
e_{f}=(1,1,0,0)\end{array}$ & $\mathscr{J}_{t}=\{(\mathrm{m}, 0)\}$ & $\begin{array}{c}\mathscr{J}_{t}=\{(\mathrm{f}, \mathrm{f}), \\
(\mathrm{m}, \mathrm{f})\}\end{array}$ & $\mathscr{J}_{t}=\{(\mathrm{m}, \mathrm{m})\}$ & $\begin{array}{c}\mathscr{J}_{t}=\{(\mathrm{m}, \mathrm{m}), \\
(\mathrm{f}, \mathrm{f}),(\mathrm{m}, \mathrm{f})\}\end{array}$ \\
\hline $\begin{array}{l}e_{m}=(1,1,1,0) \\
e_{f}=(1,0,1,0)\end{array}$ & $\mathscr{J}_{t}=\{(\mathrm{m}, \mathrm{f})\}$ & $\mathscr{J}_{t}=\{(\mathrm{m}, \mathrm{f})\}$ & $\begin{array}{c}\mathscr{J}_{t}=\{(\mathrm{m}, \mathrm{m}) \\
(\mathrm{m}, \mathrm{f})\}\end{array}$ & $\begin{array}{c}\mathscr{J}_{t}=\{(\mathrm{m}, \mathrm{m}), \\
(\mathrm{m}, \mathrm{f})\}\end{array}$ \\
\hline $\begin{array}{l}e_{m}=(1,1,1,0) \\
e_{f}=(1,0,0,0)\end{array}$ & $\mathscr{J}_{t}=\{(\mathrm{m}, 0)\}$ & $\mathscr{J}_{t}=\{(\mathrm{m}, \mathrm{f})\}$ & $\mathscr{J}_{t}=\{(\mathrm{m}, \mathrm{m})\}$ & $\begin{array}{c}\mathscr{J}_{t}=\{(\mathrm{m}, \mathrm{m}), \\
(\mathrm{m}, \mathrm{f})\}\end{array}$ \\
\hline $\begin{array}{l}e_{m}=(1,1,1,0) \\
e_{f}=(\mathbf{0 , 0 , 0 , 0 )}\end{array}$ & $\mathscr{J}_{t}=\{(\mathrm{m}, 0)\}$ & $\mathscr{J}_{t}=\{(\mathrm{m}, 0)\}$ & $\mathscr{J}_{t}=\{(\mathrm{m}, \mathrm{m})\}$ & $\mathscr{J}_{t}=\{(\mathrm{m}, \mathrm{m})\}$ \\
\hline $\begin{array}{l}e_{m}=(1,1,0,0) \\
e_{f}=(1,1,1,1)\end{array}$ & $\mathscr{J}_{t}=\{(\mathrm{f}, \mathrm{f})\}$ & $\mathscr{J}_{t}=\{(\mathrm{f}, \mathrm{f})\}$ & $\begin{array}{c}\mathscr{J}_{t}=\{(\mathrm{m}, \mathrm{m}) \\
(\mathrm{f}, \mathrm{f}),(\mathrm{m}, \mathrm{f})\}\end{array}$ & $\begin{array}{c}\mathscr{J}_{t}=\{(\mathrm{m}, \mathrm{m}), \\
(\mathrm{f}, \mathrm{f}),(\mathrm{m}, \mathrm{f})\}\end{array}$ \\
\hline $\begin{array}{l}e_{m}=(1,1,0,0) \\
e_{f}=(1,1,1,0)\end{array}$ & $\mathscr{J}_{t}=\{(0, \mathrm{f})\}$ & $\mathscr{J}_{t}=\{(\mathrm{f}, \mathrm{f})\}$ & $\begin{array}{c}\mathscr{J}_{t}=\{(\mathrm{m}, \mathrm{m}), \\
(\mathrm{m}, \mathrm{f})\}\end{array}$ & $\begin{array}{c}\mathscr{J}_{t}=\{(\mathrm{m}, \mathrm{m}), \\
(\mathrm{f}, \mathrm{f}),(\mathrm{m}, \mathrm{f})\}\end{array}$ \\
\hline $\begin{array}{l}e_{m}=(1,1, \mathbf{0}, \mathbf{0}) \\
e_{f}=(1,1,0,0)\end{array}$ & $\mathscr{J}_{t}=\{(0,0)\}$ & $\mathscr{J}_{t}=\{(\mathrm{f}, \mathrm{f})\}$ & $\mathscr{J}_{t}=\{(\mathrm{m}, \mathrm{m})\}$ & $\begin{array}{c}\mathscr{J}_{t}=\{(\mathrm{m}, \mathrm{m}), \\
(\mathrm{f}, \mathrm{f}),(\mathrm{m}, \mathrm{f})\}\end{array}$ \\
\hline $\begin{array}{l}e_{m}=(1,1,0,0) \\
e_{f}=(1,0,1,0)\end{array}$ & $\mathscr{J}_{t}=\{(0, \mathrm{f})\}$ & $\mathscr{J}_{t}=\{(0, \mathrm{f})\}$ & $\begin{array}{c}\mathscr{J}_{t}=\{(\mathrm{m}, \mathrm{m}), \\
(\mathrm{m}, \mathrm{f})\}\end{array}$ & $\begin{array}{c}\mathscr{J}_{t}=\{(\mathrm{m}, \mathrm{m}), \\
(\mathrm{m}, \mathrm{f})\}\end{array}$ \\
\hline $\begin{array}{l}e_{m}=(\mathbf{1}, \mathbf{1}, \mathbf{0}, \mathbf{0}) \\
e_{f}=(\mathbf{1}, \mathbf{0}, \mathbf{0 , 0})\end{array}$ & $\mathscr{J}_{t}=\{(0,0)\}$ & $\mathscr{J}_{t}=\{(0, \mathrm{f})\}$ & $\mathscr{J}_{t}=\{(\mathrm{m}, \mathrm{m})\}$ & $\begin{array}{c}\mathscr{J}_{t}=\{(\mathrm{m}, \mathrm{m}), \\
(\mathrm{m}, \mathrm{f})\}\end{array}$ \\
\hline $\begin{array}{l}e_{m}=(\mathbf{1}, \mathbf{1}, \mathbf{0}, \mathbf{0}) \\
e_{f}=(\mathbf{0 , 0 , 0 , 0 )}\end{array}$ & $\mathscr{J}_{t}=\{(0,0)\}$ & $\mathscr{J}_{t}=\{(0,0)\}$ & $\mathscr{J}_{t}=\{(\mathrm{m}, \mathrm{m})\}$ & $\mathscr{J}_{t}=\{(\mathrm{m}, \mathrm{m})\}$ \\
\hline $\begin{array}{l}e_{m}=(1,0,1,0) \\
e_{f}=(1,1,1,1)\end{array}$ & $\begin{array}{c}\mathscr{J}_{t}=\{(\mathrm{f}, \mathrm{f}), \\
(\mathrm{m}, \mathrm{f})\}\end{array}$ & $\begin{array}{c}\mathscr{J}_{t}=\{(\mathrm{f}, \mathrm{f}), \\
(\mathrm{m}, \mathrm{f})\}\end{array}$ & $\begin{array}{c}\mathscr{J}_{t}=\{(\mathrm{f}, \mathrm{f}), \\
(\mathrm{m}, \mathrm{f})\}\end{array}$ & $\begin{array}{c}\mathscr{J}_{t}=\{(\mathrm{f}, \mathrm{f}), \\
(\mathrm{m}, \mathrm{f})\}\end{array}$ \\
\hline $\begin{array}{l}e_{m}=(1,0,1,0) \\
e_{f}=(1,1,1,0)\end{array}$ & $\mathscr{J}_{t}=\{(\mathrm{m}, \mathrm{f})\}$ & $\begin{array}{c}\mathscr{J}_{t}=\{(\mathrm{f}, \mathrm{f}), \\
(\mathrm{m}, \mathrm{f})\}\end{array}$ & $\mathscr{J}_{t}=\{(\mathrm{m}, \mathrm{f})\}$ & $\begin{array}{c}\mathscr{J}_{t}=\{(\mathrm{f}, \mathrm{f}) \\
(\mathrm{m}, \mathrm{f})\}\end{array}$ \\
\hline $\begin{array}{l}e_{m}=(1,0,1,0) \\
e_{f}=(1,1,0,0)\end{array}$ & $\mathscr{J}_{t}=\{(\mathrm{m}, 0)\}$ & $\begin{array}{c}\mathscr{J}_{t}=\{(\mathrm{f}, \mathrm{f}), \\
(\mathrm{m}, \mathrm{f})\}\end{array}$ & $\mathscr{J}_{t}=\{(\mathrm{m}, 0)\}$ & $\begin{array}{c}\mathscr{J}_{t}=\{(\mathrm{f}, \mathrm{f}) \\
(\mathrm{m}, \mathrm{f})\}\end{array}$ \\
\hline
\end{tabular}


Table A2: Table A1 Continued

\begin{tabular}{|c|c|c|c|c|}
\hline & $L_{t}=(\mathbf{1}, \mathbf{1})$ & $L_{t}=(\mathbf{1 , 0})$ & $L_{t}=(\mathbf{0 , 1})$ & $L_{t}=(\mathbf{0 , 0})$ \\
\hline $\begin{array}{l}e_{m}=(\mathbf{1}, \mathbf{0}, \mathbf{1}, \mathbf{0}) \\
e_{f}=(\mathbf{1 , 0 , 1 , 0 )}\end{array}$ & $\mathscr{J}_{t}=\{(\mathrm{m}, \mathrm{f})\}$ & $\mathscr{J}_{t}=\{(\mathrm{m}, \mathrm{f})\}$ & $\mathscr{J}_{t}=\{(\mathrm{m}, \mathrm{f})\}$ & $\mathscr{J}_{t}=\{(\mathrm{m}, \mathrm{f})\}$ \\
\hline $\begin{array}{l}e_{m}=(\mathbf{1}, \mathbf{0}, \mathbf{1}, \mathbf{0}) \\
e_{f}=(\mathbf{1 , 0 , 0 , 0 )}\end{array}$ & $\mathscr{J}_{t}=\{(\mathrm{m}, 0)\}$ & $\mathscr{J}_{t}=\{(\mathrm{m}, \mathrm{f})\}$ & $\mathscr{J}_{t}=\{(\mathrm{m}, 0)\}$ & $\mathscr{J}_{t}=\{(\mathrm{m}, \mathrm{f})\}$ \\
\hline $\begin{array}{l}e_{m}=(1, \mathbf{0}, \mathbf{1}, \mathbf{0}) \\
e_{f}=(\mathbf{0 , 0 , 0 , 0 )}\end{array}$ & $\mathscr{J}_{t}=\{(\mathrm{m}, 0)\}$ & $\mathscr{J}_{t}=\{(\mathrm{m}, 0)\}$ & $\mathscr{J}_{t}=\{(\mathrm{m}, 0)\}$ & $\mathscr{J}_{t}=\{(\mathrm{m}, 0)\}$ \\
\hline $\begin{array}{l}e_{m}=(\mathbf{1}, \mathbf{0}, \mathbf{0 , 0}) \\
e_{f}=(\mathbf{1}, \mathbf{1}, \mathbf{1}, \mathbf{1})\end{array}$ & $\mathscr{J}_{t}=\{(\mathrm{f}, \mathrm{f})\}$ & $\mathscr{J}_{t}=\{(\mathrm{f}, \mathrm{f})\}$ & $\begin{array}{c}\mathscr{J}_{t}=\{(\mathrm{f}, \mathrm{f}), \\
(\mathrm{m}, \mathrm{f})\}\end{array}$ & $\begin{array}{c}\mathscr{J}_{t}=\{(\mathrm{f}, \mathrm{f}), \\
(\mathrm{m}, \mathrm{f})\}\end{array}$ \\
\hline $\begin{array}{l}e_{m}=(1,0,0,0) \\
e_{f}=(1,1,1,0)\end{array}$ & $\mathscr{J}_{t}=\{(0, \mathrm{f})\}$ & $\mathscr{J}_{t}=\{(\mathrm{f}, \mathrm{f})\}$ & $\mathscr{J}_{t}=\{(\mathrm{m}, \mathrm{f})\}$ & $\begin{array}{c}\mathscr{J}_{t}=\{(\mathrm{f}, \mathrm{f}), \\
(\mathrm{m}, \mathrm{f})\}\end{array}$ \\
\hline $\begin{array}{l}e_{m}=(\mathbf{1}, \mathbf{0}, \mathbf{0 , 0}) \\
e_{f}=(\mathbf{1}, \mathbf{1}, \mathbf{0 , 0})\end{array}$ & $\mathscr{J}_{t}=\{(0,0)\}$ & $\mathscr{J}_{t}=\{(\mathrm{f}, \mathrm{f})\}$ & $\mathscr{J}_{t}=\{(\mathrm{m}, 0)\}$ & $\begin{array}{c}\mathscr{J}_{t}=\{(\mathrm{f}, \mathrm{f}) \\
(\mathrm{m}, \mathrm{f})\}\end{array}$ \\
\hline $\begin{array}{l}e_{m}=(\mathbf{1}, \mathbf{0}, \mathbf{0 , 0}) \\
e_{f}=(\mathbf{1}, \mathbf{0}, \mathbf{1}, \mathbf{0})\end{array}$ & $\mathscr{J}_{t}=\{(0, \mathrm{f})\}$ & $\mathscr{J}_{t}=\{(0, \mathrm{f})\}$ & $\mathscr{J}_{t}=\{(\mathrm{m}, \mathrm{f})\}$ & $\mathscr{J}_{t}=\{(\mathrm{m}, \mathrm{f})\}$ \\
\hline $\begin{array}{l}e_{m}=(1, \mathbf{0}, \mathbf{0 , 0}) \\
e_{f}=(1, \mathbf{0}, \mathbf{0 , 0})\end{array}$ & $\mathscr{J}_{t}=\{(0,0)\}$ & $\mathscr{J}_{t}=\{(0, \mathrm{f})\}$ & $\mathscr{J}_{t}=\{(\mathrm{m}, 0)\}$ & $\mathscr{J}_{t}=\{(\mathrm{m}, \mathrm{f})\}$ \\
\hline $\begin{array}{l}e_{m}=(\mathbf{1 , 0 , 0 , 0 )} \\
e_{f}=(\mathbf{0 , 0 , 0 , 0 )}\end{array}$ & $\mathscr{J}_{t}=\{(0,0)\}$ & $\mathscr{J}_{t}=\{(0,0)\}$ & $\mathscr{J}_{t}=\{(\mathrm{m}, 0)\}$ & $\mathscr{J}_{t}=\{(\mathrm{m}, 0)\}$ \\
\hline $\begin{array}{l}e_{m}=(\mathbf{0 , 0}, \mathbf{0 , 0}) \\
e_{f}=(\mathbf{1}, \mathbf{1}, \mathbf{1}, \mathbf{1})\end{array}$ & $\mathscr{J}_{t}=\{(\mathrm{f}, \mathrm{f})\}$ & $\mathscr{J}_{t}=\{(\mathrm{f}, \mathrm{f})\}$ & $\mathscr{J}_{t}=\{(\mathrm{f}, \mathrm{f})\}$ & $\mathscr{J}_{t}=\{(\mathrm{f}, \mathrm{f})\}$ \\
\hline $\begin{array}{l}e_{m}=(\mathbf{0 , 0}, \mathbf{0 , 0}) \\
e_{f}=(\mathbf{1}, \mathbf{1}, \mathbf{1 , 0})\end{array}$ & $\mathscr{J}_{t}=\{(0, \mathrm{f})\}$ & $\mathscr{J}_{t}=\{(\mathrm{f}, \mathrm{f})\}$ & $\mathscr{J}_{t}=\{(0, \mathrm{f})\}$ & $\mathscr{J}_{t}=\{(\mathrm{f}, \mathrm{f})\}$ \\
\hline $\begin{array}{l}e_{m}=(\mathbf{0 , 0 , 0 , 0 )} \\
e_{f}=(1,1, \mathbf{0 , 0})\end{array}$ & $\mathscr{J}_{t}=\{(0,0)\}$ & $\mathscr{J}_{t}=\{(\mathrm{f}, \mathrm{f})\}$ & $\mathscr{J}_{t}=\{(0,0)\}$ & $\mathscr{J}_{t}=\{(\mathrm{f}, \mathrm{f})\}$ \\
\hline $\begin{array}{l}e_{m}=(\mathbf{0 , 0 , 0 , 0 )} \\
e_{f}=(1,0,1,0)\end{array}$ & $\mathscr{J}_{t}=\{(0, \mathrm{f})\}$ & $\mathscr{J}_{t}=\{(0, \mathrm{f})\}$ & $\mathscr{J}_{t}=\{(0, \mathrm{f})\}$ & $\mathscr{J}_{t}=\{(0, \mathrm{f})\}$ \\
\hline $\begin{array}{l}e_{m}=(\mathbf{0 , 0}, \mathbf{0 , 0}) \\
e_{f}=(\mathbf{1 , 0 , 0 , 0 )}\end{array}$ & $\mathscr{J}_{t}=\{(0,0)\}$ & $\mathscr{J}_{t}=\{(0, \mathrm{f})\}$ & $\mathscr{J}_{t}=\{(0,0)\}$ & $\mathscr{J}_{t}=\{(0, \mathrm{f})\}$ \\
\hline $\begin{array}{l}e_{m}=(\mathbf{0 , 0 , 0 , 0 )} \\
e_{f}=(\mathbf{0 , 0 , 0 , 0 )}\end{array}$ & $\mathscr{J}_{t}=\{(0,0)\}$ & $\mathscr{J}_{t}=\{(0,0)\}$ & $\mathscr{J}_{t}=\{(0,0)\}$ & $\mathscr{J}_{t}=\{(0,0)\}$ \\
\hline
\end{tabular}

In period $t$, a household's pre-tax income, $Y_{t}$, is

$$
Y_{t}=r A_{t}+\sum_{i=m, f} w_{i t}\left(1-L_{i t}\right)+\sum_{i=m, f} b_{i t} .
$$

Post-tax income, $y_{t}$, is computed by applying the three taxes on pre-tax income, $Y_{t}$, 


$$
y_{t}= \begin{cases}0.9235 Y_{t} & \text { if } \frac{Y_{t}}{2} \leqslant 12,500, \\ 2\left(11,543.75+0.7323\left(\frac{Y_{t}}{2}-12,500\right)\right) & \text { if } 12,500<\frac{Y_{t}}{2} \leqslant 42,350, \\ 2\left(33,402.91+0.5665\left(\frac{Y_{t}}{2}-42,350\right)\right) & \text { if } 42,350<\frac{Y_{t}}{2} \leqslant 102,300, \\ 2\left(67,363.67+0.5283\left(\frac{Y_{t}}{2}-102,300\right)\right) & \text { if } 102,300<\frac{Y_{t}}{2} \leqslant 136,800, \\ 2\left(85,590.02+0.5903\left(\frac{Y_{t}}{2}-136,800\right)\right) & \text { if } 136,800<\frac{Y_{t}}{2} \leqslant 155,950, \\ 2\left(96,894.27+0.5265\left(\frac{Y_{t}}{2}-155,950\right)\right) & \text { if } 155,950<\frac{Y_{t}}{2} \leqslant 278,450, \\ 2\left(161,390.52+0.4806\left(\frac{Y_{t}}{2}-278,450\right)\right) & \text { if } \frac{Y_{t}}{2}>278,450 .\end{cases}
$$

If one spouse dies, the widow or widower's pre-tax income is

$$
Y_{t}=r A_{t}+w_{i t}\left(1-L_{i t}\right)+b_{i t},
$$

and his post-tax income is

$$
y_{t}= \begin{cases}0.9235 Y_{t} & \text { if } \frac{Y_{t}}{2} \leqslant 6250, \\ 2\left(5771.87+0.7323\left(\frac{Y_{t}}{2}-6250\right)\right) & \text { if } 6,250<\frac{Y_{t}}{2} \leqslant 21175, \\ 2\left(16701.45+0.5665\left(\frac{Y_{t}}{2}-21175\right)\right) & \text { if } 21175<\frac{Y_{t}}{2} \leqslant 51150, \\ 2\left(33682.29+0.5283\left(\frac{Y_{t}}{2}-51150\right)\right) & \text { if } 51150<\frac{Y_{t}}{2} \leqslant 68400, \\ 2\left(42795.47+0.5903\left(\frac{Y_{t}}{2}-68400\right)\right) & \text { if } 68400<\frac{Y_{t}}{2} \leqslant 77975, \\ 2\left(48447.59+0.5265\left(\frac{Y_{t}}{2}-77975\right)\right) & \text { if } 77975<\frac{Y_{t}}{2} \leqslant 139225, \\ 2\left(80695.71+0.4806\left(\frac{Y_{t}}{2}-139225\right)\right) & \text { if } \frac{Y_{t}}{2}>139225 .\end{cases}
$$

\section{A.3 Social Security and Pension Benefits}

In this subsection, I first introduce the formula that determines an individual's PIA. Then, I describe the functions used to calculate Social Security benefits and DB pension benefits.

\section{A.3.1 PIA Formula}

A worker's PIA, $\Upsilon_{i t}$, is a monotone increasing function of his AIME, $\Delta_{i t}$, 


$$
\Upsilon_{i t}= \begin{cases}0.9 \Delta_{i t} & \text { if } \quad \Delta_{i t}<5724, \\ 5151.6+0.32\left(\Delta_{i t}-5724\right) & \text { if } \quad 5724 \leq \Delta_{i t}<34500, \\ 14359.9+0.15\left(\Delta_{i t}-34500\right) & \text { if } \quad \Delta_{i t} \geq 34500 .\end{cases}
$$

Note that the PIA and AIME in the function above are annualized.

\section{A.3.2 Social Security Benefits}

A worker can start his Social Security benefits as early as age 62. If he claims benefits based on his own earnings history, his benefits, $s_{i t}^{O}$, are a function of his age this period, $a_{i t}$, and his age and PIA at the time of claiming benefits, $\left(a_{i}^{c}, \Upsilon_{i}^{c}\right)$,

$$
s_{i t}^{O}\left(a_{i t}, a_{i}^{c}, \Upsilon_{i}^{c}\right)= \begin{cases}2 \Upsilon_{i}^{c} 0.933^{\left(65-a_{i}^{c}\right)} & \text { if } 62 \leqslant a_{i}^{c} \leqslant 65 \& a_{i}^{c} \leqslant a_{i t}, \\ 2 \Upsilon_{i}^{c} 1.055^{\min \left\{\left(a_{i}^{c}-65\right), 5\right\}} & \text { if } a_{i}^{c}>65 \& a_{i}^{c} \leqslant a_{i t}, \\ 0 & \text { otherwise. }\end{cases}
$$

Note that $a_{i}^{c} \leqslant a_{i t}$ means spouse $i$ has already claimed benefits before or at period $t$, and $a_{i}^{c}>a_{i t}$ means spouse $i$ has not claimed benefits before or at period $t$. In addition, each period is two years. Thus, the benefits that spouse $i$ receives during period $t$ equal two times his annual benefits.

If a worker's spouse is alive $\left(S_{-i, t}=1\right)$, the worker can claim spousal benefits as early as age 62. If he claims spousal benefits at his normal retirement age (65) or older, the spousal benefits equal one half of his spouse's benefits. If he claims benefits before age 65 , the benefits are reduced by $6.67 \%$ for every year before age 65 . His spousal benefits, $s_{i t}^{S}$, are a function of his age this period, $a_{i t}$, his age at the time of claiming benefits, $a_{i}^{c}$, and his spouse's benefits, $s_{-i, t}^{O}\left(a_{-i, t}, a_{-i}^{c}, \Upsilon_{-i}^{c}\right)$,

$$
s_{i t}^{S}\left(a_{i t}, a_{i}^{c} ; s_{-i, t}^{O}\right)= \begin{cases}\frac{1}{2} s_{-i, t}^{O}\left(a_{-i}^{c}, \Upsilon_{-i}^{c}, a_{-i, t}\right) 0.933^{\max \left\{\left(65-a_{i}^{c}\right), 0\right\}} & \text { if } a_{i}^{c} \geqslant 62 \& a_{i}^{c} \leqslant a_{i t}, \\ 0 & \text { otherwise. }\end{cases}
$$

If a worker's spouse is dead $\left(S_{-i, t}=0\right)$, the worker can claim survivor benefits. His survivor benefits, $s_{i t}^{W}$, are calculated based on the deceased spouse's basic benefits. If the deceased spouse started collecting benefits before his death $\left(a_{-i}^{c}<a_{-i}^{D}\right)$, his basic benefits 
equal the benefits he receives. If the deceased spouse did not start collecting benefits before his death $\left(a_{-i}^{c} \geqslant a_{-i}^{D}\right)$, his basic benefits are calculated as if he claimed benefits at the time of his death, or at age 62 if he died before 62. The PIA used in the calculation is his PIA at the time of his death. Thus, the deceased spouse's basic benefits, $s_{-i}^{D}$, are a function of his age and PIA at the time of death, $\left(a_{-i}^{D}, \Upsilon_{-i}^{D}\right)$, and his age and PIA at the time of claiming benefits, $\left(a_{-i}^{c}, \Upsilon_{-i}^{c}\right)$,

$$
s_{-i}^{D}\left(a_{-i}^{D}, \Upsilon_{-i}^{D}, a_{-i}^{c}, \Upsilon_{-i}^{c}\right)= \begin{cases}2 \Upsilon_{-i}^{c} 0.933^{\left(65-a_{-i}^{c}\right)} & \text { if } 62 \leqslant a_{-i}^{c} \leqslant 65 \& a_{-i}^{c}<a_{-i}^{D}, \\ 2 \Upsilon_{-i}^{c} 1.055^{\min \left\{\left(a_{-i}^{c}-65\right), 5\right\}} & \text { if } a_{-i}^{c}>65 \& a_{-i}^{c}<a_{-i}^{D}, \\ 2 \Upsilon_{-i}^{D} 0.933^{\min \left\{\left(65-a_{-i}^{D}\right), 3\right\}} & \text { if } a_{-i}^{D} \leqslant 65 \& a_{-i}^{c} \geqslant a_{-i}^{D}, \\ 2 \Upsilon_{-i}^{D} 1.055^{\min \left\{\left(a_{-i}^{D}-65\right), 5\right\}} & \text { if } a_{-i}^{D}>65 \& a_{-i}^{c} \geqslant a_{-i}^{D} .\end{cases}
$$

A survivor can claim survivor benefits as early as age 60. The full retirement age for a survivor is age 66. If the survivor claims survivor benefits at his full retirement age (66) or older, the survivor benefits equal the deceased spouse's basic benefits. If he claims benefits before age 66 , the benefits are reduced by $6 \%$ for every year before age 66 . If a survivor is getting benefits (either his own or spousal benefits) when the other spouse dies, he can switch to survivor benefits if they are higher than the benefits he is receiving now. Thus, the worker's survivor benefits, $s_{i t}^{W}$, are a function of his age this period, $a_{i t}$, his age at the time of claiming survivor benefits, $a_{i}^{c W}$, and the deceased spouse's basic benefits, $s_{-i}^{D}\left(a_{-i}^{D}, \Upsilon_{-i}^{D}, a_{-i}^{c}, \Upsilon_{-i}^{c}\right)$,

$$
s_{i t}^{W}\left(a_{i t}, a_{i}^{c W} ; s_{-i}^{D}\right)= \begin{cases}s_{-i}^{D}\left(a_{-i}^{D}, \Upsilon_{-i}^{D}, a_{-i}^{c}, \Upsilon_{-i}^{c}\right) 0.94^{\max \left\{\left(66-a_{i}^{c}\right), 0\right\}} & \text { if } a_{i}^{c W} \geqslant 60 \& a_{i}^{c W} \leqslant a_{i t}, \\ 0 & \text { otherwise. }\end{cases}
$$

In summary, the Social Security benefits a worker receives, $s_{i t}$, depend on his own benefits, $s_{i t}^{O}\left(a_{i t}, a_{i}^{c}, \Upsilon_{i}^{c}\right)$, his spouse's survival status, $S_{-i, t}$, his spousal benefits, $s_{i t}^{S}\left(a_{i t}, a_{i}^{c} ; s_{-i, t}^{O}\right)$, and his survivor benefits, $s_{i t}^{W}\left(a_{i t}, a_{i}^{c W} ; s_{-i}^{D}\right)$,

$$
s_{i t}=s\left(s_{i t}^{O}, S_{-i, t}, s_{i t}^{S}, s_{i t}^{W}\right)=\left\{\begin{array}{cc}
\max \left\{s_{i t}^{O}\left(a_{i}^{c}, \Upsilon_{i}^{c}, a_{i t}\right), s_{i t}^{S}\left(a_{i t}, a_{i}^{c} ; s_{-i, t}^{O}\right)\right\} & \text { if } S_{-i, t}=1, \\
\max \left\{s_{i t}^{O}\left(a_{i}^{c}, \Upsilon_{i}^{c}, a_{i t}\right), s_{i t}^{W}\left(a_{i t}, a_{i}^{c W} ; s_{-i}^{D}\right)\right\} & \text { if } S_{-i, t}=0 .
\end{array}\right.
$$




\section{A.3.3 DB Pension Benefits}

Following the method developed in French and Jones (2011), I model a worker's DB pension benefits, $b_{i t}^{D B}$, as a function of his age this period, $a_{i t}$, and his age, PIA, and EPHI eligibility type at the time of his retirement, $\left(a_{i}^{r}, \Upsilon_{i}^{r}, e_{i}^{r}\right)$,

$$
\begin{cases}2\left(\sum_{k=\{R, T, N\}} \gamma_{1, k}^{a_{i}^{r}} 1\left[e_{i}^{r}=k\right]+\gamma_{2}^{a_{i}^{r}} \Upsilon_{i}^{r}+\gamma_{i}^{a_{i}^{r}}, \Upsilon_{i}^{r}, e_{i}^{r} ; \gamma^{a_{i}^{r}}\right)= & \\ 0 & \text { if } \left.\left.a_{i t} \geqslant 0, \Upsilon_{i}^{r}-9,999.6\right\}+\gamma_{4}^{a_{i}^{r}}, \max \left\{0, \Upsilon_{i}^{r}-14,359.9\right\}\right) \\ 0 & \text { otherwise, }\end{cases}
$$

where $k$ denotes the category of EPHI eligibility type. Different types of EPHI eligibility can be divided into three categories: (1) $k=R$ (retiree insurance) if $e_{i}^{r}$ equals $(1,1,1,1)$, $(1,1,1,0)$, or $(1,0,1,0) ;(2) k=T$ (tied insurance) if $e_{i}^{r}$ equals $(1,1,0,0)$, or $(1,0,0,0)$; and (3) $k=N$ (no insurance) if $e_{i}^{r}$ equals $(0,0,0,0)$. The vector of parameters, $\gamma^{a_{i}^{r}}=$ $\left(\gamma_{1, k}^{a_{i}^{r}}, \gamma_{2}^{a_{i}^{r}}, \gamma_{3}^{a_{i}^{r}}, \gamma_{4}^{a_{i}^{r}}\right)$, is the same across spouses but varies with retirement age, $a_{i}^{r}$. Table A3 lists the value of $\gamma^{a_{i}^{r}}$ for different retirement ages.

Table A3: Value of $\gamma$ by Retirement Age

\begin{tabular}{c|ccc|c|c|c}
\hline \hline Retirement Age & $\gamma_{1, n o}^{a}$ & $\gamma_{1, \text { retiree }}^{a}$ & $\gamma_{1, \text { tied }}^{a}$ & $\gamma_{2}^{a}$ & $\gamma_{3}^{a}$ & $\gamma_{4}^{a}$ \\
\hline 59 & 1695 & 8446 & 5009 & -0.1955 & 1.421 & 0.8186 \\
60 & 1929 & 8854 & 5111 & -0.1955 & 1.533 & 0.3831 \\
61 & 2146 & 9222 & 5184 & -0.1955 & 1.637 & -0.023 \\
62 & 2345 & 9551 & 5227 & -0.1955 & 1.735 & -0.399 \\
63 & 2528 & 9840 & 5242 & -0.1955 & 1.826 & -0.747 \\
64 & 2693 & 10090 & 5228 & -0.1955 & 1.910 & -1.065 \\
65 & 2841 & 10300 & 5184 & -0.1955 & 1.987 & -1.354 \\
66 & 2972 & 10470 & 5112 & -0.1955 & 2.057 & -1.613 \\
67 & 3085 & 10600 & 5010 & -0.1955 & 2.120 & -1.843 \\
68 & 3182 & 10690 & 4879 & -0.1955 & 2.176 & -2.043 \\
69 & 3261 & 10740 & 4719 & -0.1955 & 2.225 & -2.214 \\
70 & 3323 & 10760 & 4530 & -0.1955 & 2.268 & -2.356 \\
71 & 3368 & 10730 & 4312 & -0.1955 & 2.303 & -2.468 \\
72 & 3396 & 10660 & 4065 & -0.1955 & 2.331 & -2.551 \\
73 & 3406 & 10550 & 3789 & -0.1955 & 2.353 & -2.605 \\
\hline \hline
\end{tabular}

Source: French and Jones (2011). 


\section{A.4 Employer-Provided Health Insurance Eligibility}

In the HRS, the only people who are selected to be surveyed about their EPHI eligibility are those covered by their own EPHI plan. Consequently, there is no information about the EPHI eligibility of those who are covered by their spouse's employer. Figure A1 shows how the HRS surveys households about their health insurance eligibility.

Figure A1: Flowchart of Survey Questions about Health Insurance Eligibility in the HRS

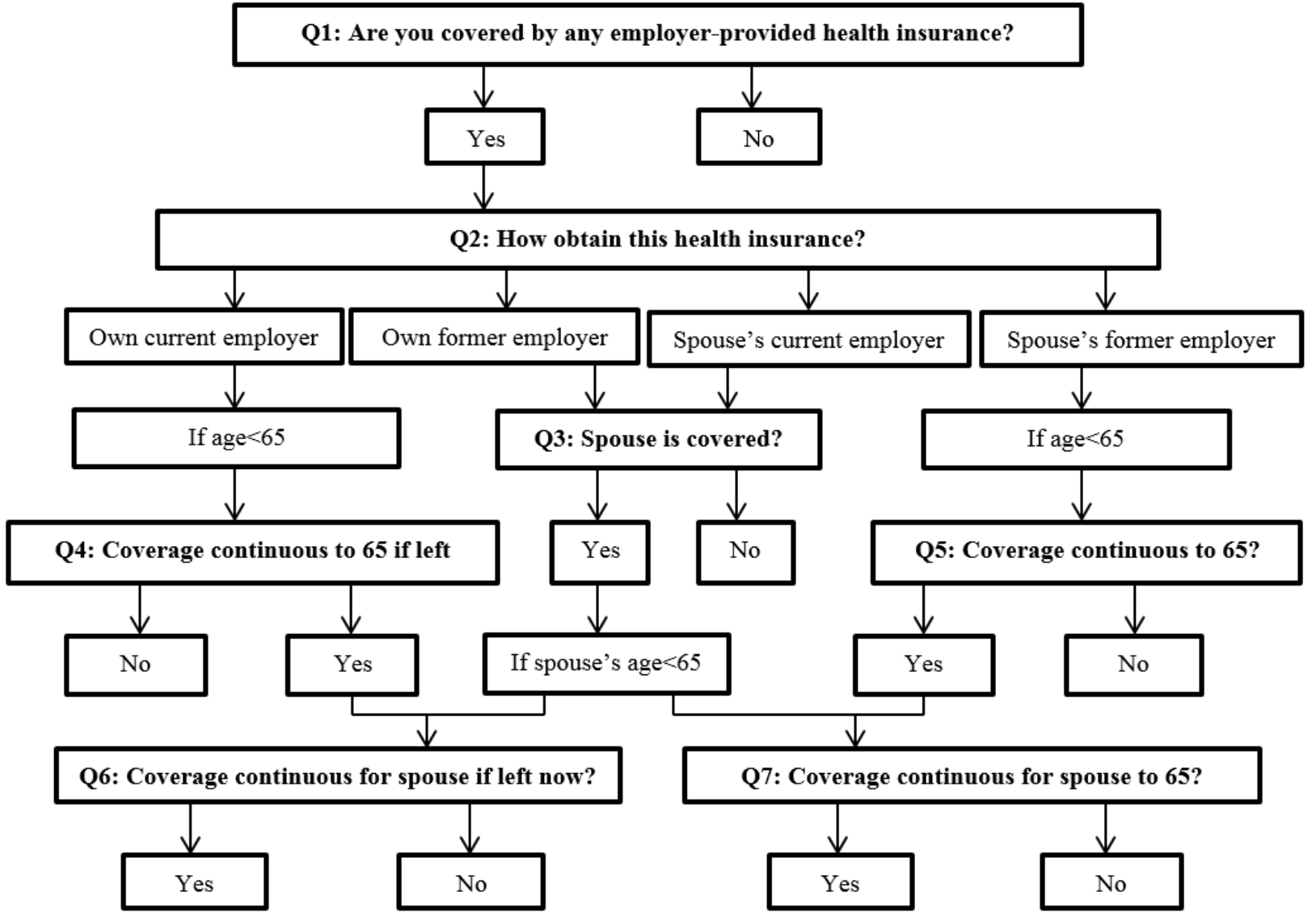

To impute the EPHI eligibility for those who are not surveyed about their EPHI eligibility, I establish a multivariate probit model of the observed EPHI eligibility and the selection of reporting EPHI eligibility (equations (4.1)-(4.5)). The error terms in the five equations are assumed to be multivariate normally distributed, 


$$
\left(\begin{array}{c}
\omega_{i t}^{w 1} \\
\omega_{i t}^{w 2} \\
\omega_{i t}^{r 1} \\
\omega_{i t}^{r 2} \\
\omega_{i t}^{s}
\end{array}\right) \sim N\left[\left(\begin{array}{l}
0 \\
0 \\
0 \\
0 \\
0
\end{array}\right),\left(\begin{array}{ccccc}
1 & \rho_{12} & \rho_{13} & \rho_{14} & \rho_{15} \\
\rho_{12} & 1 & \rho_{23} & \rho_{24} & \rho_{25} \\
\rho_{13} & \rho_{23} & 1 & \rho_{34} & \rho_{35} \\
\rho_{14} & \rho_{24} & \rho_{34} & 1 & \rho_{45} \\
\rho_{15} & \rho_{25} & \rho_{35} & \rho_{45} & 1
\end{array}\right)\right] .
$$

I use married couples in the HRS to estimate the imputation model. In this sample, each spouse's likelihood contribution is the probability of having the EPHI coverage outcome observed in the data. A coverage outcome includes two pieces of information: (1) whether a spouse reports his EPHI eligibility; and (2) his EPHI eligibility type if he reports. Table A4 defines the seven EPHI coverage outcomes observed in the data, using the five binary variables, $\left(e_{i t}^{w 1}, e_{i t}^{w 2}, e_{i t}^{r 1}, e_{i t}^{r 2}, e_{i t}^{s}\right)$.

\begin{tabular}{|c|c|c|c|c|c|}
\hline Outcome & $e^{w 1}$ & $e^{w 2}$ & $e^{r 1}$ & $e^{r 2}$ & $\bar{e} e^{s}$ \\
\hline 1 & 1 & 1 & 1 & 1 & 1 \\
\hline 2 & 1 & 1 & 1 & 0 & 1 \\
\hline 3 & 1 & 1 & 0 & 0 & 1 \\
\hline 4 & 1 & 0 & 1 & 0 & 1 \\
\hline 5 & 1 & 0 & 0 & 0 & 1 \\
\hline 6 & 0 & 0 & 0 & 0 & 1 \\
\hline 7 & & & & & 0 \\
\hline
\end{tabular}

I calculate each spouse's likelihood contribution using equations (4.1)-(4.5). Let $P 1_{i t}, P 2_{i t}, P 3_{i t}, P 4_{i t}, P 5_{i t}, P 6_{i t}$, and $P 7_{i t}$ represent the probability of observing outcomes 1-7 for spouse $i$ in period $t$, respectively,

$$
\begin{gathered}
P 1_{i t}=\operatorname{Pr}\left[e_{i t}^{w 1}=1,\left.e_{i t}^{w 2}\right|_{\left[e_{i t}^{w 1}=1\right]}=1,\left.e_{i t}^{r 1}\right|_{\left[e_{i t}^{w 1}=1\right]}=1,\left.e_{i t}^{r 2}\right|_{\left[e_{i t}^{r 1}=1, e_{i t}^{w 2}=1\right]}=1, e_{i t}^{s}=1\right] \\
=\int_{D 1} \int_{D 2} \int_{D 3} \int_{D 4} \int_{D 5} d G\left(\omega_{i t}^{w 1}, \omega_{i t}^{w 2}, \omega_{i t}^{r 1}, \omega_{i t}^{r 2}, \omega_{i t}^{s}\right), \\
P 2_{i t}=\operatorname{Pr}\left[e_{i t}^{w 1}=1,\left.e_{i t}^{w 2}\right|_{\left[e_{i t}^{w 1}=1\right]}=1,\left.e_{i t}^{r 1}\right|_{\left[e_{i t}^{w 1}=1\right]}=1,\left.e_{i t}^{r 2}\right|_{\left[e_{i t}^{r 1}=1, e_{i t}^{w 2}=1\right]}=0, e_{i t}^{s}=1\right] \\
=\int_{D 1} \int_{D 2} \int_{D 3} \int^{D 4} \int_{D 5} d G\left(\omega_{i t}^{w 1}, \omega_{i t}^{w 2}, \omega_{i t}^{r 1}, \omega_{i t}^{r 2}, \omega_{i t}^{s}\right), \\
P 3_{i t}=\operatorname{Pr}\left[e_{i t}^{w 1}=1,\left.e_{i t}^{w 2}\right|_{\left[e_{i t}^{w 1}=1\right]}=1,\left.e_{i t}^{r 1}\right|_{\left[e_{i t}^{w 1}=1\right]}=0, e_{i t}^{s}=1\right] \\
=\int_{D 1} \int_{D 2} \int^{D 3} \int_{D 5} d G_{1,2,3,5}\left(\omega_{i t}^{w 1}, \omega_{i t}^{w 2}, \omega_{i t}^{r 1}, \omega_{i t}^{s}\right),
\end{gathered}
$$




$$
\begin{gathered}
P 4_{i t}=\operatorname{Pr}\left[e_{i t}^{w 1}=1,\left.e_{i t}^{w 2}\right|_{\left[e_{i t}^{w 1}=1\right]}=0,\left.e_{i t}^{r 1}\right|_{\left[e_{i t}^{w 1}=1\right]}=1, e_{i t}^{s}=1\right] \\
=\int_{D 1} \int^{D 2} \int_{D 3} \int_{D 5} d G_{1,2,3,5}\left(\omega_{i t}^{w 1}, \omega_{i t}^{w 2}, \omega_{i t}^{r 1}, \omega_{i t}^{s}\right) \\
P 5_{i t}=\operatorname{Pr}\left[e_{i t}^{w 1}=1,\left.e_{i t}^{w 2}\right|_{\left[e_{i t}^{w 1}=1\right]}=0,\left.e_{i t}^{r 1}\right|_{\left[e_{i t}^{w 1}=1\right]}=0, e_{i t}^{s}=1\right] \\
=\int_{D 1} \int^{D 2} \int^{D 3} \int_{D 5} d G_{1,2,3,5}\left(\omega_{i t}^{w 1}, \omega_{i t}^{w 2}, \omega_{i t}^{r 1}, \omega_{i t}^{s}\right) \\
P 6_{i t}=\operatorname{Pr}\left[e_{i t}^{w 1}=0, e_{i t}^{s}=1\right] \\
=\int^{D 1} \int_{D 5} d G_{1,5}\left(\omega_{i t}^{w 1}, \omega_{i t}^{S}\right) \\
P 7_{i t}=\operatorname{Pr}\left[e_{i t}^{s}=0\right] \\
=\int^{D 5} d G_{5}\left(\omega_{i t}^{s}\right)
\end{gathered}
$$

where $D 1=-\left(\varsigma_{w 1}^{1} X_{i t}^{d}+\varsigma_{w 1}^{2} X_{i t}^{E}\right), D 2=-\left(\varsigma_{w 2}^{1} X_{i t}^{d}+\varsigma_{w 2}^{2} X_{i t}^{E}\right), D 3=-\left(\varsigma_{r 1}^{1} X_{i t}^{d}+\varsigma_{r 1}^{2} X_{i t}^{E}\right), D 4=$ $-\left(\varsigma_{r 2}^{1} X_{i t}^{d}+\varsigma_{r 2}^{2} X_{i t}^{E}\right), D 5=-\left(\varsigma_{s}^{1} X_{i t}^{d}+\varsigma_{s}^{2} X_{i t}^{E}+\varsigma_{s}^{3} X_{-i, t}^{E}\right)$, and $G(\cdot)$ is the joint distribution function of the five error terms. The term $G(\cdot)$ with subscript represents the joint distribution function of a subset of the five error terms. For example, the term $G_{1,2,3,5}(\cdot)$ represents the joint distribution function of the 1st, 2nd, 3rd, and 5th elements of the five error terms.

Spouse $i$ 's likelihood contribution in period $t, P_{i t}$, is

$$
\begin{aligned}
& P_{i t}=P 1_{i t}^{1_{[\text {Outcome } 1]}} \cdot P 2_{i t}^{1_{\text {[Outcome } 2]}} \cdot P 3_{i t}^{1_{\text {[Outcome } 3]}} \cdot P 4_{i t}^{1_{[\text {Outcome } 4]}} \\
& \cdot P 5_{i t}^{1_{\text {[outcome } 5]}} \cdot P 6_{i t}^{1_{\text {[outcome } 6]}} \cdot P 7_{i t}^{1_{[\text {outcome } 7]}} \text {, }
\end{aligned}
$$

where $1_{[\text {Outcomek }]}$ is a variable indicating whether spouse $i$ has outcome $k=\{1,2, \ldots, 7\}$ in period $t$.

The likelihood function is

$$
L(\varsigma, \rho)=\prod_{i=1}^{N} \prod_{t=1}^{T} P_{i t}
$$

Equations (A1)-A6 show that calculating the likelihood contribution requires an integration over the joint distribution of multiple error terms. Because evaluation of the multidimensional integrals is not possible analytically or numerically, I use a GHK simulator (Geweke (1989), Hajivassiliou (1990), Keane (1994)) to simulate the likelihood contribution. Parameter estimates of the EPHI eligibility imputation model maximize the likelihood function. 
Table A5 lists the estimates of parameters associated with the explanatory variables in the imputation model, $\varsigma$. These estimates represent the correlation between the explanatory variables and the dependent variables. Individuals who work for bigger firms, have a higher hourly wage, work longer hours per year, have longer tenure, or are eligible for pension benefits, are more likely to be eligible for employer-provided working and retiree insurance. They are also more likely to report their EPHI eligibility. Compared with wives, husbands are more likely to be eligible for employer-provided working and retiree insurance and to report their EPHI eligibility. Workers in good health are more likely to be eligible for employer-provided insurance (especially for the retiree insurance) and to report their EPHI eligibility. There are two possible reasons that cause the positive correlation between health and being eligible for EPHI plans. First, individuals who have insurance coverage might visit doctors more often and choose more health care treatments, and thus, have better health. Second, individuals who care about health are more likely to have better health, and they are more likely to choose a job that provides insurance coverage.

Table A6 lists the estimates of parameters in the covariance matrix of the five error terms, $\rho$. Individuals who experience shocks that increase the probability of being eligible for employer-provided working insurance also tend to experience shocks that increase the probability of being eligible for employer-provided retiree insurance and the probability of reporting their EPHI eligibility. Individuals experience shocks that increase the probability of being eligible for retiree insurance that cover themselves or their spouse also tend to experience shocks that increase the probability of reporting their EPHI eligibility.

\section{A.5 Wage Imputation Model Estimates}

In the HRS, information about annual wage is often missing (explained in data section 4.6). To solve the missing data problem, I use the two-stage Heckman selection method to impute individuals' annual wage. In the first stage, I use a probit regression to predict the probability that each individual will work (equation (4.10). In the second stage, I regress the logarithm of observed real annual wage on explanatory variables and the inverse Mills ratio (equation (4.12). I use individuals in the HRS to estimate the wage imputation model. 
Table A5: EPHI Eligibility Imputation Model Estimates

\begin{tabular}{|c|c|c|c|c|c|c|c|c|c|c|}
\hline \multirow[t]{2}{*}{ Variable } & \multicolumn{2}{|c|}{$e^{w 1}$} & \multicolumn{2}{|c|}{$\left.e^{w 2}\right|_{\left[e^{w 1}=1\right]}$} & \multicolumn{2}{|c|}{$\left.e^{r 1}\right|_{\left[e^{w 1}=1\right]}$} & \multicolumn{2}{|c|}{$\left.e^{r 2}\right|_{\left[r^{r 1}=1 ; e^{w 2}=1\right]}$} & \multicolumn{2}{|l|}{$e^{s}$} \\
\hline & Est. & S.E. & Est. & S.E. & Est. & S.E. & Est. & S.E. & Est. & S.E. \\
\hline Constant & $0.65 * *$ & 0.27 & $2.12 * * *$ & 0.43 & $1.26 * * *$ & 0.21 & $1.53 * * *$ & 0.44 & -0.23 & 0.23 \\
\hline \multicolumn{11}{|l|}{ Race } \\
\hline \multicolumn{11}{|l|}{ White (omitted) } \\
\hline Black & -0.07 & 0.13 & -0.09 & 0.17 & $-0.41 * * *$ & $=0.08$ & -0.10 & 0.13 & -0.02 & 0.09 \\
\hline Other & -0.32 & 0.21 & $-0.52 * *$ & 0.22 & 0.04 & 0.12 & 0.03 & 0.24 & 0.08 & 0.18 \\
\hline Hispanic & -0.06 & 0.17 & 0.13 & 0.23 & $-0.27 * * *$ & $=0.10$ & -0.16 & 0.19 & -0.13 & 0.14 \\
\hline \multicolumn{11}{|l|}{ Firmsize } \\
\hline \multicolumn{11}{|l|}{$[1,24]$ (omiteed) } \\
\hline$[25,99]$ & 0.05 & 0.09 & 0.19 & 0.16 & 0.02 & 0.07 & -0.04 & 0.13 & 0.06 & 0.07 \\
\hline$[100,499]$ & 0.14 & 0.10 & 0.15 & 0.15 & 0.06 & 0.07 & -0.15 & 0.13 & $0.16^{* *}$ & 0.08 \\
\hline$[500,+\infty)$ & $0.29 * *$ & 0.12 & 0.12 & 0.17 & 0.03 & 0.07 & 0.001 & 0.14 & $0.22 * * *$ & 0.09 \\
\hline Good Health & 0.11 & 0.13 & 0.26 & 0.17 & $0.23 * * *$ & 0.08 & 0.13 & 0.15 & -0.11 & 0.10 \\
\hline Log(hourly wage) & $0.42 * * *$ & 0.07 & 0.16 & 0.14 & $0.26 * * *$ & 0.05 & $0.41 * * *$ & 0.12 & 0.03 & 0.06 \\
\hline Log(annual hours) & $0.11 *$ & 0.06 & -0.08 & 0.11 & $0.46 * * *$ & 0.06 & $0.35^{* * *}$ & 0.13 & $0.36^{* * *}$ & 0.05 \\
\hline Tenure & $0.18 * *$ & 0.07 & -0.13 & 0.14 & 0.02 & 0.06 & 0.04 & 0.11 & $0.16^{* *}$ & 0.07 \\
\hline Pension & $0.58 * * *$ & 0.12 & -0.11 & 0.19 & $-0.17 * *$ & 0.08 & -0.002 & 0.16 & $0.50 * * *$ & 0.08 \\
\hline Tenure*Pension & 0.02 & 0.09 & 0.21 & 0.16 & $0.19 * * *$ & 0.06 & 0.08 & 0.11 & -0.01 & 0.08 \\
\hline \multicolumn{11}{|l|}{ Region } \\
\hline \multicolumn{11}{|l|}{ Northeast (omitted) } \\
\hline Midwest & -0.13 & 0.13 & -0.13 & 0.19 & 0.04 & 0.08 & -0.10 & 0.15 & -0.16 & 0.10 \\
\hline South & -0.17 & 0.12 & -0.02 & 0.18 & -0.07 & 0.07 & -0.01 & 0.15 & -0.06 & 0.09 \\
\hline West & 0.14 & 0.12 & -0.05 & 0.19 & 0.10 & 0.07 & -0.07 & 0.14 & 0.05 & 0.09 \\
\hline \multicolumn{11}{|l|}{ Education } \\
\hline \multicolumn{11}{|l|}{ No degree (omitted) } \\
\hline High school & 0.13 & 0.14 & 0.07 & 0.22 & 0.07 & 0.09 & $0.30^{* *}$ & 0.15 & 0.08 & 0.10 \\
\hline College+ & 0.01 & 0.16 & 0.02 & 0.25 & 0.08 & 0.10 & 0.29 & 0.18 & 0.02 & 0.12 \\
\hline Female & $-0.21 * *$ & 0.09 & -0.15 & 0.16 & $-0.19 * * *$ & 0.05 & $-0.44 * * *$ & 0.11 & $-0.43 * * *$ & 0.08 \\
\hline Spouse Self-employed & & & & & & & & & 0.08 & 0.09 \\
\hline \multicolumn{11}{|l|}{ Spouse Education } \\
\hline \multicolumn{11}{|l|}{ No degree (omitted) } \\
\hline High school & & & & & & & & & -0.01 & 0.08 \\
\hline College+ & & & & & & & & & -0.13 & 0.09 \\
\hline Spouse Full-Time & & & & & & & & & $-0.17 * *$ & 0.07 \\
\hline Spouse Tenure & & & & & & & & & -0.01 & 0.04 \\
\hline Spouse Tenure*Pension & & & & & & & & & -0.07 & 0.04 \\
\hline \multicolumn{11}{|l|}{ Sample Size: N=4,354 } \\
\hline
\end{tabular}

The sample size to estimate the first-stage probit regression is 163,538 person-periods, and the sample size to estimate the second-stage regression is 33,721 person-periods.

Table A7 lists the estimates of these two stages. The coefficients of age, education, race, gender, and marital status are statistically significant. Before age 60, aging 
Table A6: Covariance Matrix Estimates

\begin{tabular}{cll}
\hline \hline Parameter & Estimate & Std. Err. \\
\hline$\rho_{12}$ & 0.23 & 0.48 \\
$\rho_{13}$ & $0.92^{* * *}$ & 0.37 \\
$\rho_{14}$ & 0.09 & 0.33 \\
$\rho_{15}$ & $1.61^{* * *}$ & 0.59 \\
$\rho_{23}$ & 0.06 & 0.15 \\
$\rho_{24}$ & 0.58 & 0.46 \\
$\rho_{25}$ & 0.04 & 0.19 \\
$\rho_{34}$ & 0.01 & 0.46 \\
$\rho_{35}$ & $0.66^{* * *}$ & 0.14 \\
$\rho_{45}$ & $0.67^{* * *}$ & 0.18 \\
\hline \hline
\end{tabular}

Source: Health and Retirement Study;

$*, * *, * * *$ represent the 10,5 , and 1 percentage

significance level, respectively.

significantly increases the probability of working, while after age 60, aging significantly decreases the probability of working. Before age 53, aging significantly increases annual wage, while after age 53, aging significantly decreases annual wage. Having more education significantly increases annual wage and the probability of working. Whites and males are more likely to choose to work and have higher wages than non-whites and females, respectively. Being married significantly increases the probability of working for males and significantly decreases the probability of working for females. Having more working experience significantly increases annual wage.

\section{A.6 AIME and Earnings History}

In this subsection, I first describe the function that use a worker's current AIME to update his AIME in the next year. Then, I present the estimates of the modified AR(1) process used to derive each spouse's past earnings history.

\section{A.6.1 AIME Updating Function}

I can calculate each spouse's AIME in the first wave (year 1992) using the labor income history up to 1992. To calculate the AIME for future years, following French and Jones (2011), I assume that spouse $i$ 's annualized AIME in the next year is a function of his annualized AIME, $\Delta_{i t}$, labor income, $w_{i t} L_{i t}$, and age, $a_{i t}$, in the current year, 
Table A7: Annual Wage Imputation Model Estimates

\begin{tabular}{lrr|rl}
\hline \hline & \multicolumn{2}{c|}{ Probit (1st Stage) } & \multicolumn{2}{c}{ Wage (2nd Stage) } \\
Variable & Est. & S.E. & Est. & S.E. \\
\hline Age & $0.388^{* * *}$ & 0.101 & $0.939 * * *$ & 0.049 \\
Age $^{2}$ & $-0.032^{* * *}$ & 0.008 & $-0.094 * * *$ & 0.004 \\
Education & & & & \\
$\quad$ No degree (omitted) & & & & \\
$\quad$ High school degree & $0.742^{* * *}$ & 0.035 & $0.254 * * *$ & 0.011 \\
$\quad$ College degree+ & $1.421^{* * *}$ & 0.045 & $0.739 * * *$ & 0.013 \\
Race & & & & \\
$\quad$ White (omitted) & & & & \\
$\quad$ Black & $-0.150^{* * *}$ & 0.041 & $-0.059 * * *$ & 0.011 \\
$\quad$ Other & $-0.280^{* * *}$ & 0.067 & $-0.044 * *$ & 0.017 \\
Male & $0.345^{* * *}$ & 0.043 & $0.451 * * *$ & 0.008 \\
Married & $-0.308^{* * *}$ & 0.027 & & \\
Married*Male & $0.646^{* * *}$ & 0.045 & & \\
Experience & & & $0.346 * * *$ & 0.011 \\
Inverse Mills ratio & & & 0.003 & 0.006 \\
Constant & $2.944 * * *$ & 0.319 & $1.745^{* * *}$ & 0.149 \\
\hline Sample Size & $\mathrm{N}=163,538$ & $\mathrm{~N}=33,721$ \\
\hline \hline
\end{tabular}

Source: Health and Retirement Study;

Est. is short for Estimate, and S.E. is short for standard error;

Age equals real age divided by 10; Experience equals the log of working years; $*, * *, * * *$ represent the 10,5 , and 1 percentage significance level, respectively.

$$
\begin{aligned}
\Delta_{i, t+1} & =\left(1+g 1_{\left[a_{i t} \leq 60\right]} L_{i t}\right) \Delta_{i t} \\
& +\frac{1}{35} \max \left\{0, w_{i t} L_{i t}-\alpha^{a_{i t}}\left(1+g 1\left\{a_{i t} \leq 60\right\}\right) \Delta_{i t}\right\},
\end{aligned}
$$

where $g$ denotes the average real wage growth rate, set to 0.016 . The parameter $\alpha^{a_{i t}}$ is the same across people but varies with age. Table A8 lists the value of $\alpha^{a_{i t}}$ for different ages.

\section{A.6.2 Earnings History}

To calculate the AIME in 1992, I need a worker's earnings history up to 1992. To construct each spouse's earnings history backward from the annual labor income in 1992, I assume that a worker's real annual labor income is serially correlated and follow a modified AR(1) process (equation (4.13). To estimate this process, I select husbands and wives who were over age 20 in 1968 from the PSID data, and I track their earnings history until year 1988.

Table A9 shows the estimates of this modified AR(1) process. Labor incomes are highly persistent, and the level of persistence is around 0.7 . In addition, age, education, and 


\begin{tabular}{c|c}
\multicolumn{2}{c}{ Table A8: Value of $\alpha^{a_{i t}}$ by Age } \\
\hline \hline Age & $\alpha^{a_{i t}}$ \\
\hline 56 & 0.107 \\
57 & 0.213 \\
58 & 0.320 \\
59 & 0.427 \\
60 & 0.534 \\
61 & 0.570 \\
62 & 0.589 \\
63 & 0.600 \\
64 & 0.608 \\
65 & 0.614 \\
66 & 0.616 \\
67 & 0.617 \\
68 & 0.618 \\
69 & 0.618 \\
70 & 0.619 \\
71 & 0.619 \\
\hline \hline \multicolumn{2}{l}{ Source: French and Jones (2011). }
\end{tabular}

race have significant effects on predicting labor income. Before age 60, aging significantly increases the husbands' labor income; while after age 60, aging significantly decreases the husbands' labor income. Age has similar effects on predicting the wives' labor income; the age cutoff for the wives is 50 . Having more education significantly increases labor income. Whites have higher labor incomes than non-whites.

\section{A.7 Bargaining Power}

I describe how to use the method developed by Friedberg and Webb (2006) to predict the husband's bargaining power relative to that of his wife. Let $\gamma_{n}$ be the true bargaining power in household $n$ and assume that it is a function of household observables $X_{n}^{\gamma}$. Let $R_{n i}$ represents spouse $i$ 's response to the survey question, and let $R_{n i}^{*}$ be the underlying continuous measure of $R_{n i}$, which depends on the true bargaining power $\gamma_{n}$ and some reporting bias $\beta_{i}^{\gamma} X_{n}^{\gamma}$

$$
\begin{aligned}
\gamma_{n} & =\alpha^{\gamma} X_{n}^{\gamma}+u_{n}^{\gamma}, \\
R_{n i}^{*} & =\gamma_{n}+\beta_{i}^{\gamma} X_{n}^{\gamma}+u_{n i}^{\gamma}=\left(\alpha^{\gamma}+\beta_{i}^{\gamma}\right) X_{n}^{\gamma}+\tilde{u}_{n i} i \in\{m, f\} .
\end{aligned}
$$

Based on the answer to the survey question, $R_{n i}$, is defined as below 
Table A9: Modified AR(1) Process Estimates

\begin{tabular}{|c|c|c|c|c|}
\hline \multirow[b]{2}{*}{ Variable } & \multicolumn{2}{|c|}{ Husband } & \multicolumn{2}{|c|}{ Wife } \\
\hline & Est. & S.E. & Est. & S.E. \\
\hline Labor Income next period & $0.706 * * *$ & 0.003 & $0.679 * * *$ & 0.007 \\
\hline Age & $0.024 * * *$ & 0.001 & $0.009 * * *$ & 0.002 \\
\hline $\mathrm{Age}^{2}$ & $-0.0002 * * *$ & 0.00001 & $-0.00009 * * *$ & 0.00002 \\
\hline \multicolumn{5}{|l|}{ Education } \\
\hline \multicolumn{5}{|l|}{ No degree (omitted) } \\
\hline High school degree & $0.060 * * *$ & 0.004 & $0.077 * * *$ & 0.009 \\
\hline College degree+ & $0.127 * * *$ & 0.005 & $0.174 * * *$ & 0.015 \\
\hline \multicolumn{5}{|l|}{ Race } \\
\hline White (omitted) & & & & \\
\hline Black & $-0.068 * * *$ & 0.004 & $-0.046 * * *$ & 0.009 \\
\hline Other & $-0.022 * *$ & 0.009 & $-0.054^{*}$ & 0.031 \\
\hline Constant & $0.96 * * *$ & 0.025 & $1.213 * * *$ & 0.057 \\
\hline Sample Size & $\mathrm{N}=51$ & 191 & $\mathrm{~N}=10$ & \\
\hline
\end{tabular}

Source: Panel Study of Income Dynamics;

Est. is short for Estimate, and S.E. is short for standard error;

$*, * *, * * *$ represent the 10,5 , and 1 percentage significance level, respectively.

$$
R_{n i}=\left\{\begin{array}{cl}
1 & \text { if husband has final say } \\
0 & \text { if about equal } \\
-1 & \text { if wife has final say. }
\end{array}\right.
$$

Since $R_{n i}^{*}$ is the underlying continuous measure of $R_{n i}$, the definition of $R_{n i}$ can be rewritten as

$$
R_{n i}=\left\{\begin{array}{cl}
1 & \text { if } R_{n i}^{*}>\mu_{1} \\
0 & \text { if } \mu_{0}<R_{n i}^{*} \leq \mu_{1} \\
-1 & \text { if } R_{n i}^{*} \leq \mu_{0} .
\end{array}\right.
$$

Assume that $\tilde{u}_{n i}=\left(u_{n i}^{\gamma}+u_{i}^{\gamma}\right) \sim N\left(0, \sigma_{\gamma}^{2}\right)$, and $\operatorname{cor}\left(\tilde{u}_{n m}, \tilde{u}_{n f}\right)=\rho_{\gamma}$. The parameters $\left(\alpha^{\gamma}+\beta_{i}^{\gamma}\right), \sigma_{\gamma}, \rho_{\gamma}, \mu_{0}, \mu_{1}$ are identified by estimating the bivariate ordered probit model. Then, $\alpha^{\gamma}$ can be estimated after imposing the restriction $\beta_{m}^{\gamma}+\beta_{f}^{\gamma}=0$. With the estimated $\alpha^{\gamma}$, I can predict the value of the bargaining power $\hat{\gamma}_{n}=\hat{\alpha}^{\gamma} X_{n}^{\gamma}$.

For each household in my sample, I impute the husband's bargaining power relative to that of his wife using the explanatory variables and parameter estimates provided by Friedberg and Webb (2006). 


\section{A.8 First Stage Parameter Estimates}

I first present parameter estimates that affect the distribution of total medical expenses (see A8.1). Then, I list parameter estimates that determine health transitions (see A8.2). Lastly, I discuss parameter estimates that determine survival rates (see A8.3).

\section{A.8.1 Total Medical Expenditure Parameter Estimates}

As described in model section 3.4.2, I assume that each spouse's total medical expenses are generated by two separate processes: (1) whether each spouse has zero or positive total medical expenses (equation (3.8)); and (2) the amount of total medical expenditures conditional on having positive total medical expenditures (equation (3.9)). Tables A10 and A11 present estimates of parameters in the first and the second processes, respectively. In Table A10, the binary $(0 / 1)$ dependent variable equals 1 if a spouse has zero total medical expenses. In Table A11, the dependent variable is the log of positive total medical expenses, which is modeled as the sum of a mean function and a standard deviation function (equations (5.23)-(5.25) $)$. The sign of parameters are as expected, and most of the estimates are statistically significant. To put the size of the estimates into perspective, I compute the AME (average marginal effect) for each of the variables.

The effects of health status, health insurance coverage, and employment status are of particular interest. The estimates of the "Good Health" parameters indicate that being in good health increases the probability of having zero total medical expenses. It also decreases the mean and the variance of the distribution of the log positive medical expenses. The AMEs of the "Good Health" variable show that, on average, being in good health increases the probability of having zero medical expenses by 10.1 and 6.7 percentage points for husbands and wives, respectively. Additionally, it decreases the expectation of positive total medical expenses by $\$ 6,494.7$ and $\$ 5,063.6$ for husbands and wives, respectively ${ }^{162}$

The estimates of health insurance coverage parameters imply that spouses who have insurance coverage (either public or private) are more likely to have positive medical ex-

\footnotetext{
${ }^{162}$ Positive total medical expenses are the amount of total medical expenses conditional on having positive medical expenses.
} 
Table A10: Parameter Estimates For The Probability Of Having Zero Total Medical Expenses

\begin{tabular}{|c|c|c|c|c|c|c|}
\hline & \multicolumn{3}{|c|}{ Husband's Equation } & \multicolumn{3}{|c|}{ Wife's Equation } \\
\hline Variable & Estimate & S/E & AME & Estimate & $\mathrm{S} / \mathrm{E}$ & AME \\
\hline Age/10 Slope & & & -0.004 & & & -0.001 \\
\hline Age $\leq 64$ & $-0.50 * * *$ & 0.03 & & $-0.45 * * *$ & 0.03 & \\
\hline Age $\geq 65$ & -0.03 & 0.05 & & 0.11 & 0.09 & \\
\hline Hispanic & $0.35 * * *$ & 0.04 & 0.058 & $0.29 * * *$ & 0.05 & 0.032 \\
\hline Good Health & $0.67 * * *$ & 0.05 & 0.101 & $0.71 * * *$ & 0.07 & 0.067 \\
\hline Full-time Work & $0.26 * * *$ & 0.05 & 0.062 & $0.22 * * *$ & 0.07 & 0.046 \\
\hline Family Assets $* 10^{-6}$ & $-3.29 * * *$ & 0.36 & -0.566 & $-2.37 * * *$ & 0.45 & -0.241 \\
\hline \multicolumn{7}{|l|}{ Race (White is omitted) } \\
\hline Black & $0.32 * * *$ & 0.05 & 0.051 & $0.21 * * *$ & 0.06 & 0.024 \\
\hline Other & 0.01 & 0.03 & 0.001 & 0.02 & 0.04 & 0.002 \\
\hline \multicolumn{7}{|c|}{ Education (less than high school is omitted) } \\
\hline High school & $-0.19 * * *$ & 0.04 & -0.027 & $-0.13 * * *$ & 0.05 & -0.014 \\
\hline College and above & $-0.37 * * *$ & 0.05 & -0.057 & $-0.33 * * *$ & 0.06 & -0.033 \\
\hline \multicolumn{7}{|c|}{ Health Insurance (having no insurance coverage is omitted) } \\
\hline Public HI & $-0.12 * *$ & 0.06 & -0.048 & 0.03 & 0.07 & -0.015 \\
\hline Private $\mathrm{HI}$ & $-0.46 * * *$ & 0.04 & -0.085 & $-0.48 * * *$ & 0.05 & -0.053 \\
\hline Constant & $1.35 * * *$ & 0.17 & & $0.51 * * *$ & 0.19 & \\
\hline Correlation Coefficient & $0.37 * * *$ & 0.02 & & & & \\
\hline
\end{tabular}

Note: 1$)^{*}, * *$, and $* * *$ represent 10,5 and 1 percent significance, respectively;

2) the columns labelled AME list average marginal effects of variables on the probability of having zero total medical expenses;

3) the AME of the "Age/10 Slope" is the AME of increasing age by 1 year;

4) the AME of the "Family Assets" is the AME of increasing assets by $1 \%$.

penses than those who have no insurance. The distribution of the log of positive total medical expenses for those who have insurance has larger mean and variance than that for those who have no insurance. For example, the AMEs of the "Private HI" variable show that, on average, compared to having no health insurance coverage, having private coverage decreases the probability of having zero medical expenses by 8.5 and 5.3 percentage points for husbands and wives, respectively. It also increases the expectation of positive total medical expenses by $\$ 1,708.6$ and $\$ 1,307.1$ for husbands and wives, respectively.

The estimates of the "Full-time Work" parameters indicate that, on average, fulltime workers are more likely to have zero total medical expenses than retirees. The distribution of the log of positive total medical expenses for full-time workers has smaller mean and variance than the distribution for retirees. The AMEs of the "Full-time Work" variable 
Table A11: Parameter Estimates For Positive Total Medical Expenses

\begin{tabular}{|c|c|c|c|c|c|}
\hline & \multicolumn{2}{|c|}{ Mean Function $(\mu)$} & \multicolumn{2}{|c|}{ S.D. Function $(\sigma)$} & \multirow[t]{2}{*}{ AME } \\
\hline Variable & Estimate & S/E & Estimate & S/E & \\
\hline \multicolumn{6}{|l|}{ Husband's Equation } \\
\hline Age/10 Slope & & & & & 60.8 \\
\hline Age $\leq 64$ & $0.37 * * *$ & 0.02 & $-0.20 * * *$ & 0.02 & \\
\hline Age $\geq 65$ & 0.06 & 0.04 & $0.04 *$ & 0.02 & \\
\hline Hispanic & $-0.22 * * *$ & 0.05 & $-0.06 *$ & 0.03 & $-1,522.3$ \\
\hline Good Health & $-0.97 * * *$ & 0.04 & -0.02 & 0.02 & $-6,494.7$ \\
\hline Full-time Work & $-0.25 * * *$ & 0.04 & $-0.07 * * *$ & 0.02 & $-1,947.6$ \\
\hline Family Assets* $10^{-6}$ & $0.84 * * *$ & 0.32 & -0.15 & 0.19 & $3,367.2$ \\
\hline \multicolumn{6}{|l|}{ Race (White is omitted) } \\
\hline Black & $-0.18 * * *$ & 0.05 & -0.002 & 0.03 & -813.8 \\
\hline Other & 0.30 & 0.03 & 0.01 & 0.02 & $1,803.7$ \\
\hline \multicolumn{6}{|c|}{ Education (less than high school is omitted) } \\
\hline High school & $0.31 * * *$ & 0.04 & $-0.10 * * *$ & 0.03 & 816.4 \\
\hline College and above & $0.40 * * *$ & 0.04 & $-0.18 * * *$ & 0.03 & 644.4 \\
\hline \multicolumn{6}{|c|}{ Health Insurance (having no insurance coverage is omitted) } \\
\hline Public HI & $0.38 * * *$ & 0.04 & $0.14 * * *$ & 0.03 & 2198.1 \\
\hline Private HI & $0.48 * * *$ & 0.04 & -0.006 & 0.02 & 1708.6 \\
\hline Constant & $5.09 * * *$ & 0.15 & $2.72 * * *$ & 0.11 & \\
\hline \multicolumn{6}{|l|}{ Wife's Equation } \\
\hline Age/10 Slope & & & & & 38.9 \\
\hline Age $\leq 64$ & $0.22 * * *$ & 0.02 & $-0.24 * * *$ & 0.02 & \\
\hline Age $\geq 65$ & 0.04 & 0.04 & $0.08 * * *$ & 0.03 & \\
\hline Hispanic & $-0.28 * * *$ & 0.04 & 0.004 & 0.03 & $-1,061.1$ \\
\hline Good Health & $-0.86 * * *$ & 0.03 & $-0.04 *$ & 0.02 & $-5,063.6$ \\
\hline Full-time Work & $-0.36 * * *$ & 0.04 & 0.002 & 0.02 & $-1,599.2$ \\
\hline Family Assets* $10^{-6}$ & $1.7 * * *$ & 0.26 & $-1.04 * * *$ & 0.13 & $1,142.9$ \\
\hline \multicolumn{6}{|l|}{ Race (White is omitted) } \\
\hline Black & $-0.22 * * *$ & 0.05 & $0.10 * * *$ & 0.03 & -270.9 \\
\hline Other & $0.37 * * *$ & 0.02 & $0.03 *$ & 0.01 & $1,813.7$ \\
\hline \multicolumn{6}{|c|}{ Education (less than high school is omitted) } \\
\hline High school & $0.26 * * *$ & 0.04 & 0.02 & 0.02 & $1,160.1$ \\
\hline College and above & $0.25^{* * *}$ & 0.04 & -0.03 & 0.02 & 809.2 \\
\hline \multicolumn{6}{|c|}{ Health Insurance (having no insurance coverage is omitted) } \\
\hline Public HI & $0.30 * * *$ & 0.04 & $0.17 * * *$ & 0.02 & $1,867.3$ \\
\hline Private HI & $0.59 * * *$ & 0.04 & $-0.12 * * *$ & 0.02 & $1,307.1$ \\
\hline Constant & $5.98 * * *$ & 0.13 & $2.76^{* * *}$ & 0.10 & \\
\hline
\end{tabular}

Note: 1) $* * *$, and $* * *$ represent 10,5 and 1 percent significance, respectively;

2) the column labelled AME lists average marginal effects of variables on the expected positive total medical expenses, which equal $\exp \left\{\mu+0.5 \sigma^{2}\right\}$.

3 ) the AME of the "Age/10 Slope" is the AME of increasing age by 1 year;

4) the AME of the "Family Assets" is the AME of increasing assets by $1 \%$. 
show that, on average, working full-time increases the probability of having zero total medical expenses by 6.2 and 4.6 percentage points for husbands and wives, respectively. It also decreases the expectation of total medical expenses by $\$ 1,947.6$ and $\$ 1,599.2$ for husband and wives, respectively.

\section{A.8.2 Health Transitions Parameter Estimates}

Recall that I use a bivariate probit framework to model health status in the next period as a function of current health insurance coverage, health status, age, race, and education degree (equation (3.17)). Table A12 presents the estimates of parameters that affect health transitions and the AME for each of the variables. Note that I include health status this period as a factor that affects health status next period. Thus, health transition is the probability of being in good health next period conditional on health status this period. The effects of current health status and health insurance coverage are of particular interest. The AMEs of the "Good Health" variable show that, on average, improving health status from bad to good increases the probability of being in good health next period by 34.1 and 33.1 percentage points for husbands and wives, respectively. Compared to people who lack health insurance coverage, especially for those under age 65 , being covered by public health insurance, on average, decreases the probability of being in good health next period by 14.6 and 11.9 percentage points for husbands and wives, respectively. This might be because people who are under age 65 and have access to public health insurance usually have poor health, and their poor health either due to disability or lack of medical treatment (as a result of low income). By contrast, compared to people who have no health insurance, being covered by private health insurance increases the probability of being in good health next period by 1.8 and 2.5 percentage points for husbands and wives, respectively. This might be because people who have private health insurance usually work full-time and have a better financial situation, which makes them more likely to receive better health care, and thus makes them more likely to be in good health next period. 
Table A12: Health Transitions Parameter Estimates

\begin{tabular}{|c|c|c|c|c|c|c|}
\hline & \multicolumn{3}{|c|}{ "Husband's Equation } & \multicolumn{3}{|c|}{ Wife's Equation } \\
\hline Variable & Estimate & $\mathrm{S} / \mathrm{E}$ & AME & Estimate & $\mathrm{S} / \mathrm{E}$ & AME \\
\hline Age & & & 0.004 & & & 0.004 \\
\hline Age/10 & $0.19 * *$ & 0.09 & & $0.23 * * *$ & 0.08 & \\
\hline$(\text { Age } / 10)^{2}$ & $-0.03 * * *$ & 0.01 & & 0.006 & 0.09 & \\
\hline Hispanic & $-0.23 * * *$ & 0.03 & -0.052 & $-0.33 * * *$ & 0.03 & -0.064 \\
\hline Good Health & $1.47 * * *$ & 0.02 & 0.341 & $1.64 * * *$ & 0.02 & 0.331 \\
\hline \multicolumn{7}{|l|}{ Race (White is omitted) } \\
\hline Black & $-0.18 * * *$ & 0.03 & -0.042 & $-0.22 * * *$ & 0.03 & -0.046 \\
\hline Other & $-0.16 * * *$ & 0.03 & -0.036 & $-0.10 * * *$ & 0.03 & -0.019 \\
\hline \multicolumn{7}{|c|}{ Education (less than high school is omitted) } \\
\hline High school & $0.25 * * *$ & 0.02 & 0.065 & $0.33 * * *$ & 0.02 & 0.078 \\
\hline College and above & $0.52 * * *$ & 0.03 & 0.127 & $0.59 * * *$ & 0.03 & 0.129 \\
\hline \multicolumn{7}{|c|}{ Health Insurance (having no insurance coverage is omitted) } \\
\hline Public HI_65 & $-0.05^{*}$ & 0.03 & -0.010 & -0.004 & 0.03 & -0.0002 \\
\hline Public HI_64 & $-0.62 * * *$ & 0.04 & -0.146 & $-0.59 * * *$ & 0.05 & -0.119 \\
\hline Private $\mathrm{HI}$ & $0.08 * * *$ & 0.02 & 0.018 & $0.12 * * *$ & 0.02 & 0.025 \\
\hline Constant & $-0.74 * *$ & 0.33 & & $-1.04 * * *$ & 0.25 & \\
\hline Correlation Coefficient & $0.13 * * *$ & 0.01 & & & & \\
\hline \multicolumn{7}{|c|}{ Note: 1$)^{*}, * *$, and $* * *$ represent 10,5 and 1 percent significance, respectively; } \\
\hline \multirow{2}{*}{\multicolumn{7}{|c|}{$\begin{array}{l}\text { 2) indicator variable Public HI_65 equals } 1 \text { if one has public insurance and age } \geq 65 \text {; } \\
\text { 3) indicator variable Public HI } 64 \text { equals } 1 \text { if one has public insurance and age }<64 \text {; }\end{array}$}} \\
\hline & & & & & & \\
\hline \multicolumn{7}{|c|}{$\begin{array}{l}\text { 4) the columns labelled AME list average marginal effects of variables on the probability of } \\
\text { being in good health the next period. }\end{array}$} \\
\hline
\end{tabular}

\section{A.8.3 Survival Rates Parameter Estimates}

I also use a bivariate probit framework to model survival rates in the next period as a function of current health status, age, race, and education degree (equation (3.18). Table A13 lists the estimated parameters that affect survival rates and the AME for each of the variables. For example, the estimates of the "Good Health" parameters indicate that spouses who have good health this period are more likely to survive in the next period. The AMEs of the "Good Health" variable show that, on average, improving health status from bad to good increases the probability of being alive in the next period by 7.0 and 3.8 percentage points for husbands and wives, respectively. 
Table A13: Survival Rates Parameter Estimates

\begin{tabular}{|c|c|c|c|c|c|c|}
\hline & \multicolumn{3}{|c|}{ Husband's Equation } & \multicolumn{3}{|c|}{ Wife's Equation } \\
\hline Variable & Estimate & $\mathrm{S} / \mathrm{E}$ & AME & Estimate & $\mathrm{S} / \mathrm{E}$ & AME \\
\hline Age & & & 0.003 & & & 0.002 \\
\hline $\bar{A}$ Age/10 & $0.29 * *$ & 0.12 & & $0.51 * * *$ & 0.13 & \\
\hline$(\text { Age } / 10)^{2}$ & $-0.05 * * *$ & 0.01 & -0.005 & -0.06 & 0.01 & -0.003 \\
\hline Hispanic & $0.21 * * *$ & 0.04 & 0.020 & $0.29 * * *$ & 0.06 & 0.015 \\
\hline Good Health & $0.74 * * *$ & 0.02 & 0.070 & $0.74 * * *$ & 0.03 & 0.038 \\
\hline \multicolumn{7}{|l|}{ Race (White is omitted) } \\
\hline Black & -0.04 & 0.03 & -0.003 & $-0.07 *$ & 0.04 & -0.004 \\
\hline Other & -0.001 & 0.05 & -0.0007 & $-0.11 *$ & 0.06 & -0.006 \\
\hline \multicolumn{7}{|c|}{ Education (less than high school is omitted) } \\
\hline High school & 0.005 & 0.02 & 0.0005 & 0.003 & 0.03 & 0.0002 \\
\hline College and above & $0.11 * * *$ & 0.03 & 0.010 & $0.12 * *$ & 0.05 & 0.006 \\
\hline Constant & $1.58 * *$ & 0.44 & & $0.99 * *$ & 0.43 & \\
\hline Correlation Coefficient & $0.11 * * *$ & 0.02 & & & & \\
\hline
\end{tabular}

Note: 1) *, **, and *** represent 10,5 and 1 percent significance, respectively;

2) the columns labelled AME list average marginal effects of variables on the probability of being alive in the next period. 